\title{
Evidence-based
}
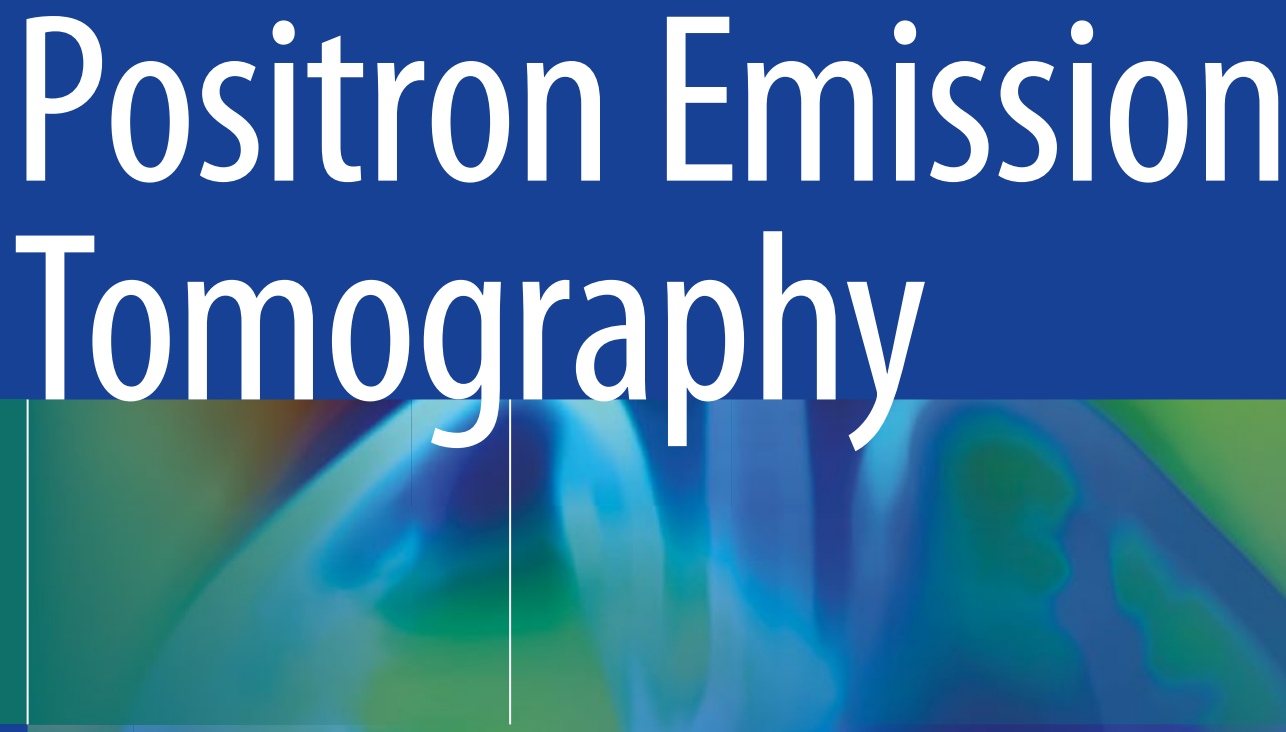

Summary of Recent

Meta-analyses on PET

Giorgio Treglia

Luca Giovanella

Editors 
Evidence-based Positron Emission Tomography 
Giorgio Treglia • Luca Giovanella Editors

\section{Evidence-based Positron Emission Tomography}

Summary of Recent Meta-analyses on PET

算 Springer 


\section{Editors}

Giorgio Treglia

Clinic of Nuclear Medicine

and Molecular Imaging, Imaging

Institute of Southern Switzerland

Ente Ospedaliero Cantonale

Bellinzona

Switzerland
Luca Giovanella

Clinic of Nuclear Medicine

and Molecular Imaging, Imaging

Institute of Southern Switzerland

Ente Ospedaliero Cantonale

Bellinzona

Switzerland

This book is an open access publication.

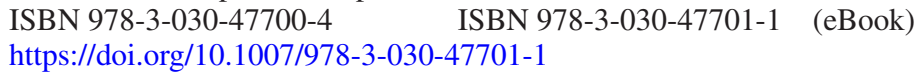

(C) The Editor(s) (if applicable) and The Author(s) 2020

Open Access This book is licensed under the terms of the Creative Commons Attribution 4.0 International License (http://creativecommons.org/licenses/by/4.0/), which permits use, sharing, adaptation, distribution and reproduction in any medium or format, as long as you give appropriate credit to the original author(s) and the source, provide a link to the Creative Commons license and indicate if changes were made.

The images or other third party material in this book are included in the book's Creative Commons license, unless indicated otherwise in a credit line to the material. If material is not included in the book's Creative Commons license and your intended use is not permitted by statutory regulation or exceeds the permitted use, you will need to obtain permission directly from the copyright holder.

The use of general descriptive names, registered names, trademarks, service marks, etc. in this publication does not imply, even in the absence of a specific statement, that such names are exempt from the relevant protective laws and regulations and therefore free for general use.

The publisher, the authors, and the editors are safe to assume that the advice and information in this book are believed to be true and accurate at the date of publication. Neither the publisher nor the authors or the editors give a warranty, expressed or implied, with respect to the material contained herein or for any errors or omissions that may have been made. The publisher remains neutral with regard to jurisdictional claims in published maps and institutional affiliations.

This Springer imprint is published by the registered company Springer Nature Switzerland AG The registered company address is: Gewerbestrasse 11, 6330 Cham, Switzerland 


\section{Preface}

Positron emission tomography (PET), by using different radiopharmaceuticals evaluating different metabolic pathways or receptor expression, is a functional imaging method widely available worldwide.

In particular, hybrid tomographs as positron emission tomography/computed tomography (PET/CT) and positron emission tomography/magnetic resonance imaging (PET/MRI) combining morphological and functional information are currently used in the clinical practice.

Even if a large amount of literature is available about PET, the number of evidence-based articles on this imaging method, such as systematic reviews and meta-analyses, is relatively limited.

A meta-analysis is a statistical analysis that combines the results of multiple scientific studies. Meta-analysis can be performed when there are multiple scientific studies addressing the same question, with each individual study reporting measurements that are expected to have some degree of error. The aim then is to use approaches from statistics to derive a pooled estimate closest to the unknown common truth. Existing methods for meta-analysis yield a weighted average from the results of the individual studies. In addition to provide an estimate of the unknown common truth, meta-analysis has the capacity to identify sources of disagreement among the different study results, or other interesting relationships that may come to light in the context of multiple studies. A key benefit of this approach is the aggregation of information leading to a higher statistical power and more robust point estimate than is possible from the measure derived from any individual study.

This unique evidence-based book summarizes the findings or recent metaanalyses on the use of PET for different clinical indications. These metaanalyses on PET have been selected by the editors after a systematic literature search performed by using PubMed databases (last search: January 2019). Meta-analytic articles published from 2012 to the date of the last literature search were selected.

About the structure of this book, after a section introducing PET and metaanalyses, respectively, several sections describe the results of meta-analyses on PET for different indications including the following medical fields: oncology, cardiology, neurology, infectious and inflammatory diseases.

The different chapters are written by researchers who are both expert in PET and familiar with meta-analytic methodology.

This book provides evidence-based information on PET, which can be very useful for clinicians of different specialties and for international 
scientific societies. In particular, the evidence-based information provided by this book could help international scientific societies and national regulatory bodies on healthcare in approving the use of PET for several emerging clinical indications.

Furthermore, the updated information provided by this book could help worldwide clinicians of different specialties in prescribing PET with several radiotracers for different clinical indications.

Bellinzona and Lugano, Switzerland

Zurich, Switzerland
Giorgio Treglia

Luca Giovanella 


\section{Contents}

\section{Part I Introduction}

1 Introduction to Different PET Radiopharmaceuticals and Hybrid Modalities (PET/CT and PET/MRI) . . . . . . . 3 Luca Giovanella, Lisa Milan, and Arnoldo Piccardo

2 A Practical Guideline on Diagnostic and Prognostic Meta-Analyses

Ramin Sadeghi and Giorgio Treglia

\section{Part II Evidence-Based PET in Oncology}

3 Evidence-Based PET for Brain Tumours Giorgio Treglia and Barbara Muoio

4 Evidence-Based PET for Head and Neck Tumours . . . . . . . . . 35 Gaetano Paone

5 Evidence-Based PET for Thoracic Tumours Filippo Lococo, Alfredo Cesario, Stefano Margaritora, and Giorgio Treglia

6 Evidence-Based PET for Breast Cancer. Giorgio Treglia

7 Evidence-Based PET for Abdominal and Pelvic Tumours . . . . 59 Salvatore Annunziata, Daniele Antonio Pizzuto, and Federica Galiandro

8 Evidence-Based PET for Cutaneous, Musculoskeletal and Unknown Primary Tumours.

Luisa Knappe and Gaetano Paone

9 Evidence-Based PET for Haematological Tumours. Francesco Bertagna, Raffaele Giubbini, and Domenico Albano

10 Evidence-Based PET for Endocrine Tumours and Disorders

Alexander Stephan Kroiss and Giorgio Treglia 


\section{Part III Evidence-Based PET in Cardiology}

11 Evidence-Based PET for Cardiac Diseases. . . . . . . . . . . . . . 99

Christel H. Kamani, Marie-Madeleine Meyer,

Sarah Boughdad, Nathalie Testart, Marie Nicod Lalonde,

Gilles Allenbach, Mario Jreige, Niklaus Schaefer,

Giorgio Treglia, and John O. Prior

Part IV Evidence-Based PET in Infection and Inflammation

12 Evidence-Based PET for Infectious

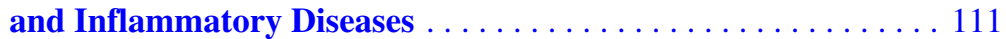

Giorgio Treglia and Barbara Muoio

\section{Part V Evidence-Based PET in Neurology}

13 Evidence-Based PET for Neurological Diseases.

125

Alberto Miceli, Selene Capitanio, Maria Isabella Donegani,

Stefano Raffa, Anna Borra, Matteo Bauckneht, and Silvia Morbelli

\section{Part VI Miscellaneous}

14 Meta-Analyses on Technical Aspects of PET . . . . . . . . . . . 139 Luca Ceriani 


\section{Part I}

Introduction 


\title{
Introduction to Different PET Radiopharmaceuticals and Hybrid Modalities (PET/CT and PET/MRI)
}

\author{
Luca Giovanella, Lisa Milan, and Arnoldo Piccardo
}

\subsection{Physical Principles of Positron Emission Tomography and Hybrid Modalities}

Positron Emission Tomography (PET) is an imaging technique performed by using positron emitting radiotracers. Positron decay occurs with neutron-poor radionuclides and consists in the conversion of a proton into a neutron with the simultaneous emission of a positron $(\beta+)$ and a

L. Giovanella $(\bowtie)$

Clinic of Nuclear Medicine and Molecular Imaging, Imaging Institute of Southern Switzerland,

Ente Ospedaliero Cantonale, Bellinzona, Switzerland

Laboratory of Radiomics and Predictive Imaging, Imaging Institute of Southern Switzerland,

Ente Ospedaliero Cantonale, Bellinzona, Switzerland

Clinic of Nuclear Medicine, University Hospital and University of Zurich, Zurich, Switzerland e-mail: luca.giovanella@eoc.ch

L. Milan

Clinic of Nuclear Medicine and Molecular Imaging, Imaging Institute of Southern Switzerland,

Ente Ospedaliero Cantonale, Bellinzona, Switzerland

Laboratory of Radiomics and Predictive Imaging, Imaging Institute of Southern Switzerland,

Ente Ospedaliero Cantonale, Bellinzona, Switzerland
A. Piccardo
Division of Nuclear Medicine, Ente Ospedaliero
"Ospedali Galliera", Genoa, Italy

neutrino $(\nu)$. The positron has a very short lifetime, and after the annihilation with an electron simultaneously produces two high-energy photons $(E=511 \mathrm{keV})$ in approximately opposite directions that are detected by an imaging camera. The PET scanning is based on the so-called annihilation coincidence detection (ACD) of the $511 \mathrm{keV} \gamma$-rays after the annihilation. Tomographic images are formed collecting data from many angles around the patient by scintillating crystals optically coupled to a photon detectors used to localize the position of the interaction and the amount of absorbed energy in the crystals (Table 1.1) [1].

Table 1.1 Properties of PET scintillator crystals

\begin{tabular}{|c|c|c|c|c|c|}
\hline & $\mathrm{NaI}(\mathrm{Tl})$ & BGO & LSO & GSO & LYSO \\
\hline $\begin{array}{l}\text { Effective atomic } \\
\text { number }(Z)\end{array}$ & 50 & 73 & 66 & 59 & 60 \\
\hline$\mu\left(\mathrm{cm}^{-1}\right)$ & 0.34 & 0.95 & 0.87 & 0.70 & 0.86 \\
\hline $\begin{array}{l}\text { Index of } \\
\text { refraction }\end{array}$ & 1.85 & 2.15 & 1.82 & 1.85 & 1.81 \\
\hline Density $\left(\mathrm{g} / \mathrm{cm}^{3}\right)$ & 3.67 & 7.13 & 7.40 & 6.71 & 7.30 \\
\hline $\begin{array}{l}\text { Photon yield } \\
\text { (per } \mathrm{kVp} \text { ) }\end{array}$ & 38 & 8 & $20-30$ & $\begin{array}{l}12- \\
15\end{array}$ & 25 \\
\hline $\begin{array}{l}\text { Peak } \\
\text { wavelength } \\
(\mathrm{nm})\end{array}$ & 410 & 480 & 420 & 430 & 420 \\
\hline $\begin{array}{l}\text { Decay time } \\
\text { constant (ns) }\end{array}$ & 230 & 300 & 40 & 65 & 41 \\
\hline $\begin{array}{l}\text { Energy } \\
\text { resolution (\% at } \\
511 \mathrm{keV})\end{array}$ & $7.8 \%$ & $20 \%$ & $10.1 \%$ & $9.5 \%$ & $20 \%$ \\
\hline Hygroscopic & Yes & No & No & No & No \\
\hline
\end{tabular}


Table 1.2 The PET scanner performance and the intrinsic PET limitations

\begin{tabular}{|c|c|c|}
\hline & Definition & Intrinsic limitation \\
\hline $\begin{array}{l}\text { Spatial } \\
\text { resolution }\end{array}$ & $\begin{array}{l}\text { The minimum distance } \\
\text { between two points in an } \\
\text { image that can be } \\
\text { detected by a scanner }\end{array}$ & $\begin{array}{l}\text { Positron range: Error occurs in the localization of the true position of the } \\
\text { positron emission resulting in the degradation of the spatial resolution } \\
\text { Non-collinearity: The two } 511 \mathrm{keV} \text { photons are not emitted at exactly } \\
\text { opposite directions: This deviation can reach a value of } \pm 0.25^{\circ} \text { at maximum } \\
\text { detector size and its intrinsic resolution: resolution is better in the centre of } \\
\text { the FOV than at the edge }\end{array}$ \\
\hline Sensitivity & $\begin{array}{l}\text { Number of counts per } \\
\text { unit time detected by the } \\
\text { system for a unitary } \\
\text { activity }\end{array}$ & $\begin{array}{l}\text { Geometric efficiency: the fraction of emitted radiation that hits the detector } \\
\text { and it depends on the source to detector distance, on the diameter of the ring } \\
\text { and on the number of detectors in each ring } \\
\text { Intrinsic efficiency: the fraction of radiation that reaches the detector and is } \\
\text { acquired. It depends on the scintillation decay time and the stopping power } \\
\text { of the detector }\end{array}$ \\
\hline $\begin{array}{l}\text { Noise- } \\
\text { equivalent } \\
\text { count rate }\end{array}$ & $\begin{array}{l}\text { Parameter used to define } \\
\text { the noise and to compare } \\
\text { the PET performance }\end{array}$ & $\begin{array}{l}\text { Takes into account the effects introduced by scatter and random } \\
\text { coincidences }\end{array}$ \\
\hline Contrast & $\begin{array}{l}\text { Difference in counts } \\
\text { between an area of } \\
\text { interest and its } \\
\text { surroundings }\end{array}$ & Scatter, random and out-of-FOV radiation \\
\hline
\end{tabular}

The key properties that characterize the PET scanner performances are the spatial resolution, the sensitivity, the Noise-Equivalent Count Rate (NECR) and the contrast [2]. The projection data acquired in the form of sinograms are affected by a number of factors that contribute to the degradation of the final images and hence to the PET scanner performances, as reported in Table 1.2.

Two classes of reconstruction techniques exist: the analytical and the iterative methods [3]. The most used analytical method is the backprojection. To compensate the blurring, a filter is applied to the projections before they are back-projected onto the image [i.e. filtered backprojection (FBP)]. In modern scanners, the image reconstruction algorithms are based on iterative methods, which approach the true image by means of successive estimations, in order to converge to an image that best represents the original object. These algorithms are known as expectation maximization (EM) and Ordered Subset Expectation Maximization (OSEM) algorithm [4].

\subsection{Hybrid Scanners: PET/CT and PET/MRI}

Combined PET/CT systems were commercially available from 2001 and in a very short time the dedicated PET scanner was completely replaced by hybrid PET/CT. The ability of hybrid PET/CT systems to accurately identify the anatomic location of diseases and to provide attenuationcorrected images are the main causes of their rapid success and diffusion [5]. Modern clinical $\mathrm{PET} / \mathrm{CT}$ consists in a high-performance PET scanner in-line with a high-performance CT scanner arranged in sequential gantries. The scanner table moves along the gantry axis in order to subsequently acquire CT and then PET data. A software integrated in the system has to check if the patient bed undergoes some deflections during the translation [6]. Images of tissue attenuation from the CT scan are used to derive the PET attenuation correction factors. The latter depends on the energy of the photons: since CT X-rays and PET $\gamma$-rays have an energy of $70 \mathrm{keV}$ and $511 \mathrm{keV}$, 
Table 1.3 The characteristics of the three commercially available PET/MRI scanners

\begin{tabular}{|c|c|c|c|}
\hline & $\begin{array}{l}\text { Siemens biograph } \\
\text { mMR }\end{array}$ & Philips ingenuity & GE Signa \\
\hline PET/MR technology & Integrated & Sequential & Integrated \\
\hline \multicolumn{4}{|l|}{ PET } \\
\hline Scintillator & LSO & LYSO & LBS \\
\hline Crystal size (mm) & $4 \times 4 \times 20$ & $4 \times 4 \times 22$ & $4 \times 5.3 \times 25$ \\
\hline Crystal number & 28,672 & 28,336 & 20,160 \\
\hline Photodetector & APD & PMT & SiPM \\
\hline TOF & No & Yes & Yes \\
\hline Energy resolution (\%) & 14.5 & 12 & 10.5 \\
\hline Energy window (keV) & $430-610$ & $460-665$ & $425-650$ \\
\hline Time resolution (ns) & 2.93 & 0.53 & 0.39 \\
\hline Coincidence window (ns) & 5.86 & 6.00 & 4.57 \\
\hline Transaxial FOV (cm) & $59.4 \mathrm{~cm}$ & // & $60 \mathrm{~cm}$ \\
\hline Axial FOV & $25.8 \mathrm{~cm}$ & 18 & $25 \mathrm{~cm}$ \\
\hline Sensitivity (kcps/MBq) & 15.0 & 7.0 & 22.2 \\
\hline Scatter fraction $(\%)$ & 37.9 & 26.0 & 43.4 \\
\hline Peak NECR (kcps@ @Bq/mL) & 184@23.1 & 88.5@13.7 & 218@17.7 \\
\hline \multicolumn{4}{|l|}{ MR } \\
\hline Field strength $(\mathrm{T})$ & 3 & 3 & 3 \\
\hline Bore $(\mathrm{cm})$ & 60 & 60 & 60 \\
\hline $\mathrm{FOV}\left(\mathrm{cm}^{3}\right)$ & $50 \times 50 \times 50$ & $50 \times 50 \times 45$ & $50 \times 50 \times 50$ \\
\hline Gradient mT/m & 45 & 40 & 44 \\
\hline Slew rate $(T / m) / s$ & 200 & 100 & 200 \\
\hline
\end{tabular}

respectively, the attenuation correction factor obtained from CT must be scaled to the $511 \mathrm{keV}$ photons applying a scaling factor defined by the ratio of the $\mu$ of the $511 \mathrm{keV}$ photons to that of the $70 \mathrm{keV} \mathrm{X}$-rays in a given tissue [1].

PET/MRI is a multi-modality technology combining the functional information of PET with the soft-tissue contrast of MRI. Actually, two approaches are implemented in the commercial PET/MRI scanners: sequential PET/MRI [7-9]. The characteristics of the three commercial PET/MRI scanners are summarized in Table 1.3.

\subsection{Positron Emission Tomography Radiopharmaceuticals}

Radiopharmaceuticals are radiolabelled molecules consisting in a molecular structure and a radioactive nuclide. The first one defines the pharmacokinetics and dynamics within the organism, while the latter is responsible for a detectable signal and for the consequent image visualization [10]. To maintain the stability of these two components, a linker may be necessary. The most important PET nuclides and their physical characteristics are summarized below:

- Carbon-11 $\left({ }^{11} \mathrm{C}\right)$ has a physical half-life of about $20 \mathrm{~min}$ and decays by $\beta^{+}$emission $(99.75 \%)$ and by electron capture $(0.25 \%)$ to the ground state of the stable nuclide Boron-11 $\left({ }^{11} \mathrm{~B}\right) . \beta^{+}$average energy is $386 \mathrm{keV}$, corresponding to a mean range in water of $1.3 \mathrm{~mm}$. ${ }^{11} \mathrm{C}$ can be produced by different nuclear reactions; however, the main production mode is targeting Nitrogen-14 $\left({ }^{14} \mathrm{~N}\right)$ with cyclotron accelerated protons: ${ }^{14} \mathrm{~N}(\mathrm{p}, \alpha){ }^{14} \mathrm{C}$.

- Fluorine-18 $\left({ }^{18} \mathrm{~F}\right)$ has a physical half-life of about 110 min and decays by $\beta^{+}$emission $(96.86 \%)$ and electron capture (3.14\%) directly to the ground state of the stable 
nuclide Oxygen-18 $\left({ }^{18} \mathrm{O}\right) . \beta^{+}$average energy is $250 \mathrm{keV}$, corresponding to a mean range in water of $0.6 \mathrm{~mm} .{ }^{18} \mathrm{~F}$ can be produced by different nuclear reactions; however, the main production mode is targeting Oxygen-18 with cyclotron accelerated protons: ${ }^{18} \mathrm{O}(\mathrm{p}, \mathrm{n}){ }^{18} \mathrm{~F}$.

- Gallium-68 $\left({ }^{68} \mathrm{Ga}\right)$ has a physical half-life of about $67.8 \mathrm{~min}$ and decays by $\beta^{+}$emission $(88.88 \%)$ and by electron capture $(11.11 \%)$ into ${ }^{68} \mathrm{Zn}$. $\beta^{+}$average energy is $830 \mathrm{keV}$, corresponding to a mean range in water of $3.6 \mathrm{~mm} .{ }^{18} \mathrm{Ga}$ can be produced by different nuclear reactions; however, the main production mode is using a Germanium-68 $\left({ }^{68} \mathrm{Ge}\right)$ ${ }^{68} \mathrm{Ga}$ generator.

- Iodine-124 ( $\left.{ }^{124} \mathrm{I}\right)$ has a physical half-life of about 4.2 days and decays by $\beta^{+}$emission $(23 \%)$ and by electron capture $(77 \%)$ to the excited level and the ground state of Tellurium-124 $\left({ }^{124} \mathrm{Te}\right) . \beta^{+}$average energy is $836 \mathrm{keV}$, corresponding to a mean range in water of $3.4 \mathrm{~mm} .{ }^{124} \mathrm{I}$ can be produced by different nuclear reactions; however, ${ }^{124} \mathrm{Te}(\mathrm{p}, \mathrm{n})$ reaction gives the purest form of ${ }^{124} \mathrm{I}$.

- Copper-64 $\left({ }^{64} \mathrm{Cu}\right)$ has a physical half-life of about $12.7 \mathrm{~h}$ and decays by $\beta^{-}$emission $(38 \%)$ to Zinc-64 ( $\left.{ }^{64} \mathrm{Zn}\right)$ and by $\beta^{+}$emission $(17.4 \%)$ or electron capture $(44.6 \%)$ to the excited level and the ground state of Nickel-64 $\left({ }^{64} \mathrm{Ni}\right)$. $\beta^{+}$average energy is $278 \mathrm{keV}$, corresponding to a mean range in water of $0.7 \mathrm{~mm}$. The main ${ }^{64} \mathrm{Cu}$ production modes are the following: ${ }^{63} \mathrm{Cu}(\mathrm{n}, \gamma){ }^{64} \mathrm{Cu},{ }^{65} \mathrm{Cu}(\mathrm{n}, 2 \mathrm{n}){ }^{64} \mathrm{Cu},{ }^{64} \mathrm{Zn}(\mathrm{n}, \mathrm{p}){ }^{64} \mathrm{Cu}$, ${ }^{64} \mathrm{Zn}(\mathrm{d}, 2 \mathrm{p}){ }^{64} \mathrm{Cu}$.

The wide and feasible availability of positron emitters radionuclides is a prerequisite for successful application on a routine basis. Fluorine-18 and Gallium-68 are the most used in a clinical setting, so far. Due to its versatility, ${ }^{18}$ F-Fluorodeoxyglucose (FDG), namely a radiolabelled analogue of glucose, is the by far most widely used PET radiopharmaceutical worldwide. FDG is very useful to detect malignant tumours characterized by increased glucose metabolism. However, FDG remains a nonspecific tracer and its uptake is also been observed in many benign conditions, such as infective and inflammatory processes. Therefore, over the last decade, there is a growing interest in researching and using new radiopharmaceuticals, such as radiolabelled amino acids, nucleoside derivatives, choline derivatives, nitroimidazole derivatives and peptides, able to carefully target specific biomarkers. These new generation radiopharmaceuticals allow the analysis of several molecular pathways in tumour biology including metabolism, proliferation, oxygen delivery and protein synthesis as well as receptor and gene expression (Tables 1.4, 1.5 and 1.6). Some examples of PET images with different radiopharmaceuticals are showed in Figs. 1.1 and 1.2. 

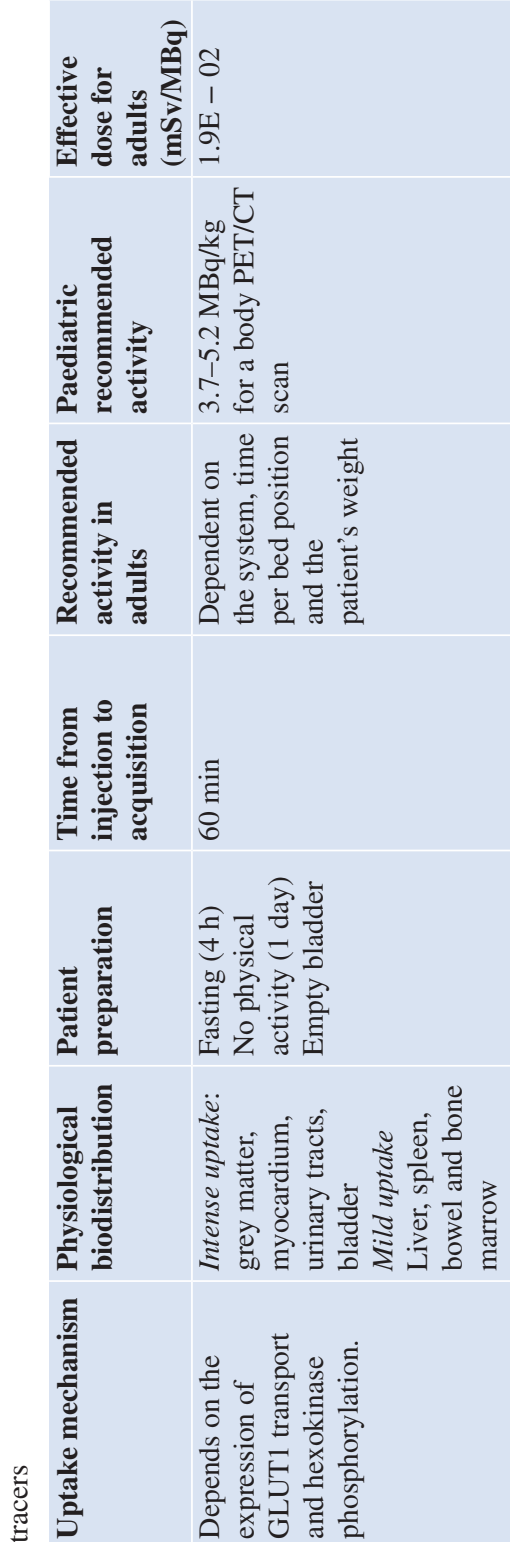

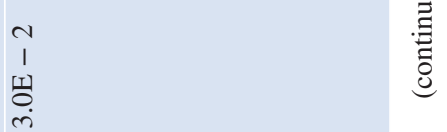

0
ज्ञ
$: 0$
:
0
Z

$\sum_{\substack{+m}}^{\infty}$
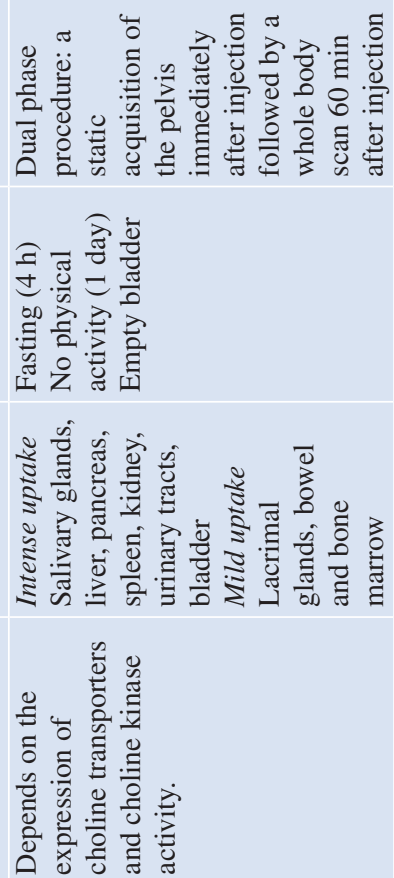

牙.

8

.

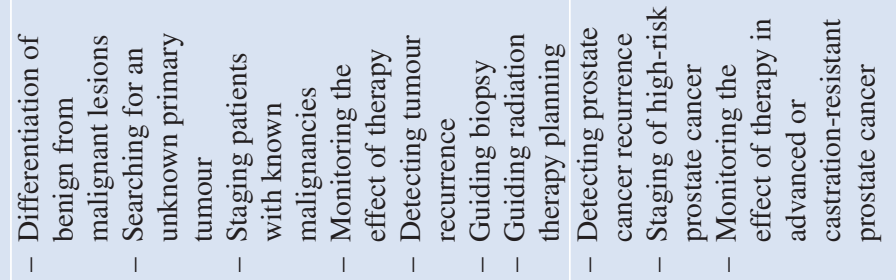

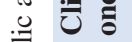

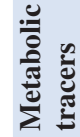

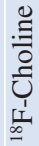



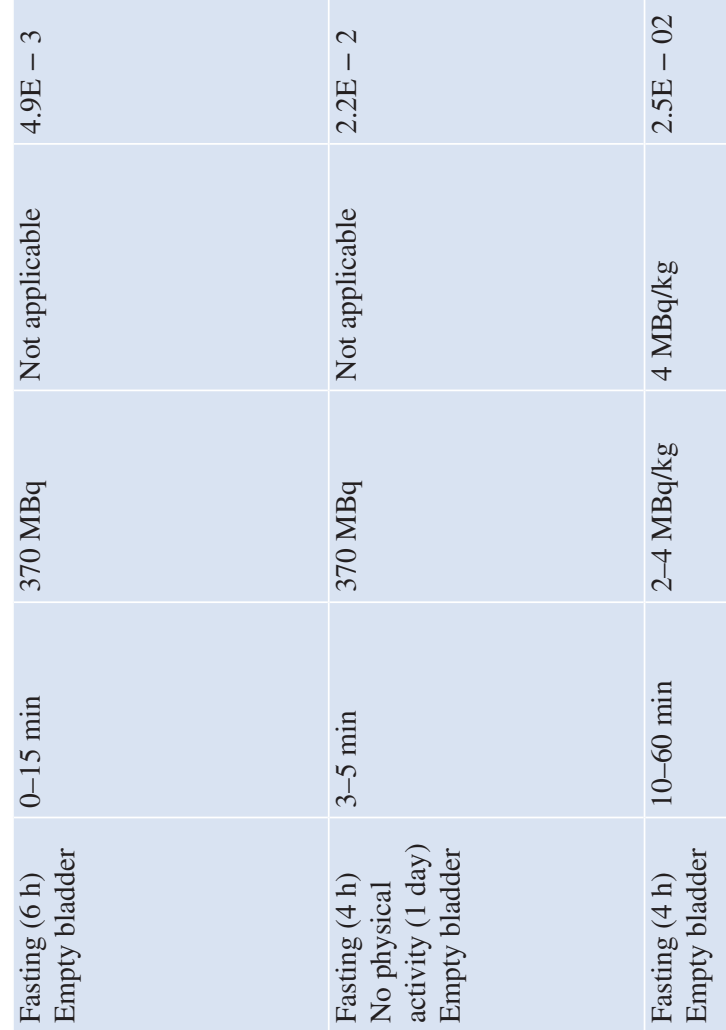

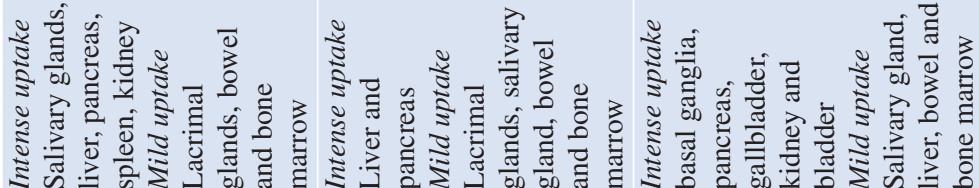
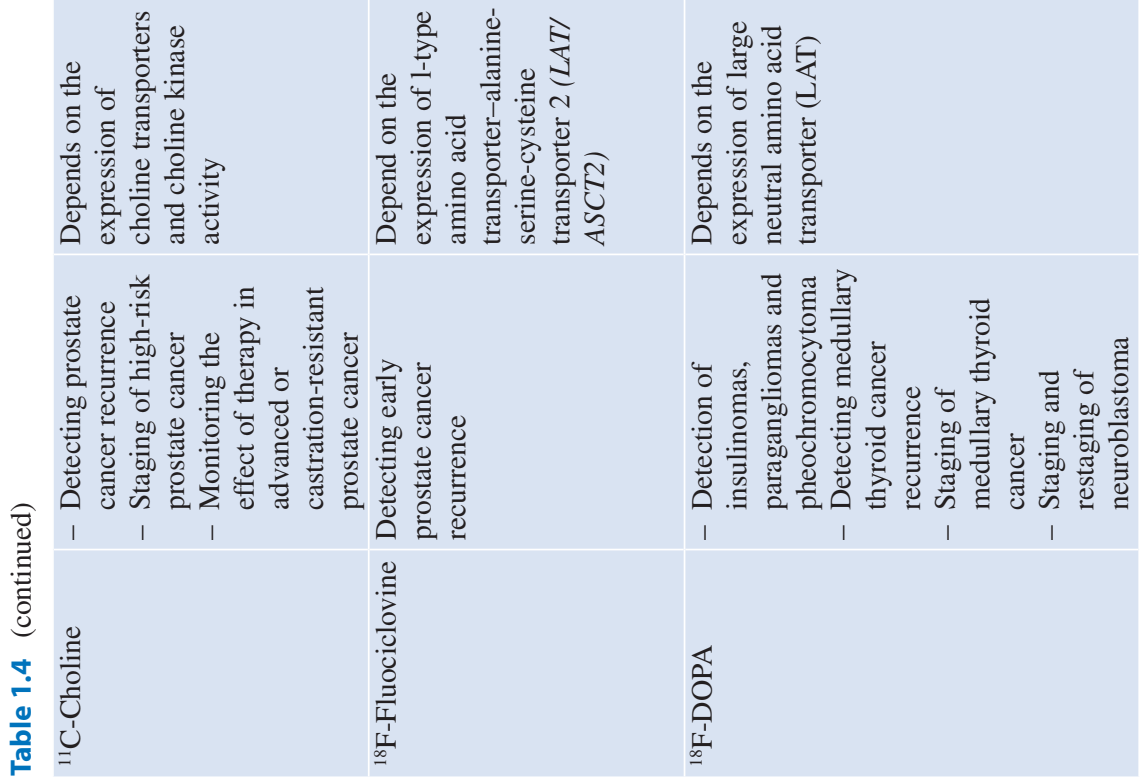

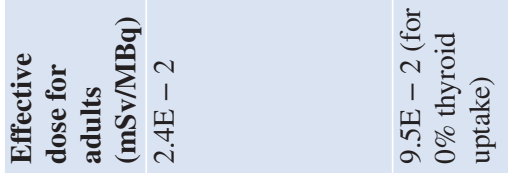

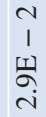

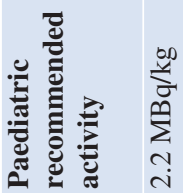

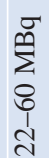

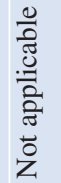
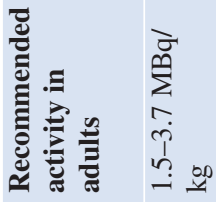

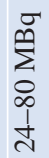

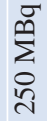

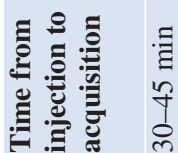

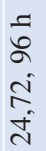

$=$

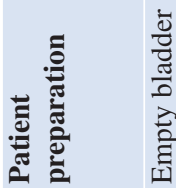

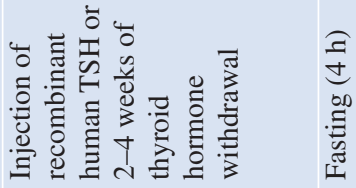

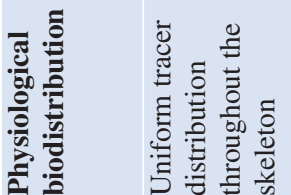

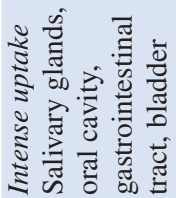

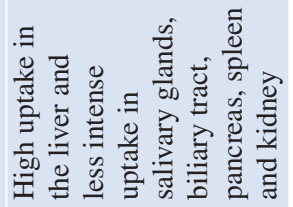

है
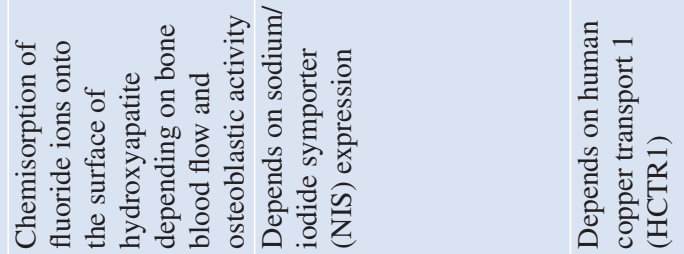

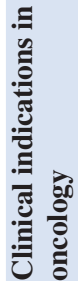

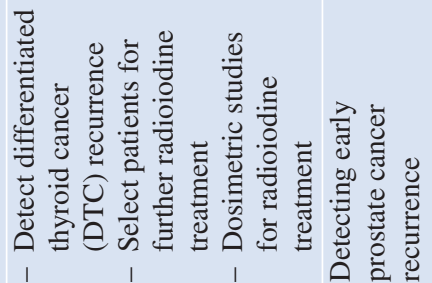

ส

:ैّ

焉焉

$\sum_{\substack{1 \\ \Xi}}^{\bar{I}}$

ర్త్రే 


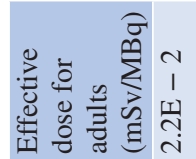

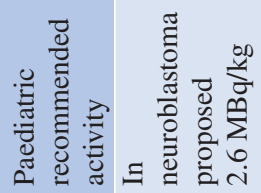

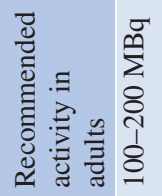

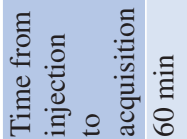

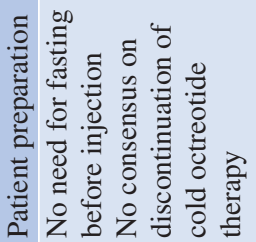

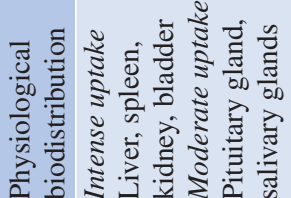

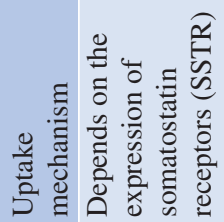

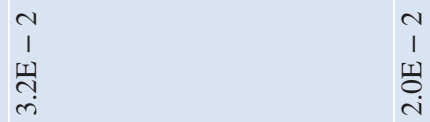

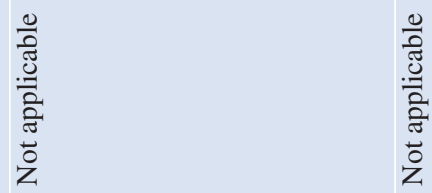

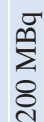

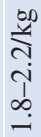

春

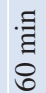

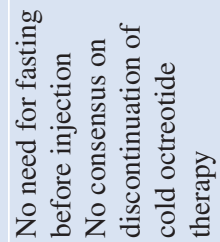

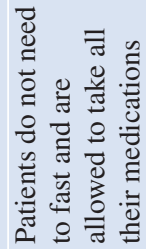

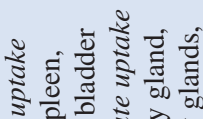

के के है त्ञचत

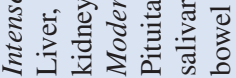

范

ते के

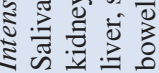

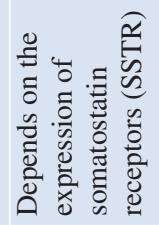

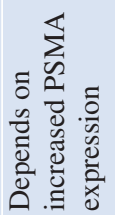

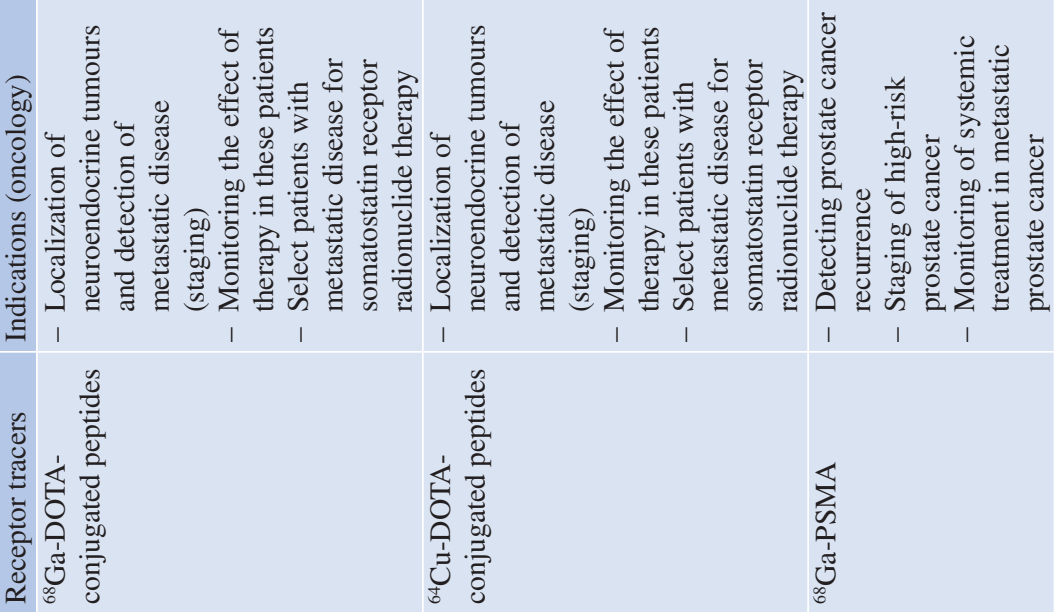




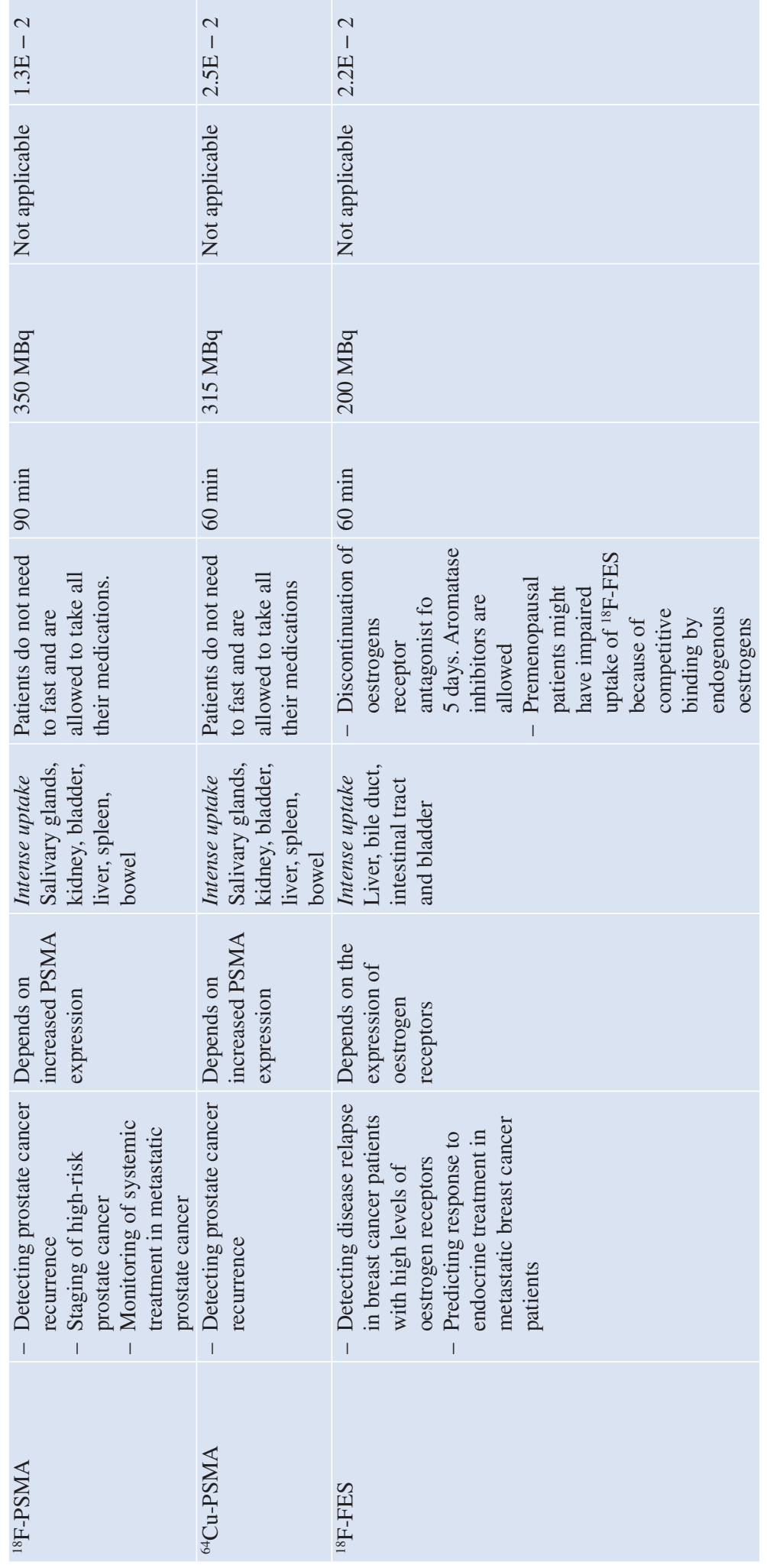



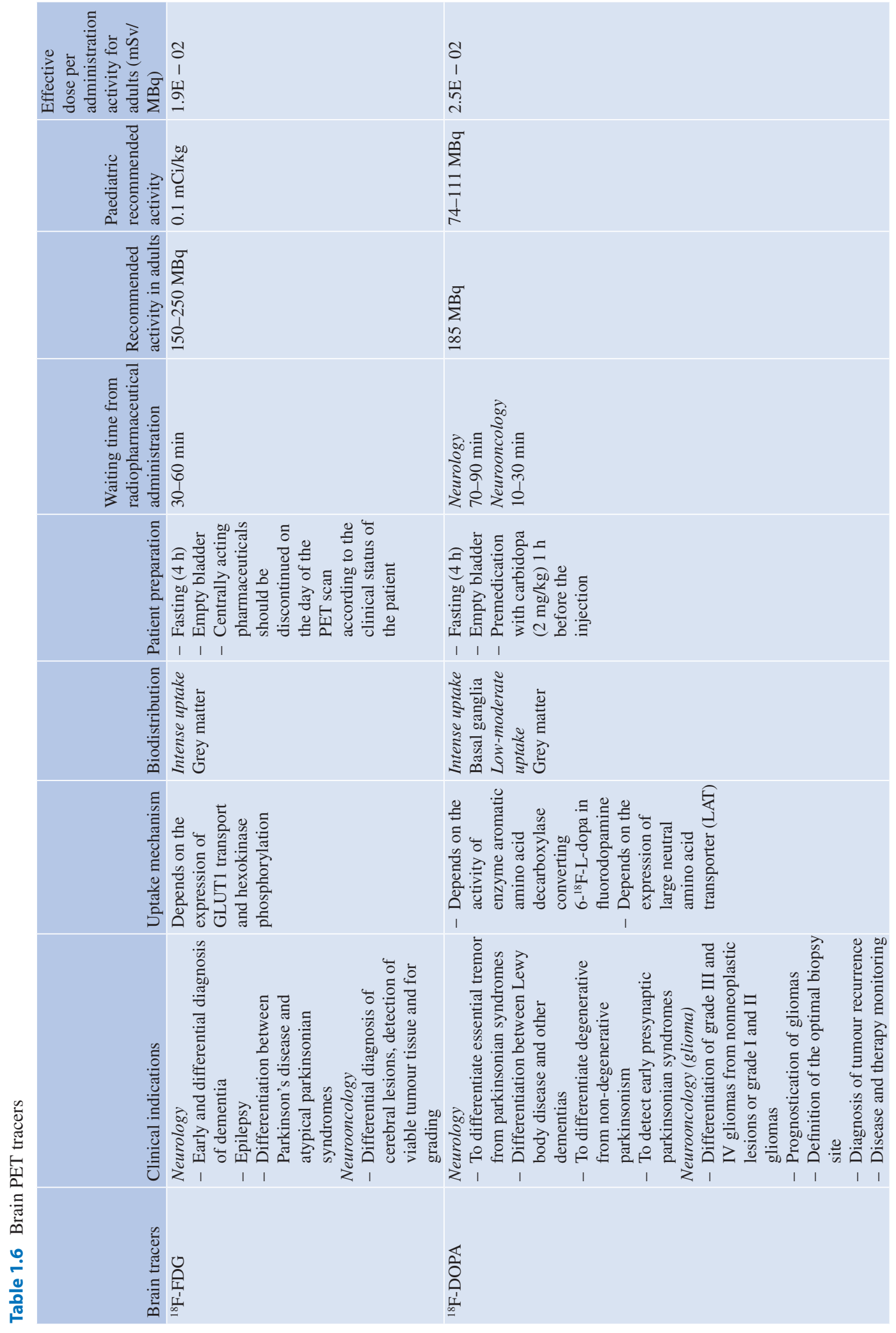


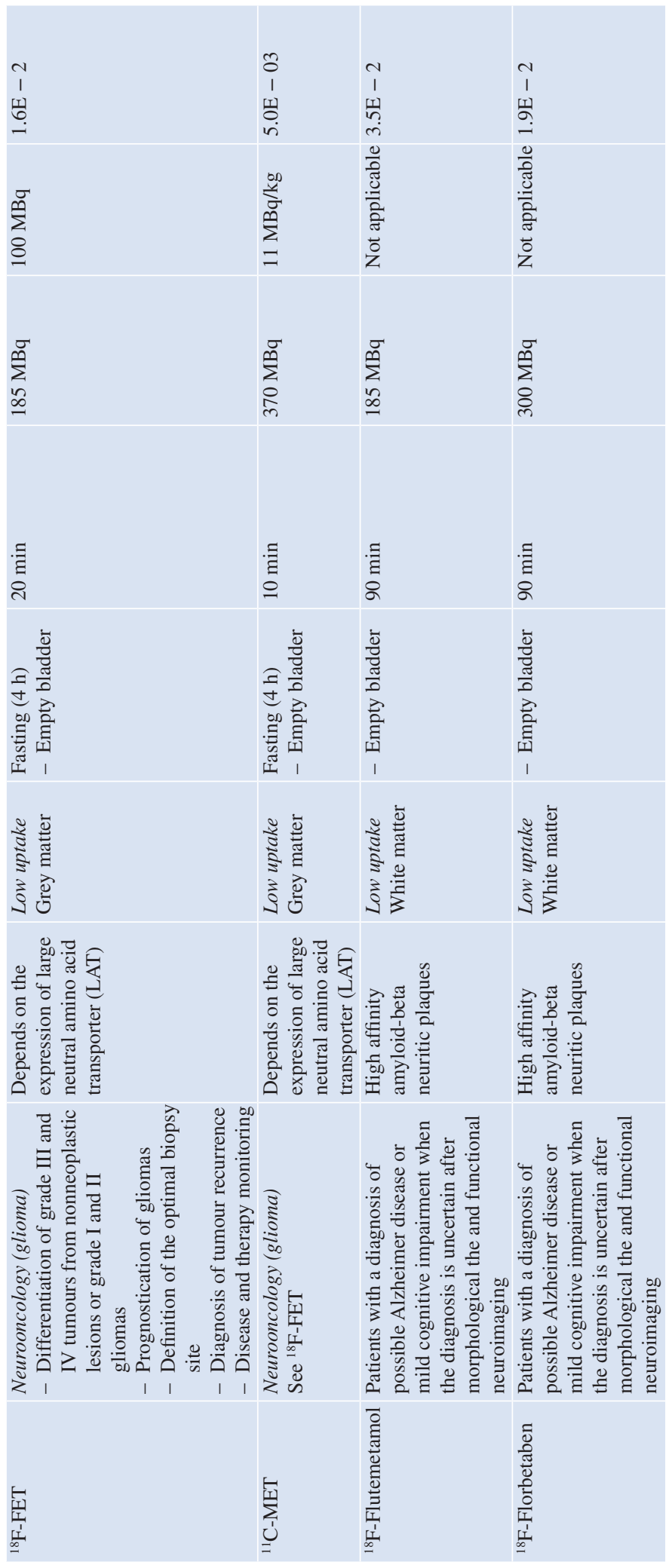


a

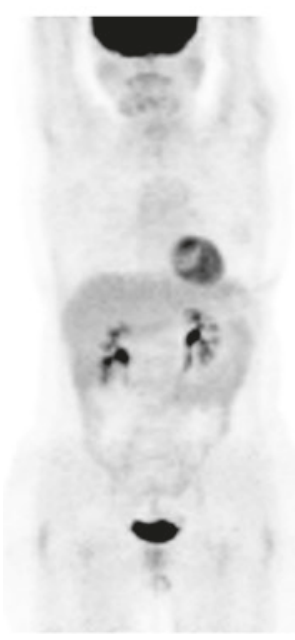

b

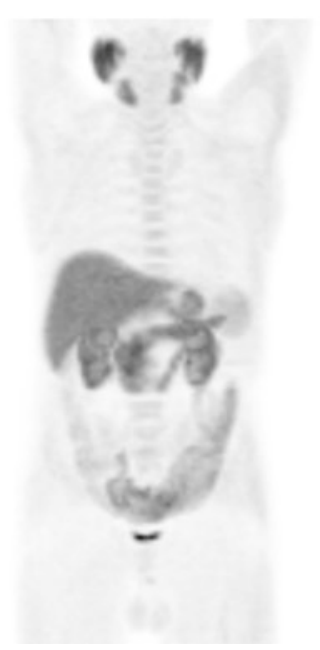

C

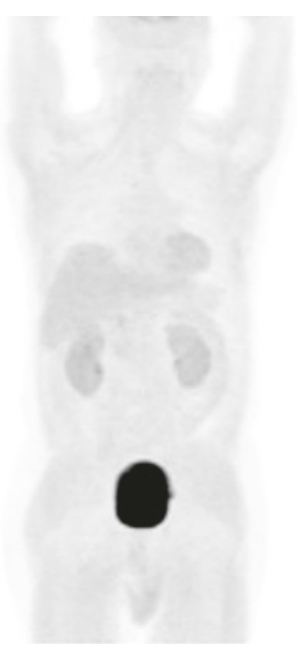

d

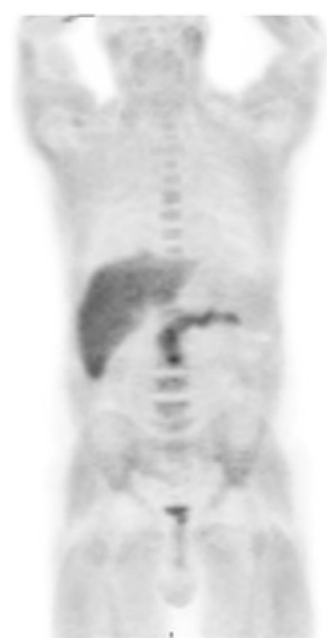

Fig. 1.1 Biodistribution of PET tracers: ${ }^{18} \mathrm{~F}-\mathrm{FDG}(\mathbf{a}),{ }^{18} \mathrm{~F}-\mathrm{FCH}(\mathbf{b}),{ }^{18} \mathrm{~F}$-DOPA $(\mathbf{c}),{ }^{18} \mathrm{~F}$-Fluociclovine $(\mathbf{d})$

a

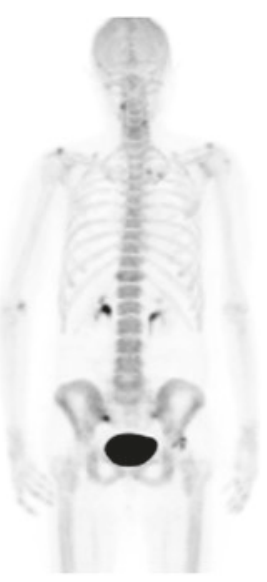

b

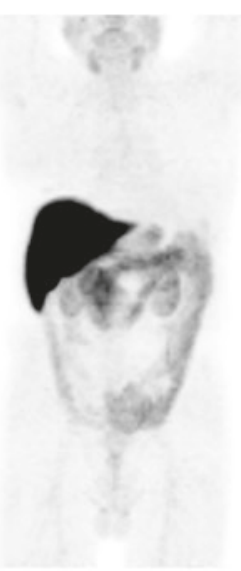

C

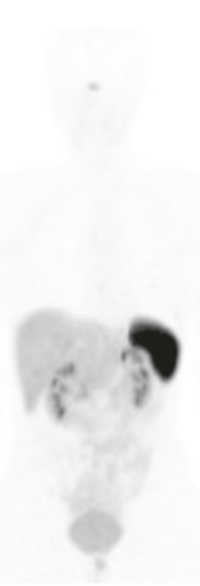

d

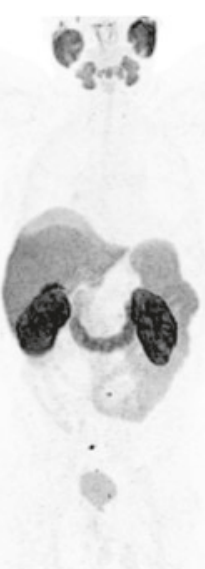

e

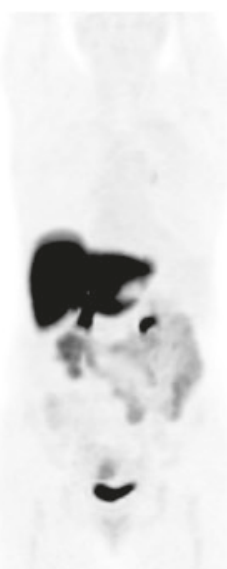

Fig. 1.2 Biodistribution of PET tracers: ${ }^{18} \mathrm{~F}-\mathrm{NaF}(\mathbf{a}),{ }^{64} \mathrm{CuCl}_{2}(\mathbf{b}){ }^{68} \mathrm{Ga}$-DOTATOC $(\mathbf{c}),{ }^{68} \mathrm{Ga}$-PSMA (d), ${ }^{18} \mathrm{~F}$-FES (e)

\section{References}

1. Saha GB. Basics of PET imaging: physics, chemistry, and regulations. New York: Springer; 2010.

2. Zanzonico P. Positron emission tomography: a review of basic principles, scanner design and performance, and current systems. Semin Nucl Med. 2004;34(2):87-111.

3. Slomka PJ, Pan T, Germano G. Recent advances and future progress in PET instrumentation. Semin Nucl Med. 2016;46(1):5-19.
4. Alessio A, Kinahan P. PET imaging reconstruction http://faculty.washington.edu/aalessio/papers/alessioPETRecon.pdf.

5. Waterstram-Rich KE, Christian PE. Nuclear medicine and PET/CT: technology and techniques. St. Louis: Elsevier Mosby; 2012.

6. Li S, Tavares JMRS. Shape analysis in medical image analysis, 51. Lecture notes in computational vision and biomechanics, vol. 14; 2014.

7. Zaidi H, Ojha N, Griesmer J, et al. Design and performance evaluation of a whole-body ingenuity TF PETMRI system. Phys Med Biol. 2011;56(10):3091-106. 
8. Delso G, Furst S, Jakoby B, et al. Performance measurements of the Siemens mMR integrated whole-body PET/MR scanner. J Nucl Med. 2011;52(12):1914-22.

9. Grant AM, Deller TW, Khalighi MM, et al. NEMA NU 2-2012 performance studies for the SiPM-based
ToF-PET component of the GE SIGNA PET/MR system. Med Phys. 2016;43(5):2334.

10. Wadsak W, Mitterhauser M. Basics and principles of radiopharmaceuticals for PET/CT. Eur J Radiol. 2010;73:461-9.

Open Access This chapter is licensed under the terms of the Creative Commons Attribution 4.0 International License (http://creativecommons.org/licenses/by/4.0/), which permits use, sharing, adaptation, distribution and reproduction in any medium or format, as long as you give appropriate credit to the original author(s) and the source, provide a link to the Creative Commons license and indicate if changes were made.

The images or other third party material in this chapter are included in the chapter's Creative Commons license, unless indicated otherwise in a credit line to the material. If material is not included in the chapter's Creative Commons license and your intended use is not permitted by statutory regulation or exceeds the permitted use, you will need to obtain permission directly from the copyright holder.

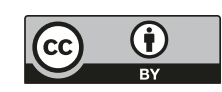




\title{
A Practical Guideline on Diagnostic and Prognostic Meta-Analyses
}

\author{
Ramin Sadeghi and Giorgio Treglia
}

\subsection{Introduction}

Evidence based medicine is defined as using the best available evidence for everyday clinical practice [1-3]. Synthetic literature including systematic reviews and meta-analyses plays an important role in evidence based medicine. Essentially systematic reviews and meta-analyses are the cornerstone of evidence based practice. The main difference between a systematic review and a narrative review is the clear method of the former including a clear search and predefined inclusion criteria. The methodology of systematic reviews makes them reproducible which is not the case in narrative reviews [1-3]. The number of systematic reviews and meta-analyses on nuclear medicine diagnostic and prognostic studies is increasing [4,

\footnotetext{
R. Sadeghi $(\bowtie)$

Nuclear Medicine Research Center, Mashhad University of Medical Sciences, Mashhad, Iran e-mail: sadeghir@mums.ac.ir

G. Treglia

Clinic of Nuclear Medicine and Molecular Imaging, Imaging Institute of Southern Switzerland, Ente Ospedaliero Cantonale,

Bellinzona and Lugano, Switzerland

Department of Nuclear Medicine and Molecular Imaging, Lausanne University Hospital and University of Lausanne, Lausanne, Switzerland

Health Technology Assessment Unit, Academic Education, Research and Innovation Area, Ente Ospedaliero Cantonale, Bellinzona, Switzerland e-mail: giorgio.treglia@eoc.ch
}

5]. In the current chapter, a practical guideline has been prepared for the researchers who intend to perform a systematic review or meta-analysis of diagnostic and prognostic studies.

\subsection{A Clear Topic for Systematic Review: Formulating the Question}

The single most important step in preparing a systematic review is to have a clear topic. The topic is usually divided into several aspects including: patients (the population of the study), intervention (the diagnostic test under study or a prognostic factor which is being evaluated), comparison (the procedures comparative to the index test), outcome (the outcome which is going to be evaluated which are usually sensitivity and specificity for diagnostic studies and overall survival (OR) and progression free survival (PFS) in prognostic ones).

The abovementioned method is called patients-intervention-comparison-outcome (PICO) $[6,7]$. The search strategy for systematic reviews is based on the PICO question.

Here are two examples:

1. How does positron emission tomography (PET) [Intervention] work for detection of recurrence [Outcome] in endometrial carcinoma [Patients]? 
2. What is the prognostic significance of PET [Intervention] for predicting survival [Outcome] in renal cell carcinoma [Patients]?

\subsection{Which Articles Should Be Included? Search Strategy, Inclusion and Exclusion Criteria}

Search strategy is based on our PICO question. The keywords and databases which are used for searching should minimize the chance of missing any relevant article. Using Boolean operators (i.e., AND, OR, NOT) is highly recommended. This makes your search as sensitive as possible.

For example for the abovementioned PICO questions the following keywords seem to be optimal:

1. (PET OR "Positron Emission Tomography") AND (endometrial OR endometrium OR uterine) AND recurrence.

2. (PET OR "Positron Emission Tomography") AND (RCC OR "renal cell carcinoma" OR kidney).

At least two databases should be included in the search strategy. PubMed/Medline and SCOPUS (or EMBASE) are two main sources for any systematic review.

The inclusion and exclusion criteria should be as clear as possible too. The following factors should be considered to set useful inclusion criteria:

(a) Standard of reference: Included studies should describe the reference or gold standard with which the diagnostic test is compared.

(b) Outcome data: Enough information should be available to reconstruct a $2 \times 2$ diagnostic table or prognostic factors (such as hazard ratio (HR)) of each study.

(c) Language and time limit: Preferably no language or time limit should be imposed.
For example for the abovementioned PICO questions, the following inclusion criteria can be set:

1. All studies which compared PET with conventional imaging for detection of recurrence in endometrial cancer.

2. All studies which evaluated the prognostic significance of PET factors (SUVmax, SUVmean, etc.) in survival (OS or PFS) of renal cell carcinoma patients.

Full texts of all relevant studies should be retrieved. The reference of primary studies and all relevant reviews should be checked to search for additional primary studies that could have been missed (backward searching of the citations). In addition, articles citing the relevant included articles can be used to find any other missing articles (forward searching of the citations). The citing articles can be found easily using Google Scholar (https://scholar.google. com/), SCOPUS, or Dimensions (a free newly launched application with many useful options: https://app.dimensions.ai/discover/publication).

Remember to keep the records of all the searches, as well as included and excluded studies.

\subsection{Quality Assessment of the Included Studies}

Not all included studies are of same quality. Quality of each study should be checked and reported. Several checklists are available for diagnostic studies $[8,9]$.

Two of the most commonly used checklists are:

1. Oxford Center for Evidence Based Medicine worksheet for diagnostic studies (available at https://www.cebm.net/wp-content/uploads/ 2018/11/Diagnostic-Accuracy-Studies.pdf).

2. Quality Assessment of Diagnostic Accuracy Studies-2 (QUADAS-2) [10]. QUADAS-2 is the revised, 2011 version of the 2003 
QUADAS and consists of four dimensions (patient selection, index test, reference standard, and finally, flow and timing), the first three of which require an answer among the three available responses (yes/high, no/low, and unclear).

Several checklists are also available for prognostic studies [11].

Two of the most commonly used checklists are:

1. Oxford Center for Evidence Based Medicine worksheet for prognostic studies (available at https://www.cebm.net/wp-content/uploads/ 2018/11/Prognosis.pdf).

2. QUIPS tool (quality in prognostic factor studies) [12]. QUIPS has several domains (study participation, study attrition, prognostic factor measurement, outcome measurement, adjustment for other prognostic factors, and statistical analysis). Risk of bias in each domain should be rated as high or low.

Checklists are usually equivalent to each other; however, each domain or dimension for all included studies should be explained in detail to give the reader of systematic reviews a clue regarding the quality of the included studies. Reporting only based on numbers (quality scores) should be discouraged.

\subsection{Data Extraction}

All relevant data should be extracted from the included studies. Detailed information regarding the study population, method of the diagnostic or prognostic test, gold standard test, follow-up times, methods of ascertaining outcomes, outcome variables such as false and true negative (FN, TN), false and true positive (FP, TP) cases for diagnostic studies, and hazard ratios (HR) for OS and PFS for prognostic studies should be extracted. Extraction of data should be as complete as possible to allow reconstruction of $2 \times 2$ diagnostic tables or HR of prognostic factors as well as sub-group analyses [11, 13, 14].
Extraction of data in prognostic studies can be very tricky: not all studies reported HR, and only Kaplan Meier (KM) curves and associated log rank tests are usually reported. HR can be extracted from KM curves. Usually the survival data can be extracted manually from KM curves using special software such as getdata graph digitizer (available at http://getdata-graph-digitizer. com/download.php). Finally the extracted survival data can be converted to HR by Parmar method using a special Excel file provided by Parmar et al. [15].

Another important aspect of extraction data in prognostic systematic reviews is type of prognostic factor (quantitative vs. qualitative factors) and evaluation of other prognostic factors (multivariate vs. univariate analysis). HR of quantitative variables (such as SUVmax) can be provided in two ways: first, the prognostic factor can be used as a quantitative variable and a HR using Cox regression is provided. The second type of HR can be calculated by categorizing a quantitative variable into two ranks (for example, SUVmax $>7$ and 57 ). These two types of HR cannot be pooled with each other even for a same prognostic factor. In addition, only univariate or multivariate HR should be used for pooling data across studies. Pooling univariate HR with a multivariate HR is discouraged as the latter (but not the former) takes into account other potential prognostic factors.

\subsection{Pooling Diagnostic Indices Across Studies and Reporting Heterogeneity}

In this final step, the numerical results of the included studies would be pooled together. First of all, diagnostic or prognostic indices of each included study should be presented.

The following diagnostic indices should be reported:

- Sensitivity $=\mathrm{TP} /(\mathrm{TP}+\mathrm{FN})$

- Specificity $=\mathrm{TN} /(\mathrm{TN}+\mathrm{FP})$

- Positive likelihood ratio $(\mathrm{LR}+)=$ sensitivity/ (1 - specificity) 
- Negative likelihood ratio $(\mathrm{LR}-)=(1-$ sensitivity)/specificity

- Diagnostic odds ratio $(\mathrm{DOR})=\mathrm{LR}-/ \mathrm{LR}+$

The following prognostic indices should be reported:

- Log rank test and $p$-value of each prognostic factor (only available for categorical variables).

- Hazard ratios (HR) for prognostic factors.

- Univariate and multivariate HR (if available) should be reported. In addition, for quantitative variables HR for the quantitative variable as well as HR for categorized variable (if available) should be reported (see the previous section for more information).

Meta-analysis is a special statistical method for pooling data across different studies and giving pooled diagnostic indices. For this purpose, a weight is attributed to each study and the weighted diagnostic indices are pooled together. Special software are available for this purpose, including SAS, R, and STATA.

For diagnostic studies, two free software are available:

1. OpenMeta [Analyst] is a free software for meta-analysis of diagnostic studies. This software is available online at http://www.cebm. brown.edu/openmeta/downloads/OpenMetaanalyst_Windows.zip [16].

2. Meta-Disc is another free software which has been specially designed for diagnostic studies. This soft'ware is available online at https:// download.freedownloadmanager.org/ Windows-PC/Meta-DiSc/FREE-1.4.html [17].

For prognostic studies, usually hazard ratios should be pooled across included studies. Several software are available in this regard, such as R, SAS, and Comprehensive Meta-Analysis (CMA).

The least required data to be provided in a meta-analysis are:

1. Pooled indices: They can be perfectly reported by forest plots which give all included studies as well as the pooled data in one view.
2. Pooling method: We recommend random effects model for pooling studies as fixed model would not account for heterogeneity among included studies [18].

3. Heterogeneity: Included studies of a systematic review are different from each other on several accounts such as studied population, methodology of the diagnostic tests or prognostic factors, etc. Several factors contribute to the heterogeneity among studies: sampling error of the individual studies including true differences between included studies and finally the threshold effect $[19,20]$. Methods for undertaking analyses which account for both sensitivity and specificity, the relationship between them, and the heterogeneity in test accuracy, require fitting hierarchical random effects models [21]. To report heterogeneity for each meta-analysis, at least Cochrane $Q$ value and its associated $p$-value and $I$ squared should be reported. Several methods are available in order to address the heterogeneity across included studies such as sub-group analysis, meta-regression, and sensitivity analysis. The authors should use these methods to explain the underlying reasons of heterogeneity across included studies.

4. Threshold effect: A unique source of heterogeneity in meta-analysis of diagnostic studies is the threshold effect. Not all studies use the same cut-off value for a positive result. This can be due to an explicit cut-off point value or explicit human or instrumental factors. This should be addressed in all diagnostic metaanalyses. Although the summary receiver operating characteristic curve (SROC) method and reporting $Q *$ have been used traditionally for evaluating the threshold effect in diagnostic studies, the best way to report the possible effect of threshold effect is bivariate metaanalyses [22, 23]. In this method, correlation between specificity and sensitivity is used as a variable to correct the results of the metaanalyses for possible threshold effect. This method has been incorporated in the last version of OpenMeta [Analyst] and can be easily reported. The traditional SROC method is no longer recommended. 
5. Publication bias: Although there is substantial literature relating to publication bias in systematic reviews and meta-analyses of randomized controlled trials, little research has been done in the context of systematic reviews and meta-analyses of diagnostic studies. However, publication bias can be visually presented by funnel plots and can be quantified by several methods such as Egger's regression intercept or trim and fill method [24, 25].

\subsection{Discussion and Conclusion of Systematic Reviews}

The discussion and final conclusion of a systematic review and meta-analysis should be as objective as possible. The authors should discuss the main results of the systematic review and metaanalysis. Final conclusion should be based on the main results of the systematic review. Any heterogeneity of the included studies should be explained and the possible reasons should be discussed.

Standard method of reporting systematic reviews and meta-analyses Preferred Reporting Items for Systematic Reviews and MetaAnalyses (PRISMA) provides a minimum requirement for reporting systematic reviews and meta-analyses [21, 26]. Although it is originally prepared for systematic reviews of randomized clinical trials, systematic reviews of diagnostic accuracy studies can be reported using PRISMA too. PRISMA statement and checklist can be found in the following link: http://www.prisma-statement.org/.

\subsection{Final Comment}

To publish a high quality systematic review or meta-analysis of diagnostic test accuracy or prognostic studies, certain methodology should be followed. Only methodologically sound systematic reviews and meta-analyses are worth publication and can change or support clinical use of a diagnostic test or a prognostic factor. Hopefully, the abovementioned methodology could help the researchers through the process of systematic review and meta-analysis preparation.

\section{References}

1. Sackett DL, Rosenberg WM, Gray JA, Haynes RB, Richardson WS. Evidence based medicine: what it is and what it isn't. BMJ. 1996;312:71-2.

2. Sadeghi R, Zakavi R, Kakhki VRD. How to apply the evidence-based medicine concept to nuclear medicine diagnostic studies-a review. Nucl Med Rev. 2009;12:59-64.

3. Kianifar H-R, Akhondian J, Najafi-Sani M, Sadeghi R. Evidence based medicine in pediatric practice: brief review. Iran J Pediatr. 2010;20:261.

4. Treglia G, Sadeghi R. Meta-analyses and systematic reviews on $\mathrm{PET}$ and $\mathrm{PET} / \mathrm{CT}$ in oncology: the state of the art. Clin Transl Imaging. 2013;1:73-5.

5. Treglia G, Sadeghi R, Del Sole A, Giovanella L. Diagnostic performance of PET/CT with tracers other than F-18-FDG in oncology: an evidence-based review. Clin Transl Oncol. 2014;16:770-5.

6. Smith V, Devane D, Begley CM, Clarke M. Methodology in conducting a systematic review of systematic reviews of healthcare interventions. BMC Med Res Methodol. 2011;11:15.

7. Khan KS, Kunz R, Kleijnen J, Antes G. Five steps to conducting a systematic review. J R Soc Med. 2003;96:118-21.

8. Sadeghi R. Evidence based medicine in nuclear medicine practice; part I: introduction, asking answerable questions and searching for the best evidence. Iran J Nucl Med. 2009;17(1):41-8.

9. Sadeghi R. Evidence based medicine in nuclear medicine practice; part II: appraising and applying the evidence. Iran J Nucl Med. 2009;17:49-56.

10. Whiting PF, Rutjes AW, Westwood ME, et al. QUADAS-2: a revised tool for the quality assessment of diagnostic accuracy studies. Ann Intern Med. 2011;155:529-36.

11. Riley RD, Moons KG, Snell KI, et al. A guide to systematic review and meta-analysis of prognostic factor studies. BMJ. 2019;364:k4597.

12. Hayden JA, van der Windt DA, Cartwright JL, Côté P, Bombardier C. Assessing bias in studies of prognostic factors. Ann Intern Med. 2013;158:280-6.

13. Devillé WL, Buntinx F, Bouter LM, et al. Conducting systematic reviews of diagnostic studies: didactic guidelines. BMC Med Res Methodol. 2002;2:9.

14. Irwig L, Tosteson AN, Gatsonis C, et al. Guidelines for meta-analyses evaluating diagnostic tests. Ann Intern Med. 1994;120:667-76.

15. Parmar MK, Torri V, Stewart L. Extracting summary statistics to perform meta-analyses of the published literature for survival endpoints. Stat Med. 1998;17:2815-34. 
16. Wallace BC, Schmid CH, Lau J, Trikalinos TA. Metaanalyst: software for meta-analysis of binary, continuous and diagnostic data. BMC Med Res Methodol. 2009;9:80.

17. Zamora J, Abraira V, Muriel A, Khan K, Coomarasamy A. Meta-DiSc: a software for metaanalysis of test accuracy data. BMC Med Res Methodol. 2006;6:31.

18. Higgins JP, Thompson SG, Spiegelhalter DJ. A reevaluation of random-effects meta-analysis. J R Stat Soc A Stat Soc. 2009;172:137-59.

19. Higgins JP, Thompson SG. Quantifying heterogeneity in a meta-analysis. Stat Med. 2002;21:1539-58.

20. Patsopoulos NA, Evangelou E, Ioannidis JP. Sensitivity of between-study heterogeneity in meta-analysis: proposed metrics and empirical evaluation. Int J Epidemiol. 2008;37:1148-57.

21. Bae J-M. An overview of systematic reviews of diagnostic tests accuracy. Epidemiol Health. 2014;36:e2014016.
22. Reitsma JB, Glas AS, Rutjes AW, Scholten RJ, Bossuyt PM, Zwinderman AH. Bivariate analysis of sensitivity and specificity produces informative summary measures in diagnostic reviews. J Clin Epidemiol. 2005;58:982-90.

23. Moses LE, Shapiro D, Littenberg B. Combining independent studies of a diagnostic test into a summary ROC curve: data-analytic approaches and some additional considerations. Stat Med. 1993;12:1293-316.

24. Duval S, Tweedie R. Trim and fill: a simple funnelplot-based method of testing and adjusting for publication bias in meta-analysis. Biometrics. 2000;56:455-63.

25. Egger M, Smith GD, Schneider M, Minder C. Bias in meta-analysis detected by a simple, graphical test. BMJ. 1997;315:629-34.

26. Moher D, Liberati A, Tetzlaff J, Altman DG. Preferred reporting items for systematic reviews and metaanalyses: the PRISMA statement. Ann Intern Med. 2009;151:264-9.

Open Access This chapter is licensed under the terms of the Creative Commons Attribution 4.0 International License (http://creativecommons.org/licenses/by/4.0/), which permits use, sharing, adaptation, distribution and reproduction in any medium or format, as long as you give appropriate credit to the original author(s) and the source, provide a link to the Creative Commons license and indicate if changes were made.

The images or other third party material in this chapter are included in the chapter's Creative Commons license, unless indicated otherwise in a credit line to the material. If material is not included in the chapter's Creative Commons license and your intended use is not permitted by statutory regulation or exceeds the permitted use, you will need to obtain permission directly from the copyright holder. 


\section{Part II}

Evidence-Based PET in Oncology 


\title{
Evidence-Based PET for Brain Tumours
}

\author{
Giorgio Treglia and Barbara Muoio
}

\subsection{Background}

Positron emission tomography (PET) using different radiotracers evaluating different metabolic patterns is able to early detect pathophysiological changes in oncological patients, including those with brain tumours. These functional changes usually occur before the development of morphological changes detected by conventional radiological imaging techniques such as computed tomography (CT) and magnetic resonance imaging (MRI) [1]. MRI is the standard neuroimaging method used for diagnosis of brain tumours, for performing stereotactic biopsy and surgical planning in neuro-oncology [2]. Currently, hybrid

G. Treglia $(\bowtie)$

Clinic of Nuclear Medicine and Molecular Imaging, Imaging Institute of Southern Switzerland, Ente Ospedaliero Cantonale,

Bellinzona and Lugano, Switzerland

Department of Nuclear Medicine and Molecular Imaging, Lausanne University Hospital and University of Lausanne, Lausanne, Switzerland

Health Technology Assessment Unit, Academic Education, Research and Innovation Area, Ente Ospedaliero Cantonale, Bellinzona, Switzerland e-mail: giorgio.treglia@eoc.ch

B. Muoio

Clinic of Oncology and Internal Medicine, San Giovanni Hospital, Oncology Institute of Southern Switzerland, Ente Ospedaliero Cantonale,

Bellinzona, Switzerland imaging techniques as PET/CT and PET/MRI, providing a combination of both functional and morphological information, may be useful methods for early diagnosis of brain tumours [1,2].

Different PET radiotracers have been used to evaluate brain tumours including fluorine-18 fluorodeoxyglucose $\left({ }^{18} \mathrm{~F}-\mathrm{FDG}\right)$, carbon-11 methionine $\quad\left({ }^{11} \mathrm{C}\right.$-methionine $), \quad$ fluorine-18 fluoroethyltyrosine $\left({ }^{18} \mathrm{~F}-\mathrm{FET}\right)$, fluorine- 18 fluorodihydroxyphenylalanine ( $\left.{ }^{18} \mathrm{~F}-\mathrm{FDOPA}\right)$, fluorine18 fluorothymidine $\left({ }^{18} \mathrm{~F}-\mathrm{FLT}\right)$ and radiolabelled choline $\left({ }^{11} \mathrm{C}\right.$-choline or ${ }^{18} \mathrm{~F}$-choline $)$.

Enough literature data already exist about the diagnostic performance and prognostic value of PET with different tracers in brain tumours. In particular, 24 meta-analyses on the use of PET or PET/CT with different tracers in brain tumours, published from 2012, were selected through a comprehensive computer literature search [3-26]. The findings of the selected meta-analyses on the diagnostic performance are presented in Table 3.1. Here below we have summarized the main findings of meta-analytic studies based on the different clinical indications of PET or PET/CT.

\subsection{Evaluation of Suspicious Primary Brain Tumour}

Four meta-analyses have assessed the diagnostic performance of PET or PET/CT with different tracers in patients for whom primary brain tumours are suspected [3, 20, 23, 26]. 
Table 3.1 Characteristics and main findings of included meta-analyses on the diagnostic performance of PET or PET/ CT with different tracers in patients with brain tumours

\begin{tabular}{|c|c|c|c|c|c|c|c|}
\hline Indication & Tracer & Authors & $\begin{array}{l}\text { Sensitivity } \\
(95 \% \mathrm{CI})\end{array}$ & $\begin{array}{l}\text { Specificity } \\
(95 \% \mathrm{CI})\end{array}$ & $\begin{array}{l}\mathrm{LR}+ \\
(95 \% \mathrm{CI})\end{array}$ & $\begin{array}{l}\mathrm{LR}- \\
(95 \% \mathrm{CI})\end{array}$ & $\begin{array}{l}\text { DOR } \\
(95 \% \mathrm{CI})\end{array}$ \\
\hline \multirow{6}{*}{$\begin{array}{l}\text { Evaluation of } \\
\text { suspicious } \\
\text { primary brain } \\
\text { tumour }\end{array}$} & \multirow[t]{2}{*}{${ }^{18} \mathrm{~F}-\mathrm{FDG}$} & Zhao et al. [23] & $\begin{array}{l}43 \% \\
(28-59)\end{array}$ & $\begin{array}{l}74 \% \\
(49-90)\end{array}$ & $\begin{array}{l}1.7 \\
(0.6-4.8)\end{array}$ & $\begin{array}{l}0.77 \\
(0.48- \\
1.24)\end{array}$ & NR \\
\hline & & Dunet et al. [20] & $\begin{array}{l}38 \% \\
(27-50)\end{array}$ & $\begin{array}{l}86 \% \\
(31-99)\end{array}$ & $\begin{array}{l}2.7 \\
(0.3- \\
27.8)\end{array}$ & $\begin{array}{l}0.72 \\
(0.47- \\
1.11)\end{array}$ & $\begin{array}{l}4 \\
(0-58)\end{array}$ \\
\hline & ${ }^{11} \mathrm{C}$-methionine & Zhao et al. [23] & $\begin{array}{l}95 \% \\
(85-98)\end{array}$ & $\begin{array}{l}83 \% \\
(65-93)\end{array}$ & $\begin{array}{l}5.5 \\
(2.5- \\
12.2)\end{array}$ & $\begin{array}{l}0.07 \\
(0.02- \\
0.2)\end{array}$ & NR \\
\hline & \multirow[t]{2}{*}{${ }^{18} \mathrm{~F}-\mathrm{FET}$} & Dunet et al. [26] & $\begin{array}{l}82 \% \\
(74-88)\end{array}$ & $\begin{array}{l}76 \% \\
(44-92)\end{array}$ & $\begin{array}{l}3.4 \\
(1.2-9.5)\end{array}$ & $\begin{array}{l}0.24 \\
(0.14- \\
0.39)\end{array}$ & $\begin{array}{l}14 \\
(3-60)\end{array}$ \\
\hline & & Dunet et al. [20] & $\begin{array}{l}94 \% \\
(79-98)\end{array}$ & $\begin{array}{l}88 \% \\
(37-99)\end{array}$ & $\begin{array}{l}8.1 \\
(0.8- \\
80.6)\end{array}$ & $\begin{array}{l}0.07 \\
(0.02- \\
0.30)\end{array}$ & $\begin{array}{l}113 \\
(4-2975)\end{array}$ \\
\hline & ${ }^{18} \mathrm{~F}-\mathrm{FDOPA}$ & Xiao et al. [3] & $\begin{array}{l}71 \% \\
(54-85)\end{array}$ & $\begin{array}{l}86 \% \\
(42-100)\end{array}$ & $\begin{array}{l}3.7 \\
(0.9- \\
15.8)\end{array}$ & $\begin{array}{l}0.36 \\
(0.19- \\
0.68)\end{array}$ & $\begin{array}{l}10.88 \\
(1.57- \\
75.31)\end{array}$ \\
\hline \multirow[t]{7}{*}{ Glioma grading } & \multirow[t]{2}{*}{${ }^{18} \mathrm{~F}-\mathrm{FDG}$} & Dunet et al. [20] & $\begin{array}{l}60 \%(\text { mean } \\
\text { TBR } \geq 1.4) \\
72 \%(\max \\
T B R \geq 1.8)\end{array}$ & $\begin{array}{l}91 \%(\text { mean } \\
\text { TBR } \geq 1.4) \\
73 \%(\max \\
\text { TBR } \geq 1.8)\end{array}$ & NR & NR & NR \\
\hline & & Katsanos et al. [6] & $\begin{array}{l}63 \% \\
(51-74)\end{array}$ & $\begin{array}{l}89 \% \\
(73-95)\end{array}$ & $\begin{array}{l}5.2 \\
(2.1-13)\end{array}$ & $\begin{array}{l}0.42 \\
(0.29- \\
0.6)\end{array}$ & $\begin{array}{l}12.4 \\
(3.86- \\
39.8)\end{array}$ \\
\hline & \multirow[t]{2}{*}{${ }^{11} \mathrm{C}$-methionine } & $\begin{array}{l}\text { Falk Delgado et al. } \\
{[14]}\end{array}$ & $\begin{array}{l}80 \% \\
(66-88)\end{array}$ & $\begin{array}{l}72 \% \\
(62-81)\end{array}$ & NR & NR & NR \\
\hline & & Katsanos et al. [6] & $\begin{array}{l}94 \% \\
(79-98)\end{array}$ & $\begin{array}{l}55 \% \\
(32-77)\end{array}$ & $\begin{array}{l}2.1 \\
(1.25- \\
3.5)\end{array}$ & $\begin{array}{l}0.11 \\
(0.03- \\
0.37)\end{array}$ & $\begin{array}{l}18.25 \\
(4.73- \\
70.5)\end{array}$ \\
\hline & \multirow[t]{2}{*}{${ }^{18} \mathrm{~F}-\mathrm{FET}$} & Dunet et al. [20] & $\begin{array}{l}88 \% \text { (mean } \\
\text { TBR } \geq 2) \\
80 \%(\max \\
T B R \geq 3)\end{array}$ & $\begin{array}{l}73 \% \text { (mean } \\
\text { TBR } \geq 2) \\
82 \%(\max \\
T B R \geq 3)\end{array}$ & NR & NR & NR \\
\hline & & Katsanos et al. [6] & $\begin{array}{l}88 \% \\
(82-93)\end{array}$ & $\begin{array}{l}57 \% \\
(40-73)\end{array}$ & $\begin{array}{l}2.1 \\
(1.4- \\
3.15)\end{array}$ & $\begin{array}{l}0.2 \\
(0.11- \\
0.37)\end{array}$ & $\begin{array}{l}10.16 \\
(3.9- \\
26.5)\end{array}$ \\
\hline & ${ }^{18} \mathrm{~F}-\mathrm{FDOPA}$ & Xiao et al. [3] & $\begin{array}{l}88 \% \\
(81-93)\end{array}$ & $\begin{array}{l}73 \\
(64-81)\end{array}$ & $\begin{array}{l}2.9 \\
(2.2- \\
3.85)\end{array}$ & $\begin{array}{l}0.16 \\
(0.08- \\
0.36)\end{array}$ & $\begin{array}{l}25.87 \\
(10.53- \\
63.54)\end{array}$ \\
\hline $\begin{array}{l}\text { Glioma } \\
\text { delineation }\end{array}$ & ${ }^{11} \mathrm{C}$-methionine & Verburg et al. [16] & $\begin{array}{l}\text { [HGG] } \\
93.7 \%\end{array}$ & $\begin{array}{l}\text { [HGG] } \\
61.3 \%\end{array}$ & NR & NR & $\begin{array}{l}{[\mathrm{HGG}]} \\
26.6\end{array}$ \\
\hline
\end{tabular}


Table 3.1 (continued)

\begin{tabular}{|c|c|c|c|c|c|c|c|}
\hline Indication & Tracer & Authors & $\begin{array}{l}\text { Sensitivity } \\
(95 \% \mathrm{CI})\end{array}$ & $\begin{array}{l}\text { Specificity } \\
(95 \% \mathrm{CI})\end{array}$ & $\begin{array}{l}\mathrm{LR}+ \\
(95 \% \mathrm{CI})\end{array}$ & $\begin{array}{l}\mathrm{LR}- \\
(95 \% \mathrm{CI})\end{array}$ & $\begin{array}{l}\text { DOR } \\
(95 \% \mathrm{CI})\end{array}$ \\
\hline \multirow[t]{18}{*}{$\begin{array}{l}\text { Diagnosis of } \\
\text { recurrent brain } \\
\text { tumour }\end{array}$} & \multirow[t]{5}{*}{${ }^{18} \mathrm{~F}-\mathrm{FDG}$} & Nihashi et al. [25] & $\begin{array}{l}77 \% \\
(66-85)\end{array}$ & $\begin{array}{l}78 \% \\
(54-91)\end{array}$ & $\begin{array}{l}3.4 \\
(1.6-7.5)\end{array}$ & $\begin{array}{l}0.3 \\
(0.21- \\
0.43)\end{array}$ & NR \\
\hline & & Zhao et al. [23] & $\begin{array}{l}75 \% \\
(67-81)\end{array}$ & $\begin{array}{l}79 \% \\
(66-88)\end{array}$ & $\begin{array}{l}3.5 \\
(2.2-5.7)\end{array}$ & $\begin{array}{l}0.32 \\
(0.25- \\
0.41)\end{array}$ & NR \\
\hline & & Li et al. [21] & $\begin{array}{l}78 \% \\
(69-85)\end{array}$ & $\begin{array}{l}77 \% \\
(66-85)\end{array}$ & $\begin{array}{l}3.3 \\
(2.2-5)\end{array}$ & $\begin{array}{l}0.29 \\
(0.20- \\
0.42)\end{array}$ & $\begin{array}{l}12 \\
(6-22)\end{array}$ \\
\hline & & Wang et al. [22] & $\begin{array}{l}70 \% \\
(64-75 \%)\end{array}$ & $\begin{array}{l}88 \% \\
(80-93 \%)\end{array}$ & $\begin{array}{l}4 \\
(2.1-7.5)\end{array}$ & $\begin{array}{l}0.38 \\
(0.29- \\
0.51)\end{array}$ & NR \\
\hline & & Furuse et al. [7] & $\begin{array}{l}81 \% \\
(67-90)\end{array}$ & $\begin{array}{l}72 \% \\
(64-79)\end{array}$ & NR & NR & NR \\
\hline & \multirow[t]{6}{*}{${ }^{11} \mathrm{C}$-methionine } & Nihashi et al. [25] & $\begin{array}{l}{[\mathrm{HGG}]} \\
70 \% \\
(50-84)\end{array}$ & $\begin{array}{l}{[\mathrm{HGG}]} \\
93 \% \\
(44-100)\end{array}$ & $\begin{array}{l}{[\mathrm{HGG}]} \\
10.3 \\
(0.8- \\
139.4)\end{array}$ & $\begin{array}{l}{[\mathrm{HGG}]} \\
0.32 \\
(0.18- \\
0.57)\end{array}$ & NR \\
\hline & & Deng et al. [24] & $\begin{array}{l}87 \% \\
(81-91.8)\end{array}$ & $\begin{array}{l}81.3 \% \\
(71.5-88.8)\end{array}$ & $\begin{array}{l}4.35 \\
(2.8-6.8)\end{array}$ & $\begin{array}{l}0.19 \\
(0.13- \\
0.29)\end{array}$ & $\begin{array}{l}21.86 \\
(10.7- \\
44.5)\end{array}$ \\
\hline & & Zhao et al. [23] & $\begin{array}{l}92 \% \\
(83-97)\end{array}$ & $\begin{array}{l}87 \% \\
(75-93)\end{array}$ & $\begin{array}{l}6.8 \\
(3.4- \\
13.7)\end{array}$ & $\begin{array}{l}0.09 \\
(0.04- \\
0.21)\end{array}$ & NR \\
\hline & & Wang et al. [22] & $\begin{array}{l}85 \% \\
(76-91 \%)\end{array}$ & $\begin{array}{l}83 \% \\
(71-92 \%)\end{array}$ & $\begin{array}{l}4.4 \\
(2.5-7.7)\end{array}$ & $\begin{array}{l}0.22 \\
(0.13- \\
0.35)\end{array}$ & NR \\
\hline & & Xu et al. [13] & $\begin{array}{l}88 \% \\
(85-91 \%)\end{array}$ & $\begin{array}{l}85 \% \\
(80-89)\end{array}$ & $\begin{array}{l}5.3 \\
(3.3-8.7)\end{array}$ & $\begin{array}{l}0.16 \\
(0.11- \\
0.23)\end{array}$ & $\begin{array}{l}35.3 \\
(22.9- \\
54.4)\end{array}$ \\
\hline & & Furuse et al. [7] & $\begin{array}{l}81 \% \\
(73-87)\end{array}$ & $\begin{array}{l}81 \% \\
(74-87)\end{array}$ & NR & NR & NR \\
\hline & \multirow[t]{2}{*}{${ }^{18} \mathrm{~F}-\mathrm{FET}$} & Yu et al. [11] & $\begin{array}{l}82 \% \\
(79-84)\end{array}$ & $\begin{array}{l}80 \% \\
(76-83)\end{array}$ & $\begin{array}{l}3.9 \\
(3.0-5.1)\end{array}$ & $\begin{array}{l}0.21 \\
(0.17- \\
0.27)\end{array}$ & $\begin{array}{l}23.03 \\
(14.42- \\
36.77)\end{array}$ \\
\hline & & Furuse et al. [7] & $\begin{array}{l}91 \% \\
(79-97)\end{array}$ & $\begin{array}{l}95 \% \\
(61-99)\end{array}$ & NR & NR & NR \\
\hline & \multirow[t]{2}{*}{${ }^{18} \mathrm{~F}-\mathrm{FDOPA}$} & Yu et al. [11] & $\begin{array}{l}85 \% \\
(81-88)\end{array}$ & $\begin{array}{l}77 \% \\
(74-81)\end{array}$ & $\begin{array}{l}3.4 \\
(2.8-4.3)\end{array}$ & $\begin{array}{l}0.21 \\
(0.16- \\
0.29)\end{array}$ & $\begin{array}{l}21.7 \\
(12.61- \\
37.33)\end{array}$ \\
\hline & & Xiao et al. [3] & $\begin{array}{l}92 \% \\
(88-95)\end{array}$ & $\begin{array}{l}76 \% \\
(66-85)\end{array}$ & $\begin{array}{l}2.9 \\
(2-4.1)\end{array}$ & $\begin{array}{l}0.13 \\
(0.07- \\
0.23)\end{array}$ & $\begin{array}{l}29.65 \\
(13.09- \\
67.15)\end{array}$ \\
\hline & $\mathrm{AA} *$ & Kim et al. [4] & $\begin{array}{l}89 \% \\
(82-94)\end{array}$ & $\begin{array}{l}88 \% \\
(76-94)\end{array}$ & $\begin{array}{l}7.3 \\
(3.6- \\
14.7)\end{array}$ & $\begin{array}{l}0.12 \\
(0.07- \\
0.21)\end{array}$ & $\begin{array}{l}60 \\
(23-152)\end{array}$ \\
\hline & ${ }^{18} \mathrm{~F}-\mathrm{FLT}$ & Li et al. [21] & $\begin{array}{l}82 \% \\
(51-95)\end{array}$ & $\begin{array}{l}76 \% \\
(50-91)\end{array}$ & $\begin{array}{l}3.5 \\
(1.6-7.7)\end{array}$ & $\begin{array}{l}0.24 \\
(0.08- \\
0.70)\end{array}$ & $\begin{array}{l}15 \\
(4-56)\end{array}$ \\
\hline & ${ }^{11} \mathrm{C}$-choline & Gao et al. [9] & $\begin{array}{l}87 \% \\
(78-93)\end{array}$ & $\begin{array}{l}82 \% \\
(69-91)\end{array}$ & $\begin{array}{l}4.9 \\
(2.6-9.1)\end{array}$ & $\begin{array}{l}0.16 \\
(0.09- \\
0.29)\end{array}$ & $\begin{array}{l}35.5 \\
(11.7- \\
107.7)\end{array}$ \\
\hline
\end{tabular}


Table 3.1 (continued)

\begin{tabular}{|c|c|c|c|c|c|c|c|}
\hline Indication & Tracer & Authors & $\begin{array}{l}\text { Sensitivity } \\
(95 \% \mathrm{CI})\end{array}$ & $\begin{array}{l}\text { Specificity } \\
(95 \% \mathrm{CI})\end{array}$ & $\begin{array}{l}\mathrm{LR}+ \\
(95 \% \mathrm{CI})\end{array}$ & $\begin{array}{l}\mathrm{LR}- \\
(95 \% \mathrm{CI})\end{array}$ & $\begin{array}{l}\text { DOR } \\
(95 \% \mathrm{CI})\end{array}$ \\
\hline $\begin{array}{l}\text { Diagnosis of } \\
\text { brain metastases }\end{array}$ & ${ }^{18} \mathrm{~F}-\mathrm{FDG}$ & Li et al. [19] & $\begin{array}{l}21 \% \\
(13-32)\end{array}$ & $\begin{array}{l}100 \% \\
(99-100)\end{array}$ & $\begin{array}{l}184.7 \\
(24.8- \\
1374)\end{array}$ & $\begin{array}{l}0.79 \\
(0.70- \\
0.89)\end{array}$ & $\begin{array}{l}235 \\
(31- \\
1799)\end{array}$ \\
\hline \multirow{10}{*}{$\begin{array}{l}\text { Diagnosis of } \\
\text { recurrent brain } \\
\text { metastases }\end{array}$} & \multirow[t]{3}{*}{${ }^{18} \mathrm{~F}-\mathrm{FDG}$} & Li et al. [12] & $\begin{array}{l}85 \% \\
(77-94)\end{array}$ & $\begin{array}{l}90 \% \\
(83-96)\end{array}$ & NR & NR & NR \\
\hline & & Suh et al. [8] & $\begin{array}{l}83 \% \\
(74-92)\end{array}$ & $\begin{array}{l}88 \% \\
(81-95)\end{array}$ & NR & NR & NR \\
\hline & & Furuse et al. [7] & $\begin{array}{l}91 \% \\
(73-97)\end{array}$ & $\begin{array}{l}80 \% \\
(60-91)\end{array}$ & NR & NR & NR \\
\hline & \multirow[t]{2}{*}{${ }^{11} \mathrm{C}$-methionine } & Li et al. [12] & $\begin{array}{l}86 \% \\
(74-97)\end{array}$ & $\begin{array}{l}79 \% \\
(66-93)\end{array}$ & NR & NR & NR \\
\hline & & Furuse et al. [7] & $\begin{array}{l}79 \% \\
(67-87)\end{array}$ & $\begin{array}{l}76 \% \\
(61-87)\end{array}$ & NR & NR & NR \\
\hline & \multirow[t]{2}{*}{${ }^{18} \mathrm{~F}-\mathrm{FET}$} & Li et al. [12] & $\begin{array}{l}83 \% \\
(76-91)\end{array}$ & $\begin{array}{l}89 \% \\
(83-95)\end{array}$ & NR & NR & NR \\
\hline & & Yu et al. [11] & $\begin{array}{l}80 \% \\
(76-84)\end{array}$ & $\begin{array}{l}79 \% \\
(75-83)\end{array}$ & 3.9 & 0.24 & 19 \\
\hline & \multirow[t]{2}{*}{${ }^{18} \mathrm{~F}-\mathrm{FDOPA}$} & Li et al. [12] & $\begin{array}{l}86 \% \\
(74-97)\end{array}$ & $\begin{array}{l}88 \% \\
(79-97)\end{array}$ & NR & NR & NR \\
\hline & & Yu et al. [11] & $\begin{array}{l}78 \% \\
(73-82)\end{array}$ & $\begin{array}{l}75 \% \\
(71-89 \%)\end{array}$ & 3 & 0.31 & 11 \\
\hline & $\mathrm{AA} *$ & Suh et al. [8] & $\begin{array}{l}84 \% \\
(79-90)\end{array}$ & $\begin{array}{l}85 \% \\
(80-91)\end{array}$ & NR & NR & NR \\
\hline \multirow[t]{2}{*}{$\begin{array}{l}\text { Diagnosis of } \\
\text { PCNSL }\end{array}$} & \multirow[t]{2}{*}{${ }^{18} \mathrm{~F}-\mathrm{FDG}$} & Zhou et al. [17] & $\begin{array}{l}88 \% \\
(80-94)\end{array}$ & $\begin{array}{l}86 \\
(73-94)\end{array}$ & $\begin{array}{l}4 \\
(2.3-6.9)\end{array}$ & $\begin{array}{l}0.11 \\
(0.04- \\
0.32)\end{array}$ & $\begin{array}{l}33.4 \\
(10.4- \\
107.3)\end{array}$ \\
\hline & & Yang et al. [18] & NR & NR & NR & NR & NR \\
\hline
\end{tabular}

$L R+$ positive likelihood ratio; $L R-$ negative likelihood ratio; DOR diagnostic odds ratio; $95 \% C I 95 \%$ confidence interval; $A A *$ radiolabelled amino acid PET including radiolabelled methionine, fluoroethyltyrosine and fluorodihydroxyphenylalanine; $N R$ not reported; $H G G$ high-grade gliomas only; $P C N S L$ primary central nervous system lymphoma; mean TBR mean tumour-to-background uptake ratio; $\max T B R$ maximum tumour-to-background uptake ratio

\subsection{1 $\quad{ }^{18}$ F-FDG}

A meta-analysis including patients with suspicious primary brain tumours showed that ${ }^{18} \mathrm{~F}-$ FDG PET or PET/CT has a moderate sensitivity and specificity for differentiating brain tumours from non-tumour lesions. False-positive findings were often due to inflammatory lesions or other non-tumour tissues; on the other hand, reduced ${ }^{18} \mathrm{~F}-\mathrm{FDG}$ uptake in brain tumours is usually influenced by the high physiological glucose metabolism in surrounding normal brain tissue, leading to a decreased sensitivity [23]. Another metaanalysis also demonstrated that ${ }^{18} \mathrm{~F}$-FDG PET or $\mathrm{PET} / \mathrm{CT}$ has a moderate diagnostic performance in distinguishing between tumour and nontumour lesions in the brain, lower than amino acid PET [20].

\subsection{2 ${ }^{11} \mathrm{C}$-Methionine}

A meta-analysis by Zhao et al. demonstrated a good diagnostic performance of ${ }^{11} \mathrm{C}$-methionine PET or PET/CT in detecting brain tumours (pooled sensitivity and specificity were of $95 \%$ and $83 \%$, respectively) with higher diagnostic accuracy values compared to ${ }^{18} \mathrm{~F}-\mathrm{FDG}$ PET or $\mathrm{PET} / \mathrm{CT}$, likely due to the higher ${ }^{11} \mathrm{C}$-methionine uptake in brain tumours and lower accumulation in normal brain tissue [23].

\subsection{3 ${ }^{18}$ F-FET}

For initial assessment of patients with a newly diagnosed brain lesion, ${ }^{18} \mathrm{~F}$-FET PET or PET/CT demonstrated a good performance in the diagno- 
sis of a brain tumour with a pooled sensitivity and specificity of $82 \%$ and $76 \%$, respectively. A mean tumour-to-background uptake ratio (TBR) threshold of at least 1.6 and a maximum TBR of at least 2.1 had the best diagnostic value for differentiating brain tumours from non-tumour brain lesions. For the diagnosis of glioma versus non-glioma brain lesions, ${ }^{18} \mathrm{~F}$-FET PET or PET/ CT demonstrated a good sensitivity (84\%) but a not adequate specificity (62\%) [26]. In a head-tohead comparative meta-analysis, the diagnostic performance of ${ }^{18} \mathrm{~F}$-FET PET or PET/CT in distinguishing between tumour and non-tumour lesions in the brain was found significantly higher compared to that of ${ }^{18} \mathrm{~F}-\mathrm{FDG}$ PET or PET/CT performed in the same patients [20].

\subsection{4 ${ }^{18}$ F-FDOPA}

${ }^{18} \mathrm{~F}$-FDOPA PET or PET/CT revealed a moderate sensitivity (71\%) and a good specificity (86\%) in detecting newly diagnosed gliomas [3].

\subsection{Glioma Grading}

Gliomas are the most frequent primary brain tumours. High-grade gliomas like glioblastomas are the most common gliomas in adults, with a poor prognosis with any current therapy. Conversely, low-grade gliomas, the second most common type of gliomas, are potentially curable with appropriate treatment. Several metaanalyses have evaluated the role of PET or PET/ CT with different tracers in differentiating between high-grade and low-grade gliomas $[3,6$, 14, 20].

\subsection{1 ${ }^{18}$ F-FDG}

${ }^{18} \mathrm{~F}-\mathrm{FDG}$ uptake is significantly higher in highgrade gliomas compared with low-grade gliomas. According to the meta-analysis of Dunet et al., a mean TBR of at least 1.4 and a maximum TBR of at least 1.8 at ${ }^{18} \mathrm{~F}-\mathrm{FDG}$ PET had the best value to distinguish between low- and high-grade gliomas, with a sensitivity, specificity and accuracy of $60 \%, 91 \%$ and $74 \%$, respectively, for mean TBR and $72 \%, 73 \%$ and $72 \%$, respectively, for maximum TBR [20]. A recent meta-analysis demonstrated a lower sensitivity of ${ }^{18} \mathrm{~F}$-FDG PET or PET/CT in differentiating between high-grade and low-grade gliomas compared to radiolabelled amino acid PET $\left({ }^{11} \mathrm{C}\right.$-methionine and ${ }^{18} \mathrm{~F}$-FET) but with higher specificity [6].

\subsection{2 ${ }^{11}$ C-Methionine}

${ }^{11} \mathrm{C}$-methionine PET or PET/CT had a moderate diagnostic accuracy in differentiating between high-grade and low-grade gliomas, according to data provided by a recent meta-analysis (pooled sensitivity and specificity of $80 \%$ and $72 \%$, respectively) [14]. Another meta-analysis demonstrated that ${ }^{11} \mathrm{C}$-methionine PET or PET/CT has a higher sensitivity compared to ${ }^{18} \mathrm{~F}-\mathrm{FDG}$ PET or PET/CT in differentiating between highgrade and low-grade gliomas but with lower specificity; diagnostic performance values were similar to those of ${ }^{18} \mathrm{~F}$-FET PET or PET/CT in this setting [6].

\subsection{3 ${ }^{18}$ F-FET}

${ }^{18}$ F-FET uptake is significantly higher in highgrade gliomas compared with low-grade gliomas. Dunet et al. reported that a mean TBR of at least 2.0 and a maximum TBR of at least 3.0 at ${ }^{18} \mathrm{~F}$ FET PET reached a sensitivity, specificity and accuracy of $88 \%, 73 \%$ and $81 \%$, respectively, for mean TBR, and $80 \%, 82 \%$ and $81 \%$, respectively, for maximum TBR [20]. A recent metaanalysis demonstrated that ${ }^{18} \mathrm{~F}$-FET PET or PET/ $\mathrm{CT}$ has a higher sensitivity compared to ${ }^{18} \mathrm{~F}-\mathrm{FDG}$ PET or PET/CT in differentiating between highgrade and low-grade gliomas but with lower specificity; diagnostic performance values were similar to those of ${ }^{11} \mathrm{C}$-methionine PET or PET/ CT in this setting [6]. 


\subsection{4 ${ }^{18}$ F-FDOPA}

For differentiating high-grade from low-grade gliomas, ${ }^{18} \mathrm{~F}$-FDOPA PET or PET/CT showed a pooled sensitivity of $88 \%$ and a pooled specificity of $73 \%$ [3].

\subsection{Delineation of Gliomas}

For surgical and radiation therapy planning in patients with glioma, a correct delineation of the target volume is needed. A recent evidence-based article suggested that radiolabelled amino acid PET may ameliorate the delineation of highgrade gliomas compared to standard MRI [16].

\subsection{Diagnosis of Recurrent Brain Tumours}

Distinguishing recurrent brain tumours from non-tumour lesions after radiation therapy and/or chemotherapy is a crucial clinical issue, because the different diagnosis will lead to divergent treatments. Several meta-analyses have assessed the diagnostic performance of PET with different tracers in this setting $[3,4,7,9,11,13,21-25]$.

\subsection{1 ${ }^{18}$ F-FDG}

A meta-analysis of Zhao et al. demonstrated a moderate diagnostic accuracy of ${ }^{18} \mathrm{~F}$-FDG PET or $\mathrm{PET} / \mathrm{CT}$ in detecting brain tumour recurrence [23]. This finding was confirmed by another meta-analysis which showed a pooled sensitivity and specificity of $78 \%$ and $77 \%$, respectively [21]. Furuse et al. showed that the diagnostic performance of ${ }^{18} \mathrm{~F}$-FDG PET or PET/CT in detecting recurrent brain tumours was lower compared to that of radiolabelled amino acid PET or PET/ CT [7]. Nihashi et al. showed that, when considering both low- and high-grade gliomas, pooled sensitivity and specificity of ${ }^{18} \mathrm{~F}$-FDG PET or $\mathrm{PET} / \mathrm{CT}$ in detecting glioma recurrence were $77 \%$ and $78 \%$, respectively. In subgroup analyses limited to high-grade gliomas, pooled sensitivity and specificity were $79 \%$ and $70 \%$, respectively [25]. Wang et al. reported a moderate sensitivity (70\%) but a good specificity $(88 \%)$ of ${ }^{18} \mathrm{~F}-\mathrm{FDG}$ PET or PET/CT in detecting recurrent glioma; however, the diagnostic accuracy was lower compared to that of ${ }^{11} \mathrm{C}$-methionine PET or PET/CT and magnetic resonance spectroscopy in this setting [22]. Another meta-analysis demonstrated that the diagnostic performance of ${ }^{18} \mathrm{~F}$-FDG PET or PET/CT in detecting recurrent glioma is not optimal, in particular if compared with other available neuroimaging methods [7].

\subsection{2 ${ }^{11} \mathrm{C}-$ Methionine}

${ }^{11} \mathrm{C}$-methionine PET or PET/CT demonstrated good diagnostic performance in detecting brain tumour recurrence (pooled sensitivity and specificity of $92 \%$ and $87 \%$, respectively), with higher values compared to ${ }^{18} \mathrm{~F}-\mathrm{FDG}$ PET or PET/CT [23]. For high-grade gliomas, pooled sensitivity and specificity of ${ }^{11} \mathrm{C}$-methionine PET or PET/ $\mathrm{CT}$ in detecting glioma recurrence were $70 \%$ and 93\%, respectively [25]. Compared to dynamic susceptibility contrast-enhanced MRI, ${ }^{11} \mathrm{C}$-methionine PET or PET/CT demonstrated comparable pooled sensitivity and specificity in detecting glioma recurrence, with pooled values of $87 \%$ and $81.3 \%$, respectively [24]. Similar values of sensitivity and specificity $(85 \%$ and $83 \%$, respectively) were described by Wang et al., which demonstrated that the diagnostic performance of ${ }^{11} \mathrm{C}$-methionine PET or PET/CT in detecting glioma recurrence was similar to that of magnetic resonance spectroscopy [22]. A large meta-analysis including 29 studies confirmed the good diagnostic performance of ${ }^{11} \mathrm{C}$-methionine PET or PET/CT in this setting with a pooled sensitivity and specificity of $88 \%$ and $85 \%$, respectively [13].

\subsection{3 ${ }^{18}$ F-FET}

A recent meta-analysis demonstrated that ${ }^{18} \mathrm{~F}$ FET PET or PET/CT has a good diagnostic accuracy in differentiating between brain tumour 
recurrence and radiation necrosis after treatment, with pooled sensitivity and specificity values of $82 \%$ and $80 \%$, respectively. In the subgroup of patients with suspicious glioma recurrence, sensitivity and specificity of ${ }^{18} \mathrm{~F}$-FET PET or PET/ CT were $83 \%$ and $81 \%$, respectively [11]. The good diagnostic performance of ${ }^{18} \mathrm{~F}$-FET PET or $\mathrm{PET} / \mathrm{CT}$ in this setting was also confirmed by Furuse et al. who reported increased diagnostic performance of ${ }^{18} \mathrm{~F}$-FET PET or PET/CT compared to ${ }^{18} \mathrm{~F}$-FDG and ${ }^{11} \mathrm{C}$-methionine PET or PET/CT [7]. Kim et al. found that amino acid PET or PET/CT, including ${ }^{18} \mathrm{~F}$-FET PET, has a good diagnostic performance in differentiating residual or recurrent brain tumour from treatmentrelated changes (pseudoprogression) in patients with high-grade gliomas [4].

\subsection{4 ${ }^{18}$ F-FDOPA}

A recent meta-analysis indicated that ${ }^{18} \mathrm{~F}$-FDOPA PET or PET/CT has a good diagnostic accuracy in differentiating between brain tumour recurrence and radiation necrosis after treatment, with pooled sensitivity and specificity values of $85 \%$ and $77 \%$, respectively. In the subgroup of patients with suspicious glioma recurrence, sensitivity and specificity of ${ }^{18} \mathrm{~F}$-FDOPA PET or PET/CT were $94 \%$ and $89 \%$, respectively [11]. Xiao et al. reported a good sensitivity of ${ }^{18} \mathrm{~F}$-FDOPA PET and PET/CT in detecting recurrent glioma $(92 \%)$ and a moderate specificity (76\%) [3].

\subsection{5 ${ }^{18} \mathrm{~F}-\mathrm{FLT}$}

${ }^{18}$ F-FLT PET or PET/CT demonstrated a similar diagnostic performance in detecting brain tumour recurrence compared to ${ }^{18} \mathrm{~F}$-FDG PET or PET/ CT with pooled sensitivity and specificity of $82 \%$ and $76 \%$, respectively [21].

\subsection{6 ${ }^{18} \mathrm{C}$-Choline}

A recent meta-analysis indicated that ${ }^{11} \mathrm{C}$-choline PET or PET/CT has a good diagnostic accuracy for differentiating glioma recurrence from radiation induced necrosis after treatment, with a pooled sensitivity and specificity of $87 \%$ and $82 \%$, respectively [9].

\subsection{Diagnosis of Brain Metastases}

The reliability of PET or PET/CT with different tracers in detecting brain metastases has been evaluated to a less extent compared to primary brain tumours. A meta-analysis demonstrated that the pooled sensitivity and specificity of ${ }^{18} \mathrm{~F}$ FDG PET or PET/CT in detecting brain metastases in patients with lung cancer were $21 \%$ and $100 \%$, respectively. In particular, the sensitivity of this method is lower compared to that of contrast-enhanced MRI [19].

\subsection{Diagnosis of Recurrent Brain Metastases}

The meta-analysis of Li et al., focused on the use of PET or PET/CT with different tracers in differentiating recurrent brain metastasis from radionecrosis after radiation therapy, demonstrated a good diagnostic accuracy of PET or $\mathrm{PET} / \mathrm{CT}$ with both ${ }^{18} \mathrm{~F}-\mathrm{FDG}$ and radiolabelled amino acid tracers $\left({ }^{11} \mathrm{C}\right.$-methionine, ${ }^{18} \mathrm{~F}$-FET, ${ }^{18} \mathrm{~F}$-FDOPA) in this setting [12]. MRI and PET with different tracers showed similar diagnostic performance for the detection of recurrent brain metastasis after stereotactic radiosurgery; nevertheless, advanced MRI methods showed a significantly higher diagnostic performance in this setting compared to PET [8].

\subsection{Diagnosis of Primary Central Nervous System Lymphoma (PCNSL)}

${ }^{18}$ F-FDG PET and PET/CT showed considerable accuracy in identifying PCNSL among various brain lesions in immunocompetent patients (pooled sensitivity and specificity of $88 \%$ and 
$86 \%$, respectively), therefore, ${ }^{18} \mathrm{~F}-\mathrm{FDG}$ PET/CT could be a valuable diagnostic imaging method in this setting [17]. High diagnostic accuracy of ${ }^{18} \mathrm{~F}-$ FDG PET and PET/CT has also been demonstrated in identifying PCNSL among various brain lesions in patients with human immunodeficiency virus (HIV) infection [18].

\subsection{Prognostic Value in Patients with Glioma}

Beyond the diagnostic accuracy, PET/CT parameters, and particularly the TBR, may be significant prognostic factors in patients with glioma. A recent meta-analysis demonstrated that increased TBR at ${ }^{18} \mathrm{~F}$-FDG PET, ${ }^{11} \mathrm{C}$-methionine PET and ${ }^{18} \mathrm{~F}$-FET PET could indicate poor overall survival (pooled hazard ratios were 3.05 for ${ }^{18} \mathrm{~F}-\mathrm{FDG}$ PET, 1.59 for ${ }^{11} \mathrm{C}$-methionine PET and 1.15 for ${ }^{18}$ F-FET PET) [5]. Another meta-analysis showed that the TBR and metabolic tumour volume at ${ }^{11} \mathrm{C}$-methionine PET are significant prognostic parameters for patients with gliomas. Patients with a high TBR have a higher risk of death, and patients with a high metabolic tumour volume have a higher risk of adverse events or death [10].

\subsection{Conclusions}

Evidence-based data demonstrated good diagnostic performance of PET with different tracers in detecting brain tumours, in particular radiolabelled amino acid tracers showed the highest diagnostic performance values. All the PET tracers evaluated had significant prognostic value in patients with glioma [27].

\section{References}

1. Treglia G, Sadeghi R, Del Sole A, Giovanella L. Diagnostic performance of PET/CT with tracers other than F-18-FDG in oncology: an evidence-based review. Clin Transl Oncol. 2014;16:770-5.

2. Muoio B, Giovanella L, Treglia G. Recent developments of 18F-FET PET in neuro-oncology. Curr Med Chem. 2018;25:3061-73.
3. Xiao J, Jin Y, Nie J, Chen F, Ma X. Diagnostic and grading accuracy of (18)F-FDOPA PET and PET/ $\mathrm{CT}$ in patients with gliomas: a systematic review and meta-analysis. BMC Cancer. 2019;19:767.

4. Kim SJ, Ryul Shim S. Diagnostic value of radiolabeled amino acid PET for detection of pseudoprogression of brain tumor after treatment: a meta-analysis. Nucl Med Commun. 2019;40:965-72.

5. Zhang Q, Gao X, Wei G, Qiu C, Qu H, Zhou $X$. Prognostic value of MTV, SUVmax and the T/N ratio of PET/CT in patients with glioma: a systematic review and meta-analysis. J Cancer. 2019;10:1707-16.

6. Katsanos AH, Alexiou GA, Fotopoulos AD, Jabbour P, Kyritsis AP, Sioka C. Performance of 18F-FDG, 11C-methionine, and 18F-FET PET for glioma grading: a meta-analysis. Clin Nucl Med. 2019;44(11):864-9.

7. Furuse M, Nonoguchi N, Yamada K, Shiga T, Combes JD, Ikeda N, et al. Radiological diagnosis of brain radiation necrosis after cranial irradiation for brain tumor: a systematic review. Radiat Oncol. 2019;14:28.

8. Suh CH, Kim HS, Jung SC, Choi CG, Kim SJ. Comparison of MRI and PET as potential surrogate endpoints for treatment response after stereotactic radiosurgery in patients with brain metastasis. AJR Am J Roentgenol. 2018;211:1332-41.

9. Gao L, Xu W, Li T, Zheng J, Chen G. Accuracy of $11 \mathrm{C}$-choline positron emission tomography in differentiating glioma recurrence from radiation necrosis: a systematic review and meta-analysis. Medicine. 2018;97:e11556.

10. Kim YI, Kim Y, Lee JY, Jang SJ. Prognostic value of the metabolic and volumetric parameters of (11) C-methionine positron-emission tomography for gliomas: a systematic review and meta-analysis. AJNR Am J Neuroradiol. 2018;39:1629-34.

11. Yu J, Zheng J, Xu W, Weng J, Gao L, Tao L, et al. Accuracy of (18)F-FDOPA positron emission tomography and (18)F-FET positron emission tomography for differentiating radiation necrosis from brain tumor recurrence. World Neurosurg. 2018;114:e1211-24.

12. Li H, Deng L, Bai HX, Sun J, Cao Y, Tao Y, et al. Diagnostic accuracy of amino acid and FDG-PET in differentiating brain metastasis recurrence from radionecrosis after radiotherapy: a systematic review and meta-analysis. AJNR Am J Neuroradiol. 2018;39:280-8.

13. Xu W, Gao L, Shao A, Zheng J, Zhang J. The performance of $11 \mathrm{C}$-methionine PET in the differential diagnosis of glioma recurrence. Oncotarget. 2017;8:91030-9.

14. Falk Delgado A, Falk DA. Discrimination between primary low-grade and high-grade glioma with (11) C-methionine PET: a bivariate diagnostic test accuracy meta-analysis. Br J Radiol. 2018;91:20170426.

15. Yang Y, He MZ, Li T, Yang X. MRI combined with PET-CT of different tracers to improve the accuracy of glioma diagnosis: a systematic review and metaanalysis. Neurosurg Rev. 2019;42:185-95. 
16. Verburg N, Hoefnagels FWA, Barkhof F, Boellaard R, Goldman S, Guo J, et al. Diagnostic accuracy of neuroimaging to delineate diffuse gliomas within the brain: a meta-analysis. AJNR Am J Neuroradiol. 2017;38:1884-91.

17. Zou Y, Tong J, Leng H, Jiang J, Pan M, Chen Z. Diagnostic value of using 18F-FDG PET and PET/ $\mathrm{CT}$ in immunocompetent patients with primary central nervous system lymphoma: a systematic review and meta-analysis. Oncotarget. 2017;8:41518-28.

18. Yang M, Sun J, Bai HX, Tao Y, Tang X, States LJ, et al. Diagnostic accuracy of SPECT, PET, and MRS for primary central nervous system lymphoma in HIV patients: a systematic review and meta-analysis. Medicine. 2017;96:e6676.

19. Li Y, Jin G, Su D. Comparison of gadoliniumenhanced MRI and 18FDG PET/PET-CT for the diagnosis of brain metastases in lung cancer patients: a meta-analysis of 5 prospective studies. Oncotarget. 2017;8:35743-9.

20. Dunet V, Pomoni A, Hottinger A, Nicod-Lalonde M, Prior JO. Performance of $18 \mathrm{~F}-\mathrm{FET}$ versus $18 \mathrm{~F}-\mathrm{FDG}-$ PET for the diagnosis and grading of brain tumors: systematic review and meta-analysis. Neuro Oncol. 2016;18:426-34.

21. Li Z, Yu Y, Zhang H, Xu G, Chen L. A meta-analysis comparing 18F-FLT PET with 18F-FDG PET for assessment of brain tumor recurrence. Nucl Med Commun. 2015;36:695-701.
22. Wang X, Hu X, Xie P, Li W, Li X, Ma L. Comparison of magnetic resonance spectroscopy and positron emission tomography in detection of tumor recurrence in posttreatment of glioma: a diagnostic metaanalysis. Asia Pac J Clin Oncol. 2015;11:97-105.

23. Zhao C, Zhang Y, Wang J. A meta-analysis on the diagnostic performance of (18)F-FDG and (11) C-methionine PET for differentiating brain tumors. AJNR Am J Neuroradiol. 2014;35:1058-65.

24. Deng SM, Zhang B, Wu YW, Zhang W, Chen YY. Detection of glioma recurrence by ${ }^{11} \mathrm{C}$-methionine positron emission tomography and dynamic susceptibility contrast-enhanced magnetic resonance imaging: a meta-analysis. Nucl Med Commun. 2013;34:758-66.

25. Nihashi T, Dahabreh IJ, Terasawa T. Diagnostic accuracy of PET for recurrent glioma diagnosis: a meta-analysis. AJNR Am J Neuroradiol. 2013;34:944-50.

26. Dunet V, Rossier C, Buck A, Stupp R, Prior JO. Performance of 18F-fluoro-ethyl-tyrosine (18FFET) PET for the differential diagnosis of primary brain tumor: a systematic review and metaanalysis. J Nucl Med. 2012;53:207-14.

27. Treglia G, Muoio B, Trevisi G, Mattoli MV, Albano D, Bertagna F, et al. Diagnostic performance and prognostic value of PET/CT with different tracers for brain tumors: a systematic review of published metaanalyses. Int J Mol Sci. 2019;20(19):E4669.

Open Access This chapter is licensed under the terms of the Creative Commons Attribution 4.0 International License (http://creativecommons.org/licenses/by/4.0/), which permits use, sharing, adaptation, distribution and reproduction in any medium or format, as long as you give appropriate credit to the original author(s) and the source, provide a link to the Creative Commons license and indicate if changes were made.

The images or other third party material in this chapter are included in the chapter's Creative Commons license, unless indicated otherwise in a credit line to the material. If material is not included in the chapter's Creative Commons license and your intended use is not permitted by statutory regulation or exceeds the permitted use, you will need to obtain permission directly from the copyright holder. 


\title{
Evidence-Based PET for Head and Neck Tumours
}

\author{
Gaetano Paone
}

\subsection{Introduction}

Head and neck cancer (HNC) accounts for approximately $5 \%$ of all malignant tumours with a continuous growing incidence. Head and neck squamous cell carcinoma (HNSCC) represents the majority of HNC $[1,2]$. Nodal involvement is frequent in HNC patients, whereas distant metastases are rather uncommon at the time of initial diagnosis and are found approximately in $10 \%$ of patients. There is a clear association with lifestyle and factors as alcoholism, smoking, alimentary factors and viruses for the etiological role, while increasing $\mathrm{T}$ and $\mathrm{N}$ stages remain the most important adverse prognostic factor [3, 4]. Diagnosis of HNC is usually achieved clinically with endoscopy to obtain direct tissue biopsies. Conventional Imaging (CI), including ultrasound (US), computed tomography (CT) and magnetic resonance imaging (MRI) is important for the evaluation of local extension and to provide information about infiltration, involvement of surrounding structures and regional nodal involvement. There is growing evidence, however, that these modalities have limitations for the diagnostic accuracy of nodal involvement and distant metastases. ${ }^{18} \mathrm{~F}-\mathrm{FDG}$ PET/CT, allowing

\section{G. Paone $(\bowtie)$}

Clinic of Nuclear Medicine and Molecular Imaging, Imaging Institute of Southern Switzerland, Ente Ospedaliero Cantonale, Bellinzona, Switzerland e-mail: gaetano.paone@eoc.ch the analysis of both metabolic and anatomic features, is a very useful imaging tool in $\mathrm{HNC}$, in particular for disease staging, detection of carcinoma of unknown primary (CUP), treatment monitoring, evaluation of residual or recurrent disease and for prognostic information [5-7].

\subsection{Staging}

Accurate staging of disease extension at the time of diagnosis is the most important factor for treatment planning and patients prognosis. Furthermore, providing information in early stage of disease is extremely useful for selecting high-risk patients with impact on specifictreatment selection.

\subsubsection{T Staging}

${ }^{18}$ F-FDG PET/CT has high accuracy in detecting the primary tumour but a moderate diagnostic performance than CI to identify the real tumour extension and infiltration of surrounding tissue and structures. These data are necessary for adequate therapeutic strategy and patient prognosis. False-negative results occur on ${ }^{18} \mathrm{~F}$-FDG PET/CT when the primary tumour is superficial or small, but also in areas of high physiologic activity such as in pharyngeal lymphoid tissue. False-positive results of ${ }^{18} \mathrm{~F}$-FDG $\mathrm{PET} / \mathrm{CT}$ may be due to 
inflammatory processes. In literature, we found conflicting data; preliminary studies have shown divergent results of ${ }^{18} \mathrm{~F}$-FDG PET/CT in diagnosis and staging of HNSCC. Rohde et al. compared the diagnostic accuracy of ${ }^{18} \mathrm{~F}-\mathrm{FDG}$ PET/ CT for diagnosing HNSCC in comparison with standard CI showing a pooled sensitivity of $89.3 \%$ and specificity of $89.5 \%$ for ${ }^{18} \mathrm{~F}$-FDG $\mathrm{PET} / \mathrm{CT}$ and a pooled sensitivity and specificity of $71.6 \%$ and $78.0 \%$, respectively, for CI. The authors concluded that ${ }^{18} \mathrm{~F}-\mathrm{FDG}$ PET/CT is highly accurate in diagnosing patients suffering from HNSCC [8]. Chen et al. compared MRI, $\mathrm{CT}$ and ${ }^{18} \mathrm{~F}-\mathrm{FDG} \mathrm{PET} / \mathrm{CT}$ in the diagnosis of local and metastatic nasopharyngeal carcinomas. Their analysis suggested that MRI has good accuracy in diagnosis of $\mathrm{T}$ stage, whereas $\mathrm{CT}$ has a good performance in diagnosis of $\mathrm{N}$ stage and ${ }^{18} \mathrm{~F}$-FDG PET/CT shows a good accuracy in diagnosis of $M$ stage [9]. Similarly for evaluation of extracapsular spread (ECS), CT and MRI may be similarly effective, whereas evidence was lacking for ${ }^{18} \mathrm{~F}$-FDG PET/CT and US [10]. ${ }^{18} \mathrm{~F}-\mathrm{FDG}$ PET/CT can provide, instead, more useful clinical information and higher sensitivity and specificity (pooled sensitivities and specificity $90 \%$ and $89 \%$, respectively) to delineate the presence and extent of mandibular involvement in patients with oral cavity cancer, especially in cases of contextual dental artefacts $[11,12]$. For evaluation of precancerous and tumour lesions of larynx, Mannelli et al. expressed the need to integrate different imaging methods, proposing a flow chart that allows to stratify patients and select the most appropriate procedure [13].

Overall, the current practice is not in favour of ${ }^{18} \mathrm{~F}-\mathrm{FDG}$ PET/CT as gold standard for T staging in HNC in exception of cases with suspect mandibular involvement in oral cavity cancer. The preliminary data about ${ }^{18} \mathrm{~F}$-FDG PET/MRI demonstrated high sensitivity and moderate specificity of this technique in the diagnosis of HNC lesions, showing also a better tumour delineation. Further investigations are needed to define the real impact of ${ }^{18} \mathrm{~F}-\mathrm{FDG}$ PET/MRI in HNC and whether the technique can improve the detection rate of occult primary HNC [14].

\subsubsection{Nodal and Distant Metastases Detection}

Lymph nodal involvement is the most important prognostic factor in patients with HNSCC with a significant impact on outcome in terms of disease free survival and overall survival. Lymph nodal (N) metastases occur in approximately $50 \%$ of HNC patients at the time of diagnosis with a consequent survival decrease. An accurate $\mathrm{N}$ staging is therefore a fundamental step. Similarly, the detection of distant metastases at initial staging influences the prognosis avoiding unnecessary radical treatments. Metastases (M) are frequently found in the lungs, followed by the liver and bone.

Several data in the literature confirm an excellent diagnostic accuracy of ${ }^{18} \mathrm{~F}-\mathrm{FDG}$ PET/CT in $\mathrm{N}$ and $\mathrm{M}$ staging. A meta-analysis of Vellayappan et al. assessed the diagnostic accuracy of ${ }^{18} \mathrm{~F}-$ FDG PET/CT for staging nasopharyngeal carcinoma (NPC), showing good accuracy of ${ }^{18} \mathrm{~F}-\mathrm{FDG}$ $\mathrm{PET} / \mathrm{CT}$ for $\mathrm{N}$ staging (pooled sensitivity and specificity were $84 \%$ and $90 \%$, respectively) and for $\mathrm{M}$ staging (pooled sensitivity and specificity were $87 \%$ and $98 \%$, respectively), but not for $\mathrm{T}$ classification [15]. Similarly, Shen et al. confirmed in their meta-analysis an excellent diagnostic performance of ${ }^{18} \mathrm{~F}-\mathrm{FDG}$ PET/CT for detecting lymph node and distant metastases in patients with NPC with a pooled sensitivity and specificity of $89 \%$ and $96 \%$, respectively [16]. Considering only the detection accuracy for regional nodal metastases in HNC before treatment, ${ }^{18} \mathrm{~F}$-FDG PET/CT showed good diagnostic performance $[17,18]$. Moreover, compared with CI, ${ }^{18}$ F-FDG PET/CT may have higher per-necklevel sensitivity [19]. These values are even more significant excluding clinically N0 patients with greater accuracy values for ${ }^{18} \mathrm{~F}-\mathrm{FDG}$ PET/ CT. Several data showed moderate sensitivity of ${ }^{18} \mathrm{~F}-\mathrm{FDG}$ PET/CT for detection of cervical lymph nodal metastases in clinical NO HNSCC patients with absence of significant better diagnostic accuracy compared to $\mathrm{CI}$; conversely, ${ }^{18} \mathrm{~F}-\mathrm{FDG}$ PET/CT has a higher specificity and negative predictive value for the detection of cervical metastatic lymph nodes compared to the other imaging 
modalities in clinical N0 HNSCC [20-22]. Avoiding elective neck dissection is a fundamental step in the diagnostic-therapeutic flow chart of these patients in order to minimize morbidity and health costs. At present elective neck dissection in patients with clinical NO should not be based upon cross-sectional imaging. A combination of $\mathrm{CI}$ and sentinel node biopsy seems to be the preferred staging strategy to reduce the risk of occult metastases in clinical N0 HNSCC [23].

On the other hand, the excellent diagnostic performance of ${ }^{18} \mathrm{~F}-\mathrm{FDG}$ PET/CT for detecting distant metastases is clearly underlined in the literature [24-29]. Xu et al. showed a pooled sensitivity and specificity of $85.7 \%$ and $98.1 \%$, respectively, for ${ }^{18} \mathrm{~F}$-FDG PET/CT, resulting in a significantly better M staging than CI [26]. This was mainly due to the superior diagnostic performance of ${ }^{18} \mathrm{~F}$-FDG PET/CT compared to $\mathrm{CI}$ in detecting bone metastases [27]. In this setting, ${ }^{18}$ F-FDG PET/CT has higher sensitivity compared to bone scintigraphy [28]. On the other hand, for detection of liver metastases ${ }^{18} \mathrm{~F}-\mathrm{FDG}$ $\mathrm{PET} / \mathrm{CT}$ requires further optimization and integration with CI, especially contrast-enhanced CT and MRI [25]. About lung metastases, a metaanalysis demonstrated that ${ }^{18} \mathrm{~F}$-FDG PET/CT is a valuable diagnostic tool for diagnosing lung malignancies in patients with HNSCC [29].

\subsection{Prognostic Value}

The prognostic value of ${ }^{18} \mathrm{~F}$-FDG PET/CT has been widely discussed with controversial results. Relevant limiting factors are the variability and reproducibility of each individual parameter. Overall, maximum standardized uptake value (SUVmax), metabolic tumour volume (MTV) and total lesion glycolysis (TLG) were significant prognostic predictors in patients with HNC [30-36].

No significant correlation was found between metabolic parameters of ${ }^{18} \mathrm{~F}-\mathrm{FDG}$ PET/CT in HNC and human papillomavirus (HPV) status [37]. Furthermore, the semi-quantitative PET/CT parameters were not related to histopathological parameters in HNSCC, as Ki67 and p53 [38].

\subsection{Post-treatment Evaluation}

Relevant applications of ${ }^{18} \mathrm{~F}-\mathrm{FDG}$ PET/CT in $\mathrm{HNC}$ are delineation of the tumour volume for radiation treatment planning, discrimination of post-treatment changes, evaluation of response to multimodality therapy and detection of recurrence.

About radiation therapy planning, Jeong et al. found that ${ }^{18} \mathrm{~F}$-FDG-avid $\mathrm{HNC}$ apparently require 10-30\% more radiation dose than FDG-non-avid tumours, supporting radiotherapy boosts for ${ }^{18}$ F-FDG-avid tumours; prospective studies are still required in this field [39].

The role of intra-therapy and post-therapy ${ }^{18} \mathrm{~F}$ FDG PET/CT in predicting long-term survival outcomes in patients treated for HNC has been widely studied. Sheikhbahaei et al. reported that positive results of intra-therapy or post-therapy ${ }^{18}$ F-FDG PET/CT could significantly predict the 2- and 5-year risk of death or disease progression [40]. The same group confirmed the high diagnostic performance of ${ }^{18} \mathrm{~F}-\mathrm{FDG}$ PET/CT in detecting local, regional and distant recurrences in curatively treated patients with HNC. The pooled sensitivity and specificity of follow-up ${ }^{18} \mathrm{~F}-\mathrm{FDG} \mathrm{PET} / \mathrm{CT}$ for detection of recurrence were $92 \%$ and $87 \%$, respectively [41]. These data support its use in clinical practice as confirmed also by other studies that highlight the high accuracy of ${ }^{18} \mathrm{~F}$-FDG PET/CT performed after the completion of therapy both in NPC and HNSCC before salvage treatment [42-44]. ${ }^{18}$ F-FDG PET/ CT is also superior to MRI in distinguishing recurrent NPC from fibrosis or scar tissue after radiotherapy in irradiated fields with distortion of normal architecture [45]. Treatment-to-time scan remains a debated aspect. Several works have indicated that early ${ }^{18} \mathrm{~F}-\mathrm{FDG} \mathrm{PET} / \mathrm{CT}$ was less accurate than more delayed imaging after therapy, particularly Cheung and coauthors supported the use of ${ }^{18} \mathrm{~F}$-FDG PET/CT more than 12 weeks after radiotherapy with or without chemotherapy for the assessment of residual or recurrent HNC [46]. Recently, Helsen et al. confirmed that ${ }^{18} \mathrm{~F}$ FDG PET/CT performed within 6 months after chemo-radiotherapy in HNSCC patients is the method of choice for ruling out residual/recurrent 
nodal disease reducing the need for therapeutic intervention [47]. Finally, sensitivity and specificity of ${ }^{18} \mathrm{~F}-\mathrm{FDG}$ PET/CT in identifying local failure following curative radiotherapy or surgery for HNSCC were significantly improved when imaging was performed 3 months after end of treatment [48].

\subsection{Carcinoma of Unknown Origin and Incidental Findings}

Several studies have investigated the accuracy of ${ }^{18}$ F-FDG PET/CT to identify carcinoma of unknown origin (CUP) in patients with cervical lymph nodal metastases. Generally, the most common sites of detection include the palatine tonsils and the base of the tongue, with increase of falsenegative results when the primary tumour is small or adjacent to physiological uptake sites. Zhu et al. showed a high sensitivity (97\%) and a moderate specificity (68\%) for the detection of CUP in patients with cervical nodal metastases [49].

Finally, Treglia et al. calculated the pooled prevalence and risk of malignancy of incidental focal ${ }^{18} \mathrm{~F}-\mathrm{FDG}$ uptake in the parotid glands. The pooled prevalence of this finding is about $1 \%$ of all ${ }^{18} \mathrm{~F}-\mathrm{FDG}$ PET/CT. Although these incidental findings are benign in most of the cases, complementary evaluation is needed to exclude malignant lesions or with possible malignant degeneration [50].

\section{References}

1. Bray F, Ferlay J, Soerjomataram I, Siegel RL, Torre LA, Jemal A. Global cancer statistics 2018: GLOBOCAN estimates of incidence and mortality worldwide for 36 cancers in 185 countries. CA Cancer J Clin. 2018;68(6):394-424.

2. Bray F, Ren JS, Masuyer E, Ferlay J. Global estimates of cancer prevalence for 27 sites in the adult population in 2008. Int J Cancer. 2013;132(5):1133-45.

3. Settle K, Posner MR, Schumaker LM, Tan M, Suntharalingam M, Goloubeva O, et al. Racial survival disparity in head and neck cancer results from low prevalence of human papillomavirus infection in black oropharyngeal cancer patients. Cancer Prev Res. 2009;2(9):776-81.
4. Wyss A, Hashibe M, Chuang SC, Lee YC, Zhang ZF, Yu GP, et al. Cigarette, cigar, and pipe smoking and the risk of head and neck cancers: pooled analysis in the International Head and Neck Cancer Epidemiology Consortium. Am J Epidemiol. 2013;178(5):679-90.

5. Rodrigues RS, Bozza FA, Christian PE, Hoffman JM, Butterfield RI, Christensen CR, et al. Comparison of whole-body PET/CT, dedicated high-resolution head and neck PET/CT, and contrast-enhanced CT in preoperative staging of clinically M0 squamous cell carcinoma of the head and neck. J Nucl Med. 2009;50(8):1205-13.

6. Oyen WJ, Marres HA, Kaanders JH. Progress in nuclear medicine procedures in head and neck oncology. Q J Nucl Med Mol Imaging. 2011;55(5):485-6.

7. Connell CA, Corry J, Milner AD, Hogg A, Hicks RJ, Rischin D, et al. Clinical impact of, and prognostic stratification by, F-18 FDG PET/CT in head and neck mucosal squamous cell carcinoma. Head Neck. 2007;29(11):986-95.

8. Rohde M, Dyrvig AK, Johansen J, Sørensen JA, Gerke $\mathrm{O}$, Nielsen AL, et al. 18F-fluoro-deoxy-glucosepositron emission tomography/computed tomography in diagnosis of head and neck squamous cell carcinoma: a systematic review and meta-analysis. Eur J Cancer. 2014;50(13):2271-9.

9. Chen WS, Li JJ, Hong L, Xing ZB, Wang F, Li CQ. Comparison of MRI, CT and 18F-FDG PET/CT in the diagnosis of local and metastatic of nasopharyngeal carcinomas: an updated meta analysis of clinical studies. Am J Transl Res. 2016;8(11):4532-47.

10. Su Z, Duan Z, Pan W, Wu C, Jia Y, Han B, et al. Predicting extracapsular spread of head and neck cancers using different imaging techniques: a systematic review and meta-analysis. Int J Oral Maxillofac Surg. 2016;45(4):413-21.

11. Qiao X, Liu W, Cao Y, Miao C, Yang W, Su N, et al. Performance of different imaging techniques in the diagnosis of head and neck cancer mandibular invasion: a systematic review and meta-analysis. Oral Oncol. 2018;86:150-64.

12. Li C, Sheng S, Men Y, Sun H, Xia H, Li L. Emission computed tomography for the diagnosis of mandibular invasion by head and neck cancers: a systematic review and meta-analysis. J Oral Maxillofac Surg. 2015;73(9):1875.

13. Mannelli G, Cecconi L, Gallo O. Laryngeal preneoplastic lesions and cancer: challenging diagnosis. Qualitative literature review and meta-analysis. Crit Rev Oncol Hematol. 2016;106:64-9.

14. Xiao Y, Chen Y, Shi Y, Wu Z. The value of fluorine-18 fluorodeoxyglucose PET/MRI in the diagnosis of head and neck carcinoma: a meta-analysis. Nucl Med Commun. 2015;36(4):312-8.

15. Vellayappan BA, Soon YY, Earnest A, Zhang Q, Koh WY, Tham IW, et al. Accuracy of (18) F-flurodeoxyglucose-positron emission tomography/ computed tomography in the staging of newly diagnosed nasopharyngeal carcinoma: a systematic review and meta-analysis. Radiol Oncol. 2014;48(4):331-8. 
16. Shen G, Zhang W, Jia Z, Li J, Wang Q, Deng H. Metaanalysis of diagnostic value of 18F-FDG PET or PET/ $\mathrm{CT}$ for detecting lymph node and distant metastases in patients with nasopharyngeal carcinoma. Br J Radiol. 2014;87(1044):20140296.

17. Yongkui L, Jian L, Wanghan, Jingui L. 18FDGPET/CT for the detection of regional nodal metastasis in patients with primary head and neck cancer before treatment: a meta-analysis. Surg Oncol. 2013;22(2):e11-6.

18. Su N, Li C, Shi Z, Yang X. Positron emission tomography/computed tomography for detecting cervical nodule metastases of oral and maxillofacial cancer. Hua Xi Kou Qiang Yi Xue Za Zhi. 2012;30(1):36-9.

19. Sun R, Tang X, Yang Y, Zhang C. (18)FDG-PET/ $\mathrm{CT}$ for the detection of regional nodal metastasis in patients with head and neck cancer: a meta-analysis. Oral Oncol. 2015;51(4):314-20.

20. Kim SJ, Pak K, Kim K. Diagnostic accuracy of F-18 FDG PET or PET/CT for detection of lymph node metastasis in clinically node negative head and neck cancer patients; a systematic review and metaanalysis. Am J Otolaryngol. 2019;40(2):297-305.

21. Li XY, Sun CL, Du XD. The role of ${ }^{18} \mathrm{~F}-\mathrm{FDG}$ PET/ $\mathrm{CT}$ for detecting nodal metastases in $\mathrm{cN} 0$ head neck cancer patients: a meta-analysis. Lin Chung Er Bi Yan Hou Tou Jing Wai Ke Za Zhi. 2018;32(9):700-4.

22. Liao LJ, Lo WC, Hsu WL, Wang CT, Lai MS. Detection of cervical lymph node metastasis in head and neck cancer patients with clinically NO neck-a meta-analysis comparing different imaging modalities. BMC Cancer. 2012;12:236.

23. Liao LJ, Hsu WL, Wang CT, Lo WC, Lai MS. Analysis of sentinel node biopsy combined with other diagnostic tools in staging $\mathrm{cNO}$ head and neck cancer: a diagnostic meta-analysis. Head Neck. 2016;38(4):628-34.

24. Chang MC, Chen JH, Liang JA, Yang KT, Cheng KY, $\mathrm{Kao} \mathrm{CH}$. Accuracy of whole-body FDG-PET and FDG-PET/CT in M staging of nasopharyngeal carcinoma: a systematic review and meta-analysis. Eur J Radiol. 2013;82(2):366-73.

25. Xu G, Li J, Zuo X, Li C. Comparison of whole body positron emission tomography (PET)/PET-computed tomography and conventional anatomic imaging for detecting distant malignancies in patients with head and neck cancer: a meta-analysis. Laryngoscope. 2012;122(9):1974-8.

26. Xu C, Zhang Y, Peng L, Liu X, Li WF, Sun Y, et al. Optimal modality for detecting distant metastasis in primary nasopharyngeal carcinoma during initial staging: a systemic review and meta-analysis of 1774 patients. J Cancer. 2017;8(7):1238-48.

27. Yi X, Fan M, Liu Y, Zhang H, Liu S. 18 FDG PET and PET-CT for the detection of bone metastases in patients with head and neck cancer. A meta-analysis. J Med Imaging Radiat Oncol. 2013;57(6):674-9.

28. Xu C, Zhang R, Zhang H, Zhang Z. Comparison of 18FDG PET/PET-CT and bone scintigraphy for detecting bone metastases in patients with naso- pharyngeal cancer: a meta-analysis. Oncotarget. 2017;8(35):59740-7.

29. Xi K, Xie X, Xi S. Meta-analysis of (18) fluorodeoxyglucose positron emission tomography-CT for diagnosis of lung malignancies in patients with head and neck squamous cell carcinomas. Head Neck. 2015;37(11):1680-4.

30. Li Q, Zhang J, Cheng W, Zhu C, Chen L, Xia F, et al. Prognostic value of maximum standard uptake value, metabolic tumor volume, and total lesion glycolysis of positron emission tomography/computed tomography in patients with nasopharyngeal carcinoma: a systematic review and meta-analysis. Medicine. 2017;96(37):e8084.

31. Pak K, Cheon GJ, Nam HY, Kim SJ, Kang KW, Chung JK, et al. Prognostic value of metabolic tumor volume and total lesion glycolysis in head and neck cancer: a systematic review and meta-analysis. J Nucl Med. 2014;55:884-90.

32. Huang Y, Feng M, He Q, Yin J, Xu P, Jiang Q, et al. Prognostic value of pretreatment 18F-FDG PET-CT for nasopharyngeal carcinoma patients. Medicine. 2017;96(17):e6721.

33. Lin J, Xie G, Liao G, Wang B, Yan M, Li H, et al. Prognostic value of 18F-FDG-PET/CT in patients with nasopharyngeal carcinoma: a systematic review and meta-analysis. Oncotarget. 2017;8(20):33884-96.

34. Zhang B, Geng J, Nie F, Li X. Primary tumor standardized uptake value predicts survival in head and neck squamous cell carcinoma. Oncol Res Treat. 2015;38(1-2):45-8.

35. Bonomo P, Merlotti A, Olmetto E, Bianchi A, Desideri I, Bacigalupo A, et al. What is the prognostic impact of FDG PET in locally advanced head and neck squamous cell carcinoma treated with concomitant chemoradiotherapy? A systematic review and meta-analysis. Eur J Nucl Med Mol Imaging. 2018;45(12):2122-38.

36. Wang L, Bai J, Duan P. Prognostic value of 18 FFDG PET/CT functional parameters in patients with head and neck cancer: a meta-analysis. Nucl Med Commun. 2019;40(4):361-9.

37. Fleming JC, Woo J, Moutasim K, Mellone M, Frampton SJ, Mead A, et al. HPV, tumour metabolism and novel target identification in head and neck squamous cell carcinoma. $\mathrm{Br} \mathrm{J}$ Cancer. 2019;120(3):356-67.

38. Surov A, Meyer HJ, Wienke A. Can imaging parameters provide information regarding histopathology in head and neck squamous cell carcinoma? A metaanalysis. Transl Oncol. 2018;11(2):498-503.

39. Jeong J, Setton JS, Lee NY, Oh JH, Deasy JO. Estimate of the impact of FDG-avidity on the dose required for head and neck radiotherapy local control. Radiother Oncol. 2014;111(3):340-7.

40. Sheikhbahaei S, Ahn SJ, Moriarty E, Kang H, Fakhry C, Subramaniam RM. Intratherapy or posttherapy FDG PET or FDG PET/CT for patients with head and neck cancer: a systematic review and metaanalysis of prognostic studies. AJR Am J Roentgenol. 2015;205(5):1102-13. 
41. Sheikhbahaei S, Taghipour M, Ahmad R, Fakhry C, Kiess AP, Chung CH, et al. Diagnostic accuracy of follow-up FDG PET or PET/CT in patients with head and neck cancer after definitive treatment: a systematic review and meta-analysis. AJR Am J Roentgenol. 2015;205(3):629-39.

42. Zhou H, Shen G, Zhang W, Cai H, Zhou Y, Li L. 18FFDG PET/CT for the diagnosis of residual or recurrent nasopharyngeal carcinoma after radiotherapy: a metaanalysis. J Nucl Med. 2016;57(3):342-7.

43. Shen G, Zhou L, Jia Z, Zhang W, Wang Q, Deng $\mathrm{H}$. Meta-analysis of PET/CT for diagnosis of residual/ recurrent nasopharyngeal carcinoma. Lin Chung Er Bi Yan Hou Tou Jing Wai Ke Za Zhi. 2015;29(1):61-7.

44. Gao S, Li S, Yang X, Tang Q. 18FDG PET-CT for distant metastases in patients with recurrent head and neck cancer after definitive treatment. A metaanalysis. Oral Oncol. 2014;50(3):163-7.

45. Wei J, Pei S, Zhu X. Comparison of 18F-FDG PET/ $\mathrm{CT}$, MRI and SPECT in the diagnosis of local residual/recurrent nasopharyngeal carcinoma: a metaanalysis. Oral Oncol. 2016;52:11-7.

46. Cheung PK, Chin RY, Eslick GD. Detecting residual/ recurrent head neck squamous cell carcinomas using
PET or PET/CT: systematic review and meta-analysis. Otolaryngol Head Neck Surg. 2016;154(3):421-32.

47. Helsen N, Van den Wyngaert T, Carp L, Stroobants $\mathrm{S}$. FDG-PET/CT for treatment response assessment in head and neck squamous cell carcinoma: a systematic review and meta-analysis of diagnostic performance. Eur J Nucl Med Mol Imaging. 2018;45(6):1063-71.

48. Wong ET, Dmytriw AA, Yu E, Waldron J, Lu L, Fazelzad R, et al. 18 F-FDG PET/CT for locoregional surveillance following definitive treatment of head and neck cancer: a meta-analysis of reported studies. Head Neck. 2019;41(2):551-61.

49. Zhu L, Wang N. 18F-fluorodeoxyglucose positron emission tomography-computed tomography as a diagnostic tool in patients with cervical nodal metastases of unknown primary site: a meta-analysis. Surg Oncol. 2013;22(3):190-4.

50. Treglia G, Bertagna F, Sadeghi R, Muoio B, Giovanella L. Prevalence and risk of malignancy of focal incidental uptake detected by fluorine-18fluorodeoxyglucose positron emission tomography in the parotid gland: a meta-analysis. Eur Arch Otorhinolaryngol. 2015;272(12):3617-26.

Open Access This chapter is licensed under the terms of the Creative Commons Attribution 4.0 International License (http://creativecommons.org/licenses/by/4.0/), which permits use, sharing, adaptation, distribution and reproduction in any medium or format, as long as you give appropriate credit to the original author(s) and the source, provide a link to the Creative Commons license and indicate if changes were made.

The images or other third party material in this chapter are included in the chapter's Creative Commons license, unless indicated otherwise in a credit line to the material. If material is not included in the chapter's Creative Commons license and your intended use is not permitted by statutory regulation or exceeds the permitted use, you will need to obtain permission directly from the copyright holder. 


\title{
Evidence-Based PET for Thoracic Tumours
}

\author{
Filippo Lococo, Alfredo Cesario, \\ Stefano Margaritora, and Giorgio Treglia
}

\subsection{Introduction}

Fluorine-18 fluorodeoxyglucose positron emission tomography/computed tomography $\left({ }^{18} \mathrm{~F}\right.$ FDG PET/CT) is a robust imaging tool that is currently used in daily clinical practice for the evaluation of thoracic malignancies. This chapter provides an overview of the current evidencebased data on the usefulness of PET/CT for the evaluation of patients with thoracic tumours including lung cancer, pleural and thymic tumours, and esophageal cancer.

F. Lococo $(\square) \cdot$ A. Cesario $\cdot$ S. Margaritora Department of General Thoracic Surgery, Catholic University of the Sacred Heart, Fondazione Policinico A. Gemelli, Rome, Italy

G. Treglia

Clinic of Nuclear Medicine and Molecular Imaging, Imaging Institute of Southern Switzerland, Ente Ospedaliero Cantonale,

Bellinzona and Lugano, Switzerland

Department of Nuclear Medicine and Molecular Imaging, Lausanne University Hospital and University of Lausanne, Lausanne, Switzerland

Health Technology Assessment Unit, Academic Education, Research and Innovation Area, Ente Ospedaliero Cantonale, Bellinzona, Switzerland e-mail: giorgio.treglia@eoc.ch

\subsection{Evidence-Based Data on PET in Primary Lung Tumours}

Herein we reviewed recent evidence-based data on the usefulness of ${ }^{18} \mathrm{~F}-\mathrm{FDG}$ PET/CT for: (1) characterization of solitary pulmonary nodules (SPNs), (2) non-small cell lung cancer (NSCLC) staging, (3) restaging after induction therapy and systemic therapy response assessment in NSCLC, (4) radiation therapy planning, (5) diagnosis of lung cancer recurrence in NSCLC, (6) prognostic evaluation, (7) management of small cell lung cancer (SCLC).

\subsubsection{Characterization of Solitary Pulmonary Nodules (SPNs)}

Characterizing a SPN detected incidentally or, as is the case more recently, on CT screening for lung cancer is a major public health issue. ${ }^{18} \mathrm{~F}$ FDG PET/CT is not indicated for characterization of SPNs of less than $8 \mathrm{~mm}$ in diameter according to current guidelines [1]. This threshold was set to take into account the spatial resolution of PET systems, due to the significant risk of false-negative findings for small lesions. However, over the last decade, the spatial resolution of ${ }^{18} \mathrm{~F}-\mathrm{FDG}$ PET/CT has significantly increased and future analysis could verify if this threshold will be modified accordingly. 


\subsubsection{Single-Time-Point ${ }^{18}$ F-FDG PET or PET/CT}

In the last decade, a robust evidence has been produced on the potential use of ${ }^{18} \mathrm{~F}$-FDG PET/ CT in early diagnosis of lung cancer (Table 5.1). Chien and colleagues [2] in 2013 conducted a systematic review on this topic reporting evidence of lung cancer screening programmes with ${ }^{18} \mathrm{~F}-\mathrm{FDG}$ PET, in which the estimated pooled sensitivity and specificity were $83 \%$ and $91 \%$, respectively. At that moment, despite PET appeared to have high sensitivity and specificity as a selective screening modality, the role of primary PET screening for lung cancer remained unknown and still undefined.

Subsequently, a further systemic analysis [3] reported a very high $(98.7 \%)$ pooled sensitivity of ${ }^{18} \mathrm{~F}$-FDG PET/CT in this setting while specificity was suboptimal (58.2\%).

In 2016, the research team headed by Madsen [4] suggested that ${ }^{18} \mathrm{~F}-\mathrm{FDG}$ PET/CT can rule out malignancy in most SPNs due to high sensitivity (recommendation level A) but at the same time the sensitivity of ${ }^{18} \mathrm{~F}-\mathrm{FDG} \mathrm{PET} / \mathrm{CT}$ in general is insufficient to rule out mediastinal lymph node metastasis (recommendation level A). Therefore, with few exceptions (lesions $<1 \mathrm{~cm}$ and non-solid lesions), they concluded that SPNs could be presumptively considered benign if ${ }^{18} \mathrm{~F}$-FDG PET is negative. In addition, lymph node metastasis in the mediastinum cannot be ruled out on the basis of a negative ${ }^{18} \mathrm{~F}-\mathrm{FDG}$ PET/CT, and confirmative (mini)invasive staging should be performed in most patients.

More recently, a further meta-analysis [5] showed that the pooled sensitivity and specificity of ${ }^{18} \mathrm{~F}-\mathrm{FDG}$ PET/CT in characterizing SPNs were $82 \%$ and $81 \%$, respectively, demonstrating moderate accuracy for ${ }^{18} \mathrm{~F}$-FDG PET/CT in differentiating malignant from benign SPNs.

A further meta-analysis exploring the value of ${ }^{18} \mathrm{~F}-\mathrm{FDG}$ PET/CT in the diagnosis of SPNs was reported in 2018 [6]. Pooled results indicated a sensitivity of $89 \%$ and a specificity of $70 \%$.

Table 5.1 Main findings of included meta-analyses on the diagnostic performance of PET or PET/CT with different tracers in patients with solitary pulmonary nodules

\begin{tabular}{|c|c|c|c|c|c|c|}
\hline Indication & Tracer & Authors & Year & $\begin{array}{l}\text { Patients } \\
\text { included }\end{array}$ & $\begin{array}{l}\text { Pooled sensitivity } \\
(95 \% \mathrm{CI})\end{array}$ & $\begin{array}{l}\text { Pooled } \\
\text { specificity } \\
(95 \% \mathrm{CI})\end{array}$ \\
\hline \multirow[t]{12}{*}{$\begin{array}{l}\text { Evaluation of suspicious } \\
\text { primary lung tumour }\end{array}$} & \multirow[t]{6}{*}{$\begin{array}{l}{ }^{18} \mathrm{~F}-\mathrm{FDG} \\
(\mathrm{STP})\end{array}$} & Chien et al. [2] & 2013 & 264 & $\begin{array}{l}83 \% \\
(75-89)\end{array}$ & $\begin{array}{l}91 \% \\
(86-95)\end{array}$ \\
\hline & & Wang et al. [3] & 2015 & 1330 & $\begin{array}{l}99 \% \\
(\mathrm{~N} / \mathrm{A})\end{array}$ & $\begin{array}{l}58 \% \\
\text { (N/A) }\end{array}$ \\
\hline & & Ruilong et al. [5] & 2017 & 1297 & $\begin{array}{l}82 \% \\
(76-87)\end{array}$ & $\begin{array}{l}81 \% \\
(66-90)\end{array}$ \\
\hline & & Li et al. [6] & 2018 & 1557 & $\begin{array}{l}89 \% \\
(87-91)\end{array}$ & $\begin{array}{l}70 \% \\
(66-73)\end{array}$ \\
\hline & & Divisi et al. [7] & 2018 & 1463 & $\begin{array}{l}82 \% \\
(79-84)\end{array}$ & $\begin{array}{l}62 \% \\
(58-66)\end{array}$ \\
\hline & & $\begin{array}{l}\text { Basso Dias et al. } \\
\text { [9] }\end{array}$ & 2019 & 4224 & $\begin{array}{l}78 \% \\
(70-84)\end{array}$ & $\begin{array}{l}81 \% \\
(72-88)\end{array}$ \\
\hline & \multirow{4}{*}{$\begin{array}{l}{ }^{18} \mathrm{~F}-\mathrm{FDG} \\
(\mathrm{DTP})\end{array}$} & Lin et al. [10] & 2012 & 788 & N/A & N/A \\
\hline & & Barger et al. [11] & 2012 & 816 & $\begin{array}{l}85 \% \\
(82-89)\end{array}$ & $\begin{array}{l}77 \% \\
(72-81)\end{array}$ \\
\hline & & Zhang et al. [12] & 2013 & 415 & $\begin{array}{l}79 \% \\
(74-84)\end{array}$ & $\begin{array}{l}73 \% \\
(65-79)\end{array}$ \\
\hline & & Zhao et al. [13] & 2016 & 962 & $\begin{array}{l}80 \% \\
(76-84)\end{array}$ & $\begin{array}{l}75 \% \\
(71-79)\end{array}$ \\
\hline & \multirow[t]{2}{*}{${ }^{18} \mathrm{~F}-\mathrm{FLT}$} & Li et al. [14] & 2015 & 301 & $\begin{array}{l}81 \% \\
(74-87)\end{array}$ & $\begin{array}{l}70 \% \\
(61-77)\end{array}$ \\
\hline & & Wang et al. [15] & 2015 & 351 & $\begin{array}{l}80 \% \\
(74-85)\end{array}$ & $\begin{array}{l}82 \% \\
(74-88)\end{array}$ \\
\hline
\end{tabular}


Considering the unsatisfactory results, especially in terms of specificity, the authors stated that ${ }^{18} \mathrm{~F}$ FDG PET/CT cannot replace the "gold standard" pathology by resection or biopsy.

Not dissimilar results have been reported in a further recent meta-analysis performed by Divisi and co-workers [7]. The authors concluded that despite ${ }^{18}$ F-FDG PET/CT presents a fairly good diagnostic accuracy in SPNs evaluation, it should not be considered as a discriminatory test rather than a method to be included in a clinical and diagnostic pathway.

Interestingly, Deppen and co-workers [8] evaluated the accuracy of ${ }^{18} \mathrm{~F}-\mathrm{FDG}$ PET in diagnosing lung cancer comparing populations with or without a risk for endemic infectious lung disease. They observed a $16 \%$ lower average adjusted specificity in regions with endemic infectious lung disease (61\%) compared with non-endemic regions (77\%). On the other hand, the sensitivity did not change appreciably by endemic infection status, even after adjusting for relevant factors. On the light of these results, the authors did not suggest the use of ${ }^{18}$ F-FDG PET to diagnose lung cancer in regions with endemic pulmonary infections unless an institution achieves test performance accuracy similar to that found in non-endemic regions.

Lastly, a meta-analysis investigates the diagnostic performance of ${ }^{18} \mathrm{~F}-\mathrm{FDG}$ PET/CT compared with diffusion-weighted magnetic resonance imaging (DW-MRI) for distinguishing malignant versus benign SPNs [9]. DW-MRI had a pooled sensitivity and specificity of $83 \%$ and $91 \%$, respectively, compared with $78 \%$ and $81 \%$, respectively, for PET/CT. The authors concluded that the diagnostic performance of DW-MRI is comparable or superior to that of ${ }^{18} \mathrm{~F}-\mathrm{FDG}$ PET/ $\mathrm{CT}$ in the differentiation of malignant and benign pulmonary lesions.

\subsubsection{Dual-Time-Point (DTP) PET}

Several authors have also explored the potential use of a DTP ${ }^{18} \mathrm{~F}$-FDG PET in differentiating malignant from benign SPNs (Table 5.1). In 2012, a meta-analysis was performed by Lin and co-workers [10] exploring the diagnostic performance of both single-time-point (STP) and DTP
${ }^{18}$ F-FDG PET techniques. Sensitivity was higher with DTP imaging at moderate levels of specificity. This potential advantage of DTP over initial STP scanning was diminished at higher levels of specificity. Although there was no clear evidence to support the routine use of DTP imaging with ${ }^{18} \mathrm{~F}-\mathrm{FDG}$ PET in the differential diagnosis of pulmonary nodules, the authors suggested as such technique may provide additional information in selected cases with equivocal results from initial scanning. Other meta-analyses [11-13] reported similar diagnostic accuracy among DTP and STP ${ }^{18} \mathrm{~F}$-FDG PET or PET/CT in the diagnosis of SPNs. According to these results, the additional value of DTP compared to STP ${ }^{18}$ F-FDG-PET/ $\mathrm{CT}$ resulted to be questionable.

\subsubsection{3 ${ }^{18}$ F-FLT PET for Evaluation of Pulmonary Lesions}

The potential use of fluorine-18 fluorothymidine $\left({ }^{18}\right.$ F-FLT) PET in patients with pulmonary lesions was evaluated by two meta-analyses $[14,15]$ (Table 5.1), which showed that ${ }^{18}$ F-FLT PET had a higher specificity but lower sensitivity compared to ${ }^{18} \mathrm{~F}$-FDG PET in the evaluation of SPNs. Therefore, the authors assumed that ${ }^{18} \mathrm{~F}-\mathrm{FLT}$ and ${ }^{18} \mathrm{~F}-\mathrm{FDG}$ together could add diagnostic confidence for pulmonary lesions.

\subsubsection{NSCLC Staging}

Nodal $(\mathrm{N})$ and distant metastases $(\mathrm{M})$ staging is one of the major prognostic factors of survival in NSCLC patients. Accurate staging of distant metastases is crucial, as the treatment strategy is directly dependent on tumour stage. Although many studies have been reported in the last decades evaluating the performance of ${ }^{18} \mathrm{~F}-\mathrm{FDG}$ $\mathrm{PET} / \mathrm{CT}$ in lung cancer staging, the results among studies are still almost controversial.

\subsubsection{N Staging}

Zhao and associates [16] performed a metaanalysis about ${ }^{18} \mathrm{~F}-\mathrm{FDG}$ PET/CT for detecting mediastinal nodal metastases in patients with NSCLC. The pooled sensitivity and specificity with $95 \%$ confidence interval values $(95 \% \mathrm{CI})$ on 
a per-patient analysis were $71.9 \%$ (95\%CI: 68.3$75.3 \%)$ and $89.8 \%$ (95\%CI: 88.2-91.2\%), respectively.

A second meta-analysis on the same issue [17] showed a pooled sensitivity of $62 \%$ for ${ }^{18} \mathrm{~F}-\mathrm{FDG}$ PET/CT (95\%CI: 54-70\%) and a pooled specificity of $92 \%$ (95\%CI: 88-95\%) on a node-based analysis. The pooled sensitivity and specificity were $67 \%$ (95\%CI: $54-79 \%$ ) and $87 \%$ (95\%CI: 82-91\%), respectively, on a patient-based analysis. Interestingly, those studies from tuberculosis endemic countries showed lower sensitivity and also lower specificity compared to nontuberculosis endemic countries [17, 18].

Two meta-analyses were specifically limited to early-stage NSCLC cases. In detail, Wang and co-workers [19] found that the negative predictive value (NPV) of ${ }^{18} \mathrm{~F}-\mathrm{FDG}$ PET/CT for lymph nodal mediastinal metastases was $94 \%$ for $\mathrm{T} 1$ disease and $89 \%$ for $\mathrm{T} 2$ disease. Including both $\mathrm{T} 1$ disease and $\mathrm{T} 2$ disease, the NPV was $93 \%$ for mediastinal metastases and $87 \%$ for overall nodal metastases. Interestingly, adenocarcinoma histology type and high ${ }^{18} \mathrm{~F}-\mathrm{FDG}$ uptake in the primary lesion were associated with greater risk of occult nodal metastases.

Similarly, a second meta-analysis [20] focused on patients with resectable NSCLC revealed that ${ }^{18}$ F-FDG PET/CT had a pooled sensitivity and specificity for N staging of $81.3 \%$ (95\%CI: $70.2-$ $88.9 \%$ ) and $79.4 \%$ (95\%CI: 70-86.5\%), respectively. The authors assumed that accuracy of ${ }^{18} \mathrm{~F}$-FDG PET/CT in N staging was insufficient to allow management and strategy of care based on ${ }^{18} \mathrm{~F}-\mathrm{FDG}$ PET/CT findings alone.

Shen et al. [21] also investigated the diagnostic value of DTP ${ }^{18} \mathrm{~F}-\mathrm{FDG}$ PET/CT versus STP imaging for detection of mediastinal nodal metastases in NSCLC patients. Pooled sensitivity and specificity for DTP PET/CT were $85 \%$ (95\% CI: $78-91 \%$ ) and 75\% (95\%CI: 68-82\%), respectively, and for STP imaging the same values were $79 \%(95 \% \mathrm{CI}: 70-85 \%)$ and $73 \%$ (95\%CI: 65-79\%), respectively. The authors were very cautious in supporting the implementation of DTP imaging in routine PET protocols for mediastinal lymph node staging of NSCLC.

Lastly, two meta-analyses compared ${ }^{18} \mathrm{~F}$-FDG PET/CT and DW-MRI for detection of mediasti- nal nodal metastases in NSCLC [22, 23] reporting similar results in terms of diagnostic accuracy among these two imaging methods.

\subsubsection{M Staging}

A meta-analysis by $\mathrm{Li}$ and co-workers [24] showed the excellent diagnostic performance of ${ }^{18} \mathrm{~F}-\mathrm{FDG}$ PET/CT for diagnosis of distant metastases in patients with NSCLC with a pooled sensitivity and specificity of 93\% (95\%CI: 88-96\%) and 96\% (95\%CI: 95-96), respectively. Similar results were reported by Yu et al. [25] who found a pooled sensitivity of $81 \%$ (95\%CI: 63-92\%) and 96\% (95\%CI: 94-98\%), respectively. A further meta-analysis on the same topic [26] demonstrated that concerning extra-thoracic metastases of NSCLC, the pooled sensitivities and specificities of ${ }^{18} \mathrm{~F}-\mathrm{FDG}$ PET/CT were $77 \%$ (95\% CI: 47-93\%) and 95\% (95\%CI: 92-97\%) for all extra-thoracic metastases, whereas the same values were 91\% (95\%CI: $80-97 \%$ ) and $98 \%$ (95\%CI: 94-99\%), respectively, for bone metastases. Conversely, ${ }^{18} \mathrm{~F}$-FDG PET/CT showed low sensitivity in detecting brain metastases.

Concerning the latter issue, a comparative meta-analysis MRI and ${ }^{18} \mathrm{~F}$-FDG PET/CT for the diagnosis of brain metastases in NSCLC [27] revealed that MRI had higher sensitivity (77\%) than ${ }^{18} \mathrm{~F}$-FDG PET/CT (21\%) for the diagnosis of brain metastases.

Chang et al. [28] found a higher sensitivity and specificity of ${ }^{18} \mathrm{~F}$-FDG PET/CT compared to bone scintigraphy (BS) in detecting bone metastases from NSCLC. A further more robust metaanalysis [29] showed that ${ }^{18} \mathrm{~F}-\mathrm{FDG}$ PET/CT is a better imaging method in terms of sensitivity and specificity compared to MRI and BS for detecting bone metastases from NSCLC, with a pooled sensitivity and specificity of $92 \%$ (95\%CI: 88-95\%) and 98\% (95\%CI: 97-98), respectively.

Finally, the diagnostic performance of ${ }^{18} \mathrm{~F}$ FDG PET/CT in detecting adrenal metastases from NSCLC was recently evaluated by $\mathrm{Wu}$ and co-workers [30]. The pooled sensitivity and specificity of ${ }^{18} \mathrm{~F}-\mathrm{FDG}$ PET/CT in this setting were $88.7 \%$ (95\%CI: 85.2-91.7\%) and 90.8\% (95\%CI: $87.5-93.4 \%)$, respectively, suggesting excellent performance. 


\subsubsection{Restaging After Induction Therapy and Prediction of Treatment Response}

The ability to identify potential responders to induction treatment may improve patient selection or surgery and may help in the development of response criteria suitable for routine monitoring of response. By providing information on the metabolic activity of tumour cells, ${ }^{18} \mathrm{~F}-\mathrm{FDG}$ PET/ $\mathrm{CT}$ has become a powerful tool in assessing treatment response. Zhang and colleagues [31] performed a meta-analysis to evaluate the value of ${ }^{18} \mathrm{~F}$-FDG PET in predicting the pathological tumour response of lung cancer to induction therapy. The authors found that ${ }^{18} \mathrm{~F}-\mathrm{FDG}$ PET could play an important role in predicting nonresponders to induction therapy in cases of lung cancer: indeed, the pooled sensitivity, specificity, positive predictive value, and negative predictive value for PET-predicted response were $83 \%$ (95\%CI: 76-89\%), 84\% (95\%CI: 79-88\%), 74\% (95\%CI: 67-81\%), and 91\% (95\%CI: 87-94\%), respectively.

A recent evidence-based article assessed the use of ${ }^{18} \mathrm{~F}-\mathrm{FDG}$ PET/CT for both assessing the efficacy of treatment response and performing post-treatment follow-up of lung cancer [32]. PET metabolic response (PERCIST criteria) has been shown to be a better predictor of histopathologic response than anatomic response metrics (WHO and RECIST criteria). ${ }^{18} \mathrm{~F}-\mathrm{FDG}$ PET/CT was indicated for treatment response assessment when it is performed within 6 months from treatment completion, though evidence for its comparative effectiveness with chest CT is still evolving.

\subsubsection{Radiation Therapy Pretreatment Planning in NSCLC}

${ }^{18}$ F-FDG PET/CT may also increase the likelihood of correctly delineating tumour tissue before radiotherapy dose planning. In 2017, Hallqvist and colleagues [33] reported the results of a meta-analysis on the use of ${ }^{18} \mathrm{~F}-\mathrm{FDG}$ PET/ $\mathrm{CT}$ for radiotherapy dose planning. According to this meta-analysis, a change in target definition was $36 \%$ in patients with a former staging PET, and $43 \%$ and $26 \%$ in patients without a staging PET for NSCLC and SCLC, respectively. The corresponding summary estimates of a change in treatment intent from curative to palliative treatment were $20 \%$ and $22 \%$ and $9 \%$, respectively. Another recent meta-analysis demonstrated that functional lung imaging, including PET, may have potential utility in radiation therapy planning and delivery [34].

\subsubsection{Diagnosis of Lung Cancer Recurrence}

Although there are no conclusive data to support the survival benefits of early detection or early treatment for recurrence of lung cancer, an early and accurate diagnosis of recurrence is critical to optimize therapy. A meta-analysis [35] was performed to assess the diagnostic value of ${ }^{18} \mathrm{~F}-\mathrm{FDG}$ PET and PET/CT for cases of recurrent lung cancer. In the patient-based analysis performed, ${ }^{18} \mathrm{~F}-$ FDG PET and PET/CT were found to provide better detection of lung cancer recurrence compared to CT. Indeed, the pooled sensitivity for ${ }^{18} \mathrm{~F}-\mathrm{FDG}$ PET, PET/CT, and CT were $94 \%$ (95\%CI: 91-97\%), 90\% (95\%CI: 84-95), and $78 \%$ (95\%CI: $71-84 \%$ ), respectively while the pooled specificity for ${ }^{18} \mathrm{~F}-\mathrm{FDG}$ PET, PET/CT, and CT were $84 \%$ (95\%CI: 77-89\%), 90\% (95\%CI: 87-93\%), and 80\% (95\%CI: 75-84\%), respectively.

\subsubsection{Prognostic Evaluation in NSCLC}

In their meta-analysis, Paesmans et al. [36] assessed the prognostic value of primary tumour maximum standardized uptake value (SUVmax) at ${ }^{18} \mathrm{~F}$-FDG PET for overall survival (OS) of NSCLC patients. At multivariate analysis, SUVmax was found to be independently associated with survival. The hazard ratio (HR) for SUVmax was 1.58 (95\%CI: 1.27-1.96).

Despite the SUVmax represents the most widely applied semi-quantitative PET parameter 
in clinical practice, volumetric PET parameters, including metabolic tumour volume (MTV) and total lesion glycolysis (TLG), have been also used to reflect disease burden and tumour aggressiveness in NSCLC. A first meta-analysis performed by Liu et al. [37] explored the prognostic value of SUVmax, MTV, and TLG on diseasefree survival (DFS) and OS in surgical NSCLC patients. The pooled HRs for OS were 1.52 for SUVmax, 1.91 for MTV, and 1.94 for TLG. On the basis of these results, the authors stated that high values of SUVmax, MTV, and TLG are able to predict a higher risk of recurrence or death in patients with surgical NSCLC, suggesting the use of ${ }^{18} \mathrm{~F}$-FDG PET/CT to select patients who are at high risk of disease recurrence or death as the best candidates from aggressive treatments. Other authors [38] conducted a meta-analysis on the prognostic value of MTV and TLG in NSCLC patients. A worse prognosis was observed in patients with high MTV (HR: 2.31) and with high TLG (HR: 2.43).

Han and colleagues [39] performed a metaanalysis exploring prognostic value of texture parameters derived by ${ }^{18} \mathrm{~F}$-FDG PET in patients with lung cancer. They concluded that there is insufficient evidence to support the prognostic value of texture analysis in ${ }^{18} \mathrm{~F}$-FDG PET in lung cancer.

Another interesting application of ${ }^{18} \mathrm{~F}-\mathrm{FDG}$ PET is the ability to predict long-term results after radiation therapy. Dong and co-workers [40] explored the prognostic relevance of SUVmax at ${ }^{18} \mathrm{~F}$-FDG PET for early-stage NSCLC patients receiving stereotactic body radiation therapy (SBRT). The authors found that those NSCLC patients presenting with high levels of pre-SBRT SUVmax had poorer OS and local control and higher risk of distant metastases. These findings were confirmed by another metaanalysis [41] showing that both pre-radiotherapy and post-radiotherapy primary tumour SUVmax can predict the outcome of patients with NSCLC treated with radiotherapy.

Other authors [42] have summarized the prognostic value of early response at ${ }^{18} \mathrm{~F}$-FDG PET in NSCLC patients treated with tyrosine-kinase inhibitors (TKI). Early response of patients with
NSCLC treated with TKIs identified on ${ }^{18} \mathrm{~F}-\mathrm{FDG}$ PET was found to be associated with improved OS and progression-free survival (PFS).

\subsubsection{Management of SCLC}

The role of ${ }^{18} \mathrm{~F}$-FDG PET in the management of SCLC has been largely investigated in the last decades. A systematic review and meta-analysis performed by Lu et al. [43] to evaluate the diagnostic accuracy of ${ }^{18} \mathrm{~F}-\mathrm{FDG}$ PET/CT in the pretherapeutic staging of patients with SCLC demonstrated a pooled sensitivity and specificity of $97.5 \%$ (95\%CI: 94.2-99.2\%) and $98.2 \%$ (95\%CI: 94.9-99.6\%), respectively, for the detection of extensive disease in SCLC patients. Therefore, evidence-based data suggest the role of ${ }^{18} \mathrm{~F}$-FDG PET/CT for discriminating between limited and extensive disease in SCLC.

The prognostic value of the SUVmax of primary SCLC at ${ }^{18} \mathrm{~F}$-FDG PET was recently investigated through a meta-analytic study [44]: the pooled HR for OS was 1.13 (95\%CI: 1.05-1.22), thus indicating that SCLC patients with high SUVmax may have poorer prognosis.

\subsection{Evidence-Based Data on PET in Pleural Tumours}

Three meta-analyses assessed the role of ${ }^{18} \mathrm{~F}$ FDG PET or PET/CT in the characterization of pleural lesions [45-47], whereas meta-analyses on the role of ${ }^{18} \mathrm{~F}$-FDG PET/CT in staging, restaging, prognostic or treatment response evaluation of pleural tumours are currently lacking.

${ }^{18}$ F-FDG-PET and PET/CT demonstrated to be accurate diagnostic imaging methods in the differential diagnosis between malignant and benign pleural lesions in patients with or without known cancer; nevertheless, possible sources of falsenegative and false-positive results should be kept in mind $[45,46]$. In patients without known cancer, sensitivity and specificity of ${ }^{18}$ F-FDG-PET and PET/CT were 95\% (95\%CI: 92-97\%) and 82\% (95\% CI: 76-88\%), respectively [45]. In patients with known cancer, pooled sensitivity 
was $86 \%$ (95\%CI: 80-91\%) and pooled specificity was $80 \%$ (95\%CI: 73-85\%) [46]. Porcel et al. in their meta-analysis [47] demonstrated that semi-quantitative PET assessment had a significantly lower sensitivity for diagnosing malignant pleural effusions than visual assessments. The pooled sensitivity and specificity of ${ }^{18} \mathrm{~F}-\mathrm{FDG}$ $\mathrm{PET} / \mathrm{CT}$ using semi-quantitative interpretation for identifying malignant pleural effusions were $81 \%$ and $74 \%$, respectively. The moderate accuracy of semi-quantitative PET assessment precludes its routine recommendation for discriminating malignant from benign pleural effusions.

\subsection{Evidence-Based Data on PET in Thymic Epithelial Tumours}

One meta-analysis [48] showed that ${ }^{18} \mathrm{~F}-\mathrm{FDG}$ PET may predict the WHO grade of malignancy in thymic epithelial tumours (TETs), reporting a statistically significant difference of SUVmax between the different TETs (low-grade thymomas, high-grade thymomas, and thymic carcinomas). In detail, the pooled mean difference of SUVmax between high-risk and low-risk thymomas was 1.2 (95\%CI: 0.4-2.0), that between thymic carcinomas and low-risk thymomas was 4.8 (95\% CI: 3.4-6.1), and that thymic carcinomas and high-risk thymomas was 3.5 (95\% CI: 2.7-4.3).

Notably, meta-analyses on the role of ${ }^{18} \mathrm{~F}-\mathrm{FDG}$ $\mathrm{PET} / \mathrm{CT}$ in staging, restaging, prognostic or treatment response evaluation of TETs are currently lacking.

\subsection{Evidence-Based Data on PET in Esophageal Tumours}

\subsubsection{Staging}

The real and unquestionable additional diagnostic value of ${ }^{18} \mathrm{~F}-\mathrm{FDG}$ PET/CT in comparison to conventional imaging methods is in evaluating distant metastases ( $\mathrm{M}$ staging) of esophageal cancer [49], whereas recent evidence-based articles have addressed the performance of ${ }^{18} \mathrm{~F}-\mathrm{FDG}$
PET/CT for detecting lymph nodal metastases ( $\mathrm{N}$ staging).

Jiang et al. [50] found that the pooled sensitivity and specificity estimates of ${ }^{18} \mathrm{~F}-\mathrm{FDG}$ PET/CT for detecting regional lymph nodal metastases at staging were $66 \%$ (95\% CI: $51-78 \%$ ) and $96 \%$ (95\% CI: 92-98\%), respectively. The corresponding values on a per-patient analysis were $65 \%$ (95\% CI: 49-78\%) and 81\% (95\%CI: 69-89\%), respectively. Overall, ${ }^{18} \mathrm{~F}-\mathrm{FDG}$ PET/CT has a moderate to low sensitivity and a high to moderate specificity for detection of regional nodal metastases in esophageal cancer. Therefore, extending the extent of lymph node dissection or radiotherapy target volume is necessary after the diagnosis of regional nodal metastases by ${ }^{18} \mathrm{~F}$ FDG PET/CT.

In another meta-analysis [51], Hu et al. evaluated the diagnostic performance of ${ }^{18} \mathrm{~F}-\mathrm{FDG}$ PET/ CT for the assessment of preoperative lymph node metastases in patients with esophageal cancer. In patients without neoadjuvant treatment, ${ }^{18} \mathrm{~F}-\mathrm{FDG}$ PET/CT had a pooled sensitivity and specificity of 57\% (95\%CI: 45-69\%) and 91\% (95\%CI: 85-95), respectively. In patients who received neoadjuvant treatment, ${ }^{18} \mathrm{~F}-\mathrm{FDG}$ PET/ CT had a pooled sensitivity and specificity of 53\% (95\%CI: 35-70\%) and 96\% (95\%CI: 86-99\%), respectively. Therefore, ${ }^{18} \mathrm{~F}-\mathrm{FDG}$ PET/CT has a high specificity but a low sensitivity; thus, it cannot accurately detect the lymph nodal involvement in patients with esophageal cancer.

Shi et al. [52] also demonstrated that ${ }^{18} \mathrm{~F}-\mathrm{FDG}$ PET/CT had lower sensitivity and accuracy for detection of regional nodal metastases in patients with esophageal cancer before surgery. The pooled sensitivity and specificity were $62 \%$ (95\%CI: 40-79\%) and 96\% (95\%CI: 93-98\%), respectively, on a per-station analysis; the corresponding values on a per-patient analysis were $55 \%$ (95\%CI: $34-74 \%)$ and $76 \%$ (95\% CI: 66-83\%), respectively.

In this setting, cervical ultrasonography has very limited additional diagnostic value as supplement to a negative ${ }^{18} \mathrm{~F}-\mathrm{FDG}$ PET/CT in the detection of cervical lymph node metastases during the initial staging of patients with esophageal cancer, as demonstrated by Goense et al. [53]. 


\subsubsection{Restaging}

Restaging after neoadjuvant therapy aims to reduce the number of patients undergoing oesophagectomy in case of distant (interval) metastases. Kroese et al. [54] assessed the diagnostic performance of ${ }^{18} \mathrm{~F}$-FDG PET or PET/CT for the detection of distant interval metastases after neoadjuvant therapy in patients with esophageal cancer. The pooled proportion of patients in whom true distant interval metastases were detected by ${ }^{18} \mathrm{~F}-\mathrm{FDG}$ PET or PET/CT at restaging was $8 \%$ (95\%CI: 5-13\%). The pooled proportion of patients in whom false-positive distant findings were detected by ${ }^{18} \mathrm{~F}-\mathrm{FDG}$ PET or PET/CT at restaging was 5\% (95\% CI: 3-9\%). In conclusion, ${ }^{18} \mathrm{~F}$-FDG PET or PET/CT at restaging after neoadjuvant therapy for esophageal cancer can considerably impact on treatment decisionmaking. However, pathological confirmation of suspected lesions is needed.

Cong et al. [55] assessed the value of ${ }^{18} \mathrm{~F}$ FDG PET or PET/CT for response prediction of primary tumour in patients with esophageal cancer during (group A) or after (group B) neoadjuvant chemoradiotherapy. The pooled sensitivity and specificity were $85 \% \quad(95 \% \mathrm{CI}$ : 76-91\%) and 59\% (95\% CI: 48-69\%), respectively, in group A. The equivalent values were $67 \%$ (95\% CI: $60-73 \%$ ) and 69\% (95\% CI: $63-74 \%)$, respectively, in group B. Interestingly, the pooled sensitivity was $90 \%$ in the studies that enrolled patients with esophageal squamous cell carcinoma merely in group B. According to the present data, ${ }^{18} \mathrm{~F}-\mathrm{FDG}$ PET/ CT should not be used routinely to guide treatment strategy in esophageal cancer patients, but an additional value is expected in patients with esophageal squamous cell carcinoma treated with neoadjuvant chemoradiotherapy.

Goense et al. [56] assessed the diagnostic performance of ${ }^{18} \mathrm{~F}$-FDG PET or PET/CT for diagnosing recurrent esophageal cancer after initial treatment with curative intent. Pooled estimates of sensitivity and specificity for ${ }^{18} \mathrm{~F}$-FDG PET and PET/CT in this setting were $96 \%$ (95\%CI: 93-97\%) and 78\% (95\% CI: 66-86\%), respec- tively. Therefore, ${ }^{18} \mathrm{~F}$-FDG PET and PET/CT are reliable imaging modalities with a high sensitivity and moderate specificity for detecting recurrent esophageal cancer after treatment with curative intent. However, histopathologic confirmation of PET/CT-suspected lesions is required, because a considerable false-positive rate is noticed.

\subsubsection{Predictive and Prognostic Value}

Han et al. [57] performed a meta-analysis on the prognostic value of volumetric parameters (MTV and TLG) derived from pretreatment ${ }^{18} \mathrm{~F}-\mathrm{FDG}$ $\mathrm{PET} / \mathrm{CT}$ in patients with esophageal cancer. The pooled HRs of MTV and TLG for OS were 2.26 (95\%CI: 1.73-2.96) and 2.23 (95\%CI: 1.732.87), respectively. Regarding event-free survival, the pooled HRs of MTV and TLG were 2.03 (95\%CI: 1.66-2.49) and 2.57 (95\% CI: 1.82-3.62), respectively. Therefore, in patients with esophageal cancer, MTV and TLG derived from pretreatment ${ }^{18} \mathrm{~F}$-FDG PET are significant prognostic factors.

Schollaert et al. [58] performed a metaanalysis on the predictive value of ${ }^{18} \mathrm{~F}$-FDG PET for assessing DFS and OS in esophageal and oesophagogastric junction cancer after neoadjuvant chemoradiation therapy. The pooled HRs for complete metabolic response versus no response were 0.51 for OS (95\%CI: $0.4-0.64$ ) and 0.47 for DFS (95\%CI: 0.38-0.57), respectively. Therefore, metabolic response on ${ }^{18} \mathrm{~F}$-FDG PET is a significant predictor of long-term survival.

Lastly, Zhu et al. [59] performed a metaanalysis on the prognostic significance of SUVmax on ${ }^{18} \mathrm{~F}$-FDG PET/CT in patients with localized oesophagogastric junction cancer receiving neoadjuvant chemotherapy/chemoradiation therapy. Significant prognostic values of SUVmax before and during therapy in localized oesophagogastric junction cancer were not found. Conversely, relative changes in ${ }^{18}$ F-FDG-uptake after therapy are significant prognostic markers for OS and DFS. 


\section{References}

1. MacMahon H, Naidich DP, Goo JM, Lee KS, Leung ANC, Mayo JR, et al. Guidelines for management of incidental pulmonary nodules detected on CT images: from the Fleischner Society 2017. Radiology. 2017;284(1):228-43.

2. Chien CR, Liang JA, Chen JH, Wang HN, Lin CC, Chen CY, et al. [(18)F]Fluorodeoxyglucose-positron emission tomography screening for lung cancer: a systematic review and meta-analysis. Cancer Imaging. 2013;13(4):458-65.

3. Wang HQ, Zhao L, Zhao J, Wang Q. Analysis on early detection of lung cancer by PET/CT scan. Asian Pac J Cancer Prev. 2015;16(6):2215-7.

4. Madsen PH, Holdgaard PC, Christensen JB, HøilundCarlsen PF. Clinical utility of F-18 FDG PET-CT in the initial evaluation of lung cancer. Eur J Nucl Med Mol Imaging. 2016;43(11):2084-97.

5. Ruilong Z, Daohai X, Li G, Xiaohong W, Chunjie W, Lei T. Diagnostic value of 18F-FDG-PET/CT for the evaluation of solitary pulmonary nodules: a systematic review and meta-analysis. Nucl Med Commun. 2017;38(1):67-75.

6. Li ZZ, Huang YL, Song HJ, Wang YJ, Huang Y. The value of 18F-FDG-PET/CT in the diagnosis of solitary pulmonary nodules: a meta-analysis. Medicine. 2018;97(12):e0130.

7. Divisi D, Barone M, Bertolaccini L, Zaccagna G, Gabriele F, Crisci R. Diagnostic performance of fluorine-18 fluorodeoxyglucose positron emission tomography in the management of solitary pulmonary nodule: a meta-analysis. J Thorac Dis. 2018;10(Suppl 7):S779-89.

8. Deppen SA, Blume JD, Kensinger CD, Morgan AM, Aldrich MC, Massion PP, et al. Accuracy of FDG-PET to diagnose lung cancer in areas with infectious lung disease: a meta-analysis. JAMA. 2014;312(12):1227-36.

9. Basso Dias A, Zanon M, Altmayer S, Sartori Pacini G, Henz Concatto N, Watte G, et al. Fluorine 18-FDG PET/CT and diffusion-weighted MRI for malignant versus benign pulmonary lesions: a Meta-analysis. Radiology. 2019;290(2):525-34.

10. Lin YY, Chen JH, Ding HJ, Liang JA, Yeh JJ, Kao $\mathrm{CH}$. Potential value of dual-time-point ${ }^{18} \mathrm{~F}-\mathrm{FDG}$ PET compared with initial single-time-point imaging in differentiating malignant from benign pulmonary nodules: a systematic review and meta-analysis. Nucl Med Commun. 2012;33(10):1011-8.

11. Barger RL Jr, Nandalur KR. Diagnostic performance of dual-time 18F-FDG PET in the diagnosis of pulmonary nodules: a meta-analysis. Acad Radiol. 2012;19(2):153-8.

12. Zhang L, Wang Y, Lei J, Tian J, Zhai Y. Dual time point 18FDG-PET/CT versus single time point 18FDG-PET/CT for the differential diagnosis of pulmonary nodules: a meta-analysis. Acta Radiol. 2013;54(7):770-7.
13. Zhao M, Ma Y, Yang B, Wang Y. A meta-analysis to evaluate the diagnostic value of dual-time-point F-fluorodeoxyglucose positron emission tomography/ computed tomography for diagnosis of pulmonary nodules. J Cancer Res Ther. 2016;12(Suppl):C304-8.

14. Li XF, Dai D, Song XY, Liu JJ, Zhu YJ, Xu WG. Comparison of the diagnostic performance of $18 \mathrm{~F}$-fluorothymidine versus $18 \mathrm{~F}$-fluorodeoxyglucose positron emission tomography on pulmonary lesions: a meta analysis. Mol Clin Oncol. 2015;3(1):101-8.

15. Wang Z, Wang Y, Sui X, Zhang W, Shi R, Zhang Y, et al. Performance of FLT-PET for pulmonary lesion diagnosis compared with traditional FDG-PET: a meta-analysis. Eur J Radiol. 2015;84(7):1371-7.

16. Zhao L, He ZY, Zhong XN, Cui ML. (18)FDG-PET/ CT for detection of mediastinal nodal metastasis in non-small cell lung cancer: a meta-analysis. Surg Oncol. 2012;21(3):230-6.

17. Pak K, Park S, Cheon GJ, Kang KW, Kim IJ, Lee DS, et al. Update on nodal staging in non-small cell lung cancer with integrated positron emission tomography/ computed tomography: a meta-analysis. Ann Nucl Med. 2015;29(5):409-19.

18. Liao CY, Chen JH, Liang JA, Yeh JJ, Kao CH. Metaanalysis study of lymph node staging by 18 F-FDG PET/CT scan in non-small cell lung cancer: comparison of TB and non-TB endemic regions. Eur J Radiol. 2012;81(11):3518-23.

19. Wang J, Welch K, Wang L, Kong FM. Negative predictive value of positron emission tomography and computed tomography for stage T1-2N0 non-smallcell lung cancer: a meta-analysis. Clin Lung Cancer. 2012;13(2):81-9.

20. Schmidt-Hansen M, Baldwin DR, Hasler E, Zamora J, Abraira V, Roqué I Figuls M. PET-CT for assessing mediastinal lymph node involvement in patients with suspected resectable non-small cell lung cancer. Cochrane Database Syst Rev. 2014;(11):CD009519.

21. Shen G, Hu S, Deng H, Jia Z. Diagnostic value of dual time-point 18 F-FDG PET/CT versus single time-point imaging for detection of mediastinal nodal metastasis in non-small cell lung cancer patients: a meta-analysis. Acta Radiol. 2015;56(6):681-7.

22. Wu LM, Xu JR, Gu HY, Hua J, Chen J, Zhang W, et al. Preoperative mediastinal and hilar nodal staging with diffusion-weighted magnetic resonance imaging and fluorodeoxyglucose positron emission tomography/computed tomography in patients with nonsmall-cell lung cancer: which is better? J Surg Res. 2012;178(1):304-14.

23. Shen G, Lan Y, Zhang K, Ren P, Jia Z. Comparison of 18F-FDG PET/CT and DWI for detection of mediastinal nodal metastasis in non-small cell lung cancer: a meta-analysis. PLoS One. 2017;12(3):e0173104.

24. Li J, Xu W, Kong F, Sun X, Zuo X. Meta-analysis: accuracy of 18FDG PET-CT for distant metastasis staging in lung cancer patients. Surg Oncol. 2013;22(3):151-5.

25. Yu B, Zhu X, Liang Z, Sun Y, Zhao W, Chen K. Clinical usefulness of 18F-FDG PET/CT for 
the detection of distant metastases in patients with non-small cell lung cancer at initial staging: a metaanalysis. Cancer Manag Res. 2018;10:1859-64.

26. Wu Y, Li P, Zhang H, Shi Y, Wu H, Zhang J, et al. Diagnostic value of fluorine 18 fluorodeoxyglucose positron emission tomography/computed tomography for the detection of metastases in non-small-cell lung cancer patients. Int J Cancer. 2013;132(2):E37-47.

27. Li Y, Jin G, Su D. Comparison of gadoliniumenhanced MRI and 18FDG PET/PET-CT for the diagnosis of brain metastases in lung cancer patients: a meta-analysis of 5 prospective studies. Oncotarget. 2017;8(22):35743-9.

28. Chang MC, Chen JH, Liang JA, Lin CC, Yang KT, Cheng KY, et al. Meta-analysis: comparison of F-18 fluorodeoxyglucose-positron emission tomography and bone scintigraphy in the detection of bone metastasis in patients with lung cancer. Acad Radiol. 2012;19(3):349-57.

29. Qu X, Huang X, Yan W, Wu L, Dai K. A meta-analysis of ${ }^{18}$ FDG-PET-CT, ${ }^{18}$ FDG-PET, MRI and bone scintigraphy for diagnosis of bone metastases in patients with lung cancer. Eur J Radiol. 2012;81(5):1007-15.

30. Wu Q, Luo W, Zhao Y, Xu F, Zhou Q. The utility of 18F-FDG PET/CT for the diagnosis of adrenal metastasis in lung cancer: a PRISMA-compliant metaanalysis. Nucl Med Commun. 2017;38(12):1117-24.

31. Zhang C, Liu J, Tong J, Sun X, Song S, Huang G. 18F-FDG-PET evaluation of pathological tumour response to neoadjuvant therapy in patients with NSCLC. Nucl Med Commun. 2013;34(1):71-7.

32. Sheikhbahaei S, Mena E, Yanamadala A, Reddy S, Solnes LB, Wachsmann J, et al. The value of FDG $\mathrm{PET} / \mathrm{CT}$ in treatment response assessment, followup, and surveillance of lung cancer. AJR Am J Roentgenol. 2017;208(2):420-33.

33. Hallqvist A, Alverbratt C, Strandell A, Samuelsson O, Björkander E, Liljegren A, et al. Positron emission tomography and computed tomographic imaging (PET/CT) for dose planning purposes of thoracic radiation with curative intent in lung cancer patients: a systematic review and meta-analysis. Radiother Oncol. 2017;123(1):71-7.

34. Bucknell NW, Hardcastle N, Bressel M, Hofman MS, Kron T, Ball D, et al. Functional lung imaging in radiation therapy for lung cancer: a systematic review and meta-analysis. Radiother Oncol. 2018;129(2):196-208.

35. He YQ, Gong HL, Deng YF, Li WM. Diagnostic efficacy of PET and PET/CT for recurrent lung cancer: a meta-analysis. Acta Radiol. 2014;55(3):309-17.

36. Paesmans M, Garcia C, Wong CY, Patz EF Jr, Komaki $\mathrm{R}$, Eschmann S, et al. Primary tumour standardised uptake value is prognostic in nonsmall cell lung cancer: a multivariate pooled analysis of individual data. Eur Respir J. 2015;46(6):1751-61.

37. Liu J, Dong M, Sun X, Li W, Xing L, Yu J. Prognostic value of $18 \mathrm{~F}-\mathrm{FDG}$ PET/CT in surgical non-small cell lung cancer: a Meta-analysis. PLoS One. 2016;11(1):e0146195.
38. Im HJ, Pak K, Cheon GJ, Kang KW, Kim SJ, Kim IJ, et al. Prognostic value of volumetric parameters of (18)F-FDG PET in non-small-cell lung cancer: a meta-analysis. Eur J Nucl Med Mol Imaging. 2015;42(2):241-51.

39. Han S, Woo S, Suh CH, Kim YJ, Oh JS, Lee JJ. A systematic review of the prognostic value of texture analysis in 18F-FDG PET in lung cancer. Ann Nucl Med. 2018;32(9):602-10.

40. Dong M, Liu J, Sun X, Xing L. Prognositc significance of SUVmax on pretreatment 18 F-FDG PET/ $\mathrm{CT}$ in early-stage non-small cell lung cancer treated with stereotactic body radiotherapy: a meta-analysis. Acta Radiol. 2018;59(9):1082-90.

41. Na F, Wang J, Li C, Deng L, Xue J, Lu Y. Primary tumor standardized uptake value measured on F18Fluorodeoxyglucose positron emission tomography is of prediction value for survival and local control in non-small-cell lung cancer receiving radiotherapy: meta-analysis. $\mathrm{J}$ Thorac Oncol. 2014;9(6):834-42.

42. Ma J, Wu X, Li J, Wang Z, Wang Y. Prognostic value of early response assessment using (18F)FDG-PET in patients with advanced non-small cell lung cancer treated with tyrosine-kinase inhibitors. J Investig Med. 2017;65(5):935-41.

43. Lu YY, Chen JH, Liang JA, Chu S, Lin WY, Kao CH. 18F-FDG PET or PET/CT for detecting extensive disease in small-cell lung cancer: a systematic review and meta-analysis. Nucl Med Commun. 2014;35(7):697-703.

44. Zhu D, Wang Y, Wang L, Chen J, Byanju S, Zhang $\mathrm{H}$, et al. Prognostic value of the maximum standardized uptake value of pre-treatment primary lesions in small-cell lung cancer on 18F-FDG PET/CT: a metaanalysis. Acta Radiol. 2018;59(9):1082-90.

45. Treglia G, Sadeghi R, Annunziata S, Lococo F, Cafarotti S, Bertagna F, et al. Diagnostic accuracy of 18F-FDG-PET and PET/CT in the differential diagnosis between malignant and benign pleural lesions: a systematic review and meta-analysis. Acad Radiol. 2014;21(1):11-20.

46. Treglia G, Sadeghi R, Annunziata S, Lococo F, Cafarotti S, Prior JO, et al. Diagnostic performance of fluorine-18-fluorodeoxyglucose positron emission tomography in the assessment of pleural abnormalities in cancer patients: a systematic review and a meta-analysis. Lung Cancer. 2014;83(1):1-7.

47. Porcel JM, Hernández P, Martínez-Alonso M, Bielsa S, Salud A. Accuracy of fluorodeoxyglucose-PET imaging for differentiating benign from malignant pleural effusions: a meta-analysis. Chest. 2015;147(2):502-12.

48. Treglia G, Sadeghi R, Giovanella L, Cafarotti S, Filosso P, Lococo F. Is (18)F-FDG PET useful in predicting the WHO grade of malignancy in thymic epithelial tumors? A meta-analysis. Lung Cancer. 2014;86(1):5-13.

49. Marzola MC, De Manzoni G, Grassetto G, Cordiano C, Al-Nahhas A, Alavi A, et al. Extended staging 
of oesophageal cancer using FDG-PET - a critical appraisal. Eur J Radiol. 2012;81(1):21-30.

50. Jiang C, Chen Y, Zhu Y, Xu Y. Systematic review and meta-analysis of the accuracy of 18F-FDG PET/CT for detection of regional lymph node metastasis in esophageal squamous cell carcinoma. J Thorac Dis. 2018;10(11):6066-76.

51. Hu J, Zhu D, Yang Y. Diagnostic value of 18F-fluorodeoxyglucose positron-emission tomography/computed tomography for preoperative lymph node metastasis of esophageal cancer: a metaanalysis. Medicine. 2018;97(50):e13722.

52. Shi W, Wang W, Wang J, Cheng H, Huo X. Metaanalysis of 18FDG PET-CT for nodal staging in patients with esophageal cancer. Surg Oncol. 2013;22(2):112-6.

53. Goense L, Meziani J, van Rossum PSN, Wessels FJ, Meijer GJ, Lam MGEH, et al. Limited additional value of cervical ultrasonography over a negative 18F-FDG PET/CT for diagnosing cervical lymph node metastases in patients with esophageal cancer: a systematic review and meta-analysis. Nucl Med Commun. 2018;39(7):645-51.

54. Kroese TE, Goense L, van Hillegersberg R, de Keizer B, Mook S, Ruurda JP, et al. Detection of distant interval metastases after neoadjuvant therapy for esophageal cancer with $18 \mathrm{~F}-\mathrm{FDG}$ PET(/CT): a systematic review and meta-analysis. Dis Esophagus. 2018;31(12).
55. Cong L, Wang S, Gao T, Hu L. The predictive value of 18F-FDG PET for pathological response of primary tumor in patients with esophageal cancer during or after neoadjuvant chemoradiotherapy: a metaanalysis. Jpn J Clin Oncol. 2016;46(12):1118-26.

56. Goense L, van Rossum PS, Reitsma JB, Lam MG, Meijer GJ, van Vulpen M, et al. Diagnostic performance of ${ }^{18} \mathrm{~F}$-FDG PET and PET/CT for the detection of recurrent esophageal cancer after treatment with curative intent: a systematic review and metaanalysis. J Nucl Med. 2015;56(7):995-1002.

57. Han S, Kim YJ, Woo S, Suh CH, Lee JJ. Prognostic value of volumetric parameters of pretreatment 18F-FDG PET/CT in esophageal cancer: a systematic review and meta-analysis. Clin Nucl Med. 2018;43(12):887-94.

58. Schollaert P, Crott R, Bertrand C, D'Hondt L, Borght TV, Krug B. A systematic review of the predictive value of (18)FDG-PET in esophageal and esophagogastric junction cancer after neoadjuvant chemoradiation on the survival outcome stratification. J Gastrointest Surg. 2014;18(5):894-905.

59. Zhu W, Xing L, Yue J, Sun X, Sun X, Zhao $\mathrm{H}$, et al. Prognostic significance of SUV on PET/CT in patients with localised oesophagogastric junction cancer receiving neoadjuvant chemotherapy/chemoradiation:a systematic review and meta-analysis. Br J Radiol. 2012;85(1017):e694-701.

Open Access This chapter is licensed under the terms of the Creative Commons Attribution 4.0 International License (http://creativecommons.org/licenses/by/4.0/), which permits use, sharing, adaptation, distribution and reproduction in any medium or format, as long as you give appropriate credit to the original author(s) and the source, provide a link to the Creative Commons license and indicate if changes were made.

The images or other third party material in this chapter are included in the chapter's Creative Commons license, unless indicated otherwise in a credit line to the material. If material is not included in the chapter's Creative Commons license and your intended use is not permitted by statutory regulation or exceeds the permitted use, you will need to obtain permission directly from the copyright holder. 


\title{
Evidence-Based PET for Breast Cancer
}

\author{
Giorgio Treglia
}

\subsection{Introduction}

Fluorine-18 fluorodeoxyglucose positron emission tomography/computed tomography $\left({ }^{18} \mathrm{~F}\right.$ FDG PET/CT) is currently used in daily clinical practice for the evaluation of breast cancer (BC) patients. This chapter provides an overview of the current evidence-based data on the usefulness of PET/CT (using ${ }^{18} \mathrm{~F}-\mathrm{FDG}$ and other radiotracers) for different indications in patients with BC.

\subsection{Staging}

A recent network meta-analysis comparing 19 different imaging methods demonstrated the relatively higher specificity of ${ }^{18} \mathrm{~F}-\mathrm{FDG}$ PET/CT compared to other imaging methods for the detection of BC lesions [1].

\footnotetext{
G. Treglia $(\bowtie)$

Clinic of Nuclear Medicine and Molecular Imaging, Imaging Institute of Southern Switzerland, Ente Ospedaliero Cantonale,

Bellinzona and Lugano, Switzerland

Department of Nuclear Medicine and Molecular Imaging, Lausanne University Hospital and University of Lausanne, Lausanne, Switzerland

Health Technology Assessment Unit, Academic Education, Research and Innovation Area, Ente Ospedaliero Cantonale, Bellinzona, Switzerland e-mail: giorgio.treglia@eoc.ch
}

Liang et al. [2] evaluated through a metaanalytic approach the accuracy of magnetic resonance imaging (MRI) and ${ }^{18} \mathrm{~F}-\mathrm{FDG}$ PET/CT for lymph nodal (N) staging of early BC. The pooled specificities of MRI and PET/CT for diagnosing regional lymph nodal status in $\mathrm{BC}$ patients were similar (93\%); however, the pooled sensitivity of MRI was significantly greater than PET/CT (82\% versus 64\%), respectively.

Hong et al. [3] performed a meta-analysis to evaluate the value of ${ }^{18} \mathrm{~F}-\mathrm{FDG}$ PET/CT for diagnosis of distant metastases of BC. Pooled sensitivity and specificity of ${ }^{18} \mathrm{~F}-\mathrm{FDG}$ PET/CT were 96\% (95\%CI: 90-98\%) and 95\% (95\%CI: 92-97\%), respectively. Compared with conventional imaging, ${ }^{18} \mathrm{~F}-\mathrm{FDG}$ PET/CT has higher sensitivity for diagnosis of distant metastases in $\mathrm{BC}$ patients.

Similar findings were reported in another meta-analysis by Sun et al. [4]: pooled sensitivity and specificity of ${ }^{18} \mathrm{~F}$-FDG PET or PET/CT were 99\% (95\%CI: $88-100 \%)$ and 95\% (95\%CI: 89-98\%), respectively, confirming the excellent diagnostic performance of ${ }^{18} \mathrm{~F}-\mathrm{FDG}$ PET/CT for distant metastasis staging in $\mathrm{BC}$ patients compared to conventional imaging.

Rong et al. [5] found that the pooled sensitivity and specificity of ${ }^{18} \mathrm{~F}$-FDG PET/CT for detecting bone metastases of $\mathrm{BC}$ were $93 \%(95 \% \mathrm{CI}$ : 82-98\%) and 99\% (95\%CI: 95-100\%), respectively. Compared with bone scintigraphy, 
${ }^{18}$ F-FDG PET/CT has higher sensitivity and accuracy for detection of bone metastases in BC patients.

\subsection{Restaging and Assessment of Response to Neoadjuvant Therapy}

Evangelista et al. [6] performed a meta-analysis on the use of tumour markers in $\mathrm{BC}$ patients as a guide for ${ }^{18} \mathrm{~F}-\mathrm{FDG}$ PET imaging. The metaanalysis provided the following results: pooled sensitivity $87.8 \%$ (95\%CI: 83.8-90.9\%) and pooled specificity $69.3 \%$ (95\%CI: $55.3-80.5 \%$ ), confirming the role of ${ }^{18} \mathrm{~F}-\mathrm{FDG} \mathrm{PET} / \mathrm{CT}$ in detecting metastases in the presence of a progressive increase of serum tumour markers in $\mathrm{BC}$ patients.

Xiao et al. [7] found that the pooled sensitivity and specificity of ${ }^{18} \mathrm{~F}-\mathrm{FDG}$ PET or PET/CT in detecting BC recurrence were $90 \%(95 \% \mathrm{CI}$ : 88-90\%) and 81\% (95\%CI: 78-84), respectively. Therefore, ${ }^{18} \mathrm{~F}$-FDG PET/CT is a valuable imaging method to detect relapse in suspected recurrent $\mathrm{BC}$ patients.

Several meta-analyses evaluated the usefulness of ${ }^{18} \mathrm{~F}-\mathrm{FDG}$ PET/CT in predicting the response to neoadjuvant therapy in $\mathrm{BC}$ patients. According to Wang et al. [8], the pooled sensitivity, specificity, positive predictive value (PPV) and negative predictive value (NPV) of ${ }^{18} \mathrm{~F}-\mathrm{FDG}$ $\mathrm{PET} / \mathrm{CT}$ in this setting were $84 \%(95 \% \mathrm{CI}$ : 78-88\%), 66\% (95\%CI: 62-70\%), 50\% (95\%CI: $44-55 \%$ ) and $91 \%$ (95\%CI: 87-94\%), respectively. For regional lymph nodes, sensitivity and NPV of ${ }^{18} \mathrm{~F}-\mathrm{FDG}$ PET/CT were $92 \%$ (95\% CI: 83-97\%) and 88\% (95\%CI: 76-95\%), respectively. Overall, ${ }^{18} \mathrm{~F}-\mathrm{FDG}$ PET/CT is useful to predict neoadjuvant therapy response in $\mathrm{BC}$ patients, but the relatively low specificity and PPV still call for caution. Cheng et al. [9] found similar results of ${ }^{18} \mathrm{~F}$-FDG PET/CT in this setting reporting a pooled sensitivity and specificity of $84.7 \%$ (95\%CI: 79.3-89.2\%) and 66.1\% (95\%CI: 59.8$72.0 \%)$, respectively, indicating that ${ }^{18} \mathrm{~F}-\mathrm{FDG}$ $\mathrm{PET} / \mathrm{CT}$ has reasonable sensitivity in evaluating response to neoadjuvant chemotherapy in $\mathrm{BC}$, but the specificity is relatively low. Mghanga et al. [10] found that ${ }^{18} \mathrm{~F}-\mathrm{FDG}$ PET has moderately high sensitivity $(80.5 \%$; 95\%CI: $75.9-$ $84.5 \%)$ and specificity (78.8\%; 95\%CI: $74.1-83.0 \%$ ) in early detection of responders from nonresponders, and it can be used for the evaluation of response to neoadjuvant chemotherapy in BC patients. Another meta-analysis [11] reported that the pooled sensitivity and specificity of ${ }^{18} \mathrm{~F}$-FDG PET/CT in this setting were 81.9\% (95\% CI: $76.0-86.6 \%$ ) and 79.3\% (95\% CI: $72.1-85.1 \%$ ), respectively, confirming the moderate accuracy of ${ }^{18} \mathrm{~F}-\mathrm{FDG} \mathrm{PET} / \mathrm{CT}$ in predicting neoadjuvant therapy response in $\mathrm{BC}$ patients.

Several meta-analyses compared ${ }^{18} \mathrm{~F}-\mathrm{FDG}$ PET/CT and MRI for evaluation of treatment response to neoadjuvant chemotherapy (NAC) in $\mathrm{BC}$ patients. Liu et al. [12] reported that ${ }^{18} \mathrm{~F}-\mathrm{FDG}$ PET/CT has a higher sensitivity and MRI has a higher specificity in assessing pathological complete response (pCR) after NAC in BC patients. The pooled sensitivity and specificity of ${ }^{18} \mathrm{~F}-\mathrm{FDG}$ PET/CT were $86 \%$ (95\%CI: 76-93\%) and 72\% (95\%CI: 49-87\%), respectively. Therefore, the combined use of these two imaging modalities may have great potential to improve the diagnostic performance in assessing pCR after NAC. Another meta-analysis [13] indicates that the timing of imaging for NAC-response assessment exerts a major influence on the estimates of diagnostic accuracy: ${ }^{18} \mathrm{~F}-\mathrm{FDG}$ PET/CT outperformed MRI in intra-NAC assessment, whereas the overall performance of MRI was higher after completion of NAC, before surgery. The pooled estimates of sensitivity and specificity were $71 \%$ and $77 \%$ for ${ }^{18} \mathrm{~F}-$ FDG PET/CT and $88 \%$ and $55 \%$ for MRI, respectively. Chen et al. [14] found that the diagnostic performance of MRI is similar to that of ${ }^{18} \mathrm{~F}-$ FDG PET/CT for the assessment of BC response to NAC. For ${ }^{18} \mathrm{~F}-\mathrm{FDG}$ PET/CT, the pooled sensitivity was $87 \%$ (95\%CI: $71-95 \%)$ and pooled specificity was $85 \%$ (95\%CI: 70-93\%). For MRI, the pooled sensitivity was $79 \%$ (95\%CI: $68-87 \%$ ) and the pooled specificity was $82 \%(95 \% \mathrm{CI}$ : $72-89 \%)$. However, ${ }^{18} \mathrm{~F}-\mathrm{FDG}$ PET/CT is more sensitive than conventional contrast-enhanced 
MRI and more specific if the second imaging scan is performed before three cycles of NAC. Lastly, Li et al. [15] found that MRI had a higher sensitivity and ${ }^{18} \mathrm{~F}-\mathrm{FDG}$ PET/CT had a higher specificity in predicting the pathologic response after NAC in patients with $\mathrm{BC}$, with similar accuracy among the two methods. The pooled sensitivity and specificity of MRI were $88 \%$ (95\% CI: 78-94\%), and 69\% (95\%CI: 51-83\%), respectively. The corresponding values for ${ }^{18} \mathrm{~F}-\mathrm{FDG}$ PET/CT were $77 \%$ (95\%CI: 58-90\%) and 78\% (95\%CI: 63-88\%), respectively.

\subsection{Prognostic Value}

Diao et al. [16] evaluated the prognostic value of maximum standardized uptake values (SUVmax) measured in the primary lesion and axillary lymph nodes (ALN) by pretreatment ${ }^{18} \mathrm{~F}$-FDG PET or PET/CT in patients with BC. For eventfree survival (EFS), patients with higher SUVmax in primary tumour and ALN showed a poorer prognosis with pooled hazard ratio (HR) of 1.96 (95\%CI: 1.40-2.73) and 1.89 (95\%CI: 0.70 5.07), respectively. In analysing invasive ductal carcinoma (IDC) patients, the pooled HR was 1.91 (95\%CI: 1.40-2.64). For overall survival (OS), the pooled HR of SUVmax in primary lesion and ALN were 0.64 (95\%CI: $0.23-1.84$ ) and 1.09 (95\%CI 0.07-16.53), respectively. Therefore, patients with BC and higher SUVmax in primary lesion or ALN may experience a higher risk for recurrence or a poor progression.

\subsection{Incidental ${ }^{18}$ F-FDG Uptake}

A meta-analysis calculated the prevalence and clinical significance of breast incidental ${ }^{18} \mathrm{~F}-\mathrm{FDG}$ uptake (BIU) detected by PET or PET/CT in patients performing PET for other reasons than $\mathrm{BC}$ evaluation [17]. The pooled prevalence of BIU on all PET scans was $0.4 \%$ (95\%CI: $0.23-$ $0.61 \%$ ), the pooled prevalence on PET scans on female patients only was $0.82 \%$ (95\% CI: $0.51-$ $1.2 \%$ ), the pooled risk of malignancy of BIU when further evaluated was $48 \%$ (95\%CI: $38-58 \%$ ) and the pooled risk of malignancy of BIU with histological examination was $60 \%$ (95\%CI: 53-66\%). Despite being uncommon, the identification of BIU frequently signals the presence of an unsuspected subclinical lesion and the risk of malignancy is very high.

\section{6 ${ }^{18}$ F-FDG Positron Emission Mammography}

The diagnostic performance of dedicated ${ }^{18} \mathrm{~F}$ FDG positron emission mammography (PEM) in evaluating suspicious $\mathrm{BC}$ has been investigated by a meta-analytic study [18]: pooled sensitivity and specificity of ${ }^{18} \mathrm{~F}-\mathrm{FDG}$ PEM in women with suspected breast malignancy were $85 \%$ (95\%CI: $83-88 \%$ ) and $79 \%$ (95\%CI: $74-83 \%$ ), respectively, on a per-lesion-based analysis. The detection of additional breast lesions and extensive intraductal involvement is improved by PEM, with comparable accuracy over that of MRI in the depiction of invasive $\mathrm{BC}$.

\subsection{PET/MRI}

Lin et al. [19] performed a meta-analysis to assess the staging/restaging performance of hybrid ${ }^{18} \mathrm{~F}-\mathrm{FDG}$ PET/MRI in BC patients. The pooled sensitivity and specificity of ${ }^{18} \mathrm{~F}-\mathrm{FDG}$ PET/MRI for staging/restaging BC were $98 \%$ (95\%CI: 95-99\%) and 87\% (95\%CI: 76-95\%), respectively, on a per-patient analysis and $91 \%$ (95\%CI: 88-94\%) and 95\% (95\%CI: 92-97\%), respectively, on a per-lesion analysis. Overall, ${ }^{18} \mathrm{~F}-\mathrm{FDG}$ PET/MRI has excellent diagnostic performance in staging/restaging $\mathrm{BC}$ patients.

\subsection{Other PET Tracers Beyond ${ }^{18}$ F-FDG}

Evangelista et al. [20] assessed the role of ${ }^{18}$ F-fluoroestradiol $\left({ }^{18} \mathrm{~F}\right.$-FES) PET in patients with BC. A pooled sensitivity of $82 \%$ (95\% CI: 
$74-88 \%$ ) and a pooled specificity of $95 \%$ (95\%CI: 86-99\%) for the evaluation of oestrogen receptor status in $\mathrm{BC}$ by ${ }^{18} \mathrm{~F}-\mathrm{FES}$ PET were found, demonstrating a good accuracy of this method in this setting. Conversely, the pooled sensitivity and specificity of ${ }^{18} \mathrm{~F}$-FES PET in predicting the response to hormonal therapy in patients with locally advanced or metastatic BC were unsatisfactory.

Deng et al. [21] evaluated the diagnostic performance of ${ }^{18} \mathrm{~F}$-fluorothymidine $\left({ }^{18} \mathrm{~F}\right.$-FLT $)$ $\mathrm{PET}$ and PET/CT for evaluating the response to chemotherapy in patients with $\mathrm{BC}$. The pooled sensitivity and specificity of ${ }^{18} \mathrm{~F}$-FLT PET in this setting were $77.3 \%$ (95\%CI: 59.4$90 \%$ ) and $68.5 \%$ (95\% CI: 47.9-84.9\%), respectively, with a moderate diagnostic accuracy.

\section{References}

1. Zhang XH, Xiao C. Diagnostic value of nineteen different imaging methods for patients with breast cancer: a network meta-analysis. Cell Physiol Biochem. 2018;46(5):2041-55.

2. Liang X, Yu J, Wen B, Xie J, Cai Q, Yang Q. MRI and FDG-PET/CT based assessment of axillary lymph node metastasis in early breast cancer: a metaanalysis. Clin Radiol. 2017;72(4):295-301.

3. Hong S, Li J, Wang S. 18FDG PET-CT for diagnosis of distant metastases in breast cancer patients. A meta-analysis. Surg Oncol. 2013;22(2):139-43.

4. Sun Z, Yi YL, Liu Y, Xiong JP, He CZ. Comparison of whole-body PET/PET-CT and conventional imaging procedures for distant metastasis staging in patients with breast cancer: a meta-analysis. Eur J Gynaecol Oncol. 2015;36(6):672-6.

5. Rong J, Wang S, Ding Q, Yun M, Zheng Z, Ye S. Comparison of 18 FDG PET-CT and bone scintigraphy for detection of bone metastases in breast cancer patients. A meta-analysis. Surg Oncol. 2013;22(2):86-91.

6. Evangelista L, Cervino AR, Ghiotto C, Al-Nahhas A, Rubello D, Muzzio PC. Tumor marker-guided PET in breast cancer patients-a recipe for a perfect wedding: a systematic literature review and meta-analysis. Clin Nucl Med. 2012;37(5):467-74.

7. Xiao Y, Wang L, Jiang X, She W, He L, Hu G. Diagnostic efficacy of 18F-FDG-PET or PET/CT in breast cancer with suspected recurrence: a systematic review and meta-analysis. Nucl Med Commun. 2016;37(11):1180-8.
8. Wang Y, Zhang C, Liu J, Huang G. Is 18F-FDG PET accurate to predict neoadjuvant therapy response in breast cancer? A meta-analysis. Breast Cancer Res Treat. 2012;131(2):357-69.

9. Cheng X, Li Y, Liu B, Xu Z, Bao L, Wang J. 18FFDG PET/CT and PET for evaluation of pathological response to neoadjuvant chemotherapy in breast cancer: a meta-analysis. Acta Radiol. 2012;53(6):615-27.

10. Mghanga FP, Lan X, Bakari KH, Li C, Zhang Y. Fluorine-18 fluorodeoxyglucose positron emission tomography-computed tomography in monitoring the response of breast cancer to neoadjuvant chemotherapy: a meta-analysis. Clin Breast Cancer. 2013;13(4):271-9.

11. Tian F, Shen G, Deng Y, Diao W, Jia Z. The accuracy of $18 \mathrm{~F}-\mathrm{FDG} \mathrm{PET} / \mathrm{CT}$ in predicting the pathological response to neoadjuvant chemotherapy in patients with breast cancer: a meta-analysis and systematic review. Eur Radiol. 2017;27(11):4786-96.

12. Liu Q, Wang C, Li P, Liu J, Huang G, Song S. The role of (18)F-FDG PET/CT and MRI in assessing pathological complete response to neoadjuvant chemotherapy in patients with breast cancer: a systematic review and meta-analysis. Biomed Res Int. 2016;2016:3746232.

13. Sheikhbahaei S, Trahan TJ, Xiao J, Taghipour M, Mena E, Connolly RM, et al. FDG-PET/CT and MRI for evaluation of pathologic response to neoadjuvant chemotherapy in patients with breast cancer: a metaanalysis of diagnostic accuracy studies. Oncologist. 2016;21(8):931-9.

14. Chen L, Yang Q, Bao J, Liu D, Huang X, Wang J. Direct comparison of PET/CT and MRI to predict the pathological response to neoadjuvant chemotherapy in breast cancer: a meta-analysis. Sci Rep. 2017;7(1):8479.

15. Li H, Yao L, Jin P, Hu L, Li X, Guo T, et al. MRI and PET/CT for evaluation of the pathological response to neoadjuvant chemotherapy in breast cancer: a systematic review and meta-analysis. Breast. 2018;40:106-15.

16. Diao W, Tian F, Jia Z. The prognostic value of SUVmax measuring on primary lesion and ALN by 18F-FDG PET or PET/CT in patients with breast cancer. Eur J Radiol. 2018;105:1-7.

17. Bertagna F, Treglia G, Orlando E, Dognini L, Giovanella L, Sadeghi R, et al. Prevalence and clinical significance of incidental F18-FDG breast uptake: a systematic review and meta-analysis. Jpn J Radiol. 2014;32(2):59-68.

18. Caldarella C, Treglia G, Giordano A. Diagnostic performance of dedicated positron emission mammography using fluorine-18-fluorodeoxyglucose in women with suspicious breast lesions: a meta-analysis. Clin Breast Cancer. 2014;14(4):241-8.

19. Lin CY, Lin CL, Kao CH. Staging/restaging performance of F18-fluorodeoxyglucose positron emission 
tomography/magnetic resonance imaging in breast cancer: a review and meta-analysis. Eur J Radiol. 2018;107:158-65.

20. Evangelista L, Guarneri V, Conte PF. 18F-Fluoroestradiol positron emission tomography in breast cancer patients: systematic review of the literature \& meta-analysis. Curr Radiopharm. 2016;9(3):244-57.

21. Deng SM, Zhang W, Zhang B, Wu YW. Assessment of tumor response to chemotherapy in patients with breast cancer using (18)F-FLT: a meta-analysis. Chin J Cancer Res. 2014;26(5):517-24.

Open Access This chapter is licensed under the terms of the Creative Commons Attribution 4.0 International License (http://creativecommons.org/licenses/by/4.0/), which permits use, sharing, adaptation, distribution and reproduction in any medium or format, as long as you give appropriate credit to the original author(s) and the source, provide a link to the Creative Commons license and indicate if changes were made.

The images or other third party material in this chapter are included in the chapter's Creative Commons license, unless indicated otherwise in a credit line to the material. If material is not included in the chapter's Creative Commons license and your intended use is not permitted by statutory regulation or exceeds the permitted use, you will need to obtain permission directly from the copyright holder. 


\title{
Evidence-Based PET for Abdominal and Pelvic Tumours
}

\author{
Salvatore Annunziata, Daniele Antonio Pizzuto, \\ and Federica Galiandro
}

\subsection{Introduction}

Evidence-based data about the usefulness of positron emission tomography (PET) and hybrid imaging methods (PET/CT and PET/MRI) in abdominal and pelvic tumours have been collected and discussed in this chapter. These data were divided in three sections: (1) gastrointestinal tumours, (2) uro-genital tumours, (3) gynaecological tumours. Several pooled data (diagnostic and prognostic data), clinical settings (e.g. staging, restaging, treatment evaluation) and radiotracers as fluorine-18 fluorodeoxyglucose $\left({ }^{18} \mathrm{~F}-\mathrm{FDG}\right)$, radiolabelled choline and prostatespecific membrane antigen (PSMA) were considered.

S. Annunziata $(\bowtie)$

Nuclear Medicine Unit, IRCCS Regina Elena

National Cancer Institute, Rome, Italy

D. A. Pizzuto

Department of Nuclear Medicine, University Hospital

Zurich and University of Zurich, Zurich, Switzerland

F. Galiandro

Department of Digestive Surgery, Fondazione Policlinico Universitario Agostino Gemelli IRCCS,

Rome, Italy

\subsection{PET in Gastrointestinal Tumours}

Fifty-two meta-analyses on the role of PET imaging in gastrointestinal tumours have been selected [1-52]. Pooled data about PET/CT in colorectal cancer, gastric cancer, anal cancer, stromal tumours, hepato-biliary tumours, liver metastases and pancreatic cancer have been reported in Table 7.1.

\subsubsection{Colorectal Cancer}

Fourteen meta-analyses about ${ }^{18} \mathrm{~F}$-FDG PET/CT in colorectal cancer have been found [1-14]. Two meta-analyses evaluated the role of this imaging method in a staging setting, showing good specificity but low sensitivity [4, 13]. Similarly, two studies showed high accuracy in a restaging setting [7, 12]. Some meta-analyses assessed sub-optimal accuracy in treatment evaluation [3, 6, 8, 10, 14]. Recent meta-analyses found that focal colorectal incidental uptake at ${ }^{18} \mathrm{~F}$-FDG PET/CT is observed in a not negligible number of patients who undergo this imaging method with a high risk of malignant or premalignant lesions $[2,9]$. Finally, poor predictive or prognostic role of ${ }^{18} \mathrm{~F}$-FDG PET/CT in colorectal cancer emerged [1, 5, 11]. 
Table 7.1 Main findings of meta-analyses about the role of PET imaging in gastrointestinal tumours

\begin{tabular}{|c|c|c|c|c|c|c|}
\hline Tumours & Authors & Topic & $\begin{array}{l}\text { Pooled } \\
\text { sensitivity }\end{array}$ & $\begin{array}{l}\text { Pooled } \\
\text { specificity }\end{array}$ & PFS HR & OS HR \\
\hline \multirow[t]{14}{*}{ Colorectal cancer } & Kim et al. [1] & Prediction & 0.66 & 0.67 & - & - \\
\hline & Son et al. [2] & Characterization & 0.87 & 0.83 & - & - \\
\hline & Rymer et al. [3] & $\begin{array}{l}\text { Treatment } \\
\text { evaluation }\end{array}$ & - & - & - & - \\
\hline & Ye et al. [4] & $\mathrm{T}$ staging & 0.73 & 0.99 & - & - \\
\hline & Xia et al. [5] & Prognosis & - & - & 0.45 & 0.36 \\
\hline & Maffione et al. [6] & $\begin{array}{l}\text { Treatment } \\
\text { evaluation }\end{array}$ & 0.73 & 0.77 & - & - \\
\hline & Yu et al. [7] & Restaging & 0.94 & 0.94 & - & - \\
\hline & Li et al. [8] & $\begin{array}{l}\text { Treatment } \\
\text { evaluation }\end{array}$ & 0.81 & - & - & - \\
\hline & Treglia et al. [9] & Characterization & - & - & - & - \\
\hline & Li et al. [10] & $\begin{array}{l}\text { Treatment } \\
\text { evaluation }\end{array}$ & 0.78 & 0.81 & - & - \\
\hline & Krug et al. [11] & Prognosis & - & - & 0.70 & 0.39 \\
\hline & Lu et al. [12] & Restaging & 0.90 & 0.80 & - & - \\
\hline & Lu et al. [13] & $\mathrm{N}$ staging & 0.43 & 0.88 & - & - \\
\hline & Zhang et al. [14] & $\begin{array}{l}\text { Treatment } \\
\text { evaluation }\end{array}$ & 0.78 & 0.66 & - & - \\
\hline \multirow[t]{7}{*}{ Gastric cancer } & Luo et al. [15] & $\mathrm{N}$ staging & 0.52 & 0.88 & - & - \\
\hline & Wu et al. [16] & Prognosis & - & - & 1.70 & 1.72 \\
\hline & Li et al. [17] & Restaging & 0.85 & 0.78 & - & - \\
\hline & Zou et al. [18] & Restaging & 0.86 & 0.88 & - & - \\
\hline & Cui et al. [19] & Staging & 0.92 & 0.89 & - & - \\
\hline & Wu et al. [20] & Restaging & 0.78 & 0.82 & - & - \\
\hline & $\begin{array}{l}\text { Seevaratnam et al. } \\
\text { [21] }\end{array}$ & $\mathrm{N}$ staging & 0.40 & 0.98 & - & - \\
\hline \multirow[t]{5}{*}{ Anal cancer } & Sadeghi et al. [22] & Prognosis & - & - & 5.36 & 5.87 \\
\hline & $\begin{array}{l}\text { Albertsson et al. } \\
\text { [23] }\end{array}$ & RT planning & - & - & - & - \\
\hline & Mahmud et al. [24] & $\mathrm{N}$ staging & 0.93 & 0.76 & - & - \\
\hline & Jones et al. [25] & Staging & 0.99 & - & - & - \\
\hline & $\begin{array}{l}\text { Caldarella et al. } \\
\text { [26] }\end{array}$ & $\mathrm{N}$ staging & 0.56 & 0.90 & - & - \\
\hline \multirow{2}{*}{$\begin{array}{l}\text { Stromal tumours } \\
\text { (GIST) }\end{array}$} & Kim et al. [27] & Predictive value & 0.88 & 0.88 & - & - \\
\hline & $\begin{array}{l}\text { Hassanzadeh et al. } \\
\text { [28] }\end{array}$ & $\begin{array}{l}\text { Treatment } \\
\text { evaluation }\end{array}$ & 0.90 & 0.62 & - & - \\
\hline \multirow{9}{*}{$\begin{array}{l}\text { Hepato-biliary } \\
\text { tumours }\end{array}$} & Liao et al. [29] & Restaging & 0.64 & 0.95 & - & - \\
\hline & Hu et al. [30] & Staging & 0.80 & 0.70 & - & - \\
\hline & Sun et al. [31] & Prognosis & - & - & 7.2 & 2.1 \\
\hline & $\begin{array}{l}\text { Annunziata et al. } \\
\text { [32] }\end{array}$ & Staging & 0.87 & 0.78 & - & - \\
\hline & Zhang et al. [33] & Staging & 0.91 & 0.81 & - & - \\
\hline & Bertagna et al. [34] & Staging & - & - & - & - \\
\hline & Chou et al. [35] & M staging & 0.82 & - & - & - \\
\hline & $\begin{array}{l}\text { Annunziata et al. } \\
\text { [36] }\end{array}$ & Staging & 0.81 & 0.82 & - & - \\
\hline & Lin et al. [37] & M staging & 0.77 & 0.98 & - & - \\
\hline
\end{tabular}


Table 7.1 (continued)

\begin{tabular}{|c|c|c|c|c|c|c|}
\hline Tumours & Authors & Topic & $\begin{array}{l}\text { Pooled } \\
\text { sensitivity }\end{array}$ & $\begin{array}{l}\text { Pooled } \\
\text { specificity }\end{array}$ & PFS HR & OS HR \\
\hline \multirow[t]{7}{*}{ Liver metastases } & Choi et al. [38] & Staging & 0.74 & 0.94 & - & - \\
\hline & Samim et al. [39] & $\begin{array}{l}\text { Treatment } \\
\text { evaluation }\end{array}$ & 0.84 & 0.92 & - & - \\
\hline & Maffione et al. [40] & Staging & 0.93 & 0.93 & - & - \\
\hline & Deng et al. [41] & Staging & 0.84 & 0.99 & - & - \\
\hline & Zheng et al. [42] & $\begin{array}{l}\text { Treatment } \\
\text { evaluation }\end{array}$ & 0.79 & 0.84 & - & - \\
\hline & Poulu et al. [43] & Restaging & 0.73 & 0.85 & - & - \\
\hline & $\begin{array}{l}\text { van Kessel et al. } \\
\text { [44] }\end{array}$ & $\begin{array}{l}\text { Treatment } \\
\text { evaluation }\end{array}$ & 0.54 & $\mathrm{n} / \mathrm{a}$ & - & - \\
\hline \multirow[t]{8}{*}{ Pancreatic cancer } & Daamen et al. [45] & Restaging & 0.88 & 0.89 & - & - \\
\hline & Wang et al. [46] & M staging & - & - & - & - \\
\hline & Zhu et al. [47] & Prognosis & - & - & 1.90 & 1.70 \\
\hline & Toft et al. [48] & Staging & 0.89 & 0.70 & - & - \\
\hline & Best et al. [49] & Characterization & 0.92 & 0.65 & - & - \\
\hline & Rijkers et al. [50] & Characterization & 0.90 & 0.76 & - & - \\
\hline & Wang et al. [51] & Staging/prognosis & 0.91 & 0.81 & - & 2.39 \\
\hline & Wu et al. [52] & Staging & 0.87 & 0.83 & - & - \\
\hline
\end{tabular}

$H R$ hazard ratio, $P F S$ progression free survival, $O S$ overall survival

\subsubsection{Gastric Cancer}

Seven meta-analyses analysed the role of ${ }^{18} \mathrm{~F}-$ FDG PET/CT in gastric cancer [15-21]. Three meta-analyses found a good accuracy in a staging setting, but with low sensitivity in detecting lymph nodal $(\mathrm{N})$ involvement $[15,19,21]$. Conversely, other meta-analyses showed a good accuracy in a restaging setting $[17,18,20]$. Only one evidence-based article demonstrated a suboptimal prognostic value of ${ }^{18} \mathrm{~F}-\mathrm{FDG} \mathrm{PET} / \mathrm{CT}$ in gastric cancer [16].

\subsubsection{Anal Cancer}

Five meta-analyses about ${ }^{18} \mathrm{~F}$-FDG PET/CT in anal cancer have been included [22-26]. Some meta-analyses evaluated the role in a staging setting, with discordant accuracy values [24-26]. One meta-analysis found a strong prognostic power of ${ }^{18} \mathrm{~F}$-FDG PET parameters for progression free survival (PFS) and overall survival (OS) [22]. Finally, another meta-analysis assessed the role of ${ }^{18} \mathrm{~F}-\mathrm{FDG}$ PET/CT in radiotherapy planning [23].

\subsubsection{Stromal Tumours (GIST)}

Two meta-analyses about the role of ${ }^{18} \mathrm{~F}-\mathrm{FDG}$ $\mathrm{PET} / \mathrm{CT}$ in treatment evaluation and prediction of malignant potential in patients with GIST have been found and included [27, 28], suggesting a role of this imaging method in these settings.

\subsubsection{Hepato-biliary Tumours}

Nine meta-analyses about ${ }^{18} \mathrm{~F}$-FDG PET/CT in hepatic and biliary tumours have been included [29-37]. Some meta-analyses found a role of ${ }^{18} \mathrm{~F}$ FDG PET/CT in a staging setting, in particular about detection of distant metastases (M) [30, 32, $33,35-37]$. One meta-analysis found low sensitivity in a restaging setting [29]. Conversely, another meta-analysis showed high prognostic power for PFS by ${ }^{18} \mathrm{~F}$-FDG PET/CT in hepatobiliary tumours [31]. Beyond ${ }^{18} \mathrm{~F}-\mathrm{FDG}$, radiolabelled choline PET/CT showed a good detection rate of tumour lesions in patients with hepatocellular carcinoma [34]. 


\subsubsection{Liver Metastases}

Seven meta-analyses about the role of ${ }^{18} \mathrm{~F}-\mathrm{FDG}$ $\mathrm{PET} / \mathrm{CT}$ in detecting liver metastases from different primary tumours have been found [38-44]. Some studies showed high specificity in a staging setting [38, 40, 41]. One study found a suboptimal sensitivity also in a restaging setting [43]. The role in treatment evaluation improved in a recent meta-analysis $[42,44]$.

\subsubsection{Pancreatic Cancer}

Eight meta-analyses about ${ }^{18} \mathrm{~F}-\mathrm{FDG}$ PET/CT in pancreatic cancer have been published and included [45-52]. Interestingly, some papers showed good sensitivity in a staging setting [46, $48,51,52]$. Two studies demonstrated a good accuracy of this imaging method in characterizing pancreatic lesions [49, 50]. Finally, two meta-analyses found a prognostic power for ${ }^{18} \mathrm{~F}$ FDG PET/CT in pancreatic cancer $[47,51]$.

\subsection{PET in Gynaecological Tumours}

Thirty-three meta-analyses on the role of ${ }^{18} \mathrm{~F}$ FDG PET imaging in gynaecological tumours have been selected [53-82]. Pooled data about ${ }^{18} \mathrm{~F}-\mathrm{FDG} \mathrm{PET} / \mathrm{CT}$ in cervical cancer, endometrial cancer, ovarian cancer and peritoneal carcinomatosis have been reported in Table 7.2.

\subsubsection{Cervical Cancer}

Twelve meta-analyses about the role of ${ }^{18} \mathrm{~F}-\mathrm{FDG}$ $\mathrm{PET} / \mathrm{CT}$ in cervical cancer have been included [53-64]. Some studies evaluated the role of ${ }^{18} \mathrm{~F}$ FDG PET/CT in staging cervical cancer, showing low sensitivity and high specificity in $\mathrm{N}$ staging $[53,56,64]$. Several studies evaluated the role of ${ }^{18} \mathrm{~F}$-FDG PET/CT in a restaging setting, with high values of sensitivity and specificity $[55,58-$
$61,63]$. Some meta-analyses found a prognostic role of ${ }^{18} \mathrm{~F}-\mathrm{FDG}$ PET/CT in cervical cancer [54, $57,62]$.

\subsubsection{Endometrial Cancer}

Seven meta-analyses about the role of ${ }^{18} \mathrm{~F}-\mathrm{FDG}$ $\mathrm{PET} / \mathrm{CT}$ in endometrial cancer have been included [65-71]. Some meta-analyses evaluated the role of ${ }^{18} \mathrm{~F}-\mathrm{FDG}$ PET/CT in a staging or restaging setting, showing good values of sensitivity and specificity [65, 68-71]. Conversely, one meta-analysis showed low sensitivity in $\mathrm{N}$ staging [71]. Finally, some meta-analyses showed a prognostic role of ${ }^{18} \mathrm{~F}-\mathrm{FDG}$ PET/CT for PFS $[66,67]$.

\subsubsection{Ovarian Cancer}

Six meta-analyses about ${ }^{18} \mathrm{~F}-\mathrm{FDG}$ PET/CT in ovarian cancer have been found [72-77]. Some meta-analyses showed high accuracy of this imaging method in a restaging setting [74-76]. Conversely, some meta-analyses showed sub-optimal sensitivity in $\mathrm{N}$ and $\mathrm{M}$ staging [72, 77]. Only one meta-analysis showed a good prognostic power of ${ }^{18} \mathrm{~F}$-FDG PET/CT in ovarian cancer, with particular regard to OS [73].

\subsubsection{Peritoneal Carcinomatosis}

Three meta-analyses were focused on the role of ${ }^{18} \mathrm{~F}-\mathrm{FDG}$ PET/CT in peritoneal carcinomatosis, showing good values of sensitivity and specificity of this method in this setting [78-80].

\subsubsection{PET/MRI}

Finally, recent studies evaluated the role of ${ }^{18} \mathrm{~F}$ FDG PET/MRI in gynaecological malignancies, showing optimal diagnostic accuracy values $[81,82]$. 
Table 7.2 Main findings of meta-analyses about the role of PET imaging in gynaecological tumours

\begin{tabular}{|c|c|c|c|c|c|c|}
\hline Tumours & Authors & Topic & $\begin{array}{l}\text { Pooled } \\
\text { sensitivity }\end{array}$ & $\begin{array}{l}\text { Pooled } \\
\text { specificity }\end{array}$ & PFS HR & OS HR \\
\hline \multirow[t]{12}{*}{ Cervical cancer } & Ruan [53] & $\mathrm{N}$ staging & 0.72 & 0.96 & - & - \\
\hline & Han [54] & Prognosis & - & - & 5.89 & 6.62 \\
\hline & Zhou [55] & Restaging & 0.97 & 0.81 & - & - \\
\hline & Liu [56] & $\mathrm{N}$ staging & 0.66 & 0.96 & - & - \\
\hline & Sarker [57] & Prognosis & - & - & 2.66 & 2.45 \\
\hline & Xiao [58] & Restaging & 0.94 & 0.92 & - & - \\
\hline & Ding [59] & Restaging & 0.92 & 0.94 & - & - \\
\hline & Meads [60] & Restaging & 0.95 & 0.87 & - & - \\
\hline & Chu [61] & Restaging & 0.87 & 0.97 & - & - \\
\hline & Zhao [62] & Prognosis & - & - & - & 2.06 \\
\hline & Meads [63] & Restaging & 0.92 & 0.88 & - & - \\
\hline & Gong [64] & $\mathrm{N}$ staging & 0.68 & 0.97 & - & - \\
\hline \multirow[t]{7}{*}{ Endometrial cancer } & Bollineni [65] & Restaging & 0.95 & 0.91 & - & - \\
\hline & Pan [66] & Prognosis & - & - & 3.33 & 1.31 \\
\hline & $\begin{array}{l}\text { Ghooshkhanei } \\
{[67]}\end{array}$ & Prognosis & - & - & 7.4 & - \\
\hline & Kakhki [68] & Staging & 0.82 & 0.90 & - & - \\
\hline & Sadeghi [69] & Restaging & 0.92 & 0.96 & - & - \\
\hline & $\begin{array}{l}\text { Kadkhodayan } \\
\text { [70] }\end{array}$ & Restaging & 0.96 & 0.92 & - & - \\
\hline & Chang [71] & $\mathrm{N}$ staging & 0.63 & 0.95 & - & - \\
\hline \multirow[t]{6}{*}{ Ovarian cancer } & Han [72] & M staging & 0.72 & 0.93 & - & - \\
\hline & Han [73] & Prognosis & - & - & 2.50 & 8.06 \\
\hline & Suppiah [74] & Restaging & 0.90 & 0.90 & - & - \\
\hline & $\mathrm{Xu}[75]$ & Restaging & 0.92 & 0.91 & - & - \\
\hline & Limei [76] & Restaging & 0.87 & 0.90 & - & - \\
\hline & Yuan [77] & $\mathrm{N}$ staging & 0.73 & 0.97 & - & - \\
\hline \multirow[t]{3}{*}{ Peritoneal carcinomatosis } & Kim [78] & Diagnosis & 0.87 & 0.92 & - & - \\
\hline & $\mathrm{Li}[79]$ & Diagnosis & 0.84 & 0.98 & - & - \\
\hline & Chang [80] & Diagnosis & 0.72 & 0.97 & - & - \\
\hline \multirow[t]{2}{*}{ PET/MRI } & Zheng [81] & Restaging & 0.96 & 0.95 & - & - \\
\hline & Nie [82] & Staging & 0.95 & 0.95 & - & - \\
\hline
\end{tabular}

$H R$ hazard ratio, $P F S$ progression free survival, $O S$ overall survival

\subsection{PET in Uro-genital Tumours}

Thirty-five meta-analyses on the role of PET imaging in uro-genital tumours have been selected [83-117]. In particular, pooled data about radiolabelled choline, PSMA and fluciclovine $\mathrm{PET} / \mathrm{CT}$ in prostate cancer and ${ }^{18} \mathrm{~F}-\mathrm{FDG}$ PET/CT in bladder cancer, renal cell carcinoma, testicular and penile cancer have been included (Table 7.3).

\subsubsection{Prostate Cancer}

\subsubsection{Radiolabelled Choline PET for Prostate Cancer}

Several meta-analyses described a very high specificity for detection of local lymph node involvement and for detection of distant metastases of prostate cancer by using radiolabelled choline PET. Radiolabelled choline PET is also widely used in patients with suspected biochemi- 
Table 7.3 Main findings of meta-analyses about the role of PET imaging in uro-genital tumours

\begin{tabular}{|c|c|c|c|c|c|}
\hline Tumours & Authors & Tracers & Topic & Sensitivity & Specificity \\
\hline \multirow{23}{*}{$\begin{array}{l}\text { Prostate } \\
\text { cancer }\end{array}$} & Evangelista et al. [83] & Choline & $\mathrm{N}$ staging & 0.49 & 0.95 \\
\hline & Evangelista et al. [85] & Choline & Restaging & 0.85 & - \\
\hline & Evangelista et al. [84] & Choline & Staging & 0.86 & 0.93 \\
\hline & Fanti et al. [86] & Choline & Restaging & 0.89 & 0.89 \\
\hline & Guo et al. [90] & Choline & M staging & 0.89 & 0.98 \\
\hline & Liu et al. [92] & Several tracers & Staging & 0.83 (choline) & 0.93 (choline) \\
\hline & Beheshti et al. [93] & Acetate & Staging & 0.75 & 0.76 \\
\hline & Ouyang et al. [94] & Several tracers & Staging & 0.78 (choline) & 0.90 (choline) \\
\hline & Ren et al. [115] & Fluciclovine & Restaging & 0.87 & 0.66 \\
\hline & $\begin{array}{l}\text { Sathianathen et al. } \\
\text { [116] }\end{array}$ & Several tracers & Restaging & $\begin{array}{l}0.81 \text { (choline) } \\
0.80 \\
\text { (fluciclovine) } \\
0.76 \text { (PSMA) }\end{array}$ & $\begin{array}{l}0.84 \text { (choline) } \\
0.62 \\
\text { (fluciclovine) } \\
0.99 \text { (PSMA) }\end{array}$ \\
\hline & Shen et al. [91] & Choline & M staging & 0.91 & 0.99 \\
\hline & Treglia et al. [88] & Choline & Restaging & - & - \\
\hline & Umbehr et al. [87] & Choline & Staging & 0.84 & 0.79 \\
\hline & Von Eyben et al. [95] & Choline & $\mathrm{M}$ restaging & - & - \\
\hline & Wei et al. [89] & Choline & Staging & 0.82 & 0.92 \\
\hline & Bertagna et al. [117] & FDG & Prediction & - & - \\
\hline & Corfield et al. [96] & PSMA & Staging & - & - \\
\hline & Han et al. [98] & PSMA & Management & $\mathrm{n} / \mathrm{a}$ & $\mathrm{n} / \mathrm{a}$ \\
\hline & Kim et al. [99] & PSMA & Staging & 0.71 & 0.95 \\
\hline & Pereira et al. [102] & PSMA & Restaging & - & - \\
\hline & Perera et al. [100] & PSMA & Staging & 0.86 & 0.86 \\
\hline & von Eyben [101] & PSMA & Staging & 0.70 & 0.84 \\
\hline & Hope et al. [97] & PSMA & Restaging & 0.74 & 0.96 \\
\hline \multirow{7}{*}{$\begin{array}{l}\text { Bladder } \\
\text { cancer }\end{array}$} & Lu et al. [105] & FDG & Staging & 0.90 & 1 \\
\hline & Soubra et al. [106] & FDG & Prediction & 0.56 & 0.95 \\
\hline & Wang et al. [107] & FDG & Staging & 0.80 & 0.84 \\
\hline & Zhang et al. [108] & FDG & Staging & 0.82 & 0.92 \\
\hline & Ha et al. [104] & FDG & $\mathrm{N}$ staging & 0.57 & 0.92 \\
\hline & Crozier et al. [103] & FDG & Staging & 0.56 & 0.92 \\
\hline & Kim et al. [109] & Choline and acetate & $\mathrm{N}$ staging & 0.66 & 0.89 \\
\hline \multirow{2}{*}{$\begin{array}{l}\text { Testicular } \\
\text { cancer }\end{array}$} & Zhao et al. [112] & FDG & Staging & 0.75 & 0.87 \\
\hline & Treglia et al. [113] & FDG & $\begin{array}{l}\text { Treatment } \\
\text { evaluation }\end{array}$ & 0.78 & 0.86 \\
\hline \multirow{2}{*}{$\begin{array}{l}\text { Renal cell } \\
\text { carcinoma }\end{array}$} & Wang et al. [111] & FDG & Staging & 0.91 & 0.88 \\
\hline & Ma et al. [110] & FDG & Restaging & 0.86 & 0.88 \\
\hline $\begin{array}{l}\text { Penile } \\
\text { cancer }\end{array}$ & Sadeghi et al. [114] & FDG & N staging & 0.81 & 0.92 \\
\hline
\end{tabular}

FDG fluorodeoxyglucose, PSMA prostate-specific membrane antigen

cal relapse after initial treatments, even as a guide for salvage lymph node dissection [83-87]. Additionally, PSA kinetics was shown to be strongly related to the detection rate in patients undergoing radiolabelled choline PET [88]. Similarly, high PSA trigger was shown to be an important risk factor for positive findings of radiolabelled choline PET/CT [89]. PET with radiolabelled choline is a well-established imaging tool in clinical practice for detection of bone metastases [90, 91]. Diagnostic accuracy of radiolabelled choline PET was proven to be superior than other radiotracers as ${ }^{18} \mathrm{~F}-\mathrm{FDG}$ and ${ }^{11} \mathrm{C}$-acetate [92], even if ${ }^{11} \mathrm{C}$-acetate PET could be 
considered in patients with relapse [93]. ${ }^{18} \mathrm{~F}$-fluorocholine $(\mathrm{FCH})$ PET showed higher specificity than ${ }^{11} \mathrm{C}$-choline PET [94]. Conversely, the choice of ${ }^{18} \mathrm{~F}-\mathrm{FCH}$ or ${ }^{11} \mathrm{C}$-choline might not affect the detection of metastases in restaging patients after primary surgery and/or radiotherapy [95].

\subsubsection{Radiolabelled PSMA PET in Prostate Cancer}

Radiolabelled PSMA PET showed higher detection rate than other imaging modalities in prostate cancer [96, 97]. It was also proven to alter significantly the clinical management of these patients [98]. Diagnostic performance of PSMA PET was high for detection of node involvement in intermediate- and high-risk prostate cancer patients [99-101]. PSA kinetics may be predictor of radiolabelled PSMA PET positivity in patients with biochemical relapse [102]. PSMA detection rate ranged from $64 \%$ to $97 \%$ when PSA trigger was over $2 \mathrm{ng} / \mathrm{ml}$ at the time of scan [97].

\subsubsection{Fluciclovine PET in Prostate Cancer}

A meta-analysis demonstrated that fluciclovine $\left({ }^{18} \mathrm{~F}-\mathrm{FACBC}\right) \mathrm{PET} / \mathrm{CT}$ had an $87 \%$ pooled sensitivity and $66 \%$ pooled specificity in detecting prostate cancer recurrence, being a useful imaging method in this setting [115].

\subsubsection{Incidental ${ }^{18}$ F-FDG Uptake in the Prostate}

A meta-analysis demonstrated that incidental ${ }^{18} \mathrm{~F}$ FDG uptake in the prostate is observed in about $2 \%$ of ${ }^{18} \mathrm{~F}-\mathrm{FDG} \mathrm{PET} / \mathrm{CT}$ scans performed in male patients carrying a significant risk of malignancy. Therefore, whenever this finding is detected further investigation is warranted to exclude malignancy [117].

\subsubsection{Bladder Cancer}

Several evidence-based articles were focused on the clinical usefulness of ${ }^{18} \mathrm{~F}-\mathrm{FDG}$ PET/CT in patients with bladder cancer [103-109]. An over- all sensitivity and specificity of $82 \%$ and $92 \%$ was reported, respectively [108]. Sensitivity and specificity were $90 \%$ and $100 \%$, respectively, for primary staging, and $82 \%$ and $89 \%$, respectively, for restaging [105]. For detection of node metastases, specificity was found high, whereas sensitivity was poor $[103,104,106]$. Additionally, detection of node involvement was assessed by other radiopharmaceuticals such as ${ }^{11} \mathrm{C}$-choline or ${ }^{11} \mathrm{C}$-acetate [109], showing low sensitivity and moderate specificity.

\subsubsection{Renal Cell Carcinoma}

Values of sensitivity and specificity of ${ }^{18} \mathrm{~F}-\mathrm{FDG}$ $\mathrm{PET} / \mathrm{CT}$ were $86 \%$ and $88 \%$, respectively, for detection of recurrence [110]. If diagnostic performance of ${ }^{18} \mathrm{~F}$-FDG PET/CT for detection of recurrent renal and extra-renal lesions was assessed separately, sensitivity and specificity of extra-renal lesions was found superior than accuracy for renal lesions [111].

\subsubsection{Testicular and Penile Cancer}

${ }^{18} \mathrm{~F}-\mathrm{FDG}$-PET sensitivity was non-optimal in the evaluation of patients with testicular cancer [112]. Similar results were drawn if PET was performed after chemotherapy treatment in patients with seminoma [113]. Clinical usefulness of ${ }^{18} \mathrm{~F}-$ FDG PET for detection of metastatic inguinal lymph nodes in patients with penile cancer is controversial [114].

\section{References}

1. Kim SJ, Pak K, Kim K. Diagnostic performance of F-18 FDG PET/CT for prediction of KRAS mutation in colorectal cancer patients: a systematic review and meta-analysis. Abdom Radiol. 2019;44(5):1703-11.

2. Son GM, Kim SJ. Diagnostic accuracy of F-18 FDG PET/CT for characterization of colorectal focal FDG uptake: a systematic review and meta-analysis. Abdom Radiol. 2019;44(2):456-63.

3. Rymer B, Curtis NJ, Siddiqui MR, Chand M. FDG $\mathrm{PET} / \mathrm{CT}$ can assess the response of locally advanced 
rectal cancer to neoadjuvant chemoradiotherapy: evidence from meta-analysis and systematic review. Clin Nucl Med. 2016;41(5):371-5.

4. Ye Y, Liu T, Lu L, Wang G, Wang M, Li J, et al. Pre-operative TNM staging of primary colorectal cancer by (18)F-FDG PET-CT or PET: a metaanalysis including 2283 patients. Int J Clin Exp Med. 2015;8(11):21773-85.

5. Xia Q, Liu J, Wu C, Song S, Tong L, Huang G, et al. Prognostic significance of (18)FDG PET/CT in colorectal cancer patients with liver metastases: a meta-analysis. Cancer Imaging. 2015;15:19.

6. Maffione AM, Marzola MC, Capirci C, Colletti PM, Rubello D. Value of (18)F-FDG PET for predicting response to neoadjuvant therapy in rectal cancer: systematic review and meta-analysis. AJR Am J Roentgenol. 2015;204(6):1261-8.

7. Yu T, Meng N, Chi D, Zhao Y, Wang K, Luo Y. Diagnostic value of (18)F-FDG PET/CT in detecting local recurrent colorectal cancer: a pooled analysis of 26 individual studies. Cell Biochem Biophys. 2015 Jun;72(2):443-51.

8. Li YL, Wu LM, Chen XX, Delproposto Z, Hu JN, $\mathrm{Xu}$ JR. Is diffusion-weighted MRI superior to FDGPET or FDG-PET/CT in evaluating and predicting pathological response to preoperative neoadjuvant therapy in patients with rectal cancer? J Dig Dis. 2014;15(10):525-37.

9. Treglia G, Taralli S, Salsano M, Muoio B, Sadeghi $\mathrm{R}$, Giovanella L. Prevalence and malignancy risk of focal colorectal incidental uptake detected by (18) F-FDG-PET or PET/CT: a meta-analysis. Radiol Oncol. 2014;48(2):99-104.

10. Li C, Lan X, Yuan H, Feng H, Xia X, Zhang Y. 18FFDG PET predicts pathological response to preoperative chemoradiotherapy in patients with primary rectal cancer: a meta-analysis. Ann Nucl Med. 2014;28(5):436-46.

11. Krug B, Crott R, de Cannière L, D'Hondt L, Vander Borght T. A systematic review of the predictive value of 18F-fluoro-2-deoxyglucose positron emission tomography on survival in locally advanced rectal cancer after neoadjuvant chemoradiation. Color Dis. 2013;15(11):e627-33.

12. Lu YY, Chen JH, Chien CR, Chen WT, Tsai SC, Lin WY, et al. Use of FDG-PET or PET/CT to detect recurrent colorectal cancer in patients with elevated CEA: a systematic review and meta-analysis. Int J Color Dis. 2013;28(8):1039-47.

13. Lu YY, Chen JH, Ding HJ, Chien CR, Lin WY, Kao $\mathrm{CH}$. A systematic review and meta-analysis of pretherapeutic lymph node staging of colorectal cancer by $18 \mathrm{~F}-F D G$ PET or PET/CT. Nucl Med Commun. 2012;33(11):1127-33.

14. Zhang C, Tong J, Sun X, Liu J, Wang Y, Huang G. 18F-FDG-PET evaluation of treatment response to neo-adjuvant therapy in patients with locally advanced rectal cancer: a meta-analysis. Int $\mathrm{J}$ Cancer. 2012;131(11):2604-11.

15. Luo M, Song H, Liu G, Lin Y, Luo L, Zhou X, Chen B. Comparison of DWI and (18)F-FDG PET/ $\mathrm{CT}$ for assessing preoperative N-staging in gastric cancer: evidence from a meta-analysis. Oncotarget. 2017;8(48):84473-88.

16. Wu Z, Zhao J, Gao P, Song Y, Sun J, Chen X, et al. Prognostic value of pretreatment standardized uptake value of F-18-fluorodeoxyglucose PET in patients with gastric cancer: a meta-analysis. BMC Cancer. 2017;17(1):275.

17. Li P, Liu Q, Wang C, Wang T, Liu J, Huang G, Song S. Fluorine-18-fluorodeoxyglucose positron emission tomography to evaluate recurrent gastric cancer after surgical resection: a systematic review and meta-analysis. Ann Nucl Med. 2016;30(3):179-87.

18. Zou H, Zhao Y. 18FDG PET-CT for detecting gastric cancer recurrence after surgical resection: a metaanalysis. Surg Oncol. 2013;22(3):162-6.

19. Cui JX, Li T, Xi HQ, Wei B, Chen L. [Evaluation of (18)F-FDG PET/CT in preoperative staging of gastric cancer: a meta-analysis]. Zhonghua Wei Chang Wai Ke Za Zhi. 2013;16(5):418-24.

20. Wu LM, Hu JN, Hua J, Gu HY, Zhu J, Xu JR. 18 F-fluorodeoxyglucose positron emission tomography to evaluate recurrent gastric cancer: a systematic review and meta-analysis. J Gastroenterol Hepatol. 2012;27(3):472-80.

21. Seevaratnam R, Cardoso R, McGregor C, Lourenco L, Mahar A, Sutradhar R, et al. How useful is preoperative imaging for tumor, node, metastasis (TNM) staging of gastric cancer? A meta-analysis. Gastric Cancer. 2011;15(Suppl 1):S3-18.

22. Sadeghi R, Harsini S, Qodsi Rad MA, Dabbagh VR, Treglia G. Prognostic significance of fluorine-18 fluorodeoxyglucose positron emission tomography in anal squamous cell carcinoma: a systematic review and a meta-analysis. Contrast Media Mol Imaging. 2018;2018:9760492.

23. Albertsson P, Alverbratt C, Liljegren A, Björkander E, Strandell A, Samuelsson O, et al. Positron emission tomography and computed tomographic (PET/ $\mathrm{CT}$ ) imaging for radiation therapy planning in anal cancer: a systematic review and meta-analysis. Crit Rev Oncol Hematol. 2018;126:6-12.

24. Mahmud A, Poon R, Jonker D. PET imaging in anal canal cancer: a systematic review and meta-analysis. Br J Radiol. 2017;90(1080):20170370.

25. Jones M, Hruby G, Solomon M, Rutherford N, Martin J. The role of FDG-PET in the initial staging and response assessment of anal cancer: a systematic review and meta-analysis. Ann Surg Oncol. 2015;22(11):3574-81.

26. Caldarella C, Annunziata S, Treglia G, Sadeghi R, Ayati N, Giovanella L. Diagnostic perfor- 
mance of positron emission tomography/computed tomography using fluorine-18 fluorodeoxyglucose in detecting locoregional nodal involvement in patients with anal canal cancer: a systematic review and meta-analysis. ScientificWorldJournal. 2014;2014:196068.

27. Kim SJ, Lee SW. Performance of F-18 FDG PET/ $\mathrm{CT}$ for predicting malignant potential of gastrointestinal stromal tumors: a systematic review and meta-analysis. J Gastroenterol Hepatol. 2018;33(3):576-82.

28. Hassanzadeh-Rad A, Yousefifard M, Katal S, Asady H, Fard-Esfahani A, Moghadas Jafari A, et al. The value of (18) F-fluorodeoxyglucose positron emission tomography for prediction of treatment response in gastrointestinal stromal tumors: a systematic review and meta-analysis. J Gastroenterol Hepatol. 2016;31(5):929-35.

29. Liao X, Wei J, Li Y, Zhong J, Liu Z, Liao S, et al. 18F-FDG PET with or without CT in the diagnosis of extrahepatic metastases or local residual/recurrent hepatocellular carcinoma. Medicine (Baltimore). 2018;97(34):e11970.

30. Hu JH, Tang JH, Lin CH, Chu YY, Liu NJ. Preoperative staging of cholangiocarcinoma and biliary carcinoma using $18 \mathrm{~F}$-fluorodeoxyglucose positron emission tomography: a meta-analysis. J Investig Med. 2018;66(1):52-61.

31. Sun DW, An L, Wei F, Mu L, Shi XJ, Wang CL, et al. Prognostic significance of parameters from pretreatment (18)F-FDG PET in hepatocellular carcinoma: a meta-analysis. Abdom Radiol. 2016;41(1):33-41.

32. Annunziata S, Pizzuto DA, Caldarella C, Galiandro F, Sadeghi R, Treglia G. Diagnostic accuracy of fluorine-18-fluorodeoxyglucose positron emission tomography in gallbladder cancer: a meta-analysis. World J Gastroenterol. 2015;21(40):11481-8.

33. Zhang H, Zhu J, Ke F, Weng M, Wu X, Li M, et al. Radiological imaging for assessing the respectability of hilar cholangiocarcinoma: a systematic review and meta-analysis. Biomed Res Int. 2015;2015:497942.

34. Bertagna F, Bertoli M, Bosio G, Biasiotto G, Sadeghi $\mathrm{R}$, Giubbini R, et al. Diagnostic role of radiolabelled choline PET or PET/CT in hepatocellular carcinoma: a systematic review and meta-analysis. Hepatol Int. 2014;8(4):493-500.

35. Chou R, Cuevas C, Fu R, Devine B, Wasson N, Ginsburg A, et al. Imaging techniques for the diagnosis and staging of hepatocellular carcinoma [Internet]. Rockville, MD: Agency for Healthcare Research and Quality (US); 2014. http://www.ncbi. nlm.nih.gov/books/NBK254191/.

36. Annunziata S, Caldarella C, Pizzuto DA, Galiandro F, Sadeghi R, Giovanella L, et al. Diagnostic accuracy of fluorine-18-fluorodeoxyglucose positron emission tomography in the evaluation of the pri- mary tumor in patients with cholangiocarcinoma: a meta-analysis. Biomed Res Int. 2014;2014:247693.

37. Lin CY, Chen JH, Liang JA, Lin CC, Jeng LB, Kao CH. 18F-FDG PET or PET/CT for detecting extrahepatic metastases or recurrent hepatocellular carcinoma: a systematic review and meta-analysis. Eur J Radiol. 2012;81(9):2417-22.

38. Choi SH, Kim SY, Park SH, Kim KW, Lee JY, Lee $\mathrm{SS}$, et al. Diagnostic performance of CT, gadoxetate disodium-enhanced MRI, and PET/CT for the diagnosis of colorectal liver metastasis: systematic review and meta-analysis. J Magn Reason Imaging. 2018;47(5):1237-50.

39. Samim M, Molenaar IQ, Seesing MFJ, van Rossum PSN, van den Bosch MAAJ, Ruers TJM, et al. The diagnostic performance of (18)F-FDG PET/ CT, CT and MRI in the treatment evaluation of ablation therapy for colorectal liver metastases: a systematic review and meta-analysis. Surg Oncol. 2017;26(1):37-45.

40. Maffione AM, Lopci E, Bluemel C, Giammarile F, Herrmann K, Rubello D. Diagnostic accuracy and impact on management of (18)F-FDG PET and PET/ $\mathrm{CT}$ in colorectal liver metastasis: a meta-analysis and systematic review. Eur J Nucl Med Mol Imaging. 2015;42(1):152-63.

41. Deng J, Tang J, Shen N. Meta-analysis of diagnosis of liver metastatic cancers: comparison of (18) FDG PET-CT and gadolinium-enhanced MRI. J Med Imaging Radiat Oncol. 2014;58(5):532-7.

42. Zheng JH, Chang ZH, Han CB, Ma JT, Liu ZY, $\mathrm{Lu} \mathrm{ZM}$, et al. Detection of residual tumor following radiofrequency ablation of liver metastases using 18F-FDG PET/PET-CT: a systematic review and meta-analysis. Nucl Med Commun. 2014;35(4):339-46.

43. Poulou LS, Ziakas PD, Ziogas DC, Doxani C, Xyla V, Vakrinos G, et al. FDG-PET for detecting local tumor recurrence of ablated liver metastases: a diagnostic meta-analysis. Biomarkers. 2012;17(6):532-8.

44. van Kessel CS, Buckens CF, van den Bosch MA, van Leeuwen MS, van Hillegersberg R, Verkooijen HM. Preoperative imaging of colorectal liver metastases after neoadjuvant chemotherapy: a metaanalysis. Ann Surg Oncol. 2012;19(9):2805-13.

45. Daamen LA, Groot VP, Goense L, Wessels FJ, Borel Rinkes IH, Intven MPW, et al. The diagnostic performance of CT versus FDG PET-CT for the detection of recurrent pancreatic cancer: a systematic review and meta-analysis. Eur J Radiol. 2018;106:128-36.

46. Wang L, Dong P, Wang WG, Tian BL. Positron emission tomography modalities prevent futile radical resection of pancreatic cancer: a meta-analysis. Int J Surg. 2017;46:119-25. 
47. Zhu D, Wang L, Zhang H, Chen J, Wang Y, Byanju S, Liao M. Prognostic value of 18F-FDG-PET/CT parameters in patients with pancreatic carcinoma: a systematic review and meta-analysis. Medicine. 2017;96(33):e7813.

48. Toft J, Hadden WJ, Laurence JM, Lam V, Yuen L, Janssen A, et al. Imaging modalities in the diagnosis of pancreatic adenocarcinoma: a systematic review and meta-analysis of sensitivity, specificity and diagnostic accuracy. Eur J Radiol. 2017;92:17-23.

49. Best LM, Rawji V, Pereira SP, Davidson BR, Gurusamy KS. Imaging modalities for characterising focal pancreatic lesions. Cochrane Database Syst Rev. 2017;4:CD010213.

50. Rijkers AP, Valkema R, Duivenvoorden HJ, van Eijck CH. Usefulness of F-18-fluorodeoxyglucose positron emission tomography to confirm suspected pancreatic cancer: a meta-analysis. Eur J Surg Oncol. 2014;40(7):794-804.

51. Wang Z, Chen JQ, Liu JL, Qin XG, Huang Y. FDGPET in diagnosis, staging and prognosis of pancreatic carcinoma: a meta-analysis. World J Gastroenterol. 2013;19(29):4808-17.

52. Wu LM, Hu JN, Hua J, Liu MJ, Chen J, Xu JR. Diagnostic value of diffusion-weighted magnetic resonance imaging compared with fluorodeoxyglucose positron emission tomography/computed tomography for pancreatic malignancy: a meta-analysis using a hierarchical regression model. J Gastroenterol Hepatol. 2012;27(6):1027-35.

53. Ruan J, Zhang Y, Ren H. Meta-analysis of PET/CT detect lymph nodes metastases of cervical cancer. Open Med. 2018;13:436-42.

54. Han S, Kim H, Kim YJ, Suh CH, Woo S. Prognostic value of volume-based metabolic parameters of (18)F-FDG PET/CT in uterine cervical cancer: a systematic review and meta-analysis. AJR Am J Roentgenol. 2018;211(5):1112-21.

55. Zhou Z, Liu X, Hu K, Zhang F. The clinical value of $\mathrm{PET}$ and PET/CT in the diagnosis and management of suspected cervical cancer recurrence. Nucl Med Commun. 2018;39(2):97-102.

56. Liu B, Gao S, Li S. A comprehensive comparison of CT, MRI, positron emission tomography or positron emission tomography/CT, and diffusion weighted imaging-MRI for detecting the lymph nodes metastases in patients with cervical cancer: a meta-analysis based on 67 studies. Gynecol Obstet Invest. 2017;82(3):209-22.

57. Sarker A, Im HJ, Cheon GJ, Chung HH, Kang KW, Chung JK, et al. Prognostic implications of the SUVmax of primary tumors and metastatic lymph node measured by 18F-FDG PET in patients with uterine cervical cancer: a meta-analysis. Clin Nucl Med. 2016;41(1):34-40.

58. Xiao Y, Wei J, Zhang Y, Xiong W. Positron emission tomography alone, positron emission tomography- computed tomography and computed tomography in diagnosing recurrent cervical carcinoma: a systematic review and meta-analysis. Arch Med Sci. 2014;10(2):222-31.

59. Ding XP, Feng L, Ma L. Diagnosis of recurrent uterine cervical cancer: PET versus PET/CT: a systematic review and meta-analysis. Arch Gynecol Obstet. 2014;290(4):741-7.

60. Meads C, Davenport C, Małysiak S, Kowalska M, Zapalska A, Guest P, et al. Evaluating PET-CT in the detection and management of recurrent cervical cancer: systematic reviews of diagnostic accuracy and subjective elicitation. BJOG. 2014;121(4):398-407.

61. Chu Y, Zheng A, Wang F, Lin W, Yang X, Han L, et al. Diagnostic value of 18F-FDG-PET or PET-CT in recurrent cervical cancer: a systematic review and meta-analysis. Nucl Med Commun. 2014;35(2):144-50.

62. Zhao Q, Feng Y, Mao X, Qie M. Prognostic value of fluorine-18-fluorodeoxyglucose positron emission tomography or PET-computed tomography in cervical cancer: a meta-analysis. Int J Gynecol Cancer. 2013;23(7):1184-90.

63. Meads C, Auguste P, Davenport C, Małysiak S, Sundar S, Kowalska M, et al. Positron emission tomography/computerised tomography imaging in detecting and managing recurrent cervical cancer: systematic review of evidence, elicitation of subjective probabilities and economic modelling. Health Technol Assess. 2013;17(12):1-323.

64. Gong Y, Wang Q, Dong L, Jia Y, Hua C, Mi F, et al. Different imaging techniques for the detection of pelvic lymph nodes metastasis from gynecological malignancies: a systematic review and metaanalysis. Oncotarget. 2017;8(8):14107-25.

65. Bollineni VR, Ytre-Hauge S, Bollineni-Balabay O, Salvesen HB, Haldorsen IS. High diagnostic value of 18F-FDG PET/CT in endometrial cancer: systematic review and meta-analysis of the literature. $\mathrm{J}$ Nucl Med. 2016;57(6):879-85.

66. Pan Y, Yao Y, Ma Y. Standardized uptake value on F-FDG PET/CT as a prognostic factor for survival of women with malignant uterine tumors: a metaanalysis. Gynecol Obstet Investig. 2016;81:124-31.

67. Ghooshkhanei H, Treglia G, Sabouri G, Davoodi R, Sadeghi R. Risk stratification and prognosis determination using (18)F-FDG PET imaging in endometrial cancer patients: a systematic review and meta-analysis. Gynecol Oncol. 2014;132(3):669-76.

68. Kakhki VR, Shahriari S, Treglia G, Hasanzadeh M, Zakavi SR, Yousefi Z, et al. Diagnostic performance of fluorine 18 fluorodeoxyglucose positron emission tomography imaging for detection of primary lesion and staging of endometrial cancer patients: systematic review and meta-analysis of the literature. Int $\mathbf{J}$ Gynecol Cancer. 2013;23(9):1536-43.

69. Sadeghi R, Zakavi SR, Hasanzadeh M, Treglia G, Giovanella L, Kadkhodayan S. Diagnostic perfor- 
mance of fluorine-18-fluorodeoxyglucose positron emission tomography imaging in uterine sarcomas: systematic review and meta-analysis of the literature. Int J Gynecol Cancer. 2013;23(8):1349-56.

70. Kadkhodayan S, Shahriari S, Treglia G, Yousefi Z, Sadeghi R. Accuracy of 18-F-FDG PET imaging in the follow up of endometrial cancer patients: systematic review and meta-analysis of the literature. Gynecol Oncol. 2013;128(2):397-404.

71. Chang MC, Chen JH, Liang JA, Yang KT, Cheng KY, Kao CH. 18F-FDG PET or PET/CT for detection of metastatic lymph nodes in patients with endometrial cancer: a systematic review and meta-analysis. Eur J Radiol. 2012;81(11):3511-7.

72. Han S, Woo S, Suh CH, Lee JJ. Performance of pretreatment ${ }^{18} \mathrm{~F}$-fluorodeoxyglucose positron emission tomography/computed tomography for detecting metastasis in ovarian cancer: a systematic review and meta-analysis. J Gynecol Oncol. 2018;29(6):e98.

73. Han S, Kim H, Kim YJ, Suh CH, Woo S. Prognostic value of volume-based metabolic parameters of (18)F-FDG PET/CT in ovarian cancer: a systematic review and meta-analysis. Ann Nucl Med. 2018;32(10):669-77.

74. Suppiah S, Chang WL, Hassan HA, Kaewput C, Asri AAA, Saad FFA, et al. Systematic review on the accuracy of positron emission tomography/computed tomography and positron emission tomography/magnetic resonance imaging in the management of ovarian cancer: is functional information really needed? World J Nucl Med. 2017;16(3):176-85.

75. Xu B, Ma J, Jiang G, Wang Y, Ma Q. Diagnostic value of positron emission tomography (PET) and $\mathrm{PET} /$ computed tomography in recurrent/metastatic ovarian cancer: a meta-analysis. J Obstet Gynaecol Res. 2017;43(2):378-86.

76. Limei Z, Yong C, Yan X, Shuai T, Jiangyan X, Zhiqing L. Accuracy of positron emission tomography/computed tomography in the diagnosis and restaging for recurrent ovarian cancer: a metaanalysis. Int J Gynecol Cancer. 2013;23(4):598-607.

77. Yuan Y, Gu ZX, Tao XF, Liu SY. Computer tomography, magnetic resonance imaging, and positron emission tomography or positron emission tomography/computer tomography for detection of metastatic lymph nodes in patients with ovarian cancer: a meta-analysis. Eur J Radiol. 2012;81(5):1002-6.

78. Kim SJ, Lee SW. Diagnostic accuracy of (18)F-FDG PET/CT for detection of peritoneal carcinomatosis; a systematic review and meta-analysis. Br J Radiol. 2018;91(1081):20170519.

79. Li J, Yan R, Lei J, Jiang C. Comparison of PET with PET/CT in detecting peritoneal carcinomatosis: a meta-analysis. Abdom Imaging. 2015;40(7):2660-6.

80. Chang MC, Chen JH, Liang JA, Huang WS, Cheng $\mathrm{KY}$, Kao CH. PET or PET/CT for detection of peritoneal carcinomatosis: a meta-analysis. Clin Nucl Med. 2013;38(8):623-9.
81. Zheng M, Xie D, Pan C, Xu Y, Yu W. Diagnostic value of $18 \mathrm{~F}-\mathrm{FDG}$ PET/MRI in recurrent pelvis malignancies of female patients: a systematic review and meta-analysis. Nucl Med Commun. 2018;39(6):479-85.

82. Nie J, Zhang J, Gao J, Guo L, Zhou H, Hu Y, et al. Diagnostic role of 18F-FDG PET/MRI in patients with gynecological malignancies of the pelvis: a systematic review and meta-analysis. PLoS One. 2017;12(5):e0175401.

83. Evangelista L, Guttilla A, Zattoni F, Muzzio PC, Zattoni F. Utility of choline positron emission tomography/computed tomography for lymph node involvement identification in intermediate- to highrisk prostate cancer: a systematic literature review and meta-analysis. Eur Urol. 2013;63(6):1040-8.

84. Evangelista L, Zattoni F, Guttilla A, Saladini G, Zattoni F, Colletti PM, et al. Choline PET or PET/ $\mathrm{CT}$ and biochemical relapse of prostate cancer: a systematic review and meta-analysis. Clin Nucl Med. 2013;38(5):305-14.

85. Evangelista L, Zattoni F, Karnes RJ, Novara G, Lowe V. Radiolabeled choline PET/CT before salvage lymphadenectomy dissection: a systematic review and meta-analysis. Nucl Med Commun. 2016;37(12):1223-31.

86. Fanti S, Minozzi S, Castellucci P, Balduzzi S, Herrmann K, Krause BJ, et al. PET/CT with (11) C-choline for evaluation of prostate cancer patients with biochemical recurrence: meta-analysis and critical review of available data. Eur J Nucl Med Mol Imaging. 2016;43(1):55-69.

87. Umbehr MH, Muntener M, Hany $\mathrm{T}$, Sulser $\mathrm{T}$, Bachmann LM. The role of 11C-choline and 18F-fluorocholine positron emission tomography (PET) and PET/CT in prostate cancer: a systematic review and meta-analysis. Eur Urol. 2013;64(1):106-17.

88. Treglia G, Ceriani L, Sadeghi R, Giovacchini G, Giovanella L. Relationship between prostatespecific antigen kinetics and detection rate of radiolabelled choline PET/CT in restaging prostate cancer patients: a meta-analysis. Clin Chem Lab Med. 2014;52(5):725-33.

89. Wei J, Zhu H, Liao X. Trigger pSA predicting recurrence from positive choline PET/CT with prostate cancer after initial treatment. Oncotarget. 2018;9(18):14630-41.

90. Guo Y, Wang L, Hu J, Feng D, Xu L. Diagnostic performance of choline PET/CT for the detection of bone metastasis in prostate cancer: a systematic review and meta-analysis. PLoS One. 2018;13(9):e0203400.

91. Shen G, Deng H, Hu S, Jia Z. Comparison of choline-PET/CT, MRI, SPECT, and bone scintigraphy in the diagnosis of bone metastases in patients with prostate cancer: a meta-analysis. Skelet Radiol. 2014;43(11):1503-13. 
92. Liu J, Chen Z, Wang T, Liu L, Zhao L, Guo G, et al. Influence of four radiotracers in PET/CT on diagnostic accuracy for prostate cancer: a bivariate random-effects meta-analysis. Cell Physiol Biochem. 2016;39(2):467-80.

93. Beheshti M, Giorgio T, Rasoul ZS, Werner L, Ali GR, Reza DK, et al. Application of C-11acetate positron-emission tomography (PET) imaging in prostate cancer: systematic review and meta-analysis of the literature. BJU Int. 2013;112(8):1062-72.

94. Ouyang Q, Duan Z, Lei J, Jiao G. Comparison of meta-analyses among elastosonography (ES) and positron emission tomography/computed tomography (PET/CT) imaging techniques in the application of prostate cancer diagnosis. Tumour Biol. 2016;37(3):2999-3007.

95. von Eyben FE, Kairemo K. Acquisition with (11) C-choline and (18)F-fluorocholine PET/CT for patients with biochemical recurrence of prostate cancer: a systematic review and meta-analysis. Ann Nucl Med. 2016;30(6):385-92.

96. Corfield J, Perera M, Bolton D, Lawrentschuk N. (68)Ga-prostate specific membrane antigen (PSMA) positron emission tomography (PET) for primary staging of high-risk prostate cancer: a systematic review. World J Urol. 2018;36(4):519-27.

97. Hope TA, Goodman JZ, Allen IE, Calais J, Fendler WP, Carroll PR. Metaanalysis of (68)Ga-PSMA-11 PET accuracy for the detection of prostate cancer validated by histopathology. J Nucl Med. 2019;60(6):786-93.

98. Han S, Woo S, Kim YJ, Suh CH. Impact of (68) Ga-PSMA PET on the management of patients with prostate cancer: a systematic review and metaanalysis. Eur Urol. 2018;74(2):179-90.

99. Kim SJ, Lee SW, Ha HK. Diagnostic performance of radiolabeled prostate-specific membrane antigen positron emission tomography/computed tomography for primary lymph node staging in newly diagnosed intermediate to high-risk prostate cancer patients: a systematic review and meta-analysis. Urol Int. 2019;102(1):27-36.

100. Perera M, Papa N, Christidis D, Wetherell D, Hofman MS, Murphy DG, et al. Sensitivity, specificity, and predictors of positive (68)Ga-prostate-specific membrane antigen positron emission tomography in advanced prostate cancer: a systematic review and meta-analysis. Eur Urol. 2016;70(6):926-37.

101. von Eyben FE, Picchio M, von Eyben R, Rhee H, Bauman G. (68)Ga-labeled prostate-specific membrane antigen ligand positron emission tomography/ computed tomography for prostate cancer: a systematic review and meta-analysis. Eur Urol Focus. 2018;4(5):686-93.
102. Pereira Mestre R, Treglia G, Ferrari M, Pascale M, Mazzara C, Azinwi NC, et al. Correlation between PSA kinetics and PSMA-PET in prostate cancer restaging: a meta-analysis. Eur J Clin Investig. 2019;49(3):e13063.

103. Crozier J, Papa N, Perera M, Ngo B, Bolton D, Sengupta $\mathrm{S}$, et al. Comparative sensitivity and specificity of imaging modalities in staging bladder cancer prior to radical cystectomy: a systematic review and meta-analysis. World $\mathrm{J}$ Urol. 2019;37(4):667-90.

104. Ha HK, Koo PJ, Kim SJ. Diagnostic accuracy of F-18 FDG PET/CT for preoperative lymph node staging in newly diagnosed bladder cancer patients: a systematic review and meta-analysis. Oncology. 2018;95(1):31-8.

105. Lu YY, Chen JH, Liang JA, Wang HY, Lin CC, Lin WY, et al. Clinical value of FDG PET or PET/CT in urinary bladder cancer: a systemic review and metaanalysis. Eur J Radiol. 2012;81(9):2411-6.

106. Soubra A, Hayward D, Dahm P, Goldfarb R, Froehlich J, Jha G, et al. The diagnostic accuracy of $18 \mathrm{~F}$-fluorodeoxyglucose positron emission tomography and computed tomography in staging bladder cancer: a single-institution study and a systematic review with meta-analysis. World J Urol. 2016;34(9):1229-37.

107. Wang N, Jiang P, Lu Y. Is fluorine-18 fluorodeoxyglucose positron emission tomography useful for detecting bladder lesions? A meta-analysis of the literature. Urol Int. 2014;92(2):143-9.

108. Zhang H, Xing W, Kang Q, Chen C, Wang L, Lu J. Diagnostic value of [18F] FDG-PET and PET/CT in urinary bladder cancer: a meta-analysis. Tumour Biol. 2015;36(5):3209-14.

109. Kim SJ, Koo PJ, Pak K, Kim IJ, Kim K. Diagnostic accuracy of C-11 choline and C-11 acetate for lymph node staging in patients with bladder cancer: a systematic review and meta-analysis. World $\mathrm{J}$ Urol. 2018;36(3):331-40.

110. Ma H, Shen G, Liu B, Yang Y, Ren P, Kuang A. Diagnostic performance of $18 \mathrm{~F}-\mathrm{FDG}$ PET or $\mathrm{PET} / \mathrm{CT}$ in restaging renal cell carcinoma: a systematic review and meta-analysis. Nucl Med Commun. 2017;38(2):156-63.

111. Wang HY, Ding HJ, Chen JH, Chao CH, Lu YY, Lin WY, et al. Meta-analysis of the diagnostic performance of [18F]FDG-PET and PET/CT in renal cell carcinoma. Cancer Imaging. 2012;12:464-74.

112. Zhao JY, Ma XL, Li YY, Zhang BL, Li MM, Ma $\mathrm{XL}$, et al. Diagnostic accuracy of 18F-FDG-PET in patients with testicular cancer: a meta-analysis. Asian Pac J Cancer Prev. 2014;15(8):3525-31.

113. Treglia G, Sadeghi R, Annunziata S, Caldarella C, Bertagna F, Giovanella L. Diagnostic performance 
of fluorine-18-fluorodeoxyglucose positron emission tomography in the postchemotherapy management of patients with seminoma: systematic review and meta-analysis. Biomed Res Int. 2014;2014:852681.

114. Sadeghi R, Gholami H, Zakavi SR, Kakhki VR, Horenblas S. Accuracy of 18F-FDG PET/CT for diagnosing inguinal lymph node involvement in penile squamous cell carcinoma: systematic review and meta-analysis of the literature. Clin Nucl Med. 2012;37(5):436-41.

115. Ren J, Yuan L, Wen G, Yang J. The value of anti1-amino-3-18F-fluorocyclobutane-1-carboxylic acid PET/CT in the diagnosis of recurrent prostate carcinoma: a meta-analysis. Acta Radiol. 2016;57(4):487-93.

116. Sathianathen NJ, Butaney M, Konety BR. The utility of PET-based imaging for prostate cancer biochemical recurrence: a systematic review and metaanalysis. World J Urol. 2019;37(7):1239-49.

117. Bertagna F, Sadeghi R, Giovanella L, Treglia G. Incidental uptake of $18 \mathrm{~F}$-fluorodeoxyglucose in the prostate gland. Systematic review and metaanalysis on prevalence and risk of malignancy. Nuklearmedizin. 2014;53(6):249-58.

Open Access This chapter is licensed under the terms of the Creative Commons Attribution 4.0 International License (http://creativecommons.org/licenses/by/4.0/), which permits use, sharing, adaptation, distribution and reproduction in any medium or format, as long as you give appropriate credit to the original author(s) and the source, provide a link to the Creative Commons license and indicate if changes were made.

The images or other third party material in this chapter are included in the chapter's Creative Commons license, unless indicated otherwise in a credit line to the material. If material is not included in the chapter's Creative Commons license and your intended use is not permitted by statutory regulation or exceeds the permitted use, you will need to obtain permission directly from the copyright holder. 


\title{
Evidence-Based PET for Cutaneous, Musculoskeletal and Unknown Primary Tumours
}

\author{
Luisa Knappe and Gaetano Paone
}

\subsection{Introduction}

PET/CT is extremely useful method in cutaneous and musculoskeletal tumours. In this chapter, the evidence from the literature concerning PET or $\mathrm{PET} / \mathrm{CT}$ in melanoma, sarcomas, bone metastases, cancer of unknown primary (CUP) and paraneoplastic syndromes were analysed.

\subsection{PET in Malignant Melanoma}

\subsubsection{Introduction}

Melanoma is a highly malignant tumour having its origin in melanocytes from the epidermal skin layer. As prognosis is highly dependent on lymph node involvement and presence of distant metastases at the time of diagnosis, a precise staging is important for determining prognosis and choosing the fittest therapy for the patient [1-4].

L. Knappe $\cdot$ G. Paone $(\bowtie)$

Clinic of Nuclear Medicine and Molecular Imaging, Imaging Institute of Southern Switzerland, Ente Ospedaliero Cantonale, Bellinzona and Lugano, Switzerland e-mail: gaetano.paone@eoc.ch

\subsubsection{Staging}

${ }^{18} \mathrm{~F}-\mathrm{FDG}$ PET/CT in staging melanoma has to be performed as a whole body protocol from head to toe to visualize the whole skin. Nonetheless, the usefulness of ${ }^{18} \mathrm{~F}$-FDG PET/CT is limited in staging of tumour expansion and detection of satellite metastases. For the recognition of lymph nodal metastases, ultrasound and histological examination of the sentinel lymph node have a higher sensitivity and specificity than ${ }^{18} \mathrm{~F}-\mathrm{FDG}$ PET/CT [5, 6]. Vural Topuz et al. showed that ${ }^{18} \mathrm{~F}-\mathrm{FDG}$ PET/ $\mathrm{CT}$ is probably negative in the first year postsurgery if the sentinel lymph node biopsy was negative. Hence, performance of ${ }^{18} \mathrm{~F}-\mathrm{FDG}$ PET/ $\mathrm{CT}$ is not recommended in early stage melanoma for not providing any significant clinical contribution [7].

In contrast, ${ }^{18} \mathrm{~F}-\mathrm{FDG}$ PET/CT is well established for imaging of distant metastases. In a meta-analysis of nine studies, Rodriguez Rivera et al. found out usefulness of ${ }^{18} \mathrm{~F}$-FDG PET/CT in staging of stage III melanoma having a high sensitivity $(89.4 \%)$ and specificity $(88.8 \%)$ [8]. Also Xing et al. valued ${ }^{18} \mathrm{~F}-\mathrm{FDG}$ PET/CT as the most sensitive and specific method for detecting distant metastases [6]. ${ }^{18} \mathrm{~F}-\mathrm{FDG} \mathrm{PET} / \mathrm{CT}$ is even superior to morphologic imaging and has replaced $\mathrm{CT}$ and magnetic resonance imaging (MRI) almost completely [1]. 


\subsubsection{Restaging and Treatment Monitoring}

The early detection of disease progression or recurrence has a huge impact on prognosis of melanoma. The usefulness of ${ }^{18} \mathrm{~F}$-FDG PET/CT has been proven not only for the staging of advanced melanoma but also for the detection of recurrences showing a sensitivity of $96 \%$ and a specificity of $92 \%$ [7]. Accordingly, ${ }^{18} \mathrm{~F}-\mathrm{FDG}$ PET/CT frequently leads to a change of treatment plan [6]. Due to a scarce number of prospective studies regarding use of ${ }^{18} \mathrm{~F}-\mathrm{FDG}$ PET/ $\mathrm{CT}$ in melanoma, more studies are needed to find the most effective and cost-effective intervals in follow-up.

\subsection{PET in Sarcomas}

\subsubsection{Introduction}

Sarcomas are malignant tumours originating from mesenchymal cells. They are a relatively rare cancer and represent only $1 \%$ of all malignant tumours but extremely frequent in children. They can be divided in soft tissue, osseous and chondral sarcomas. Soft tissue sarcomas are a group of heterogeneous tumours as rhabdomyosarcoma, leiomyosarcoma, fibrosarcoma, liposarcoma, angiosarcoma, etc. and they are the fourth most common solid tumours in children. The bone sarcomas are the osteosarcoma and the Ewing sarcoma. Classical imaging methods for sarcomas are X-ray, CT for control of stability and MRI for the illustration of the expansion in soft tissues. Biopsy and histopathological examination ensure diagnosis $[9,10]$.

\subsubsection{Staging}

PET/CT offers the possibility of simultaneous acquisition of bone lesions and their expansion in soft tissue and is very useful for the staging of sarcomas due to its high sensitivity, specificity and accuracy. The performance of ${ }^{18} \mathrm{~F}$-FDG PET/ $\mathrm{CT}$ in the initial staging provides information of the initial metabolism activity of the tumour. This is important for the follow-up and the evaluation of the therapy response [11]. About ${ }^{18} \mathrm{~F}-\mathrm{FDG}$ PET/CT in sarcomas, according to evidencebased data, the values vary between 86 and $96 \%$ for sensitivity and from 80 to $96 \%$ for specificity [12-15]. In particular, this hybrid imaging method is very useful for detecting distant metastases, as osseous and lung metastases [12, 15]. Furthermore, ${ }^{18} \mathrm{~F}-\mathrm{FDG}$ PET/CT might have a relevant impact on the development of treatment strategy plan [15]. Additional to the high diagnostic quality, ${ }^{18} \mathrm{~F}-\mathrm{FDG}$ PET/CT has also a prognostic value in sarcomas. Chen et al. found out that semi-quantitative PET parameters showed a significant prognostic value for overall survival and thus are useful tools in identifying high-risk patients [16]. These findings were confirmed by other authors reporting that a high maximum standardized uptake value (SUVmax) may predict a significantly shorter overall survival period [17].

\subsubsection{Restaging and Treatment Monitoring}

${ }^{18} \mathrm{~F}-\mathrm{FDG}$ PET/CT is a valuable method for detecting post-surgery recurrence in patients with sarcomas [12]. Liu et al. found a sensitivity of $92 \%$ and a specificity of $93 \%$ for the detection of recurrence in sarcoma [14]. Hongtao et al. reported that ${ }^{18} \mathrm{~F}$-FDG PET/CT is valuable for predicting the histological response to chemotherapy as they found a response to neoadjuvant chemotherapy in osteosarcomas with a sensitivity of $73 \%$ and a specificity of $86 \%$ [18]. Muheremu et al. showed that ${ }^{18} \mathrm{~F}-\mathrm{FDG}$ PET/CT assesses the efficacy of neoadjuvant therapy with a sensitivity and specificity of $79 \%$ and thus is a reliable imaging method not only in diagnosis but also in treatment control of osseous and soft tissue tumours [13]. Also Chen et al. valued posttreatment SUVmax as useful in monitoring therapy response [16]. Li et al. had similar results confirming that SUVmax before and after chemotherapy has effective prognostic significance for survival outcomes [19]. 


\subsection{PET for Bone Metastases}

\subsubsection{Introduction}

Bone metastases originate most frequently from breast cancer in women and from prostate carcinoma in men (each 60\%) followed by lung carcinoma (25\%), renal cell and thyroid carcinoma. Bone metastases can be differentiated in osteoblastic metastases which are typical for the prostate carcinoma, osteolytic metastases which occur in renal cell, thyroid or colon carcinomas and mixed osteoblastic and osteolytic metastases for example from breast or lung cancer. They are localized often in the spine (60\%) but also in the pelvis, proximal femur and skull, rarely in distal bones. Symptoms are mainly pain, radicular symptoms if a spine metastasis causes nerve root compression and functional impairment. Furthermore, metastases can cause instability of the bone with the consequent risk of fracture [20].

\subsubsection{Detection of Bone Metastases}

The probably most frequently performed imaging method for osseous staging is the bone scintigraphy (BS). In the actual development, this method is being replaced by PET/CT with different tracers as ${ }^{18} \mathrm{~F}-\mathrm{FDG}$ (which has the advantage to represent nearly all body districts) and ${ }^{18} \mathrm{~F}$-Fluoride which is more osseous specific. In a meta-analysis, Liu et al. found a sensitivity of $93 \%$ and a specificity of $95 \%$ for ${ }^{18} \mathrm{~F}$-fluoride $\mathrm{PET} / \mathrm{CT}$ in the detection of bone metastases. This method showed significantly higher sensitivity and specificity compared to BS and thus a superior diagnostic performance in bone metastases detection and higher accuracy [21]. Shen et al. achieved similar results showing a sensitivity of $92 \%$ and a specificity of $93 \%$ for ${ }^{18} \mathrm{~F}$-fluoride PET/CT. Compared with BS, it showed both higher sensitivity and specificity, whereas compared with ${ }^{18} \mathrm{~F}$-FDG PET/CT it showed only a higher sensitivity but no significant difference in specificity. Consequently, the authors describe an excellent diagnostic capacity for the detection of bone metastases and advantages compared with BS and ${ }^{18}$ F-FDG PET/CT [22].

Duo et al. analysed the performance of PET/ CT with different tracers in comparison with gadolinium-enhanced MRI for detecting bone metastases: similar sensitivity and specificity values for each method were found and consequently an excellent diagnostic performance for the detection of bone metastases for both methods [23]. On the contrary, regarding only vertebral metastases, MRI showed a better performance than PET/CT both in sensitivity and specificity. This procedure outranged also all other imaging methods as CT or BS with tomographic acquisition (SPECT) [24].

Concerning the prognostic value of ${ }^{18} \mathrm{~F}$-FDG PET/CT, Jeong et al. showed that patients with solid tumours and a lower level of ${ }^{18} \mathrm{~F}-\mathrm{FDG}$ uptake in the bone marrow have a better event free and overall survival than patients with higher bone marrow ${ }^{18} \mathrm{~F}$-FDG uptake and therefore propose to use the ${ }^{18} \mathrm{~F}$-FDG uptake in the bone marrow for risk stratification of tumour progression [25].

\subsection{PET for Cancer of Unknown Primary (CUP) and Paraneoplastic Syndromes}

\subsubsection{Introduction}

Cancer of unknown primary (CUP) is a syndrome defined by the presence of a metastatic disease without identified primary tumour. In $2-5 \%$ of all malignant tumours, the localization of the primary tumour is unknown. CUP occurs in a heterogeneous group of cancers most frequently in malignant melanoma, neuroendocrine tumours, carcinoids, small cell lung carcinoma and head and neck cancer. Despite of modern imaging methods, CUP remains a challenge in clinical routine. As prognosis is rather poor, the identification of the primary tumour can be important to adjust therapy and improve survival [26].

Paraneoplastic syndromes arise from tumour secretion of hormones, peptides or cytokines or 
from immune cross-reactivity between malignant and normal tissues. Paraneoplastic syndromes may affect diverse organ systems, most notably the endocrine, neurologic, dermatologic, rheumatologic and hematologic systems. The most commonly associated malignancies include small cell lung cancer, breast cancer, gynaecologic tumours and hematologic malignancies. In some instances, the timely diagnosis of these conditions may lead to detection of an otherwise clinically occult tumour at an early and highly treatable stage [27].

\subsubsection{Impact of PET in Patients with CUP}

Since patients with CUP syndrome usually underwent a vast diagnostic procedure with negative results, the patients setting in which ${ }^{18} \mathrm{~F}-\mathrm{FDG}$ $\mathrm{PET} / \mathrm{CT}$ is performed with this question is highly selected. Consequently, the search for a primary tumour in CUP syndrome is more difficult than in other diseases. Nevertheless, Burglin et al. found a detection rate of unknown primary tumours in $41 \%$ of cases by using ${ }^{18} \mathrm{~F}$-FDG PET/CT and they recommended an early use of ${ }^{18} \mathrm{~F}-\mathrm{FDG}$ PET/CT to obviate too much useless diagnostic procedures [28].

\subsubsection{Impact of PET in Patients with Paraneoplastic Syndromes}

In patients with suspected paraneoplastic syndrome, ${ }^{18}$ F-FDG PET/CT showed a high accuracy for the detection of underlying malignancies with a sensitivity of $81 \%$ and a specificity of $88 \%$ [29]. Also in patients with paraneoplastic neurological syndrome, ${ }^{18} \mathrm{~F}$ FDG PET/CT showed a high diagnostic performance with a detection rate of $15 \%$, a sensitivity of $87 \%$ and specificity of $86 \%$ [30]. Generally, a heterogeneity in study design and diagnostic workup and the small number of patients in the available studies reduce interpretability of the data $[29,30]$.

\section{References}

1. Perng P, Marcus C, Subramaniam RM. (18)F-FDG PET/CT and melanoma: staging, immune modulation and mutation-targeted therapy assessment, and prognosis. AJR Am J Roentgenol. 2015;205(2):259-70.

2. Deutsche Krebsgesellschaft (DKG), Deutsche Dermatologische Gesellschaft (DDG): S3-Leitlinie Diagnostik, Therapie und Nachsorge des Melanoms. 2016.

3. Larkin J, Chiarion-Sileni V, Gonzalez R, Grob JJ, Rutkowski P, Lao CD, et al. Five-year survival with combined nivolumab and ipilimumab in advanced melanoma. N Engl J Med. 2019;381:1535-46.

4. Danielsen M, Højgaard L, Kjær A, Fischer BM. Positron emission tomography in the followup of cutaneous malignant melanoma patients: a systematic review. Am J Nucl Med Mol Imaging. 2013;4(1):17-28.

5. Mirk P, Treglia G, Salsano M, Basile P, Giordano A, Bonomo L. Comparison between F-fluorodeoxyglucose positron emission tomography and sentinel lymph node biopsy for regional lymph nodal staging in patients with melanoma: a review of the literature. Radiol Res Pract. 2011;2011:912504.

6. Xing Y, Cromwell KD, Cormier JN. Review of diagnostic imaging modalities for the surveillance of melanoma patients. Dermatol Res Pract. 2012;2012:941921.

7. Vural Topuz Ö, Görtan FA, Kaya Döner ZR, Önsel Ç, Sayman HB. Usefulness of ${ }^{18}$ F-FDG PET/CT in cutaneous melanoma patients with negative sentinel lymph nodes and high Clark levels. Mol Imaging Radionucl Ther. 2018;27(2):66-72.

8. Rodriguez Rivera AM, Alabbas H, Ramjaun A, Meguerditchian AN. Value of positron emission tomography scan in stage III cutaneous melanoma: a systematic review and meta-analysis. Surg Oncol. 2014;23(1):11-6.

9. Doyle LA. Sarcoma classification: an update based on the 2013 World Health Organization classification of tumors of soft tissue and bone. Cancer. 2014;120(12):1763-74.

10. Amankwah EK, Conley AP, Reed DR. Epidemiology and therapies for metastatic sarcoma. Clin Epidemiol. 2013;5:147-62.

11. Katal S, Gholamrezanezhad A, Kessler M, Olyaei M, Jadvar H. PET in the diagnostic management of soft tissue sarcoma of musculoskeletal origin. PET Clin. 2018;13(4):609-2.

12. Huang T, Li F, Yan Z, Ma Y, Xiong F, Cai X, et al. Effectiveness of ${ }^{18} \mathrm{~F}-\mathrm{FDG}$ PET/CT in the diagnosis, staging and recurrence monitoring of Ewing sarcoma family of tumors: a meta-analysis of 23 studies. Medicine. 2018;97(48):e13457.

13. Muheremu A, Ma J, Amudong A, Ma Y, Niyazi M, $\mathrm{Ou} \mathrm{Y}$, et al. Positron emission tomography/computed tomography for osseous and soft tissue sarcomas: a systematic review of the literature and meta-analysis. Mol Clin Oncol. 2017;7(3):461-7. 
14. Liu F, Zhang Q, Zhu D, Li Z, Wang B, Zhou D, et al. Performance of positron emission tomography and positron emission tomography/computed tomography using fluorine-18-fluorodeoxyglucose for the diagnosis, staging, and recurrence assessment of bone sarcoma: a systematic review and meta-analysis. Medicine. 2015;94(36):e1462.

15. Treglia G, Salsano M, Stefanelli A, Mattoli MV, Giordano A, Bonomo L. Diagnostic accuracy of ${ }^{18} \mathrm{~F}-\mathrm{FDG}-\mathrm{PET}$ and $\mathrm{PET} / \mathrm{CT}$ in patients with Ewing sarcoma family tumours: a systematic review and a meta-analysis. Skelet Radiol. 2012;41(3):249-56.

16. Chen L, Wu X, Ma X, Guo L, Zhu C, Li Q. Prognostic value of 18F-FDG PET-CT-based functional parameters in patients with soft tissue sarcoma: a metaanalysis. Medicine. 2017;96(6):e5913.

17. Kubo T, Furuta T, Johan M, Ochi M. Prognostic significance of (18)F-FDG PET at diagnosis in patients with soft tissue sarcoma and bone sarcoma; systematic review and meta-analysis. Eur $\mathrm{J}$ Cancer. 2016;58:104-11.

18. Hongtao L, Hui Z, Bingshun W, Xiaojin W, Zhiyu W, Shuier Z, et al. 18F-FDG positron emission tomography for the assessment of histological response to neoadjuvant chemotherapy in osteosarcomas: a metaanalysis. Surg Oncol. 2012;21(4):e165-70.

19. Li YJ, Dai YL, Cheng YS, Zhang WB, Tu CQ. Positron emission tomography (18)F-fluorodeoxyglucose uptake and prognosis in patients with bone and soft tissue sarcoma: a meta-analysis. Eur J Surg Oncol. 2016;42(8):1103-14.

20. Grávalos C, Rodríguez C, Sabino A, Segui MA, Virizuela JA, Carmona A, et al. SEOM clinical guideline for bone metastases from solid tumours. Clin Transl Oncol. 2016;18(12):1243-53.

21. Liu Y, Sheng J, Dong Z, Xu Y, Huang Q, Pan D, et al. The diagnostic performance of 18F-fluoride PET/CT in bone metastases detection: a meta-analysis. Clin Radiol. 2019;74(3):196-206.
22. Shen CT, Qiu ZL, Han TT, Luo QY. Performance of 18F-fluoride PET or PET/CT for the detection of bone metastases: a meta-analysis. Clin Nucl Med. 2015;40(2):103-10.

23. Duo J, Han X, Zhang L, Wang G, Ma Y, Yang Y. Comparison of FDG PET/CT and gadoliniumenhanced MRI for the detection of bone metastases in patients with cancer: a meta-analysis. Clin Nucl Med. 2013;38(5):343-8.

24. Liu T, Wang S, Liu H, Meng B, Zhou F, He F, et al. Detection of vertebral metastases: a meta-analysis comparing MRI, CT, PET, BS and BS with SPECT. J Cancer Res Clin Oncol. 2017;143(3):457-65.

25. Jeong SY, Kim SJ, Pak K, Lee SW, Ahn BC, Lee J. Prognostic value of $18 \mathrm{~F}$-fluorodeoxyglucose bone marrow uptake in patients with solid tumors: a metaanalysis. Medicine. 2018;97(43):e12859.

26. Varadhachary GR. Carcinoma of unknown primary origin. Gastrointest Cancer Res. 2007;1(6):229-35.

27. Pelosof LC, Gerber DE. Paraneoplastic syndromes: an approach to diagnosis and treatment. Mayo Clin Proc. 2010;85(9):838-54.

28. Burglin SA, Hess S, Høilund-Carlsen PF, Gerke O. 18F-FDG PET/CT for detection of the primary tumor in adults with extracervical metastases from cancer of unknown primary: a systematic review and metaanalysis. Medicine. 2017;96(16):e6713.

29. Sheikhbahaei S, Marcus CV, Fragomeni RS, Rowe SP, Javadi MS, Solnes LB. Whole-body 18F-FDG PET and 18F-FDG PET/CT in patients with suspected paraneoplastic syndrome: a systematic review and meta-analysis of diagnostic accuracy. J Nucl Med. 2017;58(7):1031-6.

30. García Vicente AM, Delgado-Bolton RC, Amo-Salas M, López-Fidalgo J, Caresia Aróztegui AP, García Garzón JR, et al. 18F-fluorodeoxyglucose positron emission tomography in the diagnosis of malignancy in patients with paraneoplastic neurological syndrome: a systematic review and meta-analysis. Eur J Nucl Med Mol Imaging. 2017;44(9):1575-87.

Open Access This chapter is licensed under the terms of the Creative Commons Attribution 4.0 International License (http://creativecommons.org/licenses/by/4.0/), which permits use, sharing, adaptation, distribution and reproduction in any medium or format, as long as you give appropriate credit to the original author(s) and the source, provide a link to the Creative Commons license and indicate if changes were made.

The images or other third party material in this chapter are included in the chapter's Creative Commons license, unless indicated otherwise in a credit line to the material. If material is not included in the chapter's Creative Commons license and your intended use is not permitted by statutory regulation or exceeds the permitted use, you will need to obtain permission directly from the copyright holder.

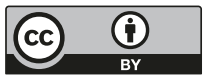




\title{
Evidence-Based PET for Haematological Tumours
}

\author{
Francesco Bertagna, Raffaele Giubbini, \\ and Domenico Albano
}

\subsection{Introduction}

Haematological malignancies include lymphomas such as Hodgkin lymphoma (HL) and nonHodgkin lymphoma (NHL), leukaemia and multiple myeloma (MM). They can affect any organ system and positron emission tomography/ computed tomography (PET/CT) has been accepted as part of the routine management of most of them. In this chapter were only considered recent systematic reviews and meta-analyses concerning the use of PET or PET/CT with ${ }^{18} \mathrm{~F}$ FDG in haematological malignancies dividing the results by the main areas of application.

\section{$9.2 \quad{ }^{18}$ F-FDG PET or PET/CT in Staging or Detection}

In staging HL and more aggressive NHL subtypes, ${ }^{18}$ F-FDG PET/CT was shown to be clearly more accurate than conventional radiological imaging to detect nodal and extranodal involvement. On the other hand, recent meta-analyses have addressed the diagnostic performance of this imaging method in some types of NHL, in $\mathrm{MM}$ and in the assessment of bone marrow involvement of HL and NHL [1-9].

F. Bertagna $(\varangle) \cdot$ R. Giubbini $\cdot$ D. Albano

Nuclear Medicine, University of Brescia and Spedali

Civili di Brescia, Brescia, Italy

e-mail: francesco.bertagna@unibs.it

\subsubsection{Post-transplant Lymphoproliferative Disorder}

Montes de Jesus et al. [1] evaluated the performance of advanced imaging modalities at diagnosis for post-transplant lymphoproliferative disorder (PTLD) after solid organ and haematopoietic stem cell transplantation. ${ }^{18} \mathrm{~F}-\mathrm{FDG}$ PET/ CT was the primary imaging modality investigated. Subgroup analysis of imaging results for detection and staging in patients with PTLD indicated that ${ }^{18} \mathrm{~F}$-FDG PET/CT identified additional lesions not detected by conventional imaging in $27.8 \%$ of cases, from which extranodal sites in $23.6 \%$. False negative results occurred in $11.5 \%$ of cases, predominantly in physiological high background activity regions and in early PTLD lesions. False positive results occurred in $4.8 \%$ of cases, predominantly due to inflammatory conditions. They concluded that ${ }^{18} \mathrm{~F}-\mathrm{FDG}$ $\mathrm{PET} / \mathrm{CT}$ is currently the most frequently investigated imaging modality in PTLD patients with promising results in detection and staging, but available studies suffer from methodological shortcomings.

\subsubsection{Follicular Lymphoma}

Adams et al. [2] studied the additional value of ${ }^{18}$ F-FDG PET to CT for staging newly diagnosed follicular lymphoma (FL) in terms of Ann Arbor 
staging and Follicular Lymphoma International Prognostic Index (FLIPI) risk stratification. The proportion of patients who were upstaged by ${ }^{18} \mathrm{~F}$ FDG PET compared with CT ranged from 0 to $45.2 \%$, with a pooled summary proportion of $18.7 \%$ (95\% confidence interval $(95 \% \mathrm{CI}): 10.8-$ $30.4 \%$ ). The single study that only included patients with CT-based limited non-bulky stage I to II disease reported ${ }^{18} \mathrm{~F}-\mathrm{FDG}$ PET-induced upstaging in $40.5 \%$ of cases. No study reported data on the influence of ${ }^{18} \mathrm{~F}$-FDG PET on FLIPI risk stratification. Although upstaging by ${ }^{18} \mathrm{~F}-$ FDG PET compared with CT occurs in a considerable proportion of patients, the available studies on this topic had numerous methodological errors. The authors concluded that future welldesigned studies are needed before ${ }^{18} \mathrm{~F}$-FDG PET can be recommended for routine pre-treatment staging of FL.

\subsubsection{Marginal Zone Lymphoma of the Mucosa-Associated Lymphoid Tissue}

Treglia et al. [3] analysed the detection rate (DR) of ${ }^{18} \mathrm{~F}-\mathrm{FDG}$ PET and PET/CT for the evaluation of patients with marginal zone lymphoma of the mucosa-associated lymphoid tissue (MALT). The pooled DR of ${ }^{18} \mathrm{~F}-\mathrm{FDG}$ PET or PET/CT was $71 \%$ (95\%CI: $61-80 \%$ ). A significant difference between the DR of PET/ CT (69\%; 95\%CI: $61-80 \%)$ and that of PET alone (73\%; 95\% CI: 60-84\%) was not demonstrated. A better DR of ${ }^{18} \mathrm{~F}-\mathrm{FDG}$ PET or PET/ CT in bronchial (94\%; 95\%CI: 85-99\%) and head-and-neck (90\%; 95\%CI: 78-98\%) MALT lymphomas compared with gastric (62\%; 95\%CI: 46-77\%) and ocular (49\%; 95\%CI: 36-63\%) MALT lymphomas was found. This meta-analysis demonstrated that MALT lymphoma is an ${ }^{18} \mathrm{~F}$-FDG-avid tumour in most of the cases, suggesting a potential clinical role in the initial evaluation of these patients. In particular, the DR of ${ }^{18} \mathrm{~F}$-FDG PET or PET/CT is related to the primary site of the MALT lymphoma.

\subsubsection{Bone Marrow Involvement in Lymphoma}

Adams et al. [4] analysed the diagnostic performance of ${ }^{18} \mathrm{~F}-\mathrm{FDG}$ PET/CT in detecting bone marrow involvement (BMI) in patients with newly diagnosed diffuse large B-cell lymphoma (DLBCL). The pooled sensitivity and specificity of ${ }^{18} \mathrm{~F}-\mathrm{FDG}$ PET/CT for detecting BMI were $88.7 \%$ (95\%CI: 82.5-93.3\%) and 99.8\% (95\% CI: 98.8-100\%), respectively. The area under the summary ROC curve was 0.9983 . They concluded that ${ }^{18} \mathrm{~F}-\mathrm{FDG}$ PET/CT is accurate and complementary to bone marrow biopsy (BMB) for detecting BMI in patients with newly diagnosed DLBCL. A negative ${ }^{18} \mathrm{~F}-\mathrm{FDG}$ PET/CT cannot rule out the presence of BMI, but positive ${ }^{18} \mathrm{~F}-\mathrm{FDG}$ PET/CT findings obviate the need for $\mathrm{BMB}$ for the detection of BMI in these patients.

The same group of authors systematically reviewed and meta-analysed published data on the diagnostic performance of ${ }^{18} \mathrm{~F}-\mathrm{FDG}$ PET/CT in detecting BMI in newly diagnosed HL to assess whether ${ }^{18} \mathrm{~F}-\mathrm{FDG}$ PET/CT can replace blind BMB in these patients [5]. The pooled sensitivity and specificity of ${ }^{18} \mathrm{~F}-\mathrm{FDG}$ PET/CT for the detection of BMI range were $96.9 \%$ (95\% CI: 93-99\%) and $99.7 \%$ (95\%CI: $98.9-100 \%)$, respectively. The area under the ROC curve was 0.986. In conclusion, although the methodological quality of studies that were included in this systematic review and meta-analysis was moderate, the meta-analysis suggests that ${ }^{18} \mathrm{~F}-\mathrm{FDG}$ $\mathrm{PET} / \mathrm{CT}$ may be an appropriate method to replace BMB in newly diagnosed HL.

Cheng et al. [6] also carried out a metaanalysis to evaluate the performance of ${ }^{18} \mathrm{~F}-\mathrm{FDG}$ PET and PET/CT against BMB in the initial diagnosis of BMI in patients with HL. Both ${ }^{18} \mathrm{~F}$ FDG PET and BMB had excellent specificity in detecting BMI. However, ${ }^{18} \mathrm{~F}-\mathrm{FDG}$ PET had excellent pooled sensitivity $(94.5 \%$; 95\% CI: 89.0-97.8\%) in detecting BMI in the initial staging of HL patients, whereas the pooled sensitivity of iliac BMB was very poor $(39.4 \%$; $95 \% \mathrm{CI}$ : $30.8-48.4 \%$ ). The authors concluded that ${ }^{18} \mathrm{~F}-$ FDG PET significantly outperforms iliac BMB in 
the detection of BMI in the initial staging of HL patients and therefore should be used as a firstline study.

\subsubsection{Natural Killer/T-Cell Lymphoma}

Ji et al. [7] evaluated the values of ${ }^{18} \mathrm{~F}-\mathrm{FDG}$ PET/ $\mathrm{CT}$ and PET in diagnosing extranodal nasal type natural killer/T-cell lymphoma (ENKTL). Pooled sensitivity, specificity and area under the curve (AUC) of ${ }^{18} \mathrm{~F}-\mathrm{FDG}$ PET/CT for diagnosing ENKTL were 97\% (95\%CI: 93-99\%), 97\% (95\%CI: 88-99\%) and 0.99 (95\%CI: 0.98-1.00). The same parameters for ${ }^{18} \mathrm{~F}-\mathrm{FDG}$ PET were 81\% (95\%CI: 70-89\%), 90\% (95\%CI: 66-98) and 0.86 (95\%CI: 0.82-0.89), respectively. The authors concluded that in comparison with PET, ${ }^{18}$ F-FDG PET/CT had excellent diagnostic value in detecting and staging ENKTL.

Zhou et al. [8] evaluated the role of ${ }^{18} \mathrm{~F}-\mathrm{FDG}$ $\mathrm{PET} / \mathrm{CT}$ in the diagnosis and staging of natural killer/T-cell lymphoma (NKTL). On a patientbased analysis, the pooled sensitivity and specificity of ${ }^{18} \mathrm{~F}-\mathrm{FDG}$ PET/CT in the diagnosis of NKTL were 95\% (95\%CI: 89-98\%) and 40\% (95\%CI: 9-78\%), respectively. For lesion-based analysis, the pooled sensitivity and specificity of ${ }^{18} \mathrm{~F}-\mathrm{FDG}$ PET/CT in the staging of NKTL were 98\% (95\%CI: 96-99\%) and 99\% (95\%CI: 99-100), respectively. The results indicated that ${ }^{18} \mathrm{~F}$-FDG PET/CT could be used as a valuable diagnostic and staging tool for NKTL.

\subsubsection{Multiple Myeloma}

Lu et al. [9] conducted a systematic review and meta-analysis to evaluate the diagnostic accuracy of ${ }^{18} \mathrm{~F}$-FDG PET or PET/CT for intramedullary and extramedullary lesions in MM. The pooled sensitivity and specificity of ${ }^{18} \mathrm{~F}$-FDG PET or PET/CT for the detection of extramedullary lesions in MM were 96.0\% (95\%CI: 79.6-99.9\%) and $77.8 \%$ (95\% CI: 40-97.2\%), respectively. The pooled sensitivity and specificity of ${ }^{18} \mathrm{~F}-\mathrm{FDG}$ PET or PET/CT for the detection of intramedul- lary lesions in $\mathrm{MM}$ were $61.1 \%$ (95\% CI: 43.5$76.9 \%$ ) and $94.1 \%$ (95\% CI: 71.3-99.9\%), respectively. They concluded that whole-body ${ }^{18} \mathrm{~F}-\mathrm{FDG}$ PET or PET/CT is a valuable imaging tool for the assessment of patients with MM, especially for the appraisal of extramedullary involvement.

\subsection{F-FDG PET or PET/CT in Treatment Response Evaluation (Interim and/or End of Therapy)}

\subsubsection{Post-transplant Lymphoproliferative Disorder}

In the meta-analysis by Montes de Jesus et al. [1] on imaging modalities in PTLD, the subgroup analysis of imaging results at treatment response evaluation indicated that ${ }^{18} \mathrm{~F}$-FDG PET/CT findings altered or guided treatment in $29 \%$ of cases. False positive results during treatment response evaluation were reported in $20 \%$ of cases, predominantly due to inflammatory conditions. They concluded that ${ }^{18} \mathrm{~F}$-FDG PET/CT may be promising in therapy evaluation but suffers from methodological shortcomings. Concerns remain with regard to occurrence of false negatives due to physiological high background activity and early PTLD lesions as well as false positives due to inflammatory conditions.

\subsubsection{Hodgkin and Non-Hodgkin Lymphomas}

Adams et al. [10] systematically reviewed and meta-analysed the proportion of false positive lesions at interim and end-of-treatment ${ }^{18} \mathrm{~F}-\mathrm{FDG}$ PET in lymphomas (both HL and NHL) using biopsy as reference standard. The pooled proportion of false positive results among all biopsied ${ }^{18}$ F-FDG-avid lesions at PET performed during or after completion of treatment was $55.7 \%$ (95\%CI: $32.6-76.6 \%)$. The pooled false positive proportions were $83 \%$ (95\% CI: $72-90.2 \%$ ) for interim ${ }^{18}$ F-FDG PET in NHL, $23.1 \%$ (95\%CI: 4.7-64.5\%) 
for end-of-treatment ${ }^{18} \mathrm{~F}-\mathrm{FDG}$ PET in $\mathrm{HL}$ and $31.5 \%$ (95\% CI: 3.9-83.9\%) for end-of-treatment ${ }^{18} \mathrm{~F}-\mathrm{FDG}$ PET in NHL. The authors concluded that both interim and end-of-treatment ${ }^{18} \mathrm{~F}$-FDG PET in patients with lymphoma suffer from a very high number of false positive findings.

Sun et al. [11] conducted a meta-analysis to evaluate the predictive value of interim ${ }^{18} \mathrm{~F}$-FDG PET/CT in patients with DLBCL treated with R-CHOP chemotherapy. The pooled sensitivity of interim ${ }^{18} \mathrm{~F}$-FDG PET/CT was $52.4 \%$ and the pooled specificity was $67.8 \%$. In conclusion, the sensitivity and specificity of interim ${ }^{18} \mathrm{~F}-\mathrm{FDG}$ PET/CT in predicting the outcome of DLBCL patients treated with R-CHOP chemotherapy were not satisfactory. To improve this, some more work should be done to unify the response criteria and some more research to assess the prognostic value of interim ${ }^{18} \mathrm{~F}$-FDG PET/CT with semi-quantitative analysis.

Ziakas et al. [12] assessed the diagnostic performance of interim ${ }^{18} \mathrm{~F}$-FDG PET with regard to the final outcome of adult patients with newly diagnosed HL. The pooled sensitivity was $67 \%$ (95\%CI: $57-76 \%$ ) and pooled specificity was 89\% (95\%CI: 84-93\%). The estimated negative predictive value was 93\% (95\%CI: $85-100 \%$ ). The diagnostic performance was influenced by most covariates tested, including age, duration of follow-up, criteria used and time of interim PET. In conclusion, the use of a PET-positive study as a surrogate marker was hampered by inconsistent interpretation criteria and study populations. However, the high negative predictive value may permit treatment stratification based on a negative outcome.

\section{$9.4 \quad{ }^{18}$ F-FDG PET or PET/CT in Prognosis/Outcome Evaluation}

\subsubsection{Hodgkin and Non-Hodgkin Lymphomas}

Wang et al. [13] carried out a meta-analysis to detect the prognostic power of ${ }^{18} \mathrm{~F}-\mathrm{FDG}$ PET in the evaluation of pre-stem cell transplantation (SCT) and post-SCT in HL and NHL. For the
pre-SCT PET or PET/CT, the combined hazard ratios (HRs) of PET for progression-free survival (PFS) and overall survival (OS) were 2.32 and 2.64, respectively. Subgroup analysis showed that the HRs of PFS for HL and NHL were 3.28 and 2.0, respectively. For the post-SCT PET scan, the combined HR for PFS was 4.61. The authors found that ${ }^{18} \mathrm{~F}$-FDG PET was especially effective in predicting pre-STC and post-STC prognosis. The patients with a negative PET scan had a better prognosis compared with those with a positive scan for PFS and OS. In the subgroup analysis, ${ }^{18}$ F-FDG PET had a higher value in predicting prognosis before SCT for HL patients.

Burggraaff et al. [14] aimed to assess the predictive value of visually assessed interim ${ }^{18} \mathrm{~F}$ FDG PET on PFS or event-free survival (EFS) in DLBCL patients treated with first-line immunochemotherapy regimens. The pooled HR was $3.13(95 \%$ CI $2.52-3.89)$ with a $95 \%$ prediction interval of $1.68-5.83$. The negative predictive value for progression generally exceeded $80 \%$, but sensitivity, specificity and positive predictive values ranged widely. These findings showed that interim ${ }^{18} \mathrm{~F}$-FDG PET has predictive value in DLBCL patients. Some diagnostic test characteristics were not satisfactory, especially the positive predictive value should be improved before a successful risk stratified treatment approach can be implemented in clinical practice.

Adams et al. [15] systematically reviewed and meta-analysed the prognostic value of complete remission status at end-of-treatment ${ }^{18} \mathrm{~F}-\mathrm{FDG}$ PET in DLBCL patients treated with R-CHOP. The disease relapse rate among all patients with complete remission status according to end-of-treatment ${ }^{18} \mathrm{~F}$-FDG PET ranged from 7 to $20 \%$, with a weighted summary proportion of $13.7 \%$. In conclusion, a non-negligible proportion of R-CHOP-treated DLBCL patients who achieve complete remission according to end-of-treatment ${ }^{18} \mathrm{~F}$-FDG PET experiences disease relapse during follow-up.

Adams et al. [16] analysed the prognostic value of interim ${ }^{18} \mathrm{~F}$-FDG PET in DLBCL patients treated with R-CHOP. At multivariable analysis, two studies reported interim ${ }^{18} \mathrm{~F}-\mathrm{FDG}$ PET to have independent prognostic value in addition to the International Prognostic Index (IPI) in pre- 
dicting treatment failure, whereas three studies reported that this was not the case. One study reported interim 18F-FDG PET to have independent prognostic value in addition to the IPI in predicting death, whereas two studies reported that this was not the case. In conclusion, interim ${ }^{18} \mathrm{~F}$-FDG-PET in R-CHOP-treated DLBCL has some correlation with outcome, but its prognostic value is homogeneously sub-optimal across studies and it has not consistently proven to surpass the prognostic potential of the IPI. Therefore, at present there is no scientific base to support the clinical use of interim ${ }^{18} \mathrm{~F}$-FDG-PET in R-CHOPtreated DLBCL.

Zhu et al. [17] analysed the prognostic value of interim ${ }^{18} \mathrm{~F}$-FDG PET in DLBCL patients treated with rituximab-based immunochemotherapy. The pooled HR comparing PFS between patients with positive and negative results was $2.96(95 \%$ CI $=2.25-3.89)$. The patients in interim ${ }^{18} \mathrm{~F}-\mathrm{FDG}$ PET-negative group had a higher complete response (CR) rates than those in interim ${ }^{18} \mathrm{~F}$-FDG PET-positive group (relative risk $=5.53,95 \% \mathrm{CI}=2.59-11.8$ ). The authors concluded that consistent evidence favouring interim ${ }^{18} \mathrm{~F}$-FDG PET-based treatment assessment should be considered in the management of patients with DLBCL.

Pyo et al. [18] evaluated post-chemotherapy response assessment in FL. The pooled HR of end-therapy ${ }^{18} \mathrm{~F}$-FDG PET and CT were 5.1 (95\%CI: 3.7-7.2) and 2.6 (95\%CI: 1.2-5.8), respectively, which implies that PET is more predictive of PFS after chemotherapy than CT. The pooled CR rates of PET- and CT-based response criteria were $75 \%$ (95\% CI: $70-79 \%$ ) and $63 \%$ (95\%CI: 53-73\%), respectively, which implies that PET is more efficient in distinguishing CR from other states with residual disease. The authors concluded that PET-based treatment assessment should be considered in the management of patients with FL.

Liao et al. [19] evaluated the prognostic value of ${ }^{18} \mathrm{~F}$-FDG PET/CT visual interpretation in patients with aggressive NHL. PFS and OS of PET/CT-positive patients were significantly lower when determined by the visual method. In subgroup analysis, International Harmonization Project (IHP), Deauville criteria, and having no standard interpretation groups were factors able to predict PFS; IHP and having no standard interpretation group were able to predict OS. With PET/CT, IHP and Deauville 5-point criteria, the PFS of patients receiving 2-4 cycles of chemotherapy before PET/CT was significantly lower than that of PET/CT-negative patients. No significant difference in OS was observed when patients received 3 or fewer cycles of chemotherapy before PET/CT, though OS was significantly lower in patients receiving more than 3 chemotherapy cycles. They concluded that interim PET/ CT analysis after 3-4 chemotherapy cycles is capable of predicting disease prognosis in aggressive NHL.

Adams et al. [20] aimed to analyse the value of pretransplant ${ }^{18} \mathrm{~F}$-FDG PET in predicting outcome after autologous stem cell transplantation in aggressive NHL. Pooled sensitivity and specificity of ${ }^{18} \mathrm{~F}$-FDG PET were 54 and $73.1 \%$ in predicting treatment failure, and 54.5 and $68.7 \%$ in predicting death. They concluded that pretransplant ${ }^{18} \mathrm{~F}$-FDG PET cannot be recommended in aggressive NHL, because available studies suffer from major methodological flaws, and reported prognostic estimates are low.

Zhu et al. [21] aimed to determine the prognostic value of interim and final ${ }^{18} \mathrm{~F}$-FDG PET in NHL patients treated with rituximab-containing chemotherapy. The combined HRs of interim PET for PFS and OS in DLBCL were 4.4 $(p=0.11)$ and $3.99(p=0.46)$, respectively. The combined HRs of final PET for PFS and OS in DLBCL were $5.91(p=0.39)$ and $6.75(p=0.92)$, respectively. Regarding non-DLBCL with final PET, the combined HRs of final PET for PFS and OS were $4.05(p=0.79)$ and $5.1(p=0.51)$, respectively. In conclusion, in DLBCL, both interim and final PET can be performed for survival and progression analysis. But in other NHL, it would be necessary to perform final PET for predictive purposes.

Adams et al. [22] aimed to systematically review and meta-analyse the value of interim ${ }^{18} \mathrm{~F}-$ FDG PET in predicting treatment failure in HL. The area under the summary ROC curve was 0.877. Pooled sensitivity and specificity were 70.8\% (95\%CI: 64.7-76.4\%) and 89.9\% (95\%CI: $88-91.6 \%)$. The overall prognostic value of 
interim PET appeared to be moderate for excluding and relatively high for identifying treatment failure in HL. However, they stated that interim PET cannot yet be implemented in routine clinical practice due to moderate-quality evidence and inter-study heterogeneity that cannot be fully explained yet.

Sickinger et al. [23, 24] assessed the effects of interim ${ }^{18} \mathrm{~F}$-FDG PET treatment modification in individuals with HL. PFS was shorter in participants with PET-adapted therapy (without radiotherapy) than in those receiving standard treatment with radiotherapy (HR: 2.38; 95\%CI: 1.62-3.5). This difference was also apparent in comparisons of participants receiving no additional radiotherapy (PET-adapted therapy) versus radiotherapy (HR: 1.86 (95\%CI: 1.07-3.23) and in those receiving chemotherapy but no radiotherapy (PET-adapted therapy) versus standard radiotherapy (HR: 3.0; 95\%CI: 1.75-5.14). Overall, this systematic review found moderatequality evidence that PFS was shorter in individuals with early-stage HL and a negative PET receiving chemotherapy only (PET-adapted therapy) than in those receiving additional radiotherapy (standard therapy). It was still uncertain whether PET-positive individuals benefit from PET-based treatment adaptation and the effect of such an approach in those with advanced HL.

Adams et al. [25] aimed to systematically review the prognostic value of pretransplant ${ }^{18} \mathrm{~F}-$ FDG PET in refractory/relapsed HL treated with autologous stem cell transplantation (SCT). Pooled sensitivity and specificity of pretransplant ${ }^{18} \mathrm{~F}-\mathrm{FDG}$ PET in predicting treatment failure (i.e. either progressive, residual, or relapsed disease) were $67.2 \%$ (95\%CI: $58.2-75.3 \%$ ) and $70.7 \%$ (95\%CI: 64.2-76.5\%), respectively. Pooled sensitivity and specificity of pretransplant ${ }^{18} \mathrm{~F}-\mathrm{FDG}$ PET in predicting death during follow-up were $74.4 \%$ (95\%CI: $58.8-86.5 \%$ ) and 58\% (95\%CI: $49.3-66.3 \%$ ), respectively. In conclusion, the moderate quality of evidence suggested pretransplant ${ }^{18} \mathrm{~F}$-FDG-PET to have value in predicting outcome in refractory/relapsed HL patients treated with autologous SCT. Nevertheless, a considerable proportion of pretransplant ${ }^{18} \mathrm{~F}-$ FDG PET-positive patients remained disease free and a considerable proportion of pretransplant ${ }^{18}$ F-FDG PET-negative patients developed disease relapse after autologous SCT.

Adams et al. [26] systematically reviewed and meta-analysed the outcome of HL patients with a post-treatment ${ }^{18} \mathrm{~F}$-FDG PET-negative residual mass. The disease relapse rate in HL patients with a ${ }^{18} \mathrm{~F}$-FDG PET-negative residual mass after first-line therapy was approximately $6.8 \%$. They concluded that the presence of a non- ${ }^{18} \mathrm{~F}-\mathrm{FDG}-$ avid residual mass has not been proven yet to be associated with a worse outcome than a posttreatment ${ }^{18} \mathrm{~F}$-FDG-PET-based complete remission status without a residual mass.

The same group [27] analysed the prognostic value of complete remission status at ${ }^{18} \mathrm{~F}-\mathrm{FDG}$ PET in HL after completion of first-line therapy. The pooled disease relapse rate during follow-up among all patients with complete remission status at end-of-treatment ${ }^{18} \mathrm{~F}$-FDG-PET was $7.5 \%$ (95\%CI: $3.9-13.8 \%$ ). They concluded that, although the disease relapse rate in HL patients who achieve an ${ }^{18} \mathrm{~F}$-FDG PET-based complete remission after first-line therapy is low, it is actually high when considering the generally favourable outcome of HL.

\subsubsection{Multiple Myeloma}

Caldarella et al. [28] aimed to evaluate the usefulness of ${ }^{18} \mathrm{~F}-\mathrm{FDG}$ PET or PET/CT in monitoring response to treatment in patients with MM. Based on the findings from the literature, ${ }^{18} \mathrm{~F}-\mathrm{FDG}$ PET or PET/CT appeared to be useful in the assessment of treatment response in patients with MM. In particular, PET or PET/CT could detect the response to treatment earlier than other imaging. Negative findings on posttreatment ${ }^{18} \mathrm{~F}$-FDG PET or PET/CT were mostly correlated with complete clinical and histological remission or, at least, low risk of recurrences or disease progression. Persistence of metabolically active lesions was related to shorter overall and event-free survival. Therefore, post-treatment ${ }^{18}$ F-FDG PET findings could be of higher prognostic significance than standard response monitoring methods. In the near future, ${ }^{18} \mathrm{~F}$-FDG PET 
or PET/CT will be used even more in the assessment of metabolic response after treatment in patients with MM, as a guidance for clinical decision and to eventually decide for alternative therapies in non-responding patients.

\subsection{Prognostic Role of Semi- quantitative PET Parameters}

Guo et al. [29] have analysed whether baseline metabolic tumour volume (MTV) and total lesion glycolysis (TLG) measured by ${ }^{18} \mathrm{~F}$-FDG PET/CT affect prognosis of patients with lymphoma. Patients with high baseline MTV showed a worse prognosis considering PFS and OS as well as patients with high baseline TLG. A high baseline MTV was significantly associated with worse survival in DLBCL patients treated with R-CHOP as well as a high baseline TLG. The negative effect of high baseline MTV on PFS was demonstrated in HL. A high baseline MTV was significantly associated with worse survival in ENKTL patients. A high baseline TLG was significantly associated with worse survival in ENKL patients. The authors concluded that high baseline MTV or TLG predict significantly worse PFS and OS in patients with lymphoma.

Wang et al. [30] evaluated the prognostic value of maximum standardized uptake value (SUVmax), MTV, and TLG of baseline, interim and end-of-treatment ${ }^{18} \mathrm{~F}$-FDG PET/CT parameters in ENKTL. SUVmax, MTV and TLG on baseline PET/CT were significantly associated with PFS and with OS. For the delta SUV (DS) on interim PET/CT, the HRs for PFS and OS were 5.15 (95\% CI 2.71-9.80) and 5.8 (95\%CI 2.28-14.73), respectively. Similarly, the DS on end-of-treatment PET/CT was a significant predictor of PFS and OS with HRs of 3.65 (95\%CI: 2.13-6.26) and 3.32 (95\%CI: 1.79-6.15), respectively. They suggested that SUVmax, MTV, TLG on baseline PET/CT, DS on interim PET/CT and DS on end-of-treatment PET/CT may be significant prognostic indicators for PFS and OS in ENKTL patients. Moreover, TLG tended to be superior to SUVmax and MTV on baseline PET/ CT for predicting survival of ENKTL patients.
Therefore, response monitoring and prognostication assessments based on multiple PET/CT parameters should be considered in the management of ENKTL patients.

Xie et al. [31] analysed whether SUVmax, MTV and TLG acquired from ${ }^{18} \mathrm{~F}$-FDG PET/CT are predictors of prognosis of DLBCL. Combined results suggested a strong link between the high SUVmax, MTV and TLG values and the poor 3-year PFS with ORs of 2.59, 3.69 and 2.29, respectively. Similarly, high MTV and TLG values unfavourably influenced the 3-year OS with ORs of 5.40 and 2.19, respectively. The pooled results also showed that high SUVmax and MTV were negative predictors of PFS. The TLG value was not predictive of PFS. And for OS, only high MTV was a strong predictor of poor prognosis in DLBCL. Their results suggested that SUVmax and MTV may be significant prognostic markers for PFS and MTV may be the only predictor for OS in DLBCL.

\section{$9.6{ }^{18}$ F-FDG PET or PET/CT in Comparison with Magnetic Resonance Imaging}

Wang et al. [32] aimed to compare the performance of whole-body magnetic resonance imaging (WB-MRI) with that of ${ }^{18} \mathrm{~F}$-FDG PET/CT for lesion detection and initial staging in patients with aggressive or indolent lymphoma. In terms of staging, the pooled accuracy of WB-MRI and ${ }^{18} \mathrm{~F}-\mathrm{FDG}$ PET/CT for HL and aggressive NHL were 98\% (95\%CI: $94-100 \%)$ and 98\% (95\%CI: 94-100\%), respectively. The pooled accuracy of ${ }^{18} \mathrm{~F}-\mathrm{FDG}$ PET/CT dropped to $87 \%$ (95\% CI: 72-97\%) for staging in patients with indolent lymphoma, whereas that of WB-MRI remained 96\% (95\%CI: 91-100\%). Subgroup analysis indicated an even lower accuracy of ${ }^{18} \mathrm{~F}-\mathrm{FDG}$ PET/CT for staging of less ${ }^{18} \mathrm{~F}-\mathrm{FDG}$-avid indolent NHLs (60\%; 95\% CI: 23-92\%), in contrast to the superior performance of WB-MRI (98\%; 95\%CI: $88-100 \%)$. The authors concluded that WB-MRI is a promising radiation-free imaging technique that may serve as a viable alternative to 
${ }^{18}$ F-FDG PET/CT for staging of ${ }^{18} \mathrm{~F}-\mathrm{FDG}$-avid lymphomas, where ${ }^{18} \mathrm{~F}$-FDG $\mathrm{PET} / \mathrm{CT}$ remains the standard of care. Additionally, WB-MRI seemed a less histology-dependent functional imaging test than ${ }^{18} \mathrm{~F}-\mathrm{FDG}$ PET/CT and may be the imaging test of choice for staging of indolent NHLs with low ${ }^{18}$ F-FDG avidity.

Regacini et al. [33] aimed to compare WB-MRI with ${ }^{18} \mathrm{~F}$-FDG PET/CT for lymphoma staging. WB-MRI and ${ }^{18} \mathrm{~F}-\mathrm{FDG}-\mathrm{PET} / \mathrm{CT}$ agreed in $90.5 \%$ of the cases. In most of the studies, when there was disagreement between the methods, WB-MRI overstaged in relation to ${ }^{18} \mathrm{~F}-\mathrm{FDG}$ PET/CT. The sensitivity of WB-MRI and ${ }^{18} \mathrm{~F}-\mathrm{FDG}$ PET/CT, in comparison with the clinical-radiological standard, ranged from 59 to $100 \%$ and from 63 to $100 \%$, respectively. The authors concluded that WB-MRI has excellent agreement with ${ }^{18} \mathrm{~F}-\mathrm{FDG}$ $\mathrm{PET} / \mathrm{CT}$ and is a great alternative for managing lymphoma patients, without using ionizing radiation or an intravenous contrast agent.

Gariani et al. [34] evaluated the diagnostic performance of WB-MRI including diffusion weighted sequences (DWI) compared to wholebody $\mathrm{CT}$ or ${ }^{18} \mathrm{~F}-\mathrm{FDG} \mathrm{PET} / \mathrm{CT}$ in patients with MM. WB-MRI detected more lesions than ${ }^{18} \mathrm{~F}-$ FDG PET/CT (sensitivity 68-100\% versus 47-100\%) but was less specific (specificity $37-83 \%$ versus 62-85.7\%). Despite these insights the authors concluded that, because of the heterogeneity of the studies, future prospective trials should assess the impact of WB-MRI on management of MM.

Weng et al. [35] conducted a systematic review of the published literature to evaluate the diagnostic accuracy of ${ }^{18} \mathrm{~F}$-FDG PET, ${ }^{18} \mathrm{~F}$-FDG $\mathrm{PET} / \mathrm{CT}, \mathrm{MRI}$ and scintigraphy for MM-related bone disease. For ${ }^{18} \mathrm{~F}$-FDG PET and PET/CT, pooled sensitivity and specificity were $91 \%$ and $69 \%$, respectively. Statistically significant differences were not found in the sensitivity and specificity between MRI, scintigraphy, ${ }^{18}$ F-FDG-PET and PET/CT. In conclusion, the authors suggested that ${ }^{18} \mathrm{~F}-\mathrm{FDG}-\mathrm{PET}$, PET/CT, MRI and scintigraphy are all associated with high detection rate of bone disease in patients with MM. Thus, in clinical practice, it is recommended that we could choose these tests according to the condition of the patient.

\subsection{Conclusions}

Overall, ${ }^{18} \mathrm{~F}-\mathrm{FDG}$ PET or PET/CT appears to be a useful and accurate diagnostic tool for haematological malignancies in clinical practice from an "evidence-based" point of view. Some topics and results need further investigations in order to overcome methodological limits and clarify the real diagnostic role of this tool and its more appropriate position in the diagnostic flow chart.

\section{References}

1. Montes de Jesus FM, Kwee TC, Nijland M, Kahle XU, Huls G, Dierckx RAJO, et al. Performance of advanced imaging modalities at diagnosis and treatment response evaluation of patients with posttransplant lymphoproliferative disorder: a systematic review and meta-analysis. Crit Rev Oncol Hematol. 2018;132:27-38.

2. Adams HJ, Nievelstein RA, Kwee TC. Systematic review on the additional value of $18 \mathrm{~F}$-fluoro-2-deoxyD-glucose positron emission tomography in staging follicular lymphoma. J Comput Assist Tomogr. 2017;41:98-103.

3. Treglia G, Zucca E, Sadeghi R, Cavalli F, Giovanella L, Ceriani L. Detection rate of fluorine-18fluorodeoxyglucose positron emission tomography in patients with marginal zone lymphoma of MALT type: a meta-analysis. Hematol Oncol. 2015;33:113-24.

4. Adams HJ, Kwee TC, de Keizer B, Fijnheer R, de Klerk JM, Nievelstein RA. FDG PET/CT for the detection of bone marrow involvement in diffuse large B-cell lymphoma: systematic review and meta-analysis. Eur J Nucl Med Mol Imaging. 2014;41:565-74.

5. Adams HJ, Kwee TC, de Keizer B, Fijnheer R, de Klerk JM, Littooij AS, et al. Systematic review and meta-analysis on the diagnostic performance of FDG$\mathrm{PET} / \mathrm{CT}$ in detecting bone marrow involvement in newly diagnosed Hodgkin lymphoma: is bone marrow biopsy still necessary? Ann Oncol. 2014;25:921-7.

6. Cheng G, Alavi A. Value of 18F-FDG PET versus iliac biopsy in the initial evaluation of bone marrow infiltration in the case of Hodgkin's disease: a metaanalysis. Nucl Med Commun. 2013;34:25-31.

7. Ji J, Liu XH, She NN, Li L, Zhang XB. Value of 18 FFDG PET/CT and PET in diagnosing and staging extranodal nasal type natural killer/T-cell lymphoma: a meta-analysis. Lin Chung Er Bi Yan Hou Tou Jing Wai Ke Za Zhi. 2018;32:1876-82.

8. Zhou X, Lu K, Geng L, Li X, Jiang Y, Wang X. Utility of PET/CT in the diagnosis and staging of extranodal natural killer/T-cell lymphoma: a systematic review and meta-analysis. Medicine. 2014;93:e258.

9. Lu YY, Chen JH, Lin WY, Liang JA, Wang HY, Tsai $\mathrm{SC}$, et al. FDG PET or PET/CT for detecting intra- 
medullary and extramedullary lesions in multiple myeloma: a systematic review and meta-analysis. Clin Nucl Med. 2012;37:833-7.

10. Adams HJA, Kwee TC. Proportion of false-positive lesions at interim and end-of-treatment FDG-PET in lymphoma as determined by histology: systematic review and meta-analysis. Eur J Radiol. 2016;85:1963-70.

11. Sun N, Zhao J, Qiao W, Wang T. Predictive value of interim PET/CT in DLBCL treated with R-CHOP: meta-analysis. Biomed Res Int. 2015;2015:648572.

12. Ziakas PD, Poulou LS, Voulgarelis M, Thanos L. The Gordian knot of interim 18-fluorodeoxyglucose positron emission tomography for Hodgkin lymphoma: a meta-analysis and commentary on published studies. Leuk Lymphoma. 2012;53:2166-74.

13. Wang C, Li P, Wu S, Lu J, Liu Q, Luo H, et al. The role of fluorine-18 fluorodeoxyglucose PET in prognosis evaluation for stem cell transplantation of lymphoma: a systematic review and meta-analysis. Nucl Med Commun. 2016;37:338-47.

14. Burggraaff $\mathrm{CN}$, de Jong A, Hoekstra OS, Hoetjes NJ, Nievelstein RAJ, Jansma EP, et al. Predictive value of interim positron emission tomography in diffuse large B-cell lymphoma: a systematic review and meta-analysis. Eur J Nucl Med Mol Imaging. 2019;46:65-79.

15. Adams HJ, Nievelstein RA, Kwee TC. Prognostic value of complete remission status at end-of-treatment FDG-PET in R-CHOP-treated diffuse large B-cell lymphoma: systematic review and meta-analysis. $\mathrm{Br}$ J Haematol. 2015;170:185-91.

16. Adams HJ, Kwee TC. Prognostic value of interim FDG-PET in R-CHOP-treated diffuse large B-cell lymphoma: systematic review and meta-analysis. Crit Rev Oncol Hematol. 2016;106:55-63.

17. Zhu D, Xu XL, Fang C, Ji M, Wu J, Wu CP, et al. Prognostic value of interim (18)F-FDG-PET in diffuse large B cell lymphoma treated with rituximab-based immune-chemotherapy: a systematic review and meta-analysis. Int J Clin Exp Med. 2015;8:15340-50.

18. Pyo J, Won Kim K, Jacene HA, Sakellis CG, Brown JR, Van den Abbeele AD. End-therapy positron emission tomography for treatment response assessment in follicular lymphoma: a systematic review and metaanalysis. Clin Cancer Res. 2013;19:6566-77.

19. Liao CC, Qin YY, Tan XH, Hu JJ, Tang Q, Rong Y, et al. Predictive value of interim PET/CT visual interpretation in the prognosis of patients with aggressive non-Hodgkin's lymphoma. Onco Targets Ther. 2017;10:5727-38.

20. Adams HJ, Kwee TC. Pretransplant FDG-PET in aggressive non-Hodgkin lymphoma: systematic review and meta-analysis. Eur J Haematol. 2017;98:337-47.

21. Zhu Y, Lu J, Wei X, Song S, Huang G. The predictive value of interim and final $[18 \mathrm{~F}]$ fluorodeoxyglucose positron emission tomography after rituximabchemotherapy in the treatment of non-Hodgkin's lymphoma: a meta-analysis. Biomed Res Int. 2013;2013:275805.
22. Adams HJ, Nievelstein RA, Kwee TC. Prognostic value of interim FDG-PET in Hodgkin lymphoma: systematic review and meta-analysis. Br J Haematol. 2015;170:356-66.

23. Sickinger MT, von Tresckow B, Kobe C, Engert A, Borchmann P, Skoetz N. Positron emission tomography-adapted therapy for first-line treatment in individuals with Hodgkin lymphoma. Cochrane Database Syst Rev. 2015;1:CD010533.

24. Sickinger MT, von Tresckow B, Kobe C, Borchmann P, Engert A, Skoetz N. PET-adapted omission of radiotherapy in early stage Hodgkin lymphoma-a systematic review and meta-analysis. Crit Rev Oncol Hematol. 2016;101:86-92.

25. Adams HJ, Kwee TC. Prognostic value of pretransplant FDG-PET in refractory/relapsed Hodgkin lymphoma treated with autologous stem cell transplantation: systematic review and meta-analysis. Ann Hematol. 2016;95:695-706.

26. Adams HJ, Nievelstein RA, Kwee TC. Outcome of Hodgkin lymphoma patients with a posttreatment 18F-fluoro-2-deoxy-d-glucose positron emission tomography (FDG-PET)-negative residual mass: systematic review and meta-analysis. Pediatr Hematol Oncol. 2015;32:515-24.

27. Adams HJ, Nievelstein RA, Kwee TC. Systematic review and meta-analysis on the prognostic value of complete remission status at FDG-PET in Hodgkin lymphoma after completion of first-line therapy. Ann Hematol. 2016;95:1-9.

28. Caldarella C, Isgrò MA, Treglia I, Treglia G. Is fluorine-18-fluorodeoxyglucose positron emission tomography useful in monitoring the response to treatment in patients with multiple myeloma? Int J Hematol. 2012;96:685-91.

29. Guo B, Tan X, Ke Q, Cen H. Prognostic value of baseline metabolic tumor volume and total lesion glycolysis in patients with lymphoma: a meta-analysis. PLoS One. 2019; 14:e0210224.

30. Wang H, Shen G, Jiang C, Li L, Cui F, Tian R. Prognostic value of baseline, interim and end-oftreatment $18 \mathrm{~F}-\mathrm{FDG}$ PET/CT parameters in extranodal natural killer/T-cell lymphoma: a meta-analysis. PLoS One. 2018;13:e0194435.

31. Xie M, Wu K, Liu Y, Jiang Q, Xie Y. Predictive value of F-18 FDG PET/CT quantization parameters in diffuse large B cell lymphoma: a meta-analysis with 702 participants. Med Oncol. 2015;32:446.

32. Wang D, Huo Y, Chen S, Wang H, Ding Y, Zhu X, et al. Whole-body MRI versus $18 \mathrm{~F}-F D G$ PET/CT for pretherapeutic assessment and staging of lymphoma: a meta-analysis. Onco Targets Ther. 2018;11:3597-608.

33. Regacini R, Puchnick A, Shigueoka DC, Iared W, Lederman HM. Whole-body diffusion-weighted magnetic resonance imaging versus FDG-PET/CT for initial lymphoma staging: systematic review on diagnostic test accuracy studies. Sao Paulo Med J. 2015;133:141-50.

34. Gariani J, Westerland O, Natas S, Verma H, Cook G, Goh V. Comparison of whole body magnetic resonance imaging (WBMRI) to whole body computed 
tomography (WBCT) or 18F-fluorodeoxyglucose positron emission tomography/CT (18F-FDG PET/ $\mathrm{CT}$ ) in patients with myeloma: systematic review of diagnostic performance. Crit Rev Oncol Hematol. 2018;124:66-72.
35. Weng WW, Dong MJ, Zhang J, Yang J, Xu Q, Zhu YJ, et al. A systematic review of MRI, scintigraphy, FDGPET and PET/CT for diagnosis of multiple myeloma related bone disease-which is best? Asian Pac J Cancer Prev. 2014;15:9879-84.

Open Access This chapter is licensed under the terms of the Creative Commons Attribution 4.0 International License (http://creativecommons.org/licenses/by/4.0/), which permits use, sharing, adaptation, distribution and reproduction in any medium or format, as long as you give appropriate credit to the original author(s) and the source, provide a link to the Creative Commons license and indicate if changes were made.

The images or other third party material in this chapter are included in the chapter's Creative Commons license, unless indicated otherwise in a credit line to the material. If material is not included in the chapter's Creative Commons license and your intended use is not permitted by statutory regulation or exceeds the permitted use, you will need to obtain permission directly from the copyright holder. 


\title{
Evidence-Based PET for Endocrine Tumours and Disorders
}

\author{
Alexander Stephan Kroiss and Giorgio Treglia
}

\subsection{Introduction}

Endocrine tumours have a wide range of clinical presentations and can be found anywhere from the neck to the pelvis. Diagnostic imaging is crucial to predict the exact tumour extent, foremost in metastatic disease. Anatomical imaging as computed tomography (CT) and magnetic resonance imaging (MRI) serves as the first-line modality in the locoregional staging of these tumours. Compared with anatomical imaging, PET shows both high sensitivity and specificity. Several meta-analyses have described the diagnostic performance of positron emission tomography (PET) and hybrid imaging (PET/CT) in endocrine tumours and disorders.

\footnotetext{
A. S. Kroiss $(\square)$

Department of Nuclear Medicine, Medical University Innsbruck, Innsbruck, Austria

e-mail: alexander.kroiss@i-med.ac.at

\section{G. Treglia}

Clinic of Nuclear Medicine and PET/CT Center, Imaging Institute of Southern Switzerland, Ente Ospedaliero Cantonale,

Bellinzona and Lugano, Switzerland

Health Technology Assessment Unit, Ente Ospedaliero Cantonale, Bellinzona, Switzerland

Department of Nuclear Medicine and Molecular Imaging, Lausanne University Hospital and University of Lausanne, Lausanne, Switzerland e-mail: giorgio.treglia@eoc.ch
}

\subsection{Adrenal Tumours and Paragangliomas}

\subsubsection{Characterization of Adrenal Masses}

Dinnes and colleagues reviewed the evidence on the accuracy of imaging tests for differentiating malignant from benign adrenal masses. They concluded that CT density $>10$ Hounsfield Unit (HU) offers high sensitivity for detection of adrenal malignancy in participants with no prior indication for adrenal imaging. With respect to a limited database and heterogeneity and low quality of included studies for meta-analysis, the authors concluded that there is insufficient evidence for the diagnostic value of individual imaging tests in distinguishing benign from malignant adrenal masses [1].

Kim and colleagues explored the role of the diagnostic accuracy of ${ }^{18} \mathrm{~F}$-FDG PET or PET/CT for characterization of adrenal lesions [2]. The pooled sensitivity for ${ }^{18} \mathrm{~F}-\mathrm{FDG}$ PET or PET/CT was $91 \%$ (95\% confidence interval $(95 \% \mathrm{CI})$ : $88-94 \%$ ) and the pooled specificity was $91 \%$ (95\%CI: 87-93\%). Although, at present, the literature regarding the use of ${ }^{18} \mathrm{~F}-\mathrm{FDG}$ PET or PET/CT for the characterization of adrenal masses remains limited, ${ }^{18} \mathrm{~F}-\mathrm{FDG}$ PET or PET/ CT demonstrated good sensitivity and specificity for the characterization of adrenal masses. 


\subsubsection{Paragangliomas}

Rufini and co-authors compared the diagnostic performance of metaiodobenzylguanidine (MIBG scintigraphy) and PET with different radiopharmaceuticals in patients with paraganglioma (PGL). The authors concluded that the diagnostic performance of PET with different radiopharmaceuticals is clearly superior to that of MIBG scintigraphy in patients with PGL, mainly for familial, extra-adrenal and metastatic diseases [3].

A review article by Treglia and co-authors investigated the diagnostic performance of ${ }^{18} \mathrm{~F}$-DOPA PET in patients with paraganglioma (PGL). The pooled sensitivity of ${ }^{18} \mathrm{~F}-\mathrm{DOPA}$ PET and PET/CT in detecting PGL was $91 \%$ (95\%CI: $87-94 \%$ ) on a per-patient-based analysis and 79\% (95\% CI 76-81\%) on a per-lesionbased analysis. The pooled specificity of ${ }^{18} \mathrm{~F}$-DOPA PET and PET/CT in detecting PGL was 95\% (95\%CI: 86-99\%) on a per-patientbased analysis and 95\% (95\%CI: 84-99\%) on a per-lesion-based analysis. The area under the receiver operating characteristic (ROC) curve was 0.95 on a per-patient- and 0.94 on a perlesion-based analysis. The authors described the possible risk of false-negative ${ }^{18} \mathrm{~F}$-DOPA PET results in metastatic PGL, besides the fact that succinate dehydrogenase subunit B (SDHB) gene mutations could influence the diagnostic performance of ${ }^{18} \mathrm{~F}-\mathrm{DOPA}$ PET or PET/CT [4].

Kan and colleagues performed a meta-analysis on the localization of metastatic pheochromocytoma (PHEO) and PGL with germline mutations, comparing ${ }^{68} \mathrm{Ga}$-somatostatin analogues and ${ }^{18} \mathrm{~F}$ FDG PET/CT. The pooled sensitivity of ${ }^{68} \mathrm{Ga}$ peptides and ${ }^{18} \mathrm{~F}-\mathrm{FDG}$ PET were $95 \%$ (95\%CI:92-97) and 85\% (95\%CI:78-91\%), respectively. The pooled specificity of ${ }^{68} \mathrm{Ga}$ peptides and ${ }^{18} \mathrm{~F}-\mathrm{FDG}$ PET were $87 \%$ (95\%CI: 63-96\%) and 55\% (95\%CI:37-73\%), respectively. The authors concluded that ${ }^{68} \mathrm{Ga}$-somatostatin analogues PET/CT demonstrated good performance in the localization of metastatic PGL, especially those with germline mutations, compared to ${ }^{18} \mathrm{~F}-\mathrm{FDG}$ PET/CT [5].

Han and colleagues performed a systematic review and meta-analysis on the performance of ${ }^{68} \mathrm{Ga}$-somatostatin analogues PET in the detection of PGL. The pooled detection rate was $93 \%$ (95\%CI: 91-95\%), which was significantly higher than that of ${ }^{18} \mathrm{~F}-\mathrm{DOPA}$ PET $(80 \%$; $95 \% \mathrm{CI}$ : 69-88\%), ${ }^{18} \mathrm{~F}-\mathrm{FDG}$ PET (74\%; 95\%CI: 46-91\%) and MIBG scintigraphy (38\%; 95\%CI: $20-59 \%)$. A greater prevalence of head and neck PGL was associated with higher detection rates of ${ }^{68} \mathrm{Ga}$-somatostatin analogues PET. The authors suggest the use of ${ }^{68} \mathrm{Ga}$-somatostatin analogues PET as a first-line imaging modality for the primary staging or restaging of PGL with unknown genetic status [6].

\subsection{Neuroblastoma}

Bleeker and colleagues described the role of MIBG scintigraphy and ${ }^{18} \mathrm{~F}-\mathrm{FDG}$ PET for diagnosing neuroblastoma (NB). In one study, the sensitivity of ${ }^{18} \mathrm{~F}-\mathrm{FDG} \mathrm{PET} / \mathrm{CT}$ compared to MIBG scintigraphy was $100 \%$ and $92 \%$, respectively. Specificity could not be calculated for both modalities. The diagnostic accuracy of ${ }^{18} \mathrm{~F}-\mathrm{FDG}$ PET/CT imaging in case of a negative ${ }^{123} \mathrm{I}-\mathrm{MIBG}$ scintigraphy could not be calculated because of very limited data. It has to be mentioned that in about $10 \%$ of the patients with histologically proven NB the tumour does not accumulate ${ }^{123} \mathrm{I}-\mathrm{MIBG}$ which underlines the importance of additional functional/anatomical imaging (e.g. ${ }^{18}$ F-FDG PET/CT) [7].

A review article by Xia and co-authors demonstrated a summary sensitivity for MIBG scintigraphy and ${ }^{18}$ F-FDG PET(/CT) of $79 \%$ and $89 \%$, respectively. The summary specificity for MIBG scintigraphy and ${ }^{18} \mathrm{~F}-\mathrm{FDG}$ PET(/CT) was $84 \%$ and $71 \%$, respectively. The authors concluded that ${ }^{18} \mathrm{~F}$-FDG PET(/CT) showed higher per-lesion accuracy than MIBG scintigraphy and might be the preferred modality for the staging of NB [8]. 


\subsection{Merkel Cell Carcinoma}

Treglia and co-authors investigated the diagnostic performance of ${ }^{18} \mathrm{~F}-\mathrm{FDG}$ PET and PET/CT in patients with Merkel cell carcinoma (MCC). The meta-analysis provided the following pooled results on a per-examination-based analysis: sensitivity was 90\% (95\%CI: 80-96\%) and specificity was 98\% (95\%CI: 90-100\%). The area under the summary ROC curve was 0.96 . No significant statistical heterogeneity between the studies was found. The authors concluded that ${ }^{18} \mathrm{~F}$-FDG PET or PET/CT demonstrated high sensitivity and specificity, being accurate methods in the detection of MCC taking into account that literature in MCC remains limited [9].

\subsection{Gastroenteropancreatic and Pulmonary Neuroendocrine Tumours}

Singh and co-authors evaluated the diagnostic performance of ${ }^{68} \mathrm{Ga}$-somatostatin analogues PET or PET/CT on neuroendocrine tumours (NETs). For the initial diagnosis of NETs, ${ }^{68} \mathrm{Ga}$-somatostatin analogues PET or PET/CT had a pooled sensitivity of $91 \%$ (95\%CI: $85-94 \%$ ) and a pooled specificity of $94 \%(95 \% \mathrm{CI}$ : 86-98\%). In the setting of staging and restaging, the sensitivity of ${ }^{68} \mathrm{Ga}$-somatostatin analogues PET or PET/CT for detecting primary and/or metastatic lesions ranged from 78.3 to $100 \%$, whereas specificity ranged from 83 to $100 \%$. Change in management occurred in $45 \%$ (95\% CI: $36-55 \%)$ of the cases, with majority of the changes involving surgical planning and patient selection for peptide receptor radionuclide therapy [10].

This is in line with a systematic review by Barrio and colleagues who investigated the impact of ${ }^{68} \mathrm{Ga}$-somatostatin analogues PET/CT in patients with NETs. A change of management occurred in $44 \%$ of cases after ${ }^{68} \mathrm{Ga}$-somatostatin analogues PET/CT (range: 16-71\%). In some studies, ${ }^{68} \mathrm{Ga}$-somatostatin analogues PET/CT was performed after conventional scintigraphy ( ${ }^{111}$ In-Octreotide). In this subgroup, additional information led to a change in management in $39 \%$ of cases (range: $16-71 \%$ ). The authors concluded that the management was changed in more than one-third of patients undergoing ${ }^{68} \mathrm{Ga}$-somatostatin analogues PET/CT even when performed after an ${ }^{111} \mathrm{In}$-Octreotide scintigraphy [11].

In this line, another meta-analysis was published by Deppen and co-authors who compared conventional ${ }^{111}$ In-Octreotide imaging with ${ }^{68} \mathrm{Ga}$-DOTATATE PET/CT in pulmonary and gastroenteropancreatic NETs, with estimated pooled sensitivity of $90.9 \%$ (95\%CI: $81.4-96.4 \%)$ and pooled specificity of $90.6 \%$ (95\%CI: 77.8$96.1 \%$ ) for ${ }^{68} \mathrm{Ga}$-DOTATATE PET/CT [12].

The high diagnostic performance of ${ }^{68} \mathrm{Ga}$-somatostatin analogues PET or PET/CT for thoracic and gastroenteropancreatic NETs was showed by the meta-analysis of Treglia et al. reporting a pooled sensitivity and specificity of 93\% (95\% CI: 91-95\%) and 91\% (95\% CI: 82-97\%), respectively. ${ }^{68} \mathrm{Ga}$-somatostatin analogues PET/CT should be considered as first-line diagnostic imaging method for these tumours [13].

An updated meta-analysis on this regard reported a pooled sensitivity of $93 \%$ (95\% CI: $91-94 \%$ ) and a pooled specificity of $96 \%$ (95\%CI: 95-98\%) for ${ }^{68} \mathrm{Ga}$-somatostatin analogues PET or PET/CT. The area under the summary ROC curve was 0.98 , confirming the good diagnostic performance of ${ }^{68} \mathrm{Ga}$-somatostatin analogues PET or PET/CT compared to diagnostic CT and conventional scintigraphy (e.g. ${ }^{111}$ In-Octreotide) [14].

An evidence-based article compared ${ }^{68} \mathrm{Ga}$-DOTATOC and ${ }^{68} \mathrm{Ga}$-DOTATATE PET in NETs, reporting no statistically significant differences of diagnostic performance among these imaging methods on a per-patient-based analysis [15].

\subsection{Congenital Hyperinsulinism}

Paediatric patients with congenital hyperinsulinism (CHI) due to pancreatic disease can be evaluated by PET or PET/CT, in particular by using 
${ }^{18}$ F-DOPA. A systematic review and metaanalysis by Blomberg and co-authors aimed to quantify the diagnostic performance of pancreatic venous sampling (PVS), selective pancreatic arterial calcium stimulation with hepatic venous sampling (ASVS) and ${ }^{18} \mathrm{~F}$-DOPA PET in diagnosing and localizing focal form of $\mathrm{CHI}$. ${ }^{18} \mathrm{~F}$-DOPA PET was superior in distinguishing focal from diffuse CHI compared to PVS and ASVS. Furthermore, it localized focal CHI in the pancreas more accurately than PVS and ASVS (pooled accuracy: $82 \%$ vs. $76 \%$ and $64 \%$, respectively) [16].

Yang and colleagues performed a metaanalysis of published data on the diagnostic role of ${ }^{18} \mathrm{~F}$-DOPA PET in patients with CHI. The pooled sensitivity of ${ }^{18} \mathrm{~F}$-DOPA PET and PET/CT in detecting $\mathrm{CHI}$ was $88 \%$. The pooled specificity of ${ }^{18} \mathrm{~F}$-DOPA PET and PET/CT in demonstrating $\mathrm{CHI}$ was $79 \%$. The area under the ROC curve was 0.92 . The authors concluded that ${ }^{18} \mathrm{~F}$-DOPA PET or PET/CT demonstrated high sensitivity and specificity in patients with CHI [17].

These findings are in line with another metaanalysis by Treglia and co-authors: the pooled sensitivity and specificity of ${ }^{18} \mathrm{~F}$-DOPA PET or PET/CT in differentiating between focal and diffuse $\mathrm{CHI}$ were $89 \%$ (95\% CI: $81-95 \%$ ) and $98 \%$ (95\%CI: 89-100\%), respectively. The area under the ROC curve was 0.95 . The pooled accuracy of these functional imaging methods in localizing focal CHI was $80 \%$ (95\%CI: 71-88\%). Although possible sources of false-negative results for focal CHI should be kept in mind, the authors concluded that ${ }^{18} \mathrm{~F}-\mathrm{DOPA}$ PET or PET/CT are accurate methods for localizing focal CHI [18].

\subsection{Thyroid Diseases}

\subsubsection{Thyroid Incidentalomas}

Nayan and colleagues evaluated through a systematic review and meta-analysis the malignancy rates of thyroid incidentalomas identified in adults by ${ }^{18} \mathrm{FDG}$ PET/CT. The pooled proportion of malignancy was $19.8 \%$ (95\%CI: $15.3-24.7 \%$ ) with most of cases being papillary thyroid cancer.
The authors stated that thyroid incidentalomas identified through ${ }^{18} \mathrm{FDG}$ PET require thorough investigation [19].

In this context, a review article by $\mathrm{Qu}$ and coauthors was focused on focal thyroid incidentalomas (FTI) identified on ${ }^{18} \mathrm{~F}$-FDG PET or PET/ CT. A meta-analysis was performed to investigate whether the maximum standardized uptake value (SUVmax) could discriminate between benign and malignant FTI and to explore the cutoff value of SUVmax for the diagnosis of malignancy. The results of this article indicated that there was no statistically significant difference in the size between benign and malignant FTI, while a significantly higher SUVmax was observed in the malignant group. The authors concluded that a higher SUVmax in FTI was associated with a higher risk of thyroid malignancy, especially at a threshold of 3.3 or more [20].

Treglia and co-authors described the prevalence and malignancy risk of FTI detected by ${ }^{18} \mathrm{~F}-$ FDG PET or PET/CT. Pooled prevalence of FTI was $1.92 \%$ (95\%CI: $1.87-1.99 \%)$. Considering FTI which underwent histopathology evaluation, the pooled risk of malignancy was $36.2 \%$ (95\%CI: 33.8-38.6\%), without significant differences among various geographic areas. The authors concluded that FTI are observed in about $2 \%$ of ${ }^{18} \mathrm{~F}-\mathrm{FDG}$-PET or PET/CT and they should be further investigated due to a significant risk of malignancy [21].

\subsubsection{Indeterminate Thyroid Nodules}

A meta-analysis by Wang and colleagues evaluated the diagnostic accuracy of ${ }^{18} \mathrm{~F}-\mathrm{FDG}$ PET or $\mathrm{PET} / \mathrm{CT}$ in discriminating between malignant and benign lesions in thyroid nodules with indeterminate fine needle aspiration biopsy (FNAB). The prevalence of malignant lesions in these patients was $26.2 \%$ (ranging from 19.6 to $40 \%$ ). The pooled sensitivity and specificity of ${ }^{18} \mathrm{~F}-\mathrm{FDG}$ PET or PET/CT for the detection of cancer were $89.0 \%$ (95\% CI: $79.0-95 \%$ ) and 55\% (95\% CI: 48-62\%), respectively. Although SUVmax was 
higher in malignant lesions, there was still a great overlap with benign lesions. In conclusion, ${ }^{18} \mathrm{~F}-$ FDG PET or PET/CT showed a high sensitivity in detecting thyroid cancers in patients with indeterminate FNAB results [22].

\subsubsection{Recurrence of Differentiated Thyroid Cancer}

A meta-analysis by Haslerud and co-authors described the role of ${ }^{18} \mathrm{~F}$-FDG PET in recurrent differentiated thyroid cancer (DTC) after total thyroidectomy and radioiodine ablative therapy. Pooled sensitivity and specificity of this method in detecting recurrent DTC were $79.4 \%$ (95\%CI: 73.9-84.1\%) and 79.4\% (95\%CI: 71.2-85.4\%), respectively, with an area under the ROC curve of 0.858. The authors concluded that this method can be useful for detecting recurrent DTC in patients having undergone radioiodine ablative therapy [23].

A meta-analysis by Caetano and co-authors aimed to evaluate the accuracy of ${ }^{18} \mathrm{~F}$-FDG PET and PET/CT for detecting recurrence of DTC, not identified by ${ }^{131} \mathrm{I}$ whole-body scintigraphy (I-WBS). The combined sensitivity, specificity and accuracy for ${ }^{18} \mathrm{~F}$-FDG PET were $84 \%, 84 \%$ and $91 \%$, respectively; for ${ }^{18} \mathrm{~F}-\mathrm{FDG}$ PET/CT, the combined sensitivity, specificity and accuracy were $93 \%, 81 \%$ and $93 \%$ respectively [24].

Another meta-analysis by Schütz and coauthors about the use of ${ }^{18} \mathrm{~F}$-FDG PET and PET/ CT for detecting recurrent DTC demonstrated that ${ }^{18} \mathrm{~F}-\mathrm{FDG}$ PET and PET/CT showed higher sensitivity (89.7\% for PET and $94.3 \%$ for PET/ CT) compared with conventional imaging $(65.4 \%)$ and comparable results for specificity [25].

Kim and colleagues investigated the diagnostic accuracy of ${ }^{18}$ F-FDG PET/CT for the detection of recurrent and/or metastatic diseases in DTC patients with progressively and/or persistently elevated thyroglobulin antibodies $(\mathrm{TgAb})$ levels and negative I-WBS through a systematic review and meta-analysis. The pooled sensitivity for ${ }^{18} \mathrm{~F}-\mathrm{FDG}$ PET or PET/CT was $84 \%$ (95\%CI: $77-89 \%)$, the pooled specificity $78 \%$ (95\%CI:
$67-86 \%)$. The area under the ROC curve was 0.88 (95\% CI: 0.85-0.90). The authors concluded that ${ }^{18} \mathrm{~F}-\mathrm{FDG}$ PET or PET/CT demonstrated moderate sensitivity and specificity for the detection of recurrent and/or metastatic diseases in DTC patients with progressively and/or persistently elevated $\mathrm{TgAb}$ levels and negative I-WBS [26].

A meta-analysis by Santhanam and co-authors investigated the accuracy of ${ }^{18} \mathrm{~F}-\mathrm{FDG}$ PET/CT in the detection of residual disease in patients with BRAF $^{\mathrm{V} 600 \mathrm{E}}$ mutated thyroid cancer. The authors demonstrated that presence of $\mathrm{BRAF}^{\mathrm{V} 600 \mathrm{E}}$ mutation in DTC confers a higher likelihood of ${ }^{18} \mathrm{~F}$ FDG avidity and is associated with higher SUVmax values compared to $\mathrm{BRAF}^{\mathrm{V} 600 \mathrm{E}_{-}}$ mutation negative status [27].

The role of ${ }^{124} \mathrm{I}-\mathrm{PET} / \mathrm{CT}$ in detecting lesions of DTC amenable to ${ }^{131}$ I-therapy was recently described. The pooled sensitivity of ${ }^{124} \mathrm{I}-\mathrm{PET} / \mathrm{CT}$ in detecting DTC lesions amenable to ${ }^{131} \mathrm{I}$-therapy was $94.2 \%$ (95\% CI: 91.3-96.4\%), and the pooled specificity was $49.0 \%$ (95\% CI: 34.8-63.4\%). The authors concluded that ${ }^{124}$ I-PET/CT is a sensitive tool to diagnose radioiodine-avid DTC lesions, but also detects some new lesions that are not visualized on the post-treatment I-WBS [28].

\subsubsection{Recurrence of Medullary Thyroid Cancer}

Treglia and co-authors described the role of ${ }^{18} \mathrm{~F}$ FDG PET or PET/CT in patients with suspected recurrent medullary thyroid cancer (MTC). A sub-analysis considering PET device used, serum calcitonin, carcino-embryonic antigen (CEA), calcitonin doubling time (CTDT) and CEA doubling time (CEADT) values was also performed. Detection rate (DR) of ${ }^{18} \mathrm{~F}$-FDG PET or PET/CT in suspected recurrent MTC on a per-patientbased analysis was 59\% (95\%CI: 54-63\%). DR increased in patients with serum calcitonin $\geq 1000 \mathrm{ng} / \mathrm{L}$ (75\%), CEA $\geq 5 \mathrm{ng} / \mathrm{mL}$ (69\%), CTDT $<12$ months (76\%) and CEADT $<24$ months $(91 \%)$. The authors reported that about $40 \%$ of suspected recurrent MTC remain usually unidentified by ${ }^{18} \mathrm{~F}-\mathrm{FDG}$ PET or PET/ 
CT. However, ${ }^{18}$ F-FDG PET and PET/CT could modify the patient management in a certain number of recurrent MTC because these methods are often performed after negative conventional imaging studies [29].

In another meta-analysis evaluating the diagnostic performance of ${ }^{18} \mathrm{~F}-\mathrm{FDG}$ and PET/CT for detection of recurrent or metastatic MTC, the pooled sensitivities of ${ }^{18} \mathrm{~F}-\mathrm{FDG}-\mathrm{PET}$ and PET/ CT were 68\% (95\%CI: $64-72 \%)$ and $69 \%$ (95\%CI: 64-74\%), respectively [30].

Other PET radiotracers beyond ${ }^{18} \mathrm{~F}-\mathrm{FDG}$ were evaluated for detecting recurrent MTC. In a metaanalysis evaluating the DR of ${ }^{18} \mathrm{~F}$-DOPA PET or PET/CT for recurrent MTC, the DR of ${ }^{18} \mathrm{~F}-\mathrm{DOPA}$ PET and PET/CT on a per-patient- and a perlesion-based analysis was $66 \%$ and $71 \%$, respectively. The DR significantly increased in patients with serum calcitonin $\geq 1000 \mathrm{ng} / \mathrm{L}(86 \%)$ and CTDT $<24$ months $(86 \%)$. Therefore, ${ }^{18} \mathrm{~F}$-DOPA PET/CT may be a very useful functional imaging method in detecting recurrent MTC [31].

Another meta-analysis assessed the DR of ${ }^{68} \mathrm{Ga}$-somatostatin analogues PET or PET/CT in patients with recurrent MTC. The DR on a perpatient-based analysis was $63.5 \% \quad(95 \% \mathrm{CI}$ : 49-77\%). DR of ${ }^{68} \mathrm{Ga}$-somatostatin analogues PET or PET/CT increased in patients with higher serum calcitonin levels (83\% for calcitonin $>500 \mathrm{ng} / \mathrm{L}$ ). The authors concluded that the diagnostic performance of ${ }^{68} \mathrm{Ga}$-somatostatin analogues PET or PET/CT in recurrent MTC was lower compared to that of the same imaging method in the majority of NETs [32].

\subsection{Parathyroid Diseases}

Different PET tracers may be used to detect hyperfunctioning parathyroid glands in patients with hyperparathyroidism (HPT), including ${ }^{11} \mathrm{C}$-methionine $\left({ }^{11} \mathrm{C}-\mathrm{MET}\right)$ and radiolabelled choline. ${ }^{11} \mathrm{C}$-MET PET has an overall good sensitivity $(69 \%)$ and positive predictive value $(98 \%)$ in detecting hyperfunctioning parathyroid glands in patients with HPT and it may be considered a reliable second-line imaging method to enable minimally invasive parathyroidectomy [33].
Yuan and co-authors published a metaanalysis on the diagnostic value of ${ }^{11} \mathrm{C}$-MET PET in detecting hyperfunctioning parathyroid glands in patients with HPT and negative ${ }^{99} \mathrm{~m}$ Tc-MIBI scan. Pooled sensitivity and specificity of ${ }^{11} \mathrm{C}$ MET PET in patients with HPT with negative or inconclusive ${ }^{99 \mathrm{~m} T c-M I B I}$ scan were $86 \%$ and $86 \%$, respectively. The authors concluded that ${ }^{11} \mathrm{C}$-MET PET can be a useful functional imaging modality in patients with negative or inconclusive ${ }^{99 \mathrm{~m}}$ Tc-MIBI scan [34].

Caldarella and co-authors investigated the diagnostic performance of ${ }^{11} \mathrm{C}$-MET PET in patients with suspected parathyroid adenoma. Pooled sensitivity and DR values of ${ }^{11} \mathrm{C}$-MET PET in patients with suspected parathyroid adenoma were $81 \%$ (95\%CI: $74-86 \%$ ) and $70 \%$ (95\%CI: 62-77\%), respectively, on a per-patientbased analysis. The authors also concluded that ${ }^{11} \mathrm{C}$-MET PET could be helpful when conventional imaging techniques are negative or inconclusive in localizing parathyroid adenoma [35].

An evidence-based article by Kim and colleagues investigated the diagnostic performance of radiolabelled choline for localization of hyperfunctioning parathyroid gland in patients with HPT. The pooled sensitivity for radiolabelled choline PET/CT was 90\% (95\% CI: 86-94\%) and the pooled specificity $94 \%$ (95\%CI: 90-96\%) [36].

These findings are in line with a recent metaanalysis on the diagnostic performance of radiolabelled choline PET for detecting hyperfunctioning parathyroid glands: on a per-patient analysis, the sensitivity was 95\% (95\%CI: 92-97\%) and the positive predictive value was $97 \%$ (95\% CI: 95-98\%); on a per-lesion analysis, pooled sensitivity and PPV were 92\% (95\%CI: 88-96) and 92\% (95\% CI: 89-95\%), respectively [37].

\section{References}

1. Dinnes J, Bancos I, Ferrante di Ruffano L, Chortis V, Davenport C, Bayliss S, et al. Management of endocrine disease: imaging for the diagnosis of malignancy in incidentally discovered adrenal masses: a systematic review and meta-analysis. Eur J Endocrinol. 2016;175:R51-64. 
2. Kim SJ, Lee SW, Pak K, Kim IJ, Kim K. Diagnostic accuracy of 18F-FDG PET or PET/CT for the characterization of adrenal masses: a systematic review and meta-analysis. Br J Radiol. 2018;91:20170520.

3. Treglia G, Cocciolillo F, de Waure C, Di Nardo F, Gualano MR, Castaldi P, et al. Diagnostic performance of 18F-dihydroxyphenylalanine positron emission tomography in patients with paraganglioma: a meta-analysis. Eur J Nucl Med Mol Imaging. 2012;39:1144-53.

4. Rufini V, Treglia G, Castaldi P, Perotti G, Giordano A. Comparison of metaiodobenzylguanidine scintigraphy with positron emission tomography in the diagnostic work-up of pheochromocytoma and paraganglioma: a systematic review. Q J Nucl Med Mol Imaging. 2013;57:122-33.

5. Kan Y, Zhang S, Wang W, Liu J, Yang J, Wang Z. $68 \mathrm{Ga}$-somatostatin receptor analogs and 18F-FDG PET/CT in the localization of metastatic pheochromocytomas and paragangliomas with germline mutations: a meta-analysis. Acta Radiol. 2018;59:1466-74.

6. Han S, Suh CH, Woo S, Kim YJ, Lee JJ. Performance of $68 \mathrm{Ga}$ DOTA conjugated somatostatin receptortargeting peptide PET in detection of pheochromocytoma and paraganglioma: a systematic review and metaanalysis. J Nucl Med. 2019;60:369-76.

7. Bleeker G, Tytgat GA, Adam JA, Caron HN, Kremer LC, Hooft L, et al. 123I MIBG scintigraphy and 18F-FDG-PET imaging for diagnosing neuroblastoma. Cochrane Database Syst Rev. 2015;9:CD009263.

8. Xia J, Zhang H, Hu Q, Liu SY, Zhang LQ, Zhang A, et al. Comparison of diagnosing and staging accuracy of PET (CT) and MIBG on patients with neuroblastoma: systemic review and meta-analysis. J Huazhong Univ Sci Technolog Med Sci. 2017;37:649-60.

9. Treglia G, Kakhki VR, Giovanella L, Sadeghi R. Diagnostic performance of fluorine-18fluorodeoxyglucose positron emission tomography in patients with Merkel cell carcinoma: a systematic review and meta analysis. Am J Clin Dermatol. 2013; 14:437-47.

10. Singh S, Poon R, Wong R, Metser U. 68Ga PET imaging in patients with neuroendocrine tumors: a systematic review and meta-analysis. Clin Nucl Med. 2018;43:802-10.

11. Barrio M, Czernin J, Fanti S, Ambrosini V, Binse I, Du L, et al. The impact of somatostatin receptordirected PET/CT on the management of patients with neuroendocrine tumor: a systematic review and metaanalysis. J Nucl Med. 2017;58:756-61.

12. Deppen SA, Blume J, Bobbey AJ, Shah C, Graham $\mathrm{MM}$, Lee P, et al. ${ }^{68} \mathrm{Ga}$-DOTATATE compared with ${ }^{111}$ In-DTPA-octreotide and conventional imaging for pulmonary and gastroenteropancreatic neuroendocrine tumors: a systematic review and meta-analysis. J Nucl Med. 2016;57:872-8.

13. Treglia G, Castaldi P, Rindi G, Giordano A, Rufini V. Diagnostic performance of Gallium-68 somatostatin receptor PET and PET/CT in patients with thoracic and gastroenteropancreatic neuroendocrine tumours: a meta-analysis. Endocrine. 2012;42:80-7.

14. Geijer H, Breimer LH. Somatostatin receptor PET/ CT in neuroendocrine tumours: update on systematic review and meta-analysis. Eur J Nucl Med Mol Imaging. 2013;40:1770-80.

15. Yang J, Kan Y, Ge BH, Yuan L, Li C, Zhao W. Diagnostic role of Gallium-68 DOTATOC and Gallium-68 DOTATATE PET in patients with neuroendocrine tumors: a meta-analysis. Acta Radiol. 2014;55:389-98.

16. Blomberg BA, Moghbel MC, Saboury B, Stanley CA, Alavi A. The value of radiologic interventions and (18)F-DOPA PET in diagnosing and localizing focal congenital hyperinsulinism: systematic review and meta-analysis. Mol Imaging Biol. 2013;15:97-105.

17. Yang J, Hao R, Zhu $X$. Diagnostic role of 18F-dihydroxyphenylalanine positron emission tomography in patients with congenital hyperinsulinism: a meta-analysis. Nucl Med Commun. 2013;34:347-53.

18. Treglia G, Mirk P, Giordano A, Rufini V. Diagnostic performance of fluorine-18-dihydroxyphenylalanine positron emission tomography in diagnosing and localizing the focal form of congenital hyperinsulinism: a meta-analysis. Pediatr Radiol. 2012;42:1372-9.

19. Nayan S, Ramakrishna J, Gupta MK. The proportion of malignancy in incidental thyroid lesions on 18-FDG PET study: a systematic review and meta-analysis. Otolaryngol Head Neck Surg. 2014;151:190-200.

20. Qu N, Zhang L, Lu ZW, Wei WJ, Zhang Y, Ji QH. Risk of malignancy in focal thyroid lesions identified by (18)F-fluorodeoxyglucose positron emission tomography or positron emission tomography/computed tomography: evidence from a large series of studies. Tumour Biol. 2014;35(6):6139-47.

21. Treglia G, Bertagna F, Sadeghi R, Verburg FA, Ceriani L, Giovanella L. Focal thyroid incidental uptake detected by ${ }^{18} \mathrm{~F}$-fluorodeoxyglucose positron emission tomography. Meta-analysis on prevalence and malignancy risk. Nuklearmedizin. 2013;52:130-6.

22. Wang N, Zhai H, Lu Y. Is fluorine-18 fluorodeoxyglucose positron emission tomography useful for the thyroid nodules with indeterminate fine needle aspiration biopsy? A meta-analysis of the literature. J Otolaryngol Head Neck Surg. 2013;42:38.

23. Haslerud T, Brauckhoff K, Reisæter L, Küfner Lein R, Heinecke A, Varhaug JE, et al. F18-FDG-PET for recurrent differentiated thyroid cancer: a systematic meta-analysis. Acta Radiol. 2016;57:1193-200.

24. Caetano R, Bastos CR, de Oliveira IA, da Silva RM, Fortes CP, Pepe VL, et al. Accuracy of positron emission tomography and positron emission tomography$\mathrm{CT}$ in the detection of differentiated thyroid cancer recurrence with negative (131) I whole-body scan results: a meta-analysis. Head Neck. 2016;38:316-27.

25. Schütz F, Lautenschläger C, Lorenz K, Haerting J. Positron emission tomography (PET) and PET/ CT in thyroid cancer: a systematic review and metaanalysis. Eur Thyroid J. 2018;7:13-20. 
26. Kim SJ, Lee SW, Pak K, Shim SR. Diagnostic performance of PET in thyroid cancer with elevated anti-Tg Ab. Endocr Relat Cancer. 2018;25:643-52.

27. Santhanam P, Khthir R, Solnes LB, Ladenson $\mathrm{PW}$. The relationship of $\mathrm{BRAF}^{\mathrm{V} 600 \mathrm{E}}$ mutation status to FDG PET/CT avidity in thyroid cancer: a review and meta-analysis. Endocr Pract. 2018;24:21-6.

28. Santhanam P, Taieb D, Solnes L, Marashdeh W, Ladenson PW. Utility of I-124 PET/CT in identifying radioiodine avid lesions in differentiated thyroid cancer: a systematic review and meta-analysis. Clin Endocrinol. 2017;86:645-51.

29. Treglia G, Villani MF, Giordano A, Rufini V. Detection rate of recurrent medullary thyroid carcinoma using fluorine-18 fluorodeoxyglucose positron emission tomography: a meta-analysis. Endocrine. 2012;42:535-45.

30. Cheng X, Bao L, Xu Z, Li D, Wang J, Li Y. ${ }^{18}$ F-FDGPET and ${ }^{18} \mathrm{~F}-\mathrm{FDG}-\mathrm{PET} / \mathrm{CT}$ in the detection of recurrent or metastatic medullary thyroid carcinoma: a systematic review and meta-analysis. J Med Imaging Radiat Oncol. 2012;56:136-42.

31. Treglia G, Cocciolillo F, Di Nardo F, Poscia A, de Waure C, Giordano A, et al. Detection rate of recurrent medullary thyroid carcinoma using fluorine-18 dihydroxyphenylalanine positron emission tomography: a meta-analysis. Acad Radiol. 2012;19(10):1290-9.
32. Treglia G, Tamburello A, Giovanella L. Detection rate of somatostatin receptor PET in patients with recurrent medullary thyroid carcinoma: a systematic review and a meta-analysis. Hormones. 2017;16:362-72.

33. Kluijfhout WP, Pasternak JD, Drake FT, Beninato T, Gosnell JE, Shen WT. Use of PET tracers for parathyroid localization: a systematic review and metaanalysis. Langenbeck's Arch Surg. 2016;401:925-35.

34. Yuan L, Liu J, Kan Y, Yang J, Wang X. The diagnostic value of 11C-methionine PET in hyperparathyroidism with negative 99mTc-MIBI SPECT: a meta-analysis. Acta Radiol. 2017;58:558-64.

35. Caldarella C, Treglia G, Isgrò MA, Giordano A. Diagnostic performance of positron emission tomography using ${ }^{11} \mathrm{C}$-methionine in patients with suspected parathyroid adenoma: a meta-analysis. Endocrine. 2013;43:78-83.

36. Kim SJ, Lee SW, Jeong SY, Pak K, Kim K. Diagnostic performance of F-18 fluorocholine PET/CT for parathyroid localization in hyperparathyroidism: a systematic review and meta-analysis. Horm Cancer. 2018;9:440-7.

37. Treglia G, Piccardo A, Imperiale A, Strobel K, Kaufmann PA, Prior JO, et al. Diagnostic performance of choline PET for detection of hyperfunctioning parathyroid glands in hyperparathyroidism: a systematic review and meta-analysis. Eur J Nucl Med Mol Imaging. 2019;46:751-65.

Open Access This chapter is licensed under the terms of the Creative Commons Attribution 4.0 International License (http://creativecommons.org/licenses/by/4.0/), which permits use, sharing, adaptation, distribution and reproduction in any medium or format, as long as you give appropriate credit to the original author(s) and the source, provide a link to the Creative Commons license and indicate if changes were made.

The images or other third party material in this chapter are included in the chapter's Creative Commons license, unless indicated otherwise in a credit line to the material. If material is not included in the chapter's Creative Commons license and your intended use is not permitted by statutory regulation or exceeds the permitted use, you will need to obtain permission directly from the copyright holder. 


\section{Part III}

Evidence-Based PET in Cardiology 


\title{
Evidence-Based PET for Cardiac Diseases
}

\author{
Christel H. Kamani, Marie-Madeleine Meyer, \\ Sarah Boughdad, Nathalie Testart, \\ Marie Nicod Lalonde, Gilles Allenbach, \\ Mario Jreige, Niklaus Schaefer, Giorgio Treglia, \\ and John O. Prior
}

\subsection{Introduction}

This chapter summarizes 15 meta-analyses published in the literature on the use of PET for cardiac diseases, with the majority $(n=8)$ concerning the diagnosis of coronary artery disease (CAD) using myocardial perfusion imaging (MPI) in comparison to other modalities. Second in the number of published meta-analyses, three studies

C. H. Kamani · M.-M. Meyer · S. Boughdad N. Testart · M. Nicod Lalonde · G. Allenbach · M. Jreige Department of Nuclear Medicine and Molecular Imaging, Lausanne University Hospital, Lausanne, Switzerland

N. Schaefer · J. O. Prior $(\bowtie)$

Department of Nuclear Medicine and Molecular Imaging, Lausanne University Hospital and University of Lausanne, Lausanne, Switzerland e-mail: john.prior@chuv.ch

\section{G. Treglia}

Department of Nuclear Medicine and Molecular Imaging, Lausanne University Hospital

and University of Lausanne, Lausanne, Switzerland

Clinic of Nuclear Medicine and Molecular Imaging, Imaging Institute of Southern Switzerland,

Ente Ospedaliero Cantonale,

Bellinzona and Lugano, Switzerland

Health Technology Assessment Unit, Academic Education, Research and Innovation Area,

Ente Ospedaliero Cantonale, Bellinzona, Switzerland e-mail: giorgio.treglia@eoc.ch concentrated on the prognostic value of MPI for adverse cardiovascular events. Finally, one metaanalysis was published on the use of PET for four indications among myocardial viability assessment, the presence of microvascular disease (impaired coronary vascular function in absence of obstructive, epicardial CAD), the use of cardiac hybrid imaging and the diagnostic of cardiac amyloidosis.

\subsection{Myocardial Blood Flow Perfusion}

\subsubsection{Performance of PET/CT in the Assessment of Myocardial Perfusion in Comparison to Other Myocardial Perfusion Imaging Modalities}

Since the years 1950s, the technology of image acquisition in nuclear cardiology has progressively evolved from initial planar to more recent rapid hybrid cadmium-zinc-telluride (CZT) single-photon emission computed tomography/ computed tomography (SPECT/CT) and digitalized 3-dimensional (3D) positron emission tomography/computed tomography (PET/CT). Contemporary to this evolution, advances in the computation of acquired quantitative data using more performant software have led to a more 
objective, digital-based assessment of the pathophysiological processes underlying cardiovascular diseases, from the stenosis of epicardial coronary artery to microvascular dysfunction, including coronary vasomotor as well as endothelial dysfunction. In the meantime, new radiotracers for perfusion imaging have been developed, from potassium-43 $\left({ }^{43} \mathrm{~K}\right)$ to thallium$201\left({ }^{201} \mathrm{Tl}\right)$ and technetium-99 metastablelabelled $\left({ }^{99 \mathrm{~m}} \mathrm{Tc}\right)$ radiotracers for SPECT/CT; rubidium-82 $\left({ }^{82} \mathrm{Rb}\right)$, oxygen-15-labelled water $\left(\left[{ }^{15} \mathrm{O}\right]-\mathrm{H}_{2} \mathrm{O}\right)$, nitrogen-13-labelled ammonia $\left(\left[{ }^{13} \mathrm{~N}\right]-\mathrm{NH}_{3}\right)$, and still under development F-18 fluorine-labelled radiotracers for PET/CT.

Apart from nuclear techniques using SPECT/ $\mathrm{CT}$ and PET/CT, numerous non-invasive modalities have been developed to assess the myocardial perfusion, including dobutamine stress echocardiography (DSE), cardiac magnetic resonance (CMR), computed tomographic myocardial perfusion imaging (CT-MPI), fractional flow reserve derived from computed tomography (FFR-CT), with different diagnostic performances [1-4]. The development of these non-invasive modalities aims to contribute to counteract the burden of coronary artery disease (CAD), as the latest represents one of the leading causes of death and disability in developing countries [5]. In the field of nuclear imaging, especially PET/CT, there are accumulating evidences on the importance of flow quantification to guide management of stable CAD [6, 7], suggesting the potential role of $\mathrm{PET} / \mathrm{CT}$ as gatekeeper for invasive coronary angiography (ICA). Therefore, following this paradigm change in the treatment of patients with $\mathrm{CAD}$, it is of great importance to accurately select the right non-invasive imaging test evaluating the hemodynamic significance of a coronary stenosis for the right patient.

Jaarsma et al. [3] performed for the first time a meta-analysis on direct comparison of the diagnostic accuracy of three imaging modalities, PET/CT, CMR and SPECT/CT, for the diagnosis of significant CAD, using ICA as reference standard. In this meta-analysis, PET/CT performed better than CMR and SPECT/CT.

Dai et al. [1] have also assessed in a metaanalysis the diagnostic performance of six different cardiac imaging modalities, including PET/CT, for the evaluation of altered myocardial perfusion, using fractional flow reserve (FFR) derived from ICA as the reference standard. Among these imaging modalities, PET/CT as well as CMR and CT-MPI demonstrate high accuracy to detect hemodynamically significant $\mathrm{CAD}$, as compared with SPECT/CT, DSE and FFR-CT on a patient and coronary territory basis. From these three best performing modalities, CMR and CT-MPI perform better than PET/CT in the evaluation of perfusion deficit. However, with the advent of 3D digital PET/CT, it is expected that the improvement in the spatial resolution would add an incremental value in the evaluation of perfusion deficit [8]. One of the strengths of PET/CT and CMR over other perfusion imaging modalities is the ability to absolutely quantify myocardial blood flow, as this has been well demonstrated to be a strong predictor of coronary artery disease [9]. In this field, PET/CT performs better than CMR according to these data. Using PET/CT, different parameters are generated for the quantitative assessment of myocardial blood flow: hyperemic MBF (hMBF) defined as the myocardial blood flow during hyperemic stress test; resting MBF (rMBF) defined as the myocardial blood flow in resting conditions; relative myocardial blood flow (RBF) defined as the ratio from hMBF in the stenosed coronary territory to hMBF of a reference non-stenotic territory; and myocardial flow reserve (MFR) defined as the ratio from $\mathrm{hMBF}$ and rMBF [10]. Evidences have demonstrated a discrepancy in the diagnostic accuracy of different MBF parameters [1, 10]. Indeed, hMBF has been found to be more accurate than CFR and FFR in the detection of significant coronary artery disease using either FFR derived from ICA or visual evaluation of the severity of the stenosis during ICA, as well as both as reference standard. The limited performance of CFR regarding sensibility and specificity as compared to the two other parameters is linked to the clinically relevant coronary pathophysiology, as MFR evaluates the global vascular response to hyperemia [9]. Thus, epicardial coronary stenosis (from mild diffuse to focal severe) and microvascular dysfunction (from vasomotor tone to endothelial 
function) are determinants for the assessment of MFR. Alterations of one of these parameters in resting conditions can already lead to an activation of compensatory vasodilation of the resistance vessels in the microcirculation, resulting in an alteration of rMBF [11]. Thus, MFR could be limited in the detection of epicardial coronary stenosis in the presence of diffuse atherosclerosis. However, in contrary to hMBF, MFR has the best prediction value for major adverse cardiovascular events (MACE) when comparing both parameters [9]. FFR showed the best specificity from all three parameters. However, unlike the two other parameters, it requires a coronary territory free from relevant coronary stenosis, what can be problematic in patients with coronary 3-vessels disease. And this explains the limited sensibility of this parameter. The results of this meta-analysis are in line with the previous published meta-analysis from Takx et al. [2], with all patients presenting an intermediate epicardial coronary stenosis in ICA, further evaluated by FFR. Interestingly, in this meta-analysis, posttest probabilities following a negative respectively a positive test result in PET/CT and CMR was calculated (derived from pre-test probability and likelihood ratio), with high accuracy, ranging from $9 \%$ to $11 \%$ respectively from $84 \%$ to $85 \%$. Indeed, over sensitivity and specificity, the clinical performance of a non-invasive perfusion modality can be best assessed by the ability of post-test probability to confidently rule-in (posttest probability $\geq 85 \%$ ) or rule-out (post-test probability $\leq 15 \%$ ) relevant $\mathrm{CAD}$. In this line, a recent meta-analysis has investigated the ranges of pre-test probability of significant CAD, in which five imaging modalities, including PET/ CT, can highlight an accurate post-test probability [12]. For this purpose, anatomic and functional reference standard were used, derived from ICA and FFR respectively with cut-off values for determining significant CAD for a stenosis $>50 \%$ on ICA or a FFR $\leq 0.80$. Depending on the reference standard used, PET/CT as well as the other functional imaging techniques (SPECT/CT, CMR) performed different. Indeed, using anatomic reference standard, they all showed only moderate accuracy, whereas there was a signifi- cant improvement of their performance when using functional reference standard.

When comparing nuclear cardiology modalities together, PET/CT appears more advantageous than SPECT/CT in many aspects in two meta-analyses [13, 14]. PET/CT has a higher spatial resolution resulting from better count sensitivity and higher energy of their radiotracers. Moreover, PET/CT has a better image quality due to short half-life of their radiotracers leading to higher signal-to-noise ratio. This short half-life of the radiotracers enables lower patient radiation exposure as compared to SPECT, with up to tenth, respectively, half of a standard dose for ${ }^{201} \mathrm{Tl}$ and ${ }^{99 \mathrm{~m}} \mathrm{Tc}$ as compared to ${ }^{82} \mathrm{Rb}$. And when evaluating the efficacy of transmyocardial laser revascularization (TMR) in patients with refractory angina not amenable to conventional percutaneous or surgery revascularization, PET/CT, in contrary to SPECT/CT, demonstrates an improvement of the subendocardial to subepicardial ratio in the follow-up, where SPECT/CT showed no changes in a meta-analysis [15]. Thus, PET/CT, as compared to SPECT/CT, did have better resolution to assess the subendocardial and subepicardial perfusion, which is a relevant factor for the detection and follow-up of patients with CAD.

There are some limitations who have to be taken into consideration when interpreting the results of the most discussed meta-analysis. In the last decade, evidences from randomized controlled trials highlighted the importance of considering the hemodynamic significance of epicardial coronary lesion using fractional flow reserve (FFR) than just the traditional visual assessment of the severity of the epicardial coronary lesion in the decision of revascularization [16]. Indeed, these evidences demonstrate a discrepancy between the visual assessment of the severity and the functional significance of the lesion, with impact on the outcome when revascularizing or not. Moreover, in many patients with stable CAD and epicardial coronary stenosis, the non-inferiority of optimal medical treatment (OMT) over percutaneous coronary intervention (PCI) on top of OMT has been well demonstrated [17]. Therefore, using visual 
assessment of the severity of coronary stenosis as reference could have introduced significant bias of the present results.

FFR is a surrogate of the coronary perfusion, derived from measurement of the coronary pressure before and after the stenosis. Thereby, it would ideally represent the proportion of blood flow available to the myocardium distally from the stenosis, as compared to the one in the absence of coronary stenosis [18]. Using FFR as reference standard to evaluate the accuracy of coronary perfusion, PET/CT is largely questionable for many reasons. First, early evidences from the 1980s have demonstrated the predominant role of coronary flow over coronary perfusion pressure for the maintenance of an adequate myocardial function. In this animal experimental study, the significant reduction of coronary perfusion pressure to values equivalent to an FFR around 0.4 did not lead to alteration of the myocardial function as long as the coronary flow was maintained [19]. Second, perfusion imaging modalities were used to validate FFR [20], making it less suitable as reference standard to determine the accuracy of perfusion PET/CT. Third, recent data from large, multicenter, prospective randomized trial demonstrate that a significant proportion of patients $(60 \%$ of the study population) with epicardial stenosis showing FFR $\leq 0.8$ did not require coronary revascularization [21]. Following all these evidences, the results of these meta-analyses should be interpreted with care. It is not excluded that one of these imaging modalities is more accurate than what it was found, but it could not be demonstrated due to the use of FFR as reference standard. Other bias could also have an impact on the results of these different meta-analyses, such as the use of different PET/ CT scans and different PET/CT scan protocols, the difference in the prevalence of CAD in the different studies, the difference in the threshold of FFR and visual assessing of the severity of the coronary stenosis. Moreover, most of the metaanalyses have evaluated the imaging modalities as a stand-alone technique, without integrating other clinical parameters such as age and gender as well as other para-clinical parameters such as ventricular function, which could have increased the accuracy of the imaging modality. Finally, even if considerable efforts have been made to reduce the radiation exposure of patients undergoing a PET/CT, it remains a matter of concern when comparing to other imaging modalities such as CMR with no radiation exposure.

Despite the significant advances in the assessment of patients with $\mathrm{CAD}$, further investigations are still needed to overcome these limitations, thus bringing a new step of comprehension in the art of performing the right exam to the right patient.

\subsubsection{Prognostic Value of Myocardial PET}

PET MPI is increasingly being used for an accurate assessment of myocardial ischemia in patients with known or suspected coronary artery disease (CAD). It has been proposed by the American Heart Association that PET MPI may play a role as a novel cardiovascular biomarker, allowing better risk stratification of patients with CAD.

A first meta-analysis by Siontis et al. [22] specifically evaluated the incremental prognostic value that PET MPI added to standard risk factors in patients with known or suspected CAD. They selected 20 studies (with possible overlap in 5) totaling 22,203 patients, during a long span of 20 years, with only seven prospective studies. There was considerable heterogeneity among studies as MPI acquisition protocols, image analysis and selected radiotracer were not standardized among the studies. Only five studies reported changes in model classification, discrimination and risk stratification. PET MPI improved risk classification in four out of these five studies Despite the limitations of the metaanalysis, the authors were able to show that there is a strong association between abnormal perfusion (both by quantitative and qualitative analysis) and patient's outcome. They concluded that the limited data suggest that PET MPI may improve risk stratification, but this should be confirmed by data from larger and standardized prospective randomized controlled trials. 
The second systematic review and metaanalysis by Chen et al. [23] focused on evaluating the prognostic value of normal PET MPI in patients with suspected or known CAD. They selected 11 studies with a total of 20,471 patients in whom PET MPI was performed for the diagnosis of coronary artery disease and with evaluation of cardiovascular death, all-cause death and major cardiovascular events (MACE) at a followup $\geq 3$ months. They found highly significant negative predictive values for cardiac death (98.8\%; 95\% confidence interval (CI), 97.64$99.39 \%)$, all-cause death $(94.8 \%$; $95 \%$ CI: 92.99-96.30\%) and MACE (90.2\%; 95\% CI: 78.01-96.03\%), with a reasonable follow-up period of 36.9 months, 26.8 months and 35.7 months, respectively. In a subgroup analysis, there was no significant difference in negative predictive value in studies with a normal PET MPI determined by absence of perfusion abnormalities compared to those using coronary flow reserve. An important limitation is that the authors were not able to differentiate patients with known coronary artery disease from patients with only clinical suspicion.

The third wide meta-analysis carried by Smulders et al. [24] compared several noninvasive tests for depiction of coronary artery disease. The aim was to evaluate the prognostic value of negative non-invasive cardiac investigations in patients with suspected or known CAD. They compared CT angiography, stress echocardiography, cardiac magnetic resonance, exercise electrocardiographic testing, SPECT and PET. The evaluated outcome was annual event rate for cardiac death and myocardial infarction. They included 165 studies with a total of 122,721 patients. Annual event rates (AER) after a negative test varied among the imaging modalities (between 0.32 for $\mathrm{CT}$ angiography and 1.36 for stress echocardiography). Some modalities are preferred in populations at higher event risk or known CAD. The authors supposed the different patient population among studies could explain the differences between modalities. Indeed, when adjusting for the population risk, the AER was similar between modalities. This meta-analysis supports that a negative non-invasive cardiac study provides predictive information with good accuracy, which should influence the clinical practice by reducing the need of further cardiac investigations.

In the last years, there is growing scientific evidence describing the value of non-invasive cardiac investigations, not only as a diagnostic tool but also as a predictive prognosis biomarker. Specifically, a negative test has an excellent prognosis, which should reasonably reassure the patient.

\subsection{Assessment of Myocardial Viability}

The concept of hibernating myocardium has been adopted in the early 1980 s following the cumulating evidences of an improvement of the myocardial regional contractile function after an aorto-coronary bypass surgery [25]. It described a condition of altered left ventricular contractile function as a consequence of prolonged reduced coronary blood supply at rest, with improving potential following coronary revascularization. Different non-invasive imaging modalities, such as dobutamine stress echocardiography, cardiac magnetic resonance imaging and nuclear imaging, focusing on different aspects of the viable myocardium, have been proposed to identify viability in dysfunctional myocardial segments, with different diagnostic accuracy [26]. Among all these modalities, PET is considered as the gold standard [27].

In the meta-analysis of Tsai et al. [28], the authors investigated the accuracy of SPECT for the diagnosis of myocardial viability in patients with CAD and left ventricular dysfunction as compared to ${ }^{18} \mathrm{~F}$-FDG PET. Although this metaanalysis was not centred on PET, which was only used as the gold-standard comparator for SPECT, it is the only one published about viability involving PET/CT. The authors found eight prospective studies totaling 320 patients (3580 segments analysed). The criteria used for SPECT viability were diverse in these eight studies, but most frequently involved the presence of myocardial rest perfusion visible (e.g. $>50 \%$ or $>55 \%$ ), while 
two studies also involved ${ }^{18} \mathrm{~F}-\mathrm{FDG}$ in the criteria for SPECT viability (usually with SPECT vs. PET mismatch indicating viability).

SPECT as compared to PET resulted in the following pooled values: pooled sensitivity $82 \%$ (95\% CI $81-84 \%$ ), pooled specificity $88 \%$ (95\% CI 86-90\%), diagnostic odd ratio 62.6 (95\% CI 19.3-203) and the area under the receiving operating characteristic curve was $0.945 \pm 0.026$. There was a significant heterogeneity among studies especially in the definition of myocardial viability and the largest study included 58 patients, but the QUADAS quality assessment was of excellent quality and the funnel plot indicated no publication bias.

Thus, this meta-analysis showed that SPECT can be used adequately to assess myocardial viability in patients with CAD and left ventricular dysfunction. However, nowadays SPECT appears to be an outdated modality for assessing myocardial viability, and cardiac PET would be preferred for this diagnosis.

\subsection{Microvascular Disease}

Coronary artery disease (CAD) has often been exclusively associated to epicardial coronary abnormalities, as visualized during invasive coronary angiography (ICA). Nowadays, there are more evidences on the involvement of the entire coronary circulation, including the microcirculation, in the development of symptoms related to CAD [29]. This issue has been highlighted in a large cohort of symptomatic patients undergoing a diagnostic ICA for suspected obstructive epicardial CAD, where about $60 \%$ of the patients did not have a significant obstructive CAD (stenosis $\leq 50 \%$ ) [30]. Microvascular dysfunction may encounter for a significant number of symptomatic patients without relevant obstructive CAD [29, 31]. Coronary microvascular disease (CMD) englobes a group of disorders affecting the structure and function of the coronary microcirculation in relation with endothelial dysfunction or a dysregulation of the vascular smooth muscle. Numerous non-invasive techniques have been proposed to assess the coronary microvascular function, such as PET/CT, dynamic CT-MPI and CMR [32]. Among these, PET/CT is the most validated modality with good reproducibility and accuracy.

In a systematic review and meta-analysis, Brainin et al. investigated the consequences of impaired coronary vascular function in the absence of obstructive coronary arterial disease [33]. In six studies ( $n=1192$ patients) endothelial dependent epicardial dysfunction was assessed, five of them measured coronary flow reserve (CFR) during angiography using coldpressure test or acetylcholine stimulation. In one study, CFR was measured using cold-pressure testing during PET. In a pooled analysis, the relative risk (RR) of 2.49 for cardiovascular events was significantly increased. In another group of ten studies $(n=5134)$, non-endothelial dependent epicardial dysfunction was assessed measuring coronary flow velocity reserve using echocardiography. These studies showed an increased RR of 4.58. In the last group including ten studies ( $n=3687$ patients) measuring CFR by PET, non-endothelial dysfunction was associated with an increased RR of 2.44 .

These results underline that coronary vascular dysfunction as assessed by PET/CT has a prognostic value on cardiovascular events in a group of patients without obstructive coronary arterial disease. RR remained significantly elevated when excluding patients with diabetes or angina, as it remained elevated when including only patients with one specific stressor. Even if the number of studies remained small with different methods applied, impaired coronary vascular function in the absence of obstructive coronary disease should be reported for its prognostic value and considered as a potential therapeutic target.

\subsection{Cardiac Hybrid Imaging}

Cardiac multimodality (hybrid) imaging is a technique relying on the combination (on a sideby-side or fusion mode) of imaging modalities providing in one hand cardiac morphological data, such as CT, echocardiography or CMR, and in the other hand imaging modalities providing myocardial functional data, such as PET/CT. The goal of this combination is to gain information of 
these different imaging modalities in a complementary fashion in order to better guide coronary revascularization [34].

Coronary CT angiography (CCTA) has high negative predictive value and sensitivity for diagnosing obstructive $\mathrm{CAD}$; however, its positive predictive value and specificity are lower. In particular, CCTA may overestimate coronary artery stenosis. Therefore, a hybrid approach combining CCTA with MPI modalities_-including PET, SPECT and CMR - may help diminish the falsepositive rate of CCTA by fusing anatomic data derived from CCTA with functional data obtained through MPI, thus potentially overcoming CCTA limitations. To evaluate the clinical utility of this approach, Rezvi et al. [35] conducted a systematic literature review and meta-analysis comparing the diagnostic performance of hybrid cardiac imaging modalities with stand-alone CCTA for assessing obstructive $\mathrm{CAD}$, using as a reference standard invasive coronary angiography (ICA).

The results of the meta-analysis showed that, at the per-patient level, CCTA and MPI demonstrated comparable sensitivity $(p=0.35)$, but CCTA displayed lower specificity (66\%) compared to MPI (83\%) for predicting obstructive CAD; at the per-vessel level, specificity of CCTA and MPI was similar $(p=0.02)$, and sensitivity was higher for CCTA (89\%) than for MPI alone $(78 \%)(p<0.001)$.

When the diagnostic performance of hybrid versus CCTA imaging method was examined on a per-patient basis, sensitivity, negative likelihood ratio (LR-) and diagnostic odds ratio (DOR) of hybrid imaging techniques compared to CCTA to detect obstructive CAD were, respectively, 91\%, 0.11 and 159.00, versus 90\%, 0.06 and $53.80(p>0.05$, for all). Specificity and positive likelihood ratio $(\mathrm{LR}+)$ were higher for hybrid imaging compared to stand-alone CCTA (93\% and 12.80 versus $66 \%$ and 3.39 , respectively). At the per-vessel level, summary receiver-operator curves (sROC) demonstrated a statistically significant and higher area under the curve (AUC) value for hybrid imaging than for CCTA (0.97 versus 0.93 , respectively; $p=0.047$ ).

In conclusion, hybrid imaging techniques outperformed stand-alone CCTA for detecting obstructive $\mathrm{CAD}$ in patients undergoing both anatomic and functional testing, demonstrating higher specificity and LR+ on a per-patient basis. In addition, at the per-vessel level, hybrid imaging could better identify CAD based on sROC curves; however, sensitivity was comparable for hybrid versus stand-alone CCTA imaging.

\subsection{Cardiac Amyloidosis}

Amyloidosis encompasses a group of infiltrative disorders characterized by extracellular accumulation of fibrillary proteins, leading to functional impairment of different tissues and organs, including the heart. In patients with systemic amyloidosis, cardiac involvement could lead to significantly increased morbidity and mortality. The most common types of cardiac amyloidosis are systemic light chain (AL) and transthyretin (ATTR) amyloidosis. This differentiation is of importance as it differs in treatment and prognosis, untreated patients with AL amyloidosis having the poorest prognosis [36]. ATTR has been long time considered as a rare disease because of the lack of disease awareness, its quiescent nature at the beginning and the heterogeneity of symptoms when clinical manifest. Nowadays, accumulating evidences showed that it may be more prevalent than thought, especially in certain groups of patients such as older people or patients with aortic stenosis [37]. Moreover, with the emergence of new treatment options, early diagnosis is critical because of the better effectiveness of the treatment in the earlier course of the disease [38]. In line with this, bone scintigraphy as a non-invasive tool in the flowchart to accurately differentiate between AL and ATTR amyloidosis is well established [39]. Moreover, recent development in amyloid tracers for positron emission tomography (PET) could lead to an early diagnosis and potentially improve the prognosis of those patients. In that setting, we shortly present the results of the first systematic review and meta-analysis on the diagnostic performance of amyloid PET imaging in cardiac amyloidosis by Kim et al. [40]. The authors also reported the potential additional value of using semi-quantitative parameters for the diagnosis of cardiac 
amyloidosis and for distinguishing between AL and ATTR amyloidosis.

Six retrospective studies with a total of 98 patients (69 patients with systemic amyloidosis and 29 control patients) were included in this meta-analysis. Among amyloid radiotracers, ${ }^{11} \mathrm{C}$ PIB was the most commonly used in four studies, whereas ${ }^{18} \mathrm{~F}$-Florbetapir and ${ }^{18} \mathrm{~F}$-Florbetaben were each used in one study.

In the whole cohort (six studies), the pooled sensitivity was 0.95 (95\% CI 0.87-0.99), and pooled specificity was 0.98 (95\% CI $0.87-1.00)$. Positive likelihood ratio (LR) was 10.130 (95\% CI 3.749-27.376), negative LR was 0.100 (95\% CI 0.045-0.221), and diagnostic odds ratio was 148.83 (95\% CI = 34.026-650.98). Summary receiver operating characteristic curve showed high performance with an area under curve of 0.9731 with a standard error of 0.0156 . Looking only at the four ${ }^{11} \mathrm{C}$-PIB studies, similar results were found with a diagnostic odds ratio of 134.19 (95\% CI 24.039-749.03).

The use of semi-quantitative parameters was reported in four studies (three with ${ }^{11} \mathrm{C}$-PIB and one with ${ }^{18} \mathrm{~F}$-Florbetaben) and consisted of retention index (RI) and/or target-to-background ratio (TBR). RI derived from dynamic acquisitions (RI = mean myocardial SUV/integral of the arterial time-activity curve). By contrast, TBR was extracted from static acquisitions $(\mathrm{TBR}=\max$ or mean myocardial SUV/mean SUV of the descending thoracic aorta). Patients with cardiac amyloidosis had significantly higher RI and TBR values in comparison to control patients. Using both, pooled standardized mean difference (SMD) was of $1.42 \quad(95 \%$ CI $0.83-2.01$; $p<0.001)$. The performance of RI and TBR for discriminating between AL and ATTR amyloidosis was assessed in three studies (two with ${ }^{11} \mathrm{C}$ PIB and one with ${ }^{18} \mathrm{~F}$-Florbetaben) and showed significantly higher uptake in the former (pooled SMD $=0.96 ; 95 \%$ CI 0.13-1.79; $p<0.001)$.

To resume, amyloid PET imaging presents with strong performance to diagnose cardiac amyloidosis with high sensitivity and specificity $(\geq 95 \%)$. The addition of semi-quantitative parameters, such as RI and TBR, could help improve the diagnosis and accurately differentiate between AL and ATTR amyloidosis.

\section{References}

1. Dai N, Zhang X, Zhang Y, Hou L, Li W, Fan B, et al. Enhanced diagnostic utility achieved by myocardial blood analysis: a meta-analysis of noninvasive cardiac imaging in the detection of functional coronary artery disease. Int J Cardiol. 2016;221:665-73. https://doi. org/10.1016/j.ijcard.2016.07.031.

2. Takx RA, Blomberg BA, El Aidi H, Habets J, de Jong PA, Nagel E, et al. Diagnostic accuracy of stress myocardial perfusion imaging compared to invasive coronary angiography with fractional flow reserve meta-analysis. Circ Cardiovasc Imaging. 2015;8(1). https://doi.org/10.1161/CIRCIMAGING.114.002666.

3. Jaarsma C, Leiner T, Bekkers SC, Crijns HJ, Wildberger JE, Nagel E, et al. Diagnostic performance of noninvasive myocardial perfusion imaging using single-photon emission computed tomography, cardiac magnetic resonance, and positron emission tomography imaging for the detection of obstructive coronary artery disease: a meta-analysis. J Am Coll Cardiol. 2012;59(19):1719-28. https://doi.org/ 10.1016/j.jacc.2011.12.040.

4. Yang K, Yu SQ, Lu MJ, Zhao SH. Comparison of diagnostic accuracy of stress myocardial perfusion imaging for detecting hemodynamically significant coronary artery disease between cardiac magnetic resonance and nuclear medical imaging: a metaanalysis. Int J Cardiol. 2019;293:278-85. https://doi. org/10.1016/j.ijcard.2019.06.054.

5. Benjamin EJ, Muntner P, Alonso A, Bittencourt MS, Callaway CW, Carson AP, et al. Heart disease and stroke statistics-2019 update: a report from the American Heart Association. Circulation. 2019;139(10):e56-e528. https://doi.org/10.1161/ CIR.0000000000000659.

6. Bober RM, Milani RV, Oktay AA, Javed F, Polin NM, Morin DP. The impact of revascularization on myocardial blood flow as assessed by positron emission tomography. Eur J Nucl Med Mol Imaging. 2019;46(6):1226-39. https://doi.org/10.1007/s00259019-04278-8.

7. Gould KL, Johnson NP, Roby AE, Nguyen T, Kirkeeide R, Haynie M, et al. Regional, artery-specific thresholds of quantitative myocardial perfusion by PET associated with reduced myocardial infarction and death after revascularization in stable coronary artery disease. J Nucl Med. 2019;60(3):410-7. https:// doi.org/10.2967/jnumed.118.211953.

8. Bendriem B, Reed J, McCullough K, Khan MR, Smith AM, Thomas D, et al. The continual innovation of commercial PET/CT solutions in nuclear cardiology: Siemens Healthineers. J Nucl Cardiol. 2018;25(4):1400-11. https://doi.org/10.1007/s12350018-1262-3.

9. Gupta A, Taqueti VR, van de Hoef TP, Bajaj NS, Bravo PE, Murthy VL, et al. Integrated noninvasive physiological assessment of coronary circulatory function and impact on cardiovascular mortality in patients with stable coronary artery disease. Circulation. 
2017;136(24):2325-36. https://doi.org/10.1161/ CIRCULATIONAHA.117.029992.

10. Cho SG, Lee SJ, Na MH, Choi YY, Bom HH. Comparison of diagnostic accuracy of PETderived myocardial blood flow parameters: a meta-analysis. J Nucl Cardiol. 2018. https://doi. org/10.1007/s12350-018-01476-z.

11. Johnson NP, Gould KL. Integrating noninvasive absolute flow, coronary flow reserve, and ischemic thresholds into a comprehensive map of physiological severity. JACC Cardiovasc Imaging. 2012;5(4):430 40. https://doi.org/10.1016/j.jcmg.2011.12.014.

12. Knuuti J, Ballo H, Juarez-Orozco LE, Saraste A, Kolh P, Rutjes AWS, et al. The performance of noninvasive tests to rule-in and rule-out significant coronary artery stenosis in patients with stable angina: a meta-analysis focused on post-test disease probability. Eur Heart J. 2018;39(35):3322-30. https://doi. org/10.1093/eurheartj/ehy267.

13. Mc Ardle BA, Dowsley TF, deKemp RA, Wells GA, Beanlands RS. Does rubidium-82 PET have superior accuracy to SPECT perfusion imaging for the diagnosis of obstructive coronary disease?: a systematic review and meta-analysis. J Am Coll Cardiol. 2012;60(18):1828-37. https://doi. org/10.1016/j.jacc.2012.07.038.

14. Parker MW, Iskandar A, Limone B, Perugini A, Kim $\mathrm{H}$, Jones $\mathrm{C}$, et al. Diagnostic accuracy of cardiac positron emission tomography versus single photon emission computed tomography for coronary artery disease: a bivariate meta-analysis. Circ Cardiovasc Imaging. 2012;5(6):700-7. https://doi.org/10.1161/ CIRCIMAGING.112.978270.

15. Iwanski J, Knapp SM, Avery R, Oliva I, Wong RK, Runyan RB, et al. Clinical outcomes meta-analysis: measuring subendocardial perfusion and efficacy of transmyocardial laser revascularization with nuclear imaging. J Cardiothorac Surg. 2017;12(1):37. https:// doi.org/10.1186/s13019-017-0602-8.

16. Bech GJ, De Bruyne B, Pijls NH, de Muinck ED, Hoorntje JC, Escaned J, et al. Fractional flow reserve to determine the appropriateness of angioplasty in moderate coronary stenosis: a randomized trial. Circulation. 2001;103(24):2928-34. https://doi.org/ 10.1161/01.cir.103.24.2928.

17. Shaw LJ, Berman DS, Maron DJ, Mancini GB, Hayes SW, Hartigan PM, et al. Optimal medical therapy with or without percutaneous coronary intervention to reduce ischemic burden: results from the Clinical Outcomes Utilizing Revascularization and Aggressive Drug Evaluation (COURAGE) trial nuclear substudy. Circulation. 2008;117(10):1283-91. https://doi. org/10.1161/CIRCULATIONAHA.107.743963.

18. Pijls NH, van Son JA, Kirkeeide RL, De Bruyne B, Gould KL. Experimental basis of determining maximum coronary, myocardial, and collateral blood flow by pressure measurements for assessing functional stenosis severity before and after percutaneous transluminal coronary angioplasty. Circulation. 1993;87(4):1354-67. https://doi.org/10.1161/01. cir.87.4.1354.
19. Smalling RW, Kelley K, Kirkeeide RL, Fisher DJ. Regional myocardial function is not affected by severe coronary depressurization provided coronary blood flow is maintained. J Am Coll Cardiol. 1985;5(4):948-55. https://doi.org/10.1016/ s0735-1097(85)80438-1.

20. Pijls NH, De Bruyne B, Peels K, Van Der Voort $\mathrm{PH}$, Bonnier HJ, Bartunek JKJJ, et al. Measurement of fractional flow reserve to assess the functional severity of coronary-artery stenoses. N Engl J Med. 1996;334(26):1703-8. https://doi.org/10.1056/ NEJM199606273342604.

21. De Bruyne B, Pijls NH, Kalesan B, Barbato E, Tonino PA, Piroth Z, et al. Fractional flow reserve-guided PCI versus medical therapy in stable coronary disease. $\mathrm{N}$ Engl J Med. 2012;367(11):991-1001. https://doi. org/10.1056/NEJMoa1205361.

22. Siontis KC, Chareonthaitawee P. Prognostic value of positron emission tomography myocardial perfusion imaging beyond traditional cardiovascular risk factors: systematic review and meta-analysis. Int J Cardiol Heart Vasc. 2015;6:54-9. https://doi. org/10.1016/j.ijcha.2015.01.005.

23. Chen A, Wang H, Fan B, Xu Y, Chen W, Dai N. Prognostic value of normal positron emission tomography myocardial perfusion imaging in patients with known or suspected coronary artery disease: a meta-analysis. Br J Radiol. 2017;90(1074):20160702. https://doi.org/10.1259/bjr.20160702.

24. Smulders MW, Jaarsma C, Nelemans PJ, Bekkers S, Bucerius J, Leiner T, et al. Comparison of the prognostic value of negative non-invasive cardiac investigations in patients with suspected or known coronary artery disease-a meta-analysis. Eur Heart J Cardiovasc Imaging. 2017;18(9):980-7. https://doi.org/10.1093/ ehjci/jex014.

25. Rahimtoola SH. The hibernating myocardium. Am Heart J. 1989;117(1):211-21. https://doi. org/10.1016/0002-8703(89)90685-6.

26. Schinkel AF, Bax JJ, Poldermans D, Elhendy A, Ferrari R, Rahimtoola SH. Hibernating myocardium: diagnosis and patient outcomes. Curr Probl Cardiol. 2007;32(7):375-410. https://doi. org/10.1016/j.cpcardiol.2007.04.001.

27. Nekolla SG, Martinez-Moeller A, Saraste A. PET and MRI in cardiac imaging: from validation studies to integrated applications. Eur J Nucl Med Mol Imaging. 2009;36(Suppl 1):S121-30. https://doi.org/10.1007/ s00259-008-0980-1.

28. Tsai JP, Yun CH, Wu TH, Yen $\mathrm{CH}$, Hou CJ, Kuo JY, et al. A meta-analysis comparing SPECT with PET for the assessment of myocardial viability in patients with coronary artery disease. Nucl Med Commun. 2014;35(9):947-54. https://doi. org/10.1097/MNM.0000000000000140.

29. Camici PG, Crea F. Coronary microvascular dysfunction. N Engl J Med. 2007;356(8):830-40. https://doi. org/10.1056/NEJMra061889.

30. Patel MR, Peterson ED, Dai D, Brennan JM, Redberg RF, Anderson HV, et al. Low diagnostic yield of elective coronary angiography. N Engl J 
Med. 2010;362(10):886-95. https://doi.org/10.1056/ NEJMoa0907272.

31. Ong P, Camici PG, Beltrame JF, Crea F, Shimokawa $\mathrm{H}$, Sechtem U, et al. International standardization of diagnostic criteria for microvascular angina. Int $\mathbf{J}$ Cardiol. 2018;250:16-20. https://doi.org/10.1016/j. ijcard.2017.08.068.

32. Feher A, Sinusas AJ. Quantitative assessment of coronary microvascular function: dynamic singlephoton emission computed tomography, positron emission tomography, ultrasound, computed tomography, and magnetic resonance imaging. Circ Cardiovasc Imaging. 2017;10(8). https://doi. org/10.1161/CIRCIMAGING.117.006427.

33. Brainin P, Frestad D, Prescott E. The prognostic value of coronary endothelial and microvascular dysfunction in subjects with normal or non-obstructive coronary artery disease: a systematic review and meta-analysis. Int J Cardiol. 2018;254:1-9. https:// doi.org/10.1016/j.ijcard.2017.10.052.

34. Prior JO, Farhad H, Muller O. Multimodality imaging in ischemic cardiomyopathy. Curr Cardiovasc Imaging Rep. 2014;7:9285. https://doi.org/10.1007/ s12410-014-9285-x.

35. Rizvi A, Han D, Danad I, Hartaigh BO, Lee JH, Gransar H, et al. Diagnostic performance of hybrid cardiac imaging methods for assessment of obstructive coronary artery disease compared with stand-alone coronary computed tomography angiography: a meta- analysis. JACC Cardiovasc Imaging. 2018;11(4):589_ 99. https://doi.org/10.1016/j.jcmg.2017.05.020.

36. Xin Y, Hu W, Chen X, Hu J, Sun Y, Zhao Y. Prognostic impact of light-chain and transthyretin-related categories in cardiac amyloidosis: a systematic review and meta-analysis. Hell J Cardiol. 2019;60(6):375-83. https://doi.org/10.1016/j.hjc.2019.01.015.

37. Maurer MS, Bokhari S, Damy T, Dorbala S, Drachman BM, Fontana M, et al. Expert consensus recommendations for the suspicion and diagnosis of transthyretin cardiac amyloidosis. Circ Heart Fail. 2019;12(9):e006075. https://doi.org/10.1161/ CIRCHEARTFAILURE.119.006075.

38. Maurer MS, Schwartz JH, Gundapaneni B, Elliott PM, Merlini G, Waddington-Cruz M, et al. Tafamidis treatment for patients with transthyretin amyloid cardiomyopathy. N Engl J Med. 2018;379(11):1007-16. https://doi.org/10.1056/NEJMoa1805689.

39. Gillmore JD, Maurer MS, Falk RH, Merlini G, Damy T, Dispenzieri A, et al. Nonbiopsy diagnosis of cardiac transthyretin amyloidosis. Circulation. 2016;133(24):2404-12. https://doi.org/10.1161/ CIRCULATIONAHA.116.021612.

40. Kim YJ, Ha S, Kim YI. Cardiac amyloidosis imaging with amyloid positron emission tomography: a systematic review and meta-analysis. J Nucl Cardiol. 2018;27(1):123-32. https://doi.org/10.1007/ s12350-018-1365-X.

Open Access This chapter is licensed under the terms of the Creative Commons Attribution 4.0 International License (http://creativecommons.org/licenses/by/4.0/), which permits use, sharing, adaptation, distribution and reproduction in any medium or format, as long as you give appropriate credit to the original author(s) and the source, provide a link to the Creative Commons license and indicate if changes were made.

The images or other third party material in this chapter are included in the chapter's Creative Commons license, unless indicated otherwise in a credit line to the material. If material is not included in the chapter's Creative Commons license and your intended use is not permitted by statutory regulation or exceeds the permitted use, you will need to obtain permission directly from the copyright holder. 


\section{Part IV}

Evidence-Based PET in Infection and Inflammation 


\title{
Evidence-Based PET for Infectious and Inflammatory Diseases
}

\author{
Giorgio Treglia and Barbara Muoio
}

\subsection{Introduction}

Nuclear medicine techniques are non-invasive tools that can early detect pathophysiological changes in affected tissues in patients with inflammatory or infectious diseases. These changes usually occur before clinical onset of symptoms and before the development of anatomical changes detected by radiological techniques [1, 2]. Currently, hybrid imaging techniques as positron emission tomography/ computed tomography (PET/CT) may provide functional and morphological information for early diagnosis of infectious and inflammatory diseases [1,2].

The ability of Fluorine-18 fluorodeoxyglucose $\left({ }^{18} \mathrm{~F}-\mathrm{FDG}\right) \mathrm{PET} / \mathrm{CT}$ to identify sites of inflamma-

\footnotetext{
G. Treglia $(\bowtie)$

Clinic of Nuclear Medicine and PET/CT Center, Imaging Institute of Southern Switzerland, Ente Ospedaliero Cantonale,

Bellinzona and Lugano, Switzerland

Health Technology Assessment Unit, Ente Ospedaliero Cantonale, Bellinzona, Switzerland

Department of Nuclear Medicine and Molecular Imaging, Lausanne University Hospital and University of Lausanne, Lausanne, Switzerland e-mail: giorgio.treglia@eoc.ch

B. Muoio

Clinic of Oncology and Internal Medicine,

San Giovanni Hospital, Oncology Institute of Southern Switzerland, Ente Ospedaliero Cantonale, Bellinzona, Switzerland
}

tion and infection is mainly related to the glycolytic activity of the cells involved in the inflammatory response [3, 4]. Enough evidence in the literature already exists about the diagnostic performance of ${ }^{18} \mathrm{~F}-\mathrm{FDG} \mathrm{PET} / \mathrm{CT}$ in the diagnosis and management of several infectious and inflammatory diseases [5]. The results of the selected articles, including pooled values and 95\% confidence interval $(95 \% \mathrm{CI})$, are presented in Table 12.1 and summarized here below.

\subsection{Fever of Unknown Origin (FUO)}

Fever of unknown origin (FUO) is commonly defined as temperature $\geq 38.3{ }^{\circ} \mathrm{C}$ on at least two occasions, duration of illness $\geq 3$ weeks or multiple febrile episodes in $\geq 3$ weeks, not immunocompromised patient, and uncertain diagnosis despite thorough history-taking, physical examination, and obligatory investigations [6]. The diagnosis in patients with FUO is a challenging medical problem; the cause of FUO may be infectious diseases, non-infectious inflammatory diseases, or tumors, and ${ }^{18} \mathrm{~F}$-FDG PET/CT detecting foci of increased glucose metabolism may be used for revealing the source of fever [6]. Several meta-analyses have estimated the diagnostic performance of ${ }^{18} \mathrm{~F}-\mathrm{FDG}$ PET/CT in the assessment of FUO unidentified by conventional workup [7-13]. 
Table 12.1 Characteristics and main findings of included meta-analyses on the diagnostic performance of ${ }^{18} \mathrm{~F}-\mathrm{FDG}$ $\mathrm{PET} / \mathrm{CT}$ in infectious or inflammatory diseases

\begin{tabular}{|c|c|c|c|c|c|c|c|}
\hline Topic & Authors & $\begin{array}{l}\text { Patients } \\
\text { included }\end{array}$ & $\begin{array}{l}\text { Sensitivity } \\
(95 \% \mathrm{CI})\end{array}$ & $\begin{array}{l}\text { Specificity } \\
(95 \% \mathrm{CI})\end{array}$ & $\begin{array}{l}\mathrm{LR}+ \\
(95 \% \mathrm{CI})\end{array}$ & $\begin{array}{l}\text { LR- } \\
(95 \% \mathrm{CI})\end{array}$ & $\begin{array}{l}\text { DOR } \\
(95 \% \mathrm{CI})\end{array}$ \\
\hline \multirow[t]{7}{*}{$\begin{array}{l}\text { Fever of } \\
\text { unknown origin }\end{array}$} & Dong et al. [7] & 174 & $\begin{array}{l}98.2 \% \\
(93.6-99.8)\end{array}$ & $\begin{array}{l}85.9 \% \\
(75.0-93.4)\end{array}$ & $\begin{array}{l}5.8 \\
(3.3-10)\end{array}$ & $\begin{array}{l}0.05 \\
(0.01-0.25)\end{array}$ & $\begin{array}{l}7.1 \\
(0.7-67.4)\end{array}$ \\
\hline & Hao et al. [8] & 595 & $\begin{array}{l}85 \% \\
(81-88)\end{array}$ & NR & NR & NR & NR \\
\hline & Besson et al. [9] & 401 & NR & NR & NR & NR & NR \\
\hline & Takeuchi et al. [10] & 1137 & $\begin{array}{l}86 \% \\
(81-90)\end{array}$ & $\begin{array}{l}52 \% \\
(36-67)\end{array}$ & NR & NR & NR \\
\hline & Bharucha et al. [11] & 905 & NR & NR & NR & NR & NR \\
\hline & Kan et al. [12] & 1927 & $\begin{array}{l}84 \% \\
(79-89)\end{array}$ & $\begin{array}{l}63 \% \\
(49-75)\end{array}$ & $\begin{array}{l}2.3 \\
(1.5-3.4)\end{array}$ & $\begin{array}{l}0.25 \\
(0.16-0.38)\end{array}$ & $\begin{array}{l}9 \\
(4-20)\end{array}$ \\
\hline & Takeuchi et al. [13] & 418 & NR & NR & NR & NR & NR \\
\hline \multirow[t]{9}{*}{$\begin{array}{l}\text { Large vessel } \\
\text { vasculitis }\end{array}$} & Besson et al. ${ }^{\mathrm{a}}[19]$ & 283 & $\begin{array}{l}{[\mathrm{GCA}] 80 \%} \\
(63-91)\end{array}$ & $\begin{array}{l}{[\mathrm{GCA}] 89 \%} \\
(78-94)\end{array}$ & $\begin{array}{l}{[\mathrm{GCA}]} \\
6.73 \\
(3.5-12.8)\end{array}$ & $\begin{array}{l}{[\mathrm{GCA}] 0.25} \\
(0.13-0.46)\end{array}$ & NR \\
\hline & Cheng et al. ${ }^{\mathrm{a}}[20]$ & 142 & $\begin{array}{l}{[\mathrm{TA}] 70.1 \%} \\
(58.6-80)\end{array}$ & $\begin{array}{l}{[\mathrm{TA}] 77.2 \%} \\
(64.2-87.3)\end{array}$ & $\begin{array}{l}{[\mathrm{TA}] 2.3} \\
(1.1-4.8)\end{array}$ & $\begin{array}{l}{[\mathrm{TA}] 0.34} \\
(0.14-0.82)\end{array}$ & $\begin{array}{l}{[\mathrm{TA}] 7.5} \\
(1.6-34)\end{array}$ \\
\hline & Soussan et al. ${ }^{\mathrm{a}}[21]$ & 712 & $\begin{array}{l}{[\mathrm{GCA}] 90 \%} \\
(79-96)\end{array}$ & $\begin{array}{l}\text { [GCA] } 98 \% \\
(94-99)\end{array}$ & $\begin{array}{l}\text { [GCA] } \\
28.7 \\
(11.5-71.6)\end{array}$ & $\begin{array}{l}{[\mathrm{GCA}] 0.15} \\
(0.07-0.29)\end{array}$ & $\begin{array}{l}\text { [GCA] } \\
256.3 \\
(70.8-927)\end{array}$ \\
\hline & & & $\begin{array}{l}{[\mathrm{TA}] 87 \%} \\
(78-93)\end{array}$ & $\begin{array}{l}{[\mathrm{TA}] 73 \%} \\
(63-81)\end{array}$ & $\begin{array}{l}{[\mathrm{TA}] 4.2} \\
(1.5-12)\end{array}$ & $\begin{array}{l}{[\mathrm{TA}] 0.2} \\
(0.1-0.5)\end{array}$ & $\begin{array}{l}{[\mathrm{TA}] 19.8} \\
(4.5-87.6)\end{array}$ \\
\hline & & & $\begin{array}{l}{\left[\mathrm{TA}^{+}\right] 84 \%} \\
(73-92)\end{array}$ & $\begin{array}{l}{\left[\mathrm{TA}^{+}\right] 84 \%} \\
(73-92)\end{array}$ & $\begin{array}{l}{\left[\mathrm{TA}^{+}\right] 4.6} \\
(2.1-9.9)\end{array}$ & $\begin{array}{l}{\left[\mathrm{TA}^{+}\right] 0.2} \\
(0.1-0.5)\end{array}$ & $\begin{array}{l}{\left[\mathrm{TA}^{+}\right] 23.4} \\
(5.2- \\
105.2)\end{array}$ \\
\hline & Lee et al. [22] & 95 & $\begin{array}{l}83.9 \% \\
(71.7-92.4)\end{array}$ & $\begin{array}{l}87.2 \% \\
(72.6-95.7)\end{array}$ & $\begin{array}{l}5.2 \\
(2.4-11.2)\end{array}$ & $\begin{array}{l}0.2 \\
(0.1-0.4)\end{array}$ & $\begin{array}{l}27.2 \\
(8.5-86.6)\end{array}$ \\
\hline & Barra et al. ${ }^{\mathrm{a}}[23]$ & 301 & $\begin{array}{l}{[\mathrm{TA}] 81 \%} \\
(69-89)\end{array}$ & $\begin{array}{l}{[\mathrm{TA}] 74 \%} \\
(55-86)\end{array}$ & NR & NR & NR \\
\hline & 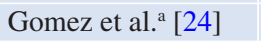 & 210 & NR & NR & NR & NR & NR \\
\hline & Lee et al. ${ }^{a}[25]$ & 298 & $\begin{array}{l}88 \% \\
(79-93)\end{array}$ & $\begin{array}{l}81 \% \\
(64-91)\end{array}$ & $\begin{array}{l}4.5 \\
(2.2-9.5)\end{array}$ & $\begin{array}{l}0.15 \\
(0.08-0.29)\end{array}$ & $\begin{array}{l}30 \\
(8-107)\end{array}$ \\
\hline \multirow[t]{3}{*}{$\begin{array}{l}\text { Infective } \\
\text { endocarditis }\end{array}$} & Yan et al. [30] & 246 & $\begin{array}{l}61 \% \\
(52-88)\end{array}$ & $\begin{array}{l}88 \% \\
(80-93)\end{array}$ & $\begin{array}{l}3.24 \\
(1.67-6.28)\end{array}$ & $\begin{array}{l}0.5 \\
(0.32-0.77)\end{array}$ & $\begin{array}{l}6.98 \\
(2.5-19.1)\end{array}$ \\
\hline & Mahmood et al. [31] & 537 & $\begin{array}{l}76.8 \% \\
(71.8-81.4)\end{array}$ & $\begin{array}{l}77.9 \% \\
(71.9-83.2)\end{array}$ & NR & NR & NR \\
\hline & Juneau et al. [32] & 329 & $\begin{array}{l}81 \% \\
(73-86)\end{array}$ & $\begin{array}{l}85 \% \\
(78-91)\end{array}$ & NR & NR & NR \\
\hline \multirow[t]{2}{*}{ CIED infections } & Mahmood et al. [33] & 492 & $\begin{array}{l}85 \% \\
(80-89)\end{array}$ & $\begin{array}{l}90 \% \\
(84-94)\end{array}$ & NR & NR & NR \\
\hline & Juneau et al. [34] & 331 & $\begin{array}{l}87 \% \\
(82-91)\end{array}$ & $\begin{array}{l}94 \% \\
(88-98)\end{array}$ & NR & NR & NR \\
\hline \multirow[t]{2}{*}{$\begin{array}{l}\text { Vascular graft } \\
\text { infection }\end{array}$} & $\begin{array}{l}\text { Reinders Folmer } \\
\text { et al. [36] }\end{array}$ & 144 & $\begin{array}{l}95 \% \\
(87-99)\end{array}$ & $\begin{array}{l}80 \% \\
(69-89)\end{array}$ & NR & NR & $\begin{array}{l}38 \\
(8.5-170)\end{array}$ \\
\hline & Rojoa et al. [37] & NR & $\begin{array}{l}97 \% \\
(89-99)\end{array}$ & $\begin{array}{l}89 \% \\
(70-96)\end{array}$ & NR & NR & NR \\
\hline \multirow[t]{3}{*}{$\begin{array}{l}\text { Cardiac } \\
\text { sarcoidosis }\end{array}$} & Youssef et al. ${ }^{\mathrm{a}}$ [42] & 164 & $\begin{array}{l}89 \% \\
(79-96)\end{array}$ & $\begin{array}{l}78 \% \\
(68-86)\end{array}$ & $\begin{array}{l}4.1 \\
(1.7-10)\end{array}$ & $\begin{array}{l}0.19 \\
(0.1-0.4)\end{array}$ & $\begin{array}{l}25.6 \\
(7.3-89.5)\end{array}$ \\
\hline & Tang et al. ${ }^{\mathrm{a}}$ [43] & 559 & $\begin{array}{l}75 \% \\
(69-80)\end{array}$ & $\begin{array}{l}81 \% \\
(76-85)\end{array}$ & NR & NR & $\begin{array}{l}16.9 \\
(7.6-37.5)\end{array}$ \\
\hline & Kim et al. ${ }^{a}[44]$ & 891 & $\begin{array}{l}84 \% \\
(71-91)\end{array}$ & $\begin{array}{l}83 \% \\
(74-89)\end{array}$ & $\begin{array}{l}4.9 \\
(3.3-7.3)\end{array}$ & $\begin{array}{l}0.2 \\
(0.11-0.35)\end{array}$ & $\begin{array}{l}27 \\
(14-55)\end{array}$ \\
\hline Osteomyelitis & Wang et al. ${ }^{\mathrm{a}}$ [46] & 319 & $\begin{array}{l}92.3 \% \\
(86.7-96.1)\end{array}$ & $\begin{array}{l}92 \% \\
(87-95.6)\end{array}$ & $\begin{array}{l}9.8 \\
(6-16)\end{array}$ & $\begin{array}{l}0.11 \\
(0.07-0.2)\end{array}$ & $\begin{array}{l}98 \\
(42.8-224)\end{array}$ \\
\hline
\end{tabular}


Table 12.1 (continued)

\begin{tabular}{|c|c|c|c|c|c|c|c|}
\hline Topic & Authors & $\begin{array}{l}\text { Patients } \\
\text { included }\end{array}$ & $\begin{array}{l}\text { Sensitivity } \\
(95 \% \mathrm{CI})\end{array}$ & $\begin{array}{l}\text { Specificity } \\
(95 \% \mathrm{CI})\end{array}$ & $\begin{array}{l}\mathrm{LR}+ \\
(95 \% \mathrm{CI})\end{array}$ & $\begin{array}{l}\mathrm{LR}- \\
(95 \% \mathrm{CI})\end{array}$ & $\begin{array}{l}\text { DOR } \\
(95 \% \mathrm{CI})\end{array}$ \\
\hline \multirow{2}{*}{$\begin{array}{l}\text { Osteomyelitis } \\
\text { related to } \\
\text { diabetic foot }\end{array}$} & Treglia et al. ${ }^{\mathrm{a}}$ [47] & 178 & $\begin{array}{l}74 \% \\
(60-85)\end{array}$ & $\begin{array}{l}91 \% \\
(85-96)\end{array}$ & $\begin{array}{l}5.6 \\
(2-15.3)\end{array}$ & $\begin{array}{l}0.37 \\
(0.1-1.35)\end{array}$ & $\begin{array}{l}16.9 \\
(2-139.6)\end{array}$ \\
\hline & Lauri et al. ${ }^{\mathrm{a}}$ [48] & 254 & $\begin{array}{l}89 \% \\
(68-97)\end{array}$ & $\begin{array}{l}92 \% \\
(85-96)\end{array}$ & $\begin{array}{l}11 \\
(4.7-25)\end{array}$ & $\begin{array}{l}0.11 \\
(0.03-0.4)\end{array}$ & $\begin{array}{l}95 \\
(18-504)\end{array}$ \\
\hline \multirow[t]{3}{*}{$\begin{array}{l}\text { Prosthetic joint } \\
\text { infection }\end{array}$} & Jin et al. ${ }^{\mathrm{a}}$ [49] & 838 & $\begin{array}{l}86 \% \\
(82-90)\end{array}$ & $\begin{array}{l}86 \% \\
83-89\end{array}$ & NR & NR & NR \\
\hline & Verberne et al. ${ }^{\mathrm{a}}[50]$ & 666 & $\begin{array}{l}86 \% \\
(80-90)\end{array}$ & $\begin{array}{l}93 \% \\
(90-95)\end{array}$ & NR & NR & NR \\
\hline & Verberne et al. ${ }^{\mathrm{a}}[51]$ & 179 & $\begin{array}{l}70 \% \\
(56-81)\end{array}$ & $\begin{array}{l}84 \% \\
(76-90)\end{array}$ & NR & NR & NR \\
\hline \multirow[t]{3}{*}{ Spondylodiscitis } & $\begin{array}{l}\text { Prodromou et al. } \\
{[52]}\end{array}$ & 224 & $\begin{array}{l}97 \% \\
(83-100)\end{array}$ & $\begin{array}{l}88 \% \\
(74-95)\end{array}$ & $\begin{array}{l}8.2 \\
(3.5-18.9)\end{array}$ & $\begin{array}{l}0.03 \\
(0-0.21)\end{array}$ & NR \\
\hline & Yin et al. ${ }^{\mathrm{a}}[53]$ & 191 & $\begin{array}{l}96 \% \\
(84-99)\end{array}$ & $\begin{array}{l}90 \% \\
(79-96)\end{array}$ & $\begin{array}{l}9.8 \\
(4.4-22)\end{array}$ & $\begin{array}{l}0.05 \\
(0.01-0.19)\end{array}$ & $\begin{array}{l}124 \\
(39-394)\end{array}$ \\
\hline & Kim et al. ${ }^{\mathrm{a}}[54]$ & 212 & $\begin{array}{l}95 \% \\
(87-98)\end{array}$ & $\begin{array}{l}88 \% \\
(73-95)\end{array}$ & $\begin{array}{l}7.6 \\
(3.4-17.2)\end{array}$ & $\begin{array}{l}0.05 \\
(0.02-0.14)\end{array}$ & $\begin{array}{l}141 \\
(44-444)\end{array}$ \\
\hline $\begin{array}{l}\text { Rheumatic } \\
\text { diseases }\end{array}$ & $\begin{array}{l}\text { Descamps et al. } \\
{[57]}\end{array}$ & 2300 & NR & NR & NR & NR & NR \\
\hline \multirow[t]{2}{*}{$\begin{array}{l}\text { Inflammatory } \\
\text { bowel diseases }\end{array}$} & Treglia et al. ${ }^{\mathrm{a}}[59]$ & 219 & $\begin{array}{l}85 \% \\
(81-88)\end{array}$ & $\begin{array}{l}87 \% \\
(84-90)\end{array}$ & $\begin{array}{l}6.2 \\
(2.9-13.4)\end{array}$ & $\begin{array}{l}0.19 \\
(0.1-0.34)\end{array}$ & $\begin{array}{l}44.3 \\
(11.8-167)\end{array}$ \\
\hline & Zhang et al. ${ }^{\mathrm{a}}[60]$ & 162 & $\begin{array}{l}84 \% \\
(78-89)\end{array}$ & $\begin{array}{l}86 \% \\
(81-89)\end{array}$ & $\begin{array}{l}5.3 \\
(1.3-22)\end{array}$ & $\begin{array}{l}0.2 \\
(0.07-0.6)\end{array}$ & $\begin{array}{l}25.9 \\
(2.8-238)\end{array}$ \\
\hline
\end{tabular}

$L R+$ positive likelihood ratio, $L R-$ negative likelihood ratio, DOR diagnostic odds ratio, $95 \% C I 95 \%$ confidence interval, $N R$ not reported, CIED cardiovascular implantable electronic device, GCA giant cell arteritis, TA Takayasu arteritis, $\mathrm{TA}^{+}$Takayasu arteritis using National Health Institute scale ${ }^{a}$ Both PET and PET/CT are included

Dong et al. firstly reported that the pooled sensitivity and specificity of ${ }^{18} \mathrm{~F}$-FDG PET/CT for the detection of FUO were 98.2\% (95\%CI: 93.699.8) and $85.9 \%$ (95\%CI: 75-93.4), respectively. Therefore, this method should be considered among the first diagnostic tools for patients with FUO in whom conventional diagnostics have been unsuccessful [7].

Hao et al. confirmed the high sensitivity of ${ }^{18} \mathrm{~F}$-FDG PET/CT for the diagnosis of patients with FUO (pooled value: $88 \%$; 95\%CI: $81-88$ ), but the possibility of false positive results should be kept in mind [8].

Another meta-analysis demonstrated that abnormal ${ }^{18} \mathrm{~F}$-FDG PET/CT findings are associated with a substantially increased final diagnostic rate in FUO (pooled odds ratio: 8.94; 95\% CI: $4.18-19.12, p<0.00001)$. Consequently, ${ }^{18} \mathrm{~F}-$ FDG PET/CT could be considered for inclusion in the first-line diagnostic workup of FUO [9].

Tateuchi et al. reported that ${ }^{18} \mathrm{~F}-\mathrm{FDG}$ PET/CT can be useful in identifying the source of fever in patients with classic FUO (immunocompetent patients). The summary sensitivity and specificity were $86 \%$ (95\%CI: 81-90) and 52\% (95\%CI: 36-67), respectively. The contribution of ${ }^{18} \mathrm{~F}-$ FDG PET/CT may be limited in clinical settings in which infectious and neoplastic causes are less common. Indirect comparisons of test performance suggested that ${ }^{18} \mathrm{~F}$-FDG PET/CT outperformed standalone ${ }^{18}$ F-FDG PET, Gallium-67 scintigraphy, and radiolabelled leukocyte scintigraphy in detecting causes of FUO. Studies using standardized diagnostic algorithms are needed to determine the optimal timing for testing and to assess the impact of tests on management decisions and patient-relevant outcomes [10].

Recently, Bharucha et al. reported an overall diagnostic contribution of 56\% (95\% CI: 50-61) of ${ }^{18} \mathrm{~F}-\mathrm{FDG}$ PET/CT in all patients with FUO. In a subgroup analysis taking into account previous investigations the diagnostic yield/added contribution of ${ }^{18} \mathrm{~F}$-FDG PET/CT over CT was $32 \%$ (95\%CI: 22-44). The pooled proportion of 
abnormal ${ }^{18} \mathrm{~F}$-FDG-PET/CT in patients with FUO was 69\% (95\%CI: 63-75); the higher proportion of abnormal scans was accounted for by a proportion of false positive abnormal scans with no contribution to the final diagnosis, with an overall result of 9\% (95\%CI: 5-14). The authors concluded that there is insufficient evidence to support the value of ${ }^{18} \mathrm{~F}$-FDG PET/CT in investigative algorithms of FUO [11].

Conversely, in an updated meta-analysis on patients with FUO or inflammation of unknown origin (IUO), ${ }^{18} \mathrm{~F}-\mathrm{FDG}$ PET/CT was demonstrated to be very helpful for recognizing and excluding diseases, directing further diagnostic decisions, and avoiding unnecessary invasive examinations. The pooled sensitivity and specificity were $84 \%$ (95\%CI: 79-89) and 63\% (95\%CI: 49-75), respectively. Based on these findings, the authors recommended ${ }^{18} \mathrm{~F}-\mathrm{FDG}$ PET/CT among the first-line diagnostic tools for patients with FUO and IUO [12].

Lastly, it has been recently demonstrated that patients with negative ${ }^{18} \mathrm{~F}-\mathrm{FDG}$ PET/CT results were significantly more likely to present with spontaneous fever regression than those with positive ${ }^{18} \mathrm{~F}$-FDG PET/CT results (summary relative risk $=5.6$ : 95\%CI: 3.4-9.2; $p<0.001$ ) [13].

Overall, there is not agreement among the selected meta-analyses about the added value of ${ }^{18} \mathrm{~F}-\mathrm{FDG}$ PET/CT in patients with FUO. The main drawback of the meta-analyses evaluating the diagnostic performance of ${ }^{18} \mathrm{~F}-\mathrm{FDG}$ PET/CT for this specific indication is that they include articles without real FUO patients or with highly variable definitions of FUO; therefore, related meta-analyses could be not accurate in this regard [14].

\subsection{Large Vessel Vasculitis (LVV)}

Large vessel vasculitis (LVV) is defined as an inflammatory disease mainly affecting the large arteries, with two major variants, Takayasu arteritis (TA) and giant cell arteritis (GCA). GCA often coexists with polymyalgia rheumatica (PMR) in the same patient, since both belong to the same disease spectrum [15]. ${ }^{18}$ F-FDG PET/ CT may demonstrate increased radiopharmaceu- tical uptake in the vascular wall of large vessels in patients with LVV; therefore, this method may be used for diagnosis, monitoring of disease activity, and evaluating disease progression in LVV [15-18], and several meta-analyses have assessed the role of this imaging method in this setting [19-25].

First meta-analyses including both ${ }^{18} \mathrm{~F}-\mathrm{FDG}$ PET and PET/CT studies reported a valuable diagnostic performance of these methods in patients with GCA with a pooled sensitivity and specificity of $80 \%$ (95\%CI: 63-91) and 89\% (95\%CI: 78-94), respectively [19], and a moderate value of these methods in assessing TA activity, with a pooled sensitivity and specificity of $70.1 \%$ (95\%CI: 58.6-80) and 77.2\% (95\%CI: 64.2-87.3), respectively [20].

In a meta-analysis of Soussan et al. including both ${ }^{18} \mathrm{~F}$-FDG PET and PET/CT studies, these imaging methods showed good performances in the diagnosis of LVV, with higher accuracy in GCA patients than in TA patients. A vascular uptake equal to or higher than the liver uptake appeared to be a good criterion for the diagnosis of vascular inflammation. ${ }^{18} \mathrm{~F}-\mathrm{FDG}$ PET or PET/ CT showed high sensitivity and specificity for the diagnosis of LVV in GCA patients in comparison to controls, with pooled values of $90 \%$ (95\% CI: 79-93) and 98\% (95\%CI: 94-99), respectively. ${ }^{18} \mathrm{~F}-\mathrm{FDG}$ PET or PET/CT had a pooled sensitivity of $87 \%$ (95\%CI: 78-93) and specificity of $73 \%$ (95\%CI: 63-81) for the assessment of disease activity in TA, with up to $84 \%$ of specificity in studies using National Institutes of Health criteria as the disease activity assessment scale [21].

Another meta-analysis by Lee et al. confirmed that ${ }^{18}$ F-FDG PET/CT has good diagnostic accuracy for LVV with a pooled sensitivity and specificity of $83.9 \%$ (95\%CI: 71.7-92.4) and $87.2 \%$ (95\%CI: 72.6-95.7), respectively [22].

In a recent meta-analysis, the pooled sensitivity and specificity of ${ }^{18} \mathrm{~F}$-FDG PET or PET/CT for detecting active disease in TA compared to clinical assessment were 81\% (95\%CI: 69-89) and 74\% (95\%CI: 55-86), respectively. Active disease by ${ }^{18} \mathrm{~F}-\mathrm{FDG}$ PET or PET/CT was also associated with elevations of acute phase reactants, as C-reactive protein (CRP) and erythrocyte sedimentation rate (ESR) [23]. Conversely, 
in another meta-analysis by Gomez et al. about the association between the CRP value and ${ }^{18} \mathrm{~F}$ FDG PET or PET/CT vascular positivity in TA, CRP concentration only moderately reflected the ${ }^{18} \mathrm{~F}-\mathrm{FDG}$ PET vascular positivity in TA, suggesting dissociated information [24]. More prospective studies are needed to assess the value of ${ }^{18} \mathrm{~F}-\mathrm{FDG}$ PET/CT as an independent biomarker for subtle vascular wall inflammation detection in patients with TA [24].

Lastly, an updated meta-analysis confirmed that ${ }^{18} \mathrm{~F}-\mathrm{FDG}$ PET or PET/CT has a good performance for the detection of active disease in patients with LVV with a pooled sensitivity and specificity of $88 \%$ (95\%CI: 79-93) and $81 \%$ (95\%CI: 64-91), respectively. Therefore, ${ }^{18} \mathrm{~F}-$ FDG PET/CT could be suggested as a surrogate biomarker for assessment of disease activity of LVV during or after immunosuppressive therapy, but further studies are warranted to determine if PET-based treatment of LVV can improve outcomes [25].

Several factors may significantly influence the diagnostic performance of ${ }^{18} \mathrm{~F}$-FDG PET/CT in LVV including different PET interpretation criteria, atherosclerotic vascular ${ }^{18} \mathrm{~F}-\mathrm{FDG}$ uptake (a possible source of false positive findings), and immunosuppressive therapy (a possible source of false findings) [15].

Overall, based on the available evidence, ${ }^{18} \mathrm{~F}$ FDG PET/CT has demonstrated high diagnostic performance for the detection of LVV. Further studies are needed to select the most clinically relevant and reproducible criteria for defining the presence of LVV with ${ }^{18} \mathrm{~F}-\mathrm{FDG}$ PET/CT, as well as to test the clinical impact of ${ }^{18} \mathrm{~F}-\mathrm{FDG}$ PET/CT on the management of patients with suspected LVV [15].

\subsection{Infectious Endocarditis and Cardiovascular Implantable Electronic Device Infections}

Infectious endocarditis (IE) is a serious and potentially life-threatening condition. The current diagnosis of IE is based on the modified Duke criteria, which has approximately $80 \%$ sen- sitivity for the diagnosis of native valve endocarditis (NVE), with lower sensitivity for the diagnosis of prosthetic valve endocarditis (PVE) and culture-negative endocarditis [26, 27]. Noninvasive imaging modalities may improve diagnosis of infective endocarditis (IE) [26, 27]. In particular, ${ }^{18} \mathrm{~F}$-FDG PET/CT is currently included as diagnostic tool in the diagnostic flow chart for IE [26-29] and some meta-analyses have evaluated the diagnostic performance of this method in patients with IE or CIED infections [30-34].

A first meta-analysis published in 2016 demonstrated that the overall diagnostic performance of ${ }^{18} \mathrm{~F}-\mathrm{FDG}$ PET/CT for the diagnosis of IE was not high due to the low sensitivity: pooled sensitivity and specificity were $61 \%$ (95\%CI: 52-88) and 88\% (95\%CI: 80-93), respectively. However, the diagnostic performance of ${ }^{18} \mathrm{~F}-\mathrm{FDG}$ PET/CT increased in the subgroup of patients with PVE [30].

Mahmood et al. demonstrated that ${ }^{18} \mathrm{~F}-\mathrm{FDG}$ $\mathrm{PET} / \mathrm{CT}$ may be a useful adjunctive diagnostic tool in the evaluation of diagnostically challenging cases of IE, particularly in PVE. The pooled sensitivity and specificity of ${ }^{18} \mathrm{~F}-\mathrm{FDG}$ PET/CT for diagnosis of IE were $76.8 \%$ (95\%CI: 71.881.4 ) and $77.9 \%$ (95\%CI: 71.9-83.2), respectively. Diagnostic accuracy was improved for PVE with pooled sensitivity of $80.5 \%$ (95\%CI: $74.1-86)$ and pooled specificity of $73.1 \%$ (95\%CI: 63.8-81.2). More recent studies published from 2015 to 2017 reported a higher pooled sensitivity of $81.3 \%$ (95\%CI: 74.3-87) and specificity of $79 \%$ (95\%CI: 71.2-85.5). The majority of the recent studies were prospective and used a specific protocol (i.e., a lowcarbohydrate fat-allowed diet for at least $24 \mathrm{~h}$ prior to imaging, a prolonged fasting prior to imaging, and/or an intravenous heparin bolus prior to ${ }^{18} \mathrm{~F}$-FDG administration). ${ }^{18} \mathrm{~F}$-FDG PET/ CT also has the potential to detect clinically relevant extra-cardiac foci of infection, malignancy, and other sources of inflammation, leading to more appropriate treatment regimens and surgical intervention. Additional extra-cardiac foci of infection were found on $17 \%$ of patients in this meta-analysis [31].

In another meta-analysis, Juneau et al. demonstrated that ${ }^{18} \mathrm{~F}-\mathrm{FDG}$ PET/CT has a good diag- 
nostic accuracy for the diagnosis of IE if adequate patient preparation for suppression of physiological myocardial ${ }^{18} \mathrm{~F}$-FDG uptake was performed, including prolonged fasting at least $12 \mathrm{~h}$ and/or heparin injection before ${ }^{18} \mathrm{~F}-\mathrm{FDG}$ administration, and/or high-fat carbohydrate-restricted proteinpermitted diet (minimum two meals for $24 \mathrm{~h}$ ). Pooled sensitivity of ${ }^{18} \mathrm{~F}$-FDG PET/CT performed with adequate cardiac preparation for the diagnosis of IE was $81 \%$ (95\% CI: 73-86) and pooled specificity was $85 \%$ (95\%CI: $78-91)$. In the subgroup of patients with PVE, the pooled sensitivity was $85 \%$ (95\%CI: 77-91) but specificity was $81 \%$ (95\%CI: 72-88). Therefore, ${ }^{18} \mathrm{~F}-$ FDG PET/CT may be useful in the investigation of IE, and should be considered in cases where the diagnosis is uncertain [32].

${ }^{18} \mathrm{~F}$-FDG PET/CT may be helpful in the diagnosis of cardiovascular implantable electronic device (CIED) infections, particularly in patients with the absence of localizing signs or definitive echocardiographic findings. In a recent metaanalysis, Mahmood et al. reported a pooled sensitivity and specificity of ${ }^{18} \mathrm{~F}$-FDG PET/CT in the diagnosis of CIED infections of $85 \%$ (95\% CI: 80-89) and 90\% (95\%CI: 84-94), respectively. ${ }^{18} \mathrm{~F}-\mathrm{FDG}$ PET/CT demonstrated a higher sensitivity of 96\% (95\%CI: 86-99) and specificity of 97\% (95\%CI: 86-99) for diagnosis of pocket infections. Diagnostic accuracy for lead infections or CIED-IE was lower with pooled sensitivity of $76 \%$ (95\% CI: 65-85) and specificity of $83 \%$ (95\% CI: 72-90). In the subgroup of studies that described the use of any myocardial suppression protocol, the pooled sensitivity was $92 \%$ (95\%CI: 85-96) and the pooled specificity was 81\% (95\%CI: 71-89) [33].

Another recent meta-analysis confirmed the high diagnostic performance of ${ }^{18}$ F-FDG PET/ $\mathrm{CT}$ for the diagnosis of CIED infections with a pooled sensitivity of $87 \%$ (95\%CI: 82-91) and a pooled specificity of $94 \%$ (95\%CI: 88-98). Pooled sensitivity and specificity for diagnosis of pocket/generator related CIED infections were 93\% (95\%CI: 84-98) and 98\% (95\%CI: 88-100), respectively. Pooled sensitivity and specificity for diagnosis of lead or IE-related CIED infection were 65\% (95\%CI: 53-76) and 88\% (95\%CI: 77-94), respectively [34].
Overall, ${ }^{18} \mathrm{~F}-\mathrm{FDG}$ PET/CT demonstrated a good diagnostic performance in patients with IE and CIED infections with higher diagnostic accuracy if adequate patient preparation for suppression of physiological myocardial ${ }^{18} \mathrm{~F}-\mathrm{FDG}$ uptake was performed.

\subsection{Vascular Graft Infections}

Vascular graft infection (VGI), a serious complication in vascular surgery, has a high morbidity and mortality rate. The diagnosis is complicated by non-specific symptoms and challenged by the variable accuracy of different imaging techniques $[35,36]$. A recent meta-analysis demonstrated a good diagnostic performance of ${ }^{18} \mathrm{~F}-\mathrm{FDG}$ PET/ $\mathrm{CT}$ in patients with VGI with a pooled sensitivity and specificity of 95\% (95\%CI: 87-99) and 80\% (95\%CI: 69-89), respectively [36].

Another recent meta-analysis investigating the diagnostic accuracy of ${ }^{18} \mathrm{~F}$-FDG PET/CT in VGI reported a pooled sensitivity and specificity for focal ${ }^{18} \mathrm{~F}-\mathrm{FDG}$ uptake of $97 \%$ (95\%CI: 89-99) and $89 \%$ (95\%CI: 70-96), respectively [37].

Factors influencing the diagnostic performance of ${ }^{18} \mathrm{~F}$-FDG PET/CT in VGI include the time at which ${ }^{18} \mathrm{~F}$-FDG PET/CT is performed after surgery (if ${ }^{18} \mathrm{~F}-\mathrm{FDG} \mathrm{PET} / \mathrm{CT}$ is performed in cases of recently implanted grafts, false positive ${ }^{18} \mathrm{~F}$-FDG PET/CT findings for VGI are possible), the use of antibiotics prior to ${ }^{18} \mathrm{~F}-\mathrm{FDG}$ PET/CT (causing possible false negative findings for VGI), and the PET interpretation criteria used [37].

\subsection{Sarcoidosis}

Sarcoidosis is a multisystem chronic inflammatory disease of unknown etiology characterized by widespread growth of non-caseating granulomas. The diagnosis of sarcoidosis is based on clinical and imaging presentation, histological confirmation, and the absence of alternative diseases. Imaging techniques may play a role in the diagnostic workup of patients with sarcoidosis to assess disease extent and activity, and treatment response evaluation [38]. The role of ${ }^{18} \mathrm{~F}-\mathrm{FDG}$ 
PET/CT in patients with sarcoidosis is well established [39, 40]. Based on evidence-based data, the recommendations for use of ${ }^{18} \mathrm{~F}-\mathrm{FDG}$ PET/CT in patients with sarcoidosis could be the following: evaluation of inflammatory active disease in patients with persistent symptoms and negative serologic markers; assessment of inflammation in radiologic stage IV sarcoidosis with lung fibrosis; evaluation of inflammatory active extrathoracic sites of sarcoidosis or assessment of cardiac sarcoidosis (especially in patients with implanted pacemakers); identification of active sites for diagnostic biopsy not revealed by other methods; evaluation of treatment response in refractory sarcoidosis [39].

The role of ${ }^{18} \mathrm{~F}-\mathrm{FDG}$ PET/CT in cardiac sarcoidosis is currently under active investigation [41] and some meta-analyses have addressed the diagnostic performance of ${ }^{18} \mathrm{~F}$-FDG PET/CT in this setting [42-44].

In the meta-analysis of Youssef et al., the pooled sensitivity and specificity of ${ }^{18} \mathrm{~F}-\mathrm{FDG}$ PET or PET/CT for diagnosis of cardiac sarcoidosis were 89\% (95\%CI: 79-96) and 78\% (95\%CI: 68-86), respectively [42].

Tang et al. demonstrated that the diagnostic accuracy of ${ }^{18} \mathrm{~F}-\mathrm{FDG}$ PET/CT for cardiac sarcoidosis depends on adequate suppression of physiological cardiac glucose uptake. Overall, ${ }^{18} \mathrm{~F}-\mathrm{FDG}$ PET/CT had a pooled sensitivity of 75\% (95\%CI: 69-80) and a pooled specificity of 81\% (95\% CI: 76-85) for the diagnosis of cardiac sarcoidosis. This modest diagnostic accuracy was attributed to the inclusion of studies in which a short fasting duration before scanning likely influenced its sensitivity. Excluding studies without adequate myocardial suppression resulted in a pooled sensitivity of $81 \%$ (95\%CI: 76-86) and a pooled specificity of $82 \%$ (95\%CI: 77-86). Fasting for at least $12 \mathrm{~h}$ before scanning or a high-fat low-carbohydrate diet given at 3-6 h before imaging or heparin infusion before imaging has shown to improve the diagnostic accuracy of ${ }^{18}$ F-FDG PET/CT in cardiac sarcoidosis [43].

Lastly, an updated meta-analysis on the diagnostic performance of ${ }^{18} \mathrm{~F}$-FDG PET or PET/CT in cardiac sarcoidosis demonstrated a pooled sensitivity and specificity of $84 \%$ (95\%CI: 71-91) and $83 \%$ (95\% CI: 74-89), respectively. The pres- ence of combined myocardial perfusion imaging improved the diagnostic accuracy of ${ }^{18} \mathrm{~F}-\mathrm{FDG}$ PET/CT for diagnosis of cardiac sarcoidosis. Nevertheless further large multicenter studies in this setting are needed [44].

\subsection{Musculoskeletal Infections}

Timely identification and precise localization of musculoskeletal infections by imaging techniques are critical for early initiation of treatment and can have a significant impact on patient outcome. In this setting, nuclear medicine and radiological imaging are complementary techniques [45]. In particular, several meta-analyses have investigated the diagnostic performance of ${ }^{18} \mathrm{~F}$ FDG PET/CT in patients with suspicious musculoskeletal infections [46-54].

Wang et al. calculated the diagnostic performance of ${ }^{18} \mathrm{~F}$-FDG PET or PET/CT in patients with suspicious osteomyelitis reporting a high pooled sensitivity and specificity in this setting: pooled values were $92.3 \%$ (95\%CI: 86.7-96.1) and 92\% (95\%CI: 87-95.6), respectively [46].

A first meta-analysis focused on the diagnostic performance of ${ }^{18} \mathrm{~F}-\mathrm{FDG}$ PET or PET/CT in osteomyelitis related to diabetic foot reported a pooled sensitivity and specificity of $74 \%$ (95\% CI: 60-85) and 91\% (95\%CI: 85-96), respectively [47]. An updated meta-analysis on the same topic demonstrated a pooled sensitivity of $89 \%$ (95\%CI: 68-97) and a pooled specificity of $92 \%$ (95\%CI: 85-96) [48].

Jin et al. calculated the diagnostic performance of ${ }^{18} \mathrm{~F}$-FDG PET or PET/CT in detecting prosthetic infection after arthroplasty. They found a pooled sensitivity and specificity of $86 \%$ (95\%CI: 82-90) and 86\% (95\%CI: 83-89), respectively. The pooled sensitivity of ${ }^{18} \mathrm{~F}-\mathrm{FDG}$ PET or PET/CT in demonstrating hip and knee prosthetic infection was $88 \%$ (95\%CI: 83-92) and $72 \%$ (95\%CI: 58-84), respectively. The pooled specificity of ${ }^{18} \mathrm{~F}$-FDG PET or PET/CT in demonstrating hip and knee prosthetic infection was 88\% (95\%CI: 84-91) and 80\% (95\% CI: 71-88), respectively [49].

A meta-analysis focused on periprosthetic hip infection confirmed the good diagnostic accuracy 
of ${ }^{18} \mathrm{~F}$-FDG PET or PET/CT in this setting with pooled sensitivity and specificity of $86 \%$ (95\%CI: 80-90) and 93\% (95\%CI: 90-95), respectively, using increased ${ }^{18} \mathrm{~F}-\mathrm{FDG}$ uptake in the boneprosthesis interface as the criterion for infection for the index test [50].

A meta-analysis focused on periprosthetic knee infection demonstrated a nonoptimal diagnostic accuracy of ${ }^{18} \mathrm{~F}$-FDG PET or PET/CT in this setting with pooled sensitivity and specificity of 70\% (95\%CI: 56-81) and 84\% (95\% CI: 76-90) [51].

Some factors influencing the diagnostic performance of ${ }^{18} \mathrm{~F}$-FDG PET/CT in patients with osteomyelitis should be underlined: first of all, several interpretation criteria of ${ }^{18} \mathrm{~F}$-FDG PET have been used in the literature, by using visual and/or semi-quantitative criteria, leading to different diagnostic accuracy values [46-51]. Furthermore, continuous physiologic ${ }^{18} \mathrm{~F}-\mathrm{FDG}$ activity around the prostheses may be cause of false positive ${ }^{18} \mathrm{~F}-\mathrm{FDG}$ PET/CT findings for periprosthetic infection [49-51].

${ }^{18}$ F-FDG PET or PET/CT has an excellent diagnostic performance in detecting infectious spondylodiscitis [55]. A first meta-analysis on ${ }^{18}$ F-FDG PET or PET/CT in patients with suspicious spondylodiscitis reported a pooled sensitivity and specificity of $97 \%$ (95\%CI: 83-100) and 88\% (95\% CI: 74-95), respectively [52]. In this setting, the diagnostic performance of ${ }^{18} \mathrm{~F}$-FDG PET or PET/CT was higher compared with magnetic resonance imaging (MRI). Considering studies comparing ${ }^{18} \mathrm{~F}$-FDG PET or PET/CT and MRI, pooled sensitivity and specificity of ${ }^{18} \mathrm{~F}-$ FDG PET or PET/CT were 96\% (95\%CI: 84-99) and 90\% (95\%CI: 79-96), whereas the pooled sensitivity and specificity of MRI were $76 \%$ (95\%CI: 65-84) and 62\% (95\%CI: 45-77) [53]. Another recent meta-analysis confirmed the better diagnostic accuracy of ${ }^{18} \mathrm{~F}$-FDG PET or PET/ CT compared to MRI for the detection of spondylodiscitis: for ${ }^{18} \mathrm{~F}-\mathrm{FDG}$ PET or PET/CT, pooled sensitivity and specificity were 95\% (95\%CI: 87-98) and 88\% (95\%CI: 73-95), respectively; for MRI, pooled sensitivity and specificity were 85\% (95\%CI: 65-95) and 66\% (95\%CI: 48-80), respectively [54].
Overall, based on the available evidence, ${ }^{18}$ F-FDG PET/CT has demonstrated a good diagnostic performance for the detection of musculoskeletal infections.

\subsection{Inflammatory Rheumatic Diseases}

Molecular imaging methods, including ${ }^{18} \mathrm{~F}-\mathrm{FDG}$ PET/CT, have been proposed for a better assessment of inflammatory rheumatic diseases [56]. ${ }^{18} \mathrm{~F}$-FDG uptake in the shoulders or hips was often reported in PMR (pooled prevalence: 76\%), especially in periarticular sites (pooled prevalence: $84 \%$ ). Furthermore, interspinous ${ }^{18} \mathrm{~F}-\mathrm{FDG}$ uptake, demonstrating interspinous bursitis, is common in PMR (pooled prevalence: 67\%). However, these findings are not very specific for PMR [57].

Patients with rheumatoid arthritis (RA) may also have interspinous ${ }^{18} \mathrm{~F}-\mathrm{FDG}$ uptake (pooled prevalence: $34 \%$ ) or articular ${ }^{18} \mathrm{~F}-\mathrm{FDG}$ uptake in shoulders or hips (pooled prevalence: 66\%) or in other articular regions (pooled prevalence: $78 \%$ ). Articular ${ }^{18} \mathrm{~F}$-FDG uptake is not specific for PMR or RA, as it is common in other connective tissue diseases (pooled prevalence: $70 \%$ ). Overall, ${ }^{18} \mathrm{~F}$ FDG PET/CT is helpful in diagnostic research, but the interpretation of ${ }^{18} \mathrm{~F}-\mathrm{FDG}$ uptake at each site is not characteristic of a specific inflammatory rheumatic disease [57].

\subsection{Inflammatory Bowel Diseases}

${ }^{18}$ F-FDG PET/CT may also be used to image areas of active inflammation, such as those occurring in patients with active inflammatory bowel disease (IBD) as Crohn's disease and ulcerative colitis [58]. In this setting, ${ }^{18} \mathrm{~F}-\mathrm{FDG}$ PET or PET/CT showed a good accuracy with a pooled sensitivity and specificity of $85 \%$ (95\%CI: 81-88) and 87\% (95\%CI 84-90), respectively [59]. These findings were confirmed by another meta-analysis including prospective studies only [60]. Nevertheless, more prospec- 
tive studies evaluating the role of ${ }^{18} \mathrm{~F}-\mathrm{FDG}$ PET/ $\mathrm{CT}$ for this indication are needed. Specific challenges for the use of ${ }^{18} \mathrm{~F}-\mathrm{FDG}$ PET/CT in IBD are the physiological ${ }^{18} \mathrm{~F}-\mathrm{FDG}$ uptake in the bowel and the movement of the bowel that may influence a correct co-registration of ${ }^{18} \mathrm{~F}-\mathrm{FDG}$ PET and CT images [59].

\section{References}

1. Signore A, Anzola KL, Auletta S, Varani M, Petitti A, Pacilio M, et al. Current status of molecular imaging in inflammatory and autoimmune disorders. Curr Pharm Des. 2018;24(7):743-53.

2. Sollini M, Lauri C, Boni R, Lazzeri E, Erba PA, Signore A. Current status of molecular imaging in infections. Curr Pharm Des. 2018;24(7):754-71.

3. Jamar F, Buscombe J, Chiti A, Christian PE, Delbeke $\mathrm{D}$, Donohoe KJ, et al. EANM/SNMMI guideline for 18F-FDG use in inflammation and infection. J Nucl Med. 2013;54(4):647-58.

4. Meyer M, Testart N, Jreige M, Kamani C, Moshebah M, Muoio B, et al. Diagnostic performance of PET or PET/CT using (18)F-FDG labeled white blood cells in infectious diseases: a systematic review and a bivariate meta-analysis. Diagnostics. 2019;9(2):E60.

5. Treglia G. Diagnostic performance of (18)F-FDG $\mathrm{PET} / \mathrm{CT}$ in infectious and inflammatory diseases according to published meta-analyses. Contrast Media Mol Imaging. 2019;2019:3018349.

6. Kouijzer IJE, Mulders-Manders CM, Bleeker-Rovers CP, Oyen WJG. Fever of unknown origin: the value of FDG-PET/CT. Semin Nucl Med. 2018;48(2):100-7.

7. Dong MJ, Zhao K, Liu ZF, Wang GL, Yang SY, Zhou GJ. A meta-analysis of the value of fluorodeoxyglucose-PET/PET-CT in the evaluation of fever of unknown origin. Eur $\mathrm{J}$ Radiol. 2011;80(3):834-44.

8. Hao R, Yuan L, Kan Y, Li C, Yang J. Diagnostic performance of 18F-FDG PET/CT in patients with fever of unknown origin: a meta-analysis. Nucl Med Commun. 2013;34(7):682-8.

9. Besson FL, Chaumet-Riffaud P, Playe M, Noel N, Lambotte O, Goujard C, et al. Contribution of (18) F-FDG PET in the diagnostic assessment of fever of unknown origin (FUO): a stratification-based meta-analysis. Eur J Nucl Med Mol Imaging. 2016;43(10):1887-95.

10. Takeuchi M, Dahabreh IJ, Nihashi T, Iwata M, Varghese GM, Terasawa T. Nuclear imaging for classic fever of unknown origin: meta-analysis. J Nucl Med. 2016;57(12):1913-9.

11. Bharucha T, Rutherford A, Skeoch S, Alavi A, Brown M, Galloway J, FDG-PET/CT in fever of unknown origin working group. Diagnostic yield of FDG-PET/ $\mathrm{CT}$ in fever of unknown origin: a systematic review, meta-analysis, and Delphi exercise. Clin Radiol. 2017;72(9):764-71.

12. Kan Y, Wang W, Liu J, Yang J, Wang Z. Contribution of 18F-FDG PET/CT in a case-mix of fever of unknown origin and inflammation of unknown origin: a meta-analysis. Acta Radiol. 2019;60(6):716-25.

13. Takeuchi M, Nihashi T, Gafter-Gvili A, GarcíaGómez FJ, Andres E, Blockmans D, et al. Association of 18F-FDG PET or PET/CT results with spontaneous remission in classic fever of unknown origin: a systematic review and meta-analysis. Medicine. 2018;97(43):e12909.

14. Kouijzer IJE, van der Meer JWM, Oyen WJG, Bleeker-Rovers CP. Diagnostic yield of FDG-PET/ $\mathrm{CT}$ in fever of unknown origin: a systematic review, meta-analysis, and Delphi exercise. Clin Radiol. 2018;73(6):588-9.

15. Slart RHJA, Writing group, Reviewer group, Members of EANM Cardiovascular, Members of EANM Infection \& Inflammation, Members of Committees, SNMMI Cardiovascular, Members of Council, PET Interest Group, Members of ASNC, EANM Committee Coordinator. FDG-PET/CT(A) imaging in large vessel vasculitis and polymyalgia rheumatica: joint procedural recommendation of the EANM, SNMMI, and the PET Interest Group (PIG), and endorsed by the ASNC. Eur J Nucl Med Mol Imaging. 2018;45(7):1250-69.

16. Treglia G, Mattoli MV, Leccisotti L, Ferraccioli G, Giordano A. Usefulness of whole-body fluorine-18fluorodeoxyglucose positron emission tomography in patients with large-vessel vasculitis: a systematic review. Clin Rheumatol. 2011;30(10):1265-75.

17. Treglia G, Versari A, Giovanella L, Pipitone N, Salvarani C. Is 18F-FDG PET a 'potentially hazardous' or an effective tool in evaluating patients with large-vessel vasculitis? Clin Exp Rheumatol. 2013;31(1 Suppl 75):S93.

18. Dejaco C, Ramiro S, Duftner C, Besson FL, Bley TA, Blockmans D, et al. EULAR recommendations for the use of imaging in large vessel vasculitis in clinical practice. Ann Rheum Dis. 2018;77(5):636-43.

19. Besson FL, Parienti JJ, Bienvenu B, Prior JO, Costo $\mathrm{S}$, Bouvard G, et al. Diagnostic performance of ${ }^{18}$ F-fluorodeoxyglucose positron emission tomography in giant cell arteritis: a systematic review and meta-analysis. Eur J Nucl Med Mol Imaging. 2011;38(9):1764-72.

20. Cheng Y, Lv N, Wang Z, Chen B, Dang A. 18-FDGPET in assessing disease activity in Takayasu arteritis: a meta-analysis. Clin Exp Rheumatol. 2013;31(1 Suppl 75):S22-7.

21. Soussan M, Nicolas P, Schramm C, Katsahian S, Pop G, Fain O, et al. Management of large-vessel vasculitis with FDG-PET: a systematic literature review and meta-analysis. Medicine. 2015;94(14):e622.

22. Lee YH, Choi SJ, Ji JD, Song GG. Diagnostic accuracy of 18F-FDG PET or PET/CT for large vessel vasculitis: a meta-analysis. Z Rheumatol. 2016;75(9):924-31. 
23. Barra L, Kanji T, Malette J, Pagnoux C, CanVasc. Imaging modalities for the diagnosis and disease activity assessment of Takayasu's arteritis: a systematic review and meta-analysis. Autoimmun Rev. 2018;17(2):175-87.

24. Gomez L, Chaumet-Riffaud P, Noel N, Lambotte O, Goujard C, Durand E, et al. Effect of CRP value on (18)F-FDG PET vascular positivity in Takayasu arteritis: a systematic review and per-patient based meta-analysis. Eur J Nucl Med Mol Imaging. 2018;45(4):575-81.

25. Lee SW, Kim SJ, Seo Y, Jeong SY, Ahn BC, Lee J. F-18 FDG PET for assessment of disease activity of large vessel vasculitis: a systematic review and metaanalysis. J Nucl Cardiol. 2019;26(1):59-67.

26. Erba PA, Lancellotti P, Vilacosta I, Gaemperli O, Rouzet F, Hacker M, et al. Recommendations on nuclear and multimodality imaging in IE and CIED infections. Eur J Nucl Med Mol Imaging. 2018;45(10):1795-815.

27. Gomes A, Glaudemans AWJM, Touw DJ, van Melle JP, Willems TP, Maass AH, et al. Diagnostic value of imaging in infective endocarditis: a systematic review. Lancet Infect Dis. 2017;17(1):e1-e14.

28. Treglia G, Bertagna F. Factors influencing the sensitivity of 18F-FDG PET/CT in the detection of infective endocarditis. Eur $\mathrm{J}$ Nucl Med Mol Imaging. 2013;40(7):1112-3.

29. Caldarella C, Leccisotti L, Treglia G, Giordano A. Which is the optimal acquisition time for FDG PET/CT imaging in patients with infective endocarditis? J Nucl Cardiol. 2013;20(2):307-9.

30. Yan J, Zhang C, Niu Y, Yuan R, Zeng X, Ge X, et al. The role of 18F-FDG PET/CT in infectious endocarditis: a systematic review and meta-analysis. Int J Clin Pharmacol Ther. 2016;54(5):337-42.

31. Mahmood M, Kendi AT, Ajmal S, Farid S, O'Horo JC, Chareonthaitawee P, et al. Meta-analysis of 18F-FDG PET/CT in the diagnosis of infective endocarditis. J Nucl Cardiol. 2019;26(3):922-35.

32. Juneau D, Golfam M, Hazra S, Erthal F, Zuckier LS, Bernick J, et al. Molecular imaging for the diagnosis of infective endocarditis: a systematic literature review and meta-analysis. Int $\mathrm{J}$ Cardiol. 2018;253:183-8.

33. Mahmood M, Kendi AT, Farid S, Ajmal S, Johnson GB, Baddour LM, et al. Role of (18)F-FDG PET/ $\mathrm{CT}$ in the diagnosis of cardiovascular implantable electronic device infections: a meta-analysis. J Nucl Cardiol. 2019;26(3):958-70.

34. Juneau D, Golfam M, Hazra S, Zuckier LS, Garas S, Redpath C, et al. Positron emission tomography and single-photon emission computed tomography imaging in the diagnosis of cardiac implantable electronic device infection: a systematic review and meta-analysis. Circ Cardiovasc Imaging. 2017;10(4):e005772.

35. Treglia G, Maggi F, Bonomo L, Giordano A. Usefulness of fluorine-18 fluorodeoxyglucose PET/ computed tomography in diagnosis of aortitis and treatment response evaluation in a patient with aortic prosthesis. J Cardiovasc Med. 2011;12(11):814-6.

36. Reinders Folmer EI, Von Meijenfeldt GCI, Van der Laan MJ, Glaudemans AWJM, Slart RHJA, Saleem $\mathrm{BR}$, et al. Diagnostic imaging in vascular graft infection: a systematic review and meta-analysis. Eur J Vasc Endovasc Surg. 2018;56(5):719-29.

37. Rojoa D, Kontopodis N, Antoniou SA, Ioannou CV, Antoniou GA. 18F-FDG PET in the diagnosis of vascular prosthetic graft infection: a diagnostic test accuracy meta-analysis. Eur J Vasc Endovasc Surg. 2019;57(2):292-301.

38. Larici AR, Glaudemans AW, Del Ciello A, Slart RH, Calandriello L, Gheysens O. Radiological and nuclear medicine imaging of sarcoidosis. Q J Nucl Med Mol Imaging. 2018;62(1):14-33.

39. Treglia G, Annunziata S, Sobic-Saranovic D, Bertagna F, Caldarella C, Giovanella L. The role of 18F-FDG-PET and PET/CT in patients with sarcoidosis: an updated evidence-based review. Acad Radiol. 2014;21(5):675-84.

40. Treglia G, Taralli S, Giordano A. Emerging role of whole-body 18F-fluorodeoxyglucose positron emission tomography as a marker of disease activity in patients with sarcoidosis: a systematic review. Sarcoidosis Vasc Diffuse Lung Dis. 2011;28(2):87-94.

41. Slart RHJA, Glaudemans AWJM, Lancellotti P, Hyafil F, Blankstein R, Schwartz RG, et al. A joint procedural position statement on imaging in cardiac sarcoidosis: from the Cardiovascular and Inflammation \& Infection Committees of the European Association of Nuclear Medicine, the European Association of Cardiovascular Imaging, and the American Society of Nuclear Cardiology. J Nucl Cardiol. 2018;25(1):298-319.

42. Youssef G, Leung E, Mylonas I, Nery P, Williams K, Wisenberg G, et al. The use of 18F-FDG PET in the diagnosis of cardiac sarcoidosis: a systematic review and metaanalysis including the Ontario experience. J Nucl Med. 2012;53(2):241-8.

43. Tang R, Wang JT, Wang L, Le K, Huang Y, Hickey AJ, et al. Impact of patient preparation on the diagnostic performance of 18F-FDG PET in cardiac sarcoidosis: a systematic review and meta-analysis. Clin Nucl Med. 2016;41(7):e327-39.

44. Kim SJ, Pak K, Kim K. Diagnostic performance of F-18 FDG PET for detection of cardiac sarcoidosis; a systematic review and meta-analysis. J Nucl Cardiol. 2019. https://doi.org/10.1007/ s12350-018-01582-y.

45. Glaudemans AW, Prandini N, Di Girolamo M, Argento G, Lauri C, Lazzeri E, et al. Hybrid imaging of musculoskeletal infections. Q J Nucl Med Mol Imaging. 2018;62(1):3-13.

46. Wang GL, Zhao K, Liu ZF, Dong MJ, Yang SY. A meta-analysis of fluorodeoxyglucose-positron emission tomography versus scintigraphy in the evaluation of suspected osteomyelitis. Nucl Med Commun. 2011;32(12):1134-42. 
47. Treglia G, Sadeghi R, Annunziata S, Zakavi SR, Caldarella C, Muoio B, et al. Diagnostic performance of fluorine-18-fluorodeoxyglucose positron emission tomography for the diagnosis of osteomyelitis related to diabetic foot: a systematic review and a metaanalysis. Foot. 2013;23(4):140-8.

48. Lauri C, Tamminga M, Glaudemans AWJM, Juárez Orozco LE, Erba PA, Jutte PC, et al. Detection of osteomyelitis in the diabetic foot by imaging techniques: a systematic review and meta-analysis comparing MRI, white blood cell scintigraphy, and FDG-PET. Diabetes Care. 2017;40(8):1111-20.

49. Jin H, Yuan L, Li C, Kan Y, Hao R, Yang J. Diagnostic performance of FDG PET or PET/CT in prosthetic infection after arthroplasty: a meta-analysis. Q J Nucl Med Mol Imaging. 2014;58(1):85-93.

50. Verberne SJ, Raijmakers PG, Temmerman OP. The accuracy of imaging techniques in the assessment of periprosthetic hip infection: a systematic review and meta-analysis. J Bone Joint Surg Am. 2016;98(19):1638-45.

51. Verberne SJ, Sonnega RJ, Temmerman OP, Raijmakers PG. What is the accuracy of nuclear imaging in the assessment of periprosthetic knee infection? A meta-analysis. Clin Orthop Relat Res. 2017;475(5):1395-410.

52. Prodromou ML, Ziakas PD, Poulou LS, Karsaliakos P, Thanos L, Mylonakis E. FDG PET is a robust tool for the diagnosis of spondylodiscitis: a meta-analysis of diagnostic data. Clin Nucl Med. 2014;39(4):330-5.

53. Yin Y, Liu X, Yang X, Guo J, Wang Q, Chen L. Diagnostic value of FDG-PET versus magnetic resonance imaging for detecting spondylitis: a systematic review and meta-analysis. Spine J. 2018;18(12):2323-32.
54. Kim SJ, Pak K, Kim K, Lee JS. Comparing the diagnostic accuracies of F-18 fluorodeoxyglucose positron emission tomography and magnetic resonance imaging for the detection of spondylodiscitis: a metaanalysis. Spine. 2019;44(7):E414-22.

55. Treglia G, Focacci C, Caldarella C, Mattoli MV, Salsano M, Taralli S, et al. The role of nuclear medicine in the diagnosis of spondylodiscitis. Eur Rev Med Pharmacol Sci. 2012;16(Suppl 2):20-5.

56. Jamar F, Versari A, Galli F, Lecouvet F, Signore A. Molecular imaging of inflammatory arthritis and related disorders. Semin Nucl Med. 2018;48(3):277-90.

57. Descamps L, Olagne L, Merlin C, Cachin F, Soubrier M, Mathieu S. Utility of PET/CT in the diagnosis of inflammatory rheumatic diseases: a systematic review and meta-analysis. Ann Rheum Dis. 2018;77(11):e81.

58. Catalano O, Maccioni F, Lauri C, Auletta S, Dierckx R, Signore A. Hybrid imaging in Crohn's disease: from SPECT/CT to PET/MR and new image interpretation criteria. Q J Nucl Med Mol Imaging. 2018;62(1):40-55.

59. Treglia G, Quartuccio N, Sadeghi R, Farchione A, Caldarella C, Bertagna F, et al. Diagnostic performance of fluorine-18-fluorodeoxyglucose positron emission tomography in patients with chronic inflammatory bowel disease: a systematic review and a meta-analysis. J Crohns Colitis. 2013;7(5):345-54.

60. Zhang J, Li LF, Zhu YJ, Qiu H, Xu Q, Yang J, et al. Diagnostic performance of 18F-FDG-PET versus scintigraphy in patients with inflammatory bowel disease: a meta-analysis of prospective literature. Nucl Med Commun. 2014;35(12):1233-46.

Open Access This chapter is licensed under the terms of the Creative Commons Attribution 4.0 International License (http://creativecommons.org/licenses/by/4.0/), which permits use, sharing, adaptation, distribution and reproduction in any medium or format, as long as you give appropriate credit to the original author(s) and the source, provide a link to the Creative Commons license and indicate if changes were made.

The images or other third party material in this chapter are included in the chapter's Creative Commons license, unless indicated otherwise in a credit line to the material. If material is not included in the chapter's Creative Commons license and your intended use is not permitted by statutory regulation or exceeds the permitted use, you will need to obtain permission directly from the copyright holder.

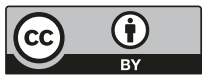




\section{Part V}

Evidence-Based PET in Neurology 


\title{
Evidence-Based PET for Neurological Diseases
}

\author{
Alberto Miceli, Selene Capitanio, \\ Maria Isabella Donegani, Stefano Raffa, \\ Anna Borra, Matteo Bauckneht, \\ and Silvia Morbelli
}

\subsection{Introduction}

Over the past two decades, one of the major breakthroughs for the approach to neurological diseases both in the clinical and research settings has been represented by the validation of diagnostic biomarkers able to demonstrate the presence of pathological mechanisms, alteration in neurotransmission as well as to predict disease progression $[1,2]$. The use of PET with different tracers as well as other imaging biomarkers support the etiological diagnosis of neurological disorders in vivo. This approach is particularly relevant in the field of neurodegenerative diseases. In fact, neurodegenerative diseases are characterized by the progressive degeneration and death of neurons. They represent a heterogeneous group of conditions characterized by different etiologies, different neuropathological and neurochemical alterations leading to different clinical pictures and courses [3]. Indeed, an early accurate diagnosis allows to tackle the disease with available or experimental intervention, lifestyle changes, or logistical arrangements, before disability has developed. Early intervention is

A. Miceli - S. Capitanio - M. I. Donegani - S. Raffa A. Borra $\cdot$ M. Bauckneht $\cdot$ S. Morbelli $(\bowtie)$

Nuclear Medicine Unit, IRCCS Ospedale Policlinico San Martino, Genoa, Italy

Department of Health Sciences, University of Genoa, Genoa, Italy

e-mail: silviadaniela.morbelli@hsanmartino.it expected to have greater clinical impact, extend independent and active life, improve its quality, and decrease the burden and costs of the disease [4]. However, the validation of PET tracers in neurological disease is still ongoing, and evidence on its comparative and combined diagnostic value with respect to other biomarkers is incomplete $[4,5]$. As a matter of fact, the increasing pressure for cost-effectiveness requires systematic assessment and validation of all biomarker performance in the clinical settings. Similarly only an evidence-based approach to new PET tracers can allow to select the most promising tracers for PET imaging in the research field both for pathophysiological investigations and for upcoming diagnostic approaches.

\subsection{Evidence-Based PET in Neurodegenerative Dementia}

Although the use of PET tracers for neurotransmission is also actively investigated, the vast majority of PET tracers recently developed for the clinical and pathophysiological evaluation of neurodegenerative dementia aim to evaluate the presence of specific pathological proteins deposition or mechanisms underlying neurodegeneration [3]. Tracers targeting neuroinflammation are also under investigation in this field but their use is still very far from the clinical 
setting [6]. Alzheimer's disease (AD) is by far the most relevant target for brain PET clinical imaging in neurodegenerative diseases [5]. The 2011 World Alzheimer Report has underlined that only a relatively small percentage of dementia cases (ranging between 20 and 50\%) are identified and correctly diagnosed in the early stages. This evidence means that at least half of the population of dementia patients does not receive a complete diagnostic workup at disease onset. This diagnostic delay gives rise to a socalled "treatment gap" between early stages of the disease and formal diagnosis, thus delaying correct care and preventing organized support which ameliorates patient's quality of life (and positively impacting also on caregivers and family members). In the field of $\mathrm{AD}$, two main categories of biomarkers have been proposed to identify the prodromal stage of disease [2, 7]. On the one side, amyloidosis biomarkers are able to identify the molecular/neuropathological feature of $\mathrm{AD}$ and include cerebrospinal fluid (CSF) amyloid- $\beta 1-42$ reduction and brain amyloid accumulation as imaged through PET technology using radiopharmaceuticals that selectively bind to the fibrillar aggregates of amyloid- $\beta$ plaques (AMY-PET) [2]. On the other side, neurodegeneration biomarkers reflect neuronal injury and downstream neurodegeneration, which can be measured by the increase of tau protein in the CSF, regional atrophy on MRI or synaptic metabolic dysfunction on fluorine-18 fluorodeoxyglucose PET $\left({ }^{18} \mathrm{~F}-\mathrm{FDG}\right.$ PET) [2]. As a matter of fact, the progressive dysfunction and loss of neurons lead to distinct involvement of functional systems and major clinical symptoms are mainly determined by the anatomical regions showing neuronal and synaptic dysfunction (which however do not necessarily reflect the molecular changes in the background) [8]. In this framework, MRI has both an exclusionary and inclusionary role for the early assessment of MCI. In fact on one side it can exclude secondary etiology of cognitive symptoms (i.e., vascular damage or normal pressure hydrocephalus) and it can increase the likelihood of a neurodegenerative dementia by highlighting the presence of atrophy in specific cortical regions [9]. Similarly, ${ }^{18}$ F-FDG PET is a well-founded method for evaluation of brain function and it is useful for the early diagnosis of $\mathrm{AD}$ and other dementias in people with mild cognitive impairment (MCI). ${ }^{18} \mathrm{~F}-\mathrm{FDG}$ PET is a sensitive and specific imaging modality available to support the etiological diagnosis of the underlying neurodegenerative dementia in demented patients. In particular, hypometabolism in the temporoparietal lobe, assessed by qualitative visual interpretation of the scans, represents the typical pattern found in AD [10]. However, despite its widespread use and the well-established role in the clinical settings, the quality of the available studies and thus the role of ${ }^{18} \mathrm{~F}$-FDG PET in identifying patients affected by AD who are still at the stage of MCI are less validated. As a matter of fact, discriminating between patients who will and will not progress to dementia due to AD is critical in the context of care and it must be pursued before patients have crossed the threshold into dementia. One of the background reasons associated with this surprising lack of evidence is related to evolving definition of MCI in the last decade. Unfortunately, the characteristics of the MCI patients recruited in the available published studies are quite diverse across the literature of the last 10 years and this heterogeneity is largely reflected but the lack of a reproducible value of sensitivity and specificity of ${ }^{18} \mathrm{~F}$-FDG PET for the identification of MCI due to AD. Moreover, the sensitivity and specificity of ${ }^{18} \mathrm{~F}$-FDG PET (as well as of all AD biomarkers) depend largely on the method of interpretation. It is, nowadays, advisable to use a combination of visual qualitative and semiquantitative analysis. In fact, the actual general sensitivity and specificity values, although still variable, are higher than $80 \%$ for both in the centers where it is utilized computer aided visual read approach such as Statistical Parametric Mapping (SPM), three-dimensional Stereotactic Surface Projection (3-D-SSP) statistics (Neurostat) or AD t-sum implemented in other software $[11,12]$. Software able to combine information from MRI and ${ }^{18} \mathrm{~F}$-FDG PET (even in the multicenter settings) have also been developed and have been demonstrated to 
improve detection and differentiation of $\mathrm{AD}$ and FTD (with $88-100 \%$ accuracy for AD detection) [13].

In more recent years, the availability of PET biomarkers of amyloid deposition such as ${ }^{11} \mathrm{C}$ $\mathrm{PiB}$ and ${ }^{18} \mathrm{~F}$-labeled tracers $\left({ }^{18} \mathrm{~F}\right.$-Flutemetamol, ${ }^{18} \mathrm{~F}$-Florbetaben, and ${ }^{18} \mathrm{~F}$-Florbetapir) has gained great attention [14]. These tracers exhibit high affinity binding for fibrillary amyloid that is a hallmark of $\mathrm{AD}$ and can be found in moderate to high number in cortical gray matter in all cases of $\mathrm{AD}$ developing many years before the onset of dementia. The vast majority of preliminary studies with amyloid PET has been carried out with ${ }^{11} \mathrm{C}$-PIB. It has been reported by measuring ${ }^{11} \mathrm{C}$ $\mathrm{PiB}$ distribution in $\mathrm{MCI}$ and control subjects, that MCI patients who converted to $\mathrm{AD}$, at an estimated rate of $25 \%$ per year, had greater ${ }^{11} \mathrm{C}-\mathrm{PiB}$ retention in several brain area with a $93.5 \%$ sensitivity and $56 \%$ specificity [15]. Moreover, none of the ${ }^{11} \mathrm{C}-\mathrm{PiB}$ negative $\mathrm{MCI}$ patients demonstrated to be converted to $\mathrm{AD}$ indicating that ${ }^{11} \mathrm{C}$ PiB negativity had a $100 \%$ negative predictive value for progression to $\mathrm{AD}[7,16]$. However, due to the 20 -min half-life of ${ }^{11} \mathrm{C},{ }^{11} \mathrm{C}$-PiB can only be used in PET centers with on-site cyclotron and radiopharmacy facilities while ${ }^{18} \mathrm{~F}$ is a more suitable radioisotope for widespread clinical use. Accordingly, the availability of fluorinated amyloid PET tracers has favored a greater impact of this tool also in the clinical settings [17]. In particular, a sensitivity of amyloid ${ }^{18} \mathrm{~F}$-labeled tracers ranging from 89 to $97 \%$, with a specificity ranging from 63 to $93 \%$ has been reported both for visual and semiquantitative analysis and no significant differences have been highlighted among the different agents [18].

The overall impacts of AMY-PET from the reported literature are a change of diagnosis and management in $35.2 \%$ and $59.6 \%$ of cases, respectively, leading to reduction in unnecessary investigations, treatments, relief of distress of caregivers, and potential involvement in clinical trials [19].

In particular, AMY-PET (as well as CSF data) are relevant for the differential diagnosis of etiologies underlying primary progressive aphasia (PPA). In fact, it has been suggested that the cur- rent clinical classification system for PPA should aim to predict underlying pathology across different cohorts and clinical settings which has a greater specificity with respect to neurodegeneration biomarkers (MRI and ${ }^{18}$ F-FDG PET) [20]. In fact, although patients' characteristics including age and ApoE genotype should be considered when interpreting AMY-PET, it has been highlighted that AMY-PET positivity is significantly more prevalent in logopenic variant of PPA, which belongs to the AD spectrum, (86\%) than in non-fluent variant of PPA $(20 \%)$ or semantic variant of PPA (16\%) which should be part of the spectrum of fronto-temporal degeneration [21]. It should be noted however that cognitive normal older people has a high burden of amyloid defined as incidental amyloidosis. Indeed, the presence of amyloid deposition is not sufficient to define the presence of pathophysiologic processes associated with $\mathrm{AD}$ which has to include the concomitant tau deposition [22]. Analyses in AMY-PET positive cognitive normal subjects have shown that the episodic memory and global cognitive function consistently had the largest, albeit still modest, effect sizes between performance and amyloid burden, whereas executive function, working memory, processing speed, visuospatial function, and semantic memory exhibited relatively smaller effect sizes [23]. Moreover, the incidence of brain amyloidosis increases with aging in all non-AD populations and has been repeatedly reported in other neurological conditions such as in dementia with Lewy bodies (DLB) and Parkinson's disease (PD). Similarly, all amyloid PET tracers have affinity to amyloid in vessel walls, and can thus result in positive scans in case of cerebral amyloid angiopathy (CAA) [7]. In this framework, it has been demonstrated that the ratio between the occipital and the whole brain uptake is higher in patients with CAA than in patients with $\mathrm{AD}$, possibly suggesting a more limited regional amyloid deposition on CAA [24]. Accordingly, AMY-PET has a moderate to good diagnostic accuracy for the identification of patients with CAA; especially as a negative scan it is useful to rule out CAA in the appropriate clinical setting [25]. Finally, it should be noted 
that soluble $\mathrm{A} \beta$ oligomers and neurofibrillary tangles (NFTs), the other histopathologic cores of Alzheimer's disease are not detected by this method, possibly producing false negative results [26].

\subsection{Evidence-Based PET for Movement Disorders}

Movement disorders are a group of neurologic syndromes characterized by an excess of movement or a scarcity of voluntary and automatic movements [27] related to different neurodegenerative or acquired central nervous system diseases affecting structures involved in movement control and modulation such as basal ganglia, cerebellum, cortex, and different thalamic nuclei. Parkinson's disease (PD) represents the second most common neurodegenerative disorder after $\mathrm{AD}$ and is typically characterized by motor and non-motor manifestations. Motor dysfunctions include bradykinesia, resting tremor, and muscular rigidity [28] as the result of dopaminergic deficit due to degeneration of the dopaminergic nigrostriatal system [29]. On the other hand, nonmotor features usually associated with the damage in non-dopaminergic pathways may include depression, olfactory and autonomic dysfunction, sleep disorders, psychiatric symptoms, pain, fatigue, and cognitive impairment [30] and can, in some case, even precede the motor phase by several years [31]. Besides the most prevalent PD, there are other related atypical parkinsonian syndromes (APS) also known as Parkinson-plus syndromes. From the neuropathological point of view, on the basis of the predominant multisystemic progressive accumulation of misfolded proteins, parkinsonian disorders could be classified into $\alpha$ synucleinopathies (PD with and without cognitive impairment/dementia, dementia with Lewy bodies-DLB, and multiple system atrophy-MSA) and tauopathies (corticobasal degeneration-CBD and progressive supranuclear palsy-PSP). All the aforementioned conditions must be distinguished from non-degenerative causes of parkinsonism (e.g., toxic/drug-induced, psychogenic, or vascular eti- ologies) in which presynaptic nigrostriatal pathways are preserved. Molecular imaging has proven to be a powerful tool for improving our understanding of the pathophysiology underlying parkinsonian disorders. In particular, PET and single photon emission computed tomography (SPECT) imaging are used as surrogate of unique in vivo functional measurement of monoaminergic pathways impairment in neurodegenerative diseases since the early 1980s [32]. Actually, these techniques are able to evaluate and detect nigrostriatal degeneration from different points of view. The analogue of levodopa ${ }^{18} \mathrm{~F}$-fluorodopa $\left({ }^{18} \mathrm{~F}\right.$-DOPA $)$ is a PET tracer that estimates the activity of aromatic amino acid decarboxylase enzyme (AADC), which converts levodopa into dopamine in striatal cells, thus reflecting dopamine synthesis. After its conversion in ${ }^{18}$ F-fluorodopamine, it follows the same fate of endogenous dopamine and is thus transported to intraneuronal storage vesicles by vesicular monoamine transporter 2 (VMAT2) [33] to then be released into the synaptic cleft and interact with postsynaptic dopamine receptors.

On the other hand, presynaptic dopamine transporter (DAT) density, responsible for reuptake of dopamine (DA) from the synaptic cleft and typically reduced in PD [34], can be measured through ${ }^{123}$ I-FP-CIT ( ${ }^{123}$ I-ioflupane), one of the most used radiotracers for SPECT imaging, or with specific PET tracers $\left({ }^{18} \mathrm{~F}-\mathrm{PE} 2 \mathrm{I}\right.$; $\mathrm{N}$-(3iodoprop-2Eenyl)-2 $\beta$-carbomethoxy-3 $\beta$-(4methyl-phenyl)nortropane). Finally, specific radiolabeled ligands for VMAT2 also exist and can be used in PET imaging for research purposes $\left({ }^{11} \mathrm{C}\right.$ - and ${ }^{18} \mathrm{~F}$-dihydrotetrabenazine). The applicability of functional imaging in the evaluation of striatal dopaminergic degeneration in control subjects and PD patients is well documented. Actually, PET and SPECT studies with AADC, VMAT2, and DAT tracers are able to monitor nigrostriatal deficit over time demonstrating the negative effects of age on DA transporters and receptors. According to Karrer et al. [35], age has a significantly larger effect on D1- than D2-like receptors with an average age reduction across the DA system of about 3.7-14.0\% per decade. On the contrary, DA synthesis capacity seems to 
be spared from this detrimental effect. This finding nicely fit with the results of a contemporary meta-analysis of Kaasinen et al. [36] including PD patients submitted to PET and SPECT studies for the evaluation of striatal presynaptic dopamine function. In this meta-analysis, it was demonstrated a higher defect in DAT and VMAT2 function compared to AADC defect in PD patients. This difference is possibly due to the effect of a compensatory upregulation in AADC function, confirming vesicular monoamine transporter 2 and dopamine transporter as the most sensitive targets to assess. In the same study, a linear correlation between disease severity and dopamine loss was demonstrated and a mean motor disease duration of 4-7 years was needed to overcome the general compensatory changes in the terminal area of the nigrostriatal tract in PD and induce a detectable loss of about $50 \%$ of putaminal presynaptic dopamine function. It should be noted, however, that ${ }^{18} \mathrm{~F}$-DOPA PET is a valid alternative to ${ }^{123}$ I-FP-CIT SPECT. Similarly, PET VMAT2 tracers as ${ }^{11} \mathrm{C}$ and ${ }^{18} \mathrm{~F}$-labeled dihydrotetrabenazine are very sensitive in detecting presynaptic dysfunction in PD without significant influence by compensatory changes [37] but are less available than other tracers. Besides dopaminergic dysfunction, serotonergic system exerts an important role in PD pathophysiology. Among PET ligands that have been developed for the evaluation of serotonergic receptors and serotonin transporter (SERT), ${ }^{11} \mathrm{C}$-DASB is a second-generation PET ligand with the best selectivity for the SERT [38]. In their systematic review examining the in vivo SERT changes in PD measured by ${ }^{11} \mathrm{C}$-DASB PET, Pagano et al. [39] demonstrated that SERT dysfunction is associated with the development of several motor (tremor and dyskinesias) and non-motor symptoms (depression, fatigue, apathy, and weight changes). In particular, they observe a highest decrease in SERT binding in the rostral raphe and caudate followed by putamen, thalamus, ventral striatum, caudal raphe, and hypothalamus, according to succession of pathological events in serotonergic neurons described by Braak's PD staging [29]. Furthermore, reduced SERT binding in putamen is associated with longer duration of the disease, whereas lower ${ }^{11} \mathrm{C}$-DASB binding in caudate is associated with worse cognitive function and older age. Interestingly, although SERT binding in putamen decreased with the progression of the disease, PD patients with dyskinesias have relatively preserved putaminal serotonergic function with mechanisms not fully clarified.

Moreover, PET and SPECT are able to detect pathologic changes from the earliest phase of the disease, improving diagnostic accuracy in the early stages [40]. REM sleep behavior disorder (RBD) confirmed by polysomnography is a parasomnia occurring during REM sleep characterized by the loss of physiological muscle atonia and associated with dream-enacted behaviors. It is defined "idiopathic" when appears isolated, without any other clinical sign of a neurological disorder. However, more than $80 \%$ of idiopathic RBD patients will develop a definite neurodegenerative disease, mostly a synucleinopathy. Furthermore, the presence of abnormal presynaptic dopaminergic PET or SPECT scan is considered the second most relevant risk factor for prodromal PD [41] predicting a high risk for short-term conversion into a synucleinopathy in idiopathic RBD patients [42]. A recent metaanalysis about the role of presynaptic dopaminergic imaging in RBD shows that idiopathic RBD patients exhibit decreased nigrostriatal dopaminergic functioning in comparison with healthy controls, especially at the putamen level. Furthermore, patients with idiopathic RBD and patients with PD without RBD exhibit a similar degree of nigro-caudate dopaminergic deafferentation [43].

Molecular imaging can also facilitate the differential diagnosis among PD, atypical parkinsonian syndromes (APS), essential tremors, and other degenerative conditions that represent a group of complex and heterogeneous diseases with overlapping symptomatology and variable response to dopaminergic medications. ${ }^{123} \mathrm{I}-\mathrm{FP}$ CIT SPECT can distinguish degenerative forms of parkinsonism from essential tremor [44], druginduced parkinsonism [45] and could also differentiate DLB from AD. Subjects with PD and APS show indeed an early reduction of striatal 
dopaminergic binding [46] usually before the appearance of motor symptoms. On the contrary, patients with essential tremor, drug-induced parkinsonism, and $\mathrm{AD}$ are characterized by normal dopamine transporter uptake [47]. Although a differential pattern has been described at the group level, a real distinction between the various degenerative forms of parkinsonism is not possible by means of SPECT assessment only. To this purpose, ${ }^{18} \mathrm{~F}-\mathrm{FDG}$ PET has demonstrated to be more promising. As suggested by Albrecht et al. [48], glucose hypometabolism at ${ }^{18} \mathrm{~F}$-FDG PET can identify consistent functional brain abnormalities in PD, outperforming structural MRI. In particular, while MRI showed only focal and inconsistent alterations, in PD patients the authors found an extensive glucose hypometabolism in bilateral inferior parietal cortex and left caudate nucleus that is related to cognitive deficits (inferior parietal cortex) and motor symptoms (caudate nucleus). Disease-specific patterns of regional glucose metabolism in patients with parkinsonism are well documented [49, 50]. However, the valuable capability of ${ }^{18} \mathrm{~F}-\mathrm{FDG}$ PET for accurate differentiation between PD and APS has been unanimously accepted only in recent years. In a preliminary meta-analysis, Meyer et al. well described the different ${ }^{18} \mathrm{~F}$-FDG uptake pattern in PD and APS [51]. PD is characterized by a posterior temporoparietal, occipital, and sometimes frontal hypometabolism with a relative hypermetabolism of the putamen, pallidum, thalamus sensorimotor cortex, pons, and cerebellum.

MSA patients show instead a marked hypometabolism of the putamen (mainly in its posterior portion), pons, and cerebellum, which may be more pronounced in the striatum or in the pons and cerebellum, on the basis of the clinical presentation. Conversely, PSP is characterized by a regional hypometabolism preferentially involving the medial, dorsal, and ventrolateral frontal areas (i.e., the anterior cingulate gyrus, supplementary motor area, precentral gyrus, and premotor-to-posterior prefrontal areas); caudate, thalamus, and upper brain stem. Finally, CBD patients have a typically highly asymmetric hypometabolism of the frontoparietal areas, striatum, and thalamus contralateral to the most affected body side. A concomitant cortical hypometabolism may be mainly found in the parietal cortex and usually extends across the sensorimotor cortex into the cingulate gyrus and premotorto-posterior prefrontal areas.

${ }^{18}$ F-FDG PET has proved to be particularly relevant also for the diagnosis of DLB and is actually listed among the supportive biomarkers for its identification [52]. DLB is characterized by a more prominent hypometabolism affecting the primary visual cortex and occipital cortex with relative preservation of subcortical structures and primary somatomotor cortex and with a concomitant hypometabolism in posterior associative cortex. In particular, the presence of a hypometabolism in the precuneus with a relative sparing of glucose uptake in posterior cingulate gyrus is known as "cingulate island sign" and has proved to significantly increase ${ }^{18} \mathrm{~F}-\mathrm{FDG}$ PET specificity for the differential diagnosis with respect to $\mathrm{AD}$, although lower than DAT SPECT [53].

${ }^{18} \mathrm{~F}$-FDG PET evidence is also available for Huntington's disease gene expression carriers (HDGECs). Actually, several PET imaging studies investigating the glucose metabolism in HDGECs have shown specific metabolic patterns mainly characterized by a progressive reduction of subcortical and cortical glucose metabolism in the striatum, thalamus, insula, posterior cingulate gyrus, and prefrontal and occipital cortex associated to a relative hypermetabolism in the cerebellum and pons [54]. In particular, reduction in striatal metabolism seems to be an early feature of the disease, preceding neuronal loss and thus motor onset of the disease. However, glucose metabolism deficits are only one of the many factors involved in Huntington's disease and ${ }^{18} \mathrm{~F}-\mathrm{FDG}$ PET is not indicated for the diagnosis of this disease. Besides ${ }^{18} \mathrm{~F}-\mathrm{FDG}$, other striatal PET radioligands have been used in this context. In particular, a meta-analysis aiming to investigate striatal molecular changes in 158 premanifest and 191 manifest HDGECs patients [10] demonstrates a significant decrease not only in glucose metabolism in caudate and putamen but also in dopamine D2 receptors and in striatal phosphodiesterase $10 \mathrm{~A}$ binding. This findings well reflect the different 
neuropathological mechanisms underlying the development of the disease.

Finally, PET and SPECT could guide the clinician in the choice of the different therapeutic modalities and in monitoring therapy response. PET has proved to be able to determine drug dosage for optimal efficacy in movement disorders as in the case of PD patients under deprenyl treatment evaluated with ${ }^{11} \mathrm{C}$-deprenyl PET [55]. ${ }^{18} \mathrm{~F}$-DOPA PET has been used in several studies to evaluate the effects of potential neuroprotective agents on dopaminergic function [56]. ${ }^{11} \mathrm{C}$-raclopride PET was used to evaluate striatal D2 receptor status in PD patients showing a normal or raised striatal D2 binding potential in untreated patients with PD but reduced in patients with $\mathrm{PD}$ and a fluctuating response to L-dopa [57].

Finally, PET and SPECT studies have proved the existence of a link between impulse control disorders (ICD) and dopamine activity dysfunction across ventral and dorsal striatum in PD patients [58]. ICD are a class of psychiatric disorders including pathological gambling, hypersexuality, binge-eating, and compulsive shopping that could appear in around $30 \%$ of PD patients as a complication of D2/3 dopamine agonist treatment and, to a lesser extent, levodopa. A recent meta-analysis demonstrated the PET/ SPECT dopaminergic striatal correlates of ICD in PD. In particular, in ICD patients authors find lower DAT levels in the dorsal striatum and in its subdivisions (i.e., putamen, caudate) and reduced binding (i.e., increased dopamine release) in the ventral striatum in response to reward-related stimuli or gambling task. These lines of evidence highlight the importance of PET pharmacokinetic and pharmacodynamic studies in our understanding of the mechanisms of action, efficacy, and complications of medical interventions in patients with neurological diseases.

\subsection{Evidence-Based PET for Psychiatric Disorders}

While in the clinical settings either ${ }^{18} \mathrm{~F}-\mathrm{FDG}$ or AMY-PET can be used to support the differential diagnosis between neurodegenerative dementia and depressive pseudodementia, in the specific field of psychiatric disorders, PET technology has more extensively been used for research purposes to determine pathophysiology of diseases and response to intervention [59]. In particular, the availability of tracers for imaging of neurotransmission allows the investigation of different systems (i.e., serotonin, dopamine GABA pathways) and to investigate a wide range of psychiatric diseases. Similarly, brain PET with different tracers (i.e., tracers for neuroinflammation) has been used to explore new hypotheses related to the onset of psychiatric diseases. The vast majority of PET studies carried out in the last 20 years in psychiatric patients have aimed to map functional alterations and mechanism underlying major depressive disorder (MDD), a common mental illness with high lifetime prevalence (close to 20\%.). Indeed, although the presence of aberrant brain activation during cognitive and emotional processing has been extensively evaluated in MDD patients, results of available studies vary considerably. Muller and colleagues summarized the evidence derived from neuroimaging experiments (using fMRI or PET) of group comparisons between adults with unipolar depression and healthy controls and reporting significant activation differences between patients and controls during emotional or cognitive tasks [60]. Several inconsistencies across available studies emerged from this systematic review. Brain metabolism in MDD was also specifically addressed in several voxel-based PET studies which were submitted to a meta-analytical approach by Su et al. [61]. Again while decreased prefrontal, insular, and limbic cerebral glucose metabolism was repeatedly highlighted in depressed patients with respect to healthy controls, available literature has not always been consistent. In this framework, the involvement of specific regions such as insula, limbic system, basal ganglia, thalamus, and cerebellum was more frequently reported, suggesting that these regions are likely to play a key role in the pathophysiology of depression. In keeping with these results, convergent change in the limbic-cortical brain circuit in depression compared to controls was also found in multi-modal imaging studies involving both PET and MRI data. Reported 
specific changes include lower gray matter volumes in amygdala, dorsal frontomedian cortex, and the right paracingulate cortex, as well as relative hypermetabolism in the right subgenual and pregenual anterior cingulate cortices. Building a strong and evidence-based mapping of these alterations in MDD is relevant as these regions could serve as a specific region-of-interest-fordisease template for both in vivo imaging in individual patients and postmortem histopathologic exploration [62]. Other PET studies investigated altered function related to different pathways including 5-HT receptor and transporter dysfunction in neuropsychiatric disorders. Indeed, impairment of serotonin receptor and transporter function is increasingly recognized to play a major role in the pathophysiology of neuropsychiatric diseases including anxiety disorder, major depressive disorder, bipolar disorder, and schizophrenia. In particular, a retrospective analysis revealed that these psychiatric disorders differed in affected brain regions, affected synaptic constituents as well as direction of dysfunction in terms of either sensitization or desensitization of transporter and receptor binding sites [63].

Striatal presynaptic dopamine pathway has been the most frequent target for PET and SPECT imaging in schizophrenia [64]. As a matter of fact, the role of striatal dopaminergic neurotransmission in the onset of symptoms of schizophrenia (including psychotic symptoms) is currently targeted by dopaminergic drugs. A specific marker of the integrity of presynaptic dopamine neurons in the striatum, the density of striatal dopamine terminals, can be quantified through molecular neuroimaging of DAT. A meta-analysis of DAT density in the striatum of schizophrenic patients demonstrated that striatal DAT density was not significantly different between patients and controls [64]. Similar negative findings were regionally confirmed in putamen and caudate. There was no moderating effect for external factors such as antipsychotic medication or illness duration. Accordingly, the authors concluded that loss of integrity of striatal dopaminergic synapses is not critical for the emergence of schizophrenia and these findings are relevant for further refining dopaminergic hypotheses of schizophrenia (with possible repercussion on interventional studies aiming to identify new treatment options). By contrast, a different window on presynaptic dopaminergic function was opened by studies exploring this pathway through ${ }^{11} \mathrm{C}-/{ }^{18} \mathrm{~F}$-DOPA PET [65]. Available studies were summarized in the meta-analysis by Fusar-Poli and MeyerLindenberg [65]: patients with schizophrenia showed increased striatal uptake as compared with controls and this finding was regionally confirmed in both caudate and putamen. Finally, no significant effect of age, illness duration, gender, psychotic symptoms, and exposure to antipsychotics was highlighted. Of note, sensitivity analysis confirmed robustness of meta-analytic findings. Finally, data from animal models and from postmortem studies suggest that schizophrenia is associated with brain GABAergic dysfunction. However, it is still unclear the extent of this effect in vivo studies of GABA function in patients with schizophrenia [66].

PET and SPECT studies with several tracers have been used on other neuropsychiatric diseases including obsessive compulsive disorders, Tourette's syndrome (TS), and attention deficit hyperactivity disorder (ADHD) as well as to test brain function in specific conditions such as in case of ecstasy/polydrug use and disorders of consciousness. In particular, dopaminergic imaging with PET and SPECT was able to demonstrate dopaminergic alterations in TS and pathophysiology and psychostimulant treatment of attention deficit in ADHD. In fact, dopaminergic alterations in TS are in line with the current pathophysiological hypotheses of a tonic-phasic dysfunction in the dopamine system although available studies are characterized by low effect sizes due to the heterogeneity of the disease [67]. Similarly, although dopaminergic studies in ADHD yielded inconsistent results often demonstrating either high and low striatal dopamine transporter levels across different studies, a systematic review of the available evidence highlighted that striatal dopamine transporter density in ADHD is depended on previous psychostimulant exposure, with lower density in drug-naive subjects and higher density in previously medicated patients [68]. More general approaches on brain perfusion and metabolism by means of SPECT and PET allowed to demonstrate that 
pharmacological and psychological treatments reduce resting cortico-striato-thalamo-cortical circuit activity in obsessive compulsive disorder. Similarly markedly reduced activity within midline cortical and subcortical sites (anatomical structures linked to the default-mode network) are present in patients with disorders of consciousness $[69,70]$. Finally, PET studies on postsynaptic 5HT2A receptor imaging allowed to highlight that serotonin axons with the longest projections from the raphe nuclei might be more markedly affected by ecstasy/MDMA use.

\subsection{Conclusions}

In conclusion, a huge body of literature has highlighted an ongoing and promising role of PET with different tracers in neurodegenerative dementia, movement and psychiatric disorders. In some clinical settings such as in case patients with mild cognitive impairment and dementia, for the differential diagnosis of underlying etiology as well as for the early and accurate identification of patients with neurodegenerative parkinsonian syndromes, PET has gained an increasing relevant clinical role. By contrast the possibility to accurately quantify neurotransmission with different tracers is increasingly supporting the use of PET technology for pathophysiological and interventional studies in patients with psychiatric disorders. In both cases (clinical use of PET in neurodegenerative dementia and parkinsonian syndromes and research use of PET in psychiatric disorders), it is crucial to proceed with robust methodology which starts with the systematic evaluation of evidence-based results of previous studies. Only this approach will allow to balance costs and clinical advancement, thus meeting the needs of both patients and health-care systems.

\section{References}

1. Albert MS, DeKosky ST, Dickson D, et al. The diagnosis of mild cognitive impairment due to Alzheimer's disease: recommendations from the National Institute on Aging and Alzheimer's Association workgroup. Alzheimers Dement. 2011;7:270-9.
2. Dubois B, Feldman HH, Jacova C, et al. Advancing research diagnostic criteria for Alzheimer's disease: the IWG-2 criteria. Lancet Neurol. 2014;13:614-29.

3. Nasrallah IM, Wolk DA. Multimodality imaging of Alzheimer disease and other neurodegenerative dementias. J Nucl Med. 2014;55:2003-11.

4. Boccardi M, Nicolosi V, Festari C, Bianchetti A, Cappa S, Chiasserini D, et al. Italian consensus recommendations for a biomarker-based aetiological diagnosis in mild cognitive impairment patients. Eur J Neurol. 2019;27(3):475-83. https://doi.org/10.1111/ ene.14117.

5. Frisoni GB, Boccardi M, Barkhof F, Blennow K, Cappa S, Chiotis K, et al. Strategic roadmap for an early diagnosis of Alzheimer's disease based on biomarkers. Lancet Neurol. 2017;16(8):661-76.

6. Narayanaswami V, Dahl K, Bernard-Gauthier V, Josephson L, Cumming P, Vasdev N. Emerging PET radiotracers and targets for imaging of neuroinflammation in neurodegenerative diseases: outlook beyond TSPO. Mol Imaging. 2018;17:1536012118792317.

7. Chen X, Li M, Wang S, Zhu H, Xiong Y, Liu $\mathrm{X}$. Pittsburgh compound B retention and progression of cognitive status - a meta-analysis. Eur J Neurol. 2014;21(8):1060-7.

8. Kovacs GG. Molecular pathology of neurodegenerative diseases: principles and practice. J Clin Pathol. 2019;72(11):725-35.

9. Seo EH, Park WY, Choo IH. Structural MRI and amyloid PET imaging for prediction of conversion to Alzheimer's disease in patients with mild cognitive impairment: a meta-analysis. Psychiatry Investig. 2017;14(2):205-15.

10. Niccolini F, Pagano G, Fusar-Poli P, Wood A, Mrzljak L, Sampaio C, et al. Striatal molecular alterations in HD gene carriers: a systematic review and meta-analysis of PET studies. J Neurol Neurosurg Psychiatry. 2018;89(2):185-96.

11. Smailagic N, Lafortune L, Kelly S, Hyde C, Brayne C. 18F-FDG PET for prediction of conversion to Alzheimer's disease dementia in people with mild cognitive impairment: an updated systematic review of test accuracy. J Alzheimers Dis. 2018;64(4):1175-94.

12. Morbelli S, Garibotto V, Van De Giessen E, Arbizu J, Chételat G, Drezgza A, et al. European Association of Nuclear Medicine. A Cochrane review on brain $\left[{ }^{18} \mathrm{~F}\right] \mathrm{FDG}$ PET in dementia: limitations and future perspectives. Eur J Nucl Med Mol Imaging. 2015;42(10):1487-91.

13. Dukart J, Mueller K, Barthel H, Villringer A, Sabri O, Schroeter ML, Alzheimer's Disease Neuroimaging Initiative. Meta-analysis based SVM classification enables accurate detection of Alzheimer's disease across different clinical centers using FDG-PET and MRI. Psychiatry Res. 2012;212(3):230-6.

14. Morbelli S, Bauckneht M. Amyloid PET imaging: standardization and integration with other Alzheimer's disease biomarkers. Methods Mol Biol. 1750;2018:203-12. 
15. Zhang S, Han D, Tan X, Feng J, Guo Y, Ding Y. Diagnostic accuracy of 18 F-FDG and 11 C-PIBPET for prediction of short-term conversion to Alzheimer's disease in subjects with mild cognitive impairment. Int J Clin Pract. 2012;66(2):185-98.

16. He W, Liu D, Radua J, Li G, Han B, Sun Z. Metaanalytic comparison between PIB-PET and FDG-PET results in Alzheimer's disease and MCI. Cell Biochem Biophys. 2015;71(1):17-26.

17. Morbelli S, Bauckneht M, Scheltens P. Imaging biomarkers in Alzheimer's disease: added value in the clinical setting. Q J Nucl Med Mol Imaging. 2017;61(4):360-71.

18. Morris E, Chalkidou A, Hammers A, Peacock J, Summers J, Keevil S. Diagnostic accuracy of (18)F amyloid PET tracers for the diagnosis of Alzheimer's disease: a systematic review and meta-analysis. Eur J Nucl Med Mol Imaging. 2016;43(2):374-85.

19. Shea YF, Barker W, Greig-Gusto MT, Loewenstein DA, Duara R, DeKosky ST. Impact of amyloid PET imaging in the memory clinic: a systematic review and meta-analysis. J Alzheimers Dis. 2018;64(1):323-35.

20. Bisenius S, Neumann J, Schroeter ML. Validating new diagnostic imaging criteria for primary progressive aphasia via anatomical likelihood estimation meta-analyses. Eur J Neurol. 2016;23(4):704-12.

21. Bergeron D, Gorno-Tempini ML, Rabinovici GD, Santos-Santos MA, Seeley W, Miller BL, et al. Prevalence of amyloid- $\beta$ pathology in distinct variants of primary progressive aphasia. Ann Neurol. 2018;84(5):729-40.

22. Baker JE, Lim YY, Pietrzak RH, Hassenstab J, Snyder PJ, Masters CL, et al. Cognitive impairment and decline in cognitively normal older adults with high amyloid- $\beta$ : a meta-analysis. Alzheimers Dement. 2017;6:108-21.

23. Hedden T, Oh H, Younger AP, Patel TA. Meta-analysis of amyloid-cognition relations in cognitively normal older adults. Neurology. 2013;80(14):1341-8.

24. Charidimou A, Farid K, Tsai HH, Tsai LK, Yen RF, Baron JC. Amyloid-PET burden and regional distribution in cerebral amyloid angiopathy: a systematic review and meta-analysis of biomarker performance. J Neurol Neurosurg Psychiatry. 2018;89(4):410-7.

25. Charidimou A, Farid K, Baron JC. AmyloidPET in sporadic cerebral amyloid angiopathy: a diagnostic accuracy meta-analysis. Neurology. 2017;89(14):1490-8.

26. Martínez G, Vernooij RW, Fuentes Padilla P, Zamora J, Bonfill Cosp X, Flicker L. 18F PET with florbetapir for the early diagnosis of Alzheimer's disease dementia and other dementias in people with mild cognitive impairment (MCI). Cochrane Database Syst Rev. 2017;11:CD012216.

27. Fahn S. Classification of movement disorders. Mov Disord. 2011;26(6):947-57.

28. Jankovic J. Parkinson's disease: clinical features and diagnosis. J Neurol Neurosurg Psychiatry. 2008;79(4):368-76.
29. Braak H, Del Tredici K, Rüb U, de Vos RA, Jansen Steur EN, Braak E. Staging of brain pathology related to sporadic Parkinson's disease. Neurobiol Aging. 2003;24(2):197-211.

30. Kalia LV, Lang AE. Parkinson's disease. Lancet. 2015;386(9996):896-912.

31. Politis M, Wu K, Molloy S, Bain PG, Chaudhuri KR, Piccini P. Parkinson's disease symptoms: the patient's perspective. Mov Disord. 2010;25(11):1646-51.

32. Garnett ES, Firnau G, Nahmias C. Dopamine visualized in the basal ganglia of living man. Nature. 1983;305(5930):137-8.

33. Meiser J, Weindl D, Hiller K. Complexity of dopamine metabolism. Cell Commun Signal. 2013;11(1):34.

34. Uhl GR. Dopamine transporter: basic science and human variation of a key molecule for dopaminergic function, locomotion, and parkinsonism. Mov Disord. 2003;18(Suppl 7):S71-80.

35. Karrer TM, Josef AK, Mata R, Morris ED, SamanezLarkin GR. Reduced dopamine receptors and transporters but not synthesis capacity in normal aging adults: a meta-analysis. Neurobiol Aging. 2017;57:36-46.

36. Kaasinen V, Vahlberg T. Striatal dopamine in Parkinson disease: a meta-analysis of imaging studies. Ann Neurol. 2017;82(6):873-82.

37. Lee CS, Samii A, Sossi V, Ruth TJ, Schulzer M, Holden JE, et al. In vivo positron emission tomographic evidence for compensatory changes in presynaptic dopaminergic nerve terminals in Parkinson's disease. Ann Neurol. 2000;47(4):493-503.

38. Houle S, Ginovart N, Hussey D, Meyer JH, Wilson AA. Imaging the serotonin transporter with positron emission tomography: initial human studies with [11C]DAPP and [11C]DASB. Eur J Nucl Med. 2000;27(11):1719-22.

39. Pagano G, Niccolini F, Fusar-Poli P, Politis M. Serotonin transporter in Parkinson's disease: a meta-analysis of positron emission tomography studies. Ann Neurol. 2017;81(2):171-80.

40. Rizzo G, Copetti M, Arcuti S, Martino D, Fontana A, Logroscino G. Accuracy of clinical diagnosis of Parkinson disease: a systematic review and metaanalysis. Neurology. 2016;86(6):566-76.

41. Berg D, Postuma RB, Adler CH, Bloem BR, Chan P, Dubois B, et al. MDS research criteria for prodromal Parkinson's disease. Mov Disord. 2015;30(12):1600-11.

42. Iranzo A, Santamaría J, Valldeoriola F, Serradell M, Salamero M, Gaig C, et al. Dopamine transporter imaging deficit predicts early transition to synucleinopathy in idiopathic rapid eye movement sleep behavior disorder. Ann Neurol. 2017;82(3):419-28.

43. Bauckneht M, Chincarini A, De Carli F, Terzaghi M, Morbelli S, Nobili F, et al. Presynaptic dopaminergic neuroimaging in REM sleep behavior disorder: a systematic review and meta-analysis. Sleep Med Rev. 2017;41:266-74. 
44. Benamer TS, Patterson J, Grosset DG, Booij J, de Bruin K, van Royen E, et al. Accurate differentiation of parkinsonism and essential tremor using visual assessment of [123I]-FP-CIT SPECT imaging: the [123I]-FP-CIT study group. Mov Disord. 2000;15(3):503-10.

45. Tinazzi M, Antonini A, Bovi T, Pasquin I, Steinmayr M, Moretto G, et al. Clinical and [123I]FP-CIT SPET imaging follow-up in patients with drug-induced parkinsonism. J Neurol. 2009;256(6):910-5.

46. Nicastro N, Garibotto V, Badoud S, Burkhard PR. Scan without evidence of dopaminergic deficit: a 10-year retrospective study. Parkinsonism Relat Disord. 2016;31:53-8.

47. Brücke T, Asenbaum S, Pirker W, Djamshidian S, Wenger S, Wöber C, et al. Measurement of the dopaminergic degeneration in Parkinson's disease with [123I] beta-CIT and SPECT. Correlation with clinical findings and comparison with multiple system atrophy and progressive supranuclear palsy. J Neural Transm Suppl. 1997;50:9-24.

48. Albrecht F, Ballarini T, Neumann J, Schroeter ML. FDG-PET hypometabolism is more sensitive than MRI atrophy in Parkinson's disease: a wholebrain multimodal imaging meta-analysis. Neuroimage Clin. 2019;21:101594.

49. D’Antona R, Baron JC, Samson Y, Serdaru M, Viader F, Agid Y, et al. Subcortical dementia. Frontal cortex hypometabolism detected by positron tomography in patients with progressive supranuclear palsy. Brain. 1985;108(Pt 3):785-99.

50. Eidelberg D, Dhawan V, Moeller JR, Sidtis JJ, Ginos JZ, Strother SC, et al. The metabolic landscape of cortico-basal ganglionic degeneration: regional asymmetries studied with positron emission tomography. J Neurol Neurosurg Psychiatry. 1991;54(10):856-62.

51. Meyer PT, Frings L, Rücker G, Hellwig S. (18) F-FDG PET in parkinsonism: differential diagnosis and evaluation of cognitive impairment. J Nucl Med. 2017;58(12):1888-98.

52. McKeith IG, Boeve BF, Dickson DW, Halliday G, Taylor JP, Weintraub D, et al. Diagnosis and management of dementia with Lewy bodies: fourth consensus report of the DLB Consortium. Neurology. 2017;89(1):88-100.

53. Graff-Radford J, Murray ME, Lowe VJ, Boeve BF, Ferman TJ, Przybelski SA, et al. Dementia with Lewy bodies: basis of cingulate island sign. Neurology. 2014;83(9):801-9.

54. Tang CC, Feigin A, Ma Y, Habeck C, Paulsen JS, Leenders KL, et al. Metabolic network as a progression biomarker of premanifest Huntington's disease. J Clin Invest. 2013;123(9):4076-88.

55. Fowler JS, Volkow ND, Logan J, Wang GJ, MacGregor RR, Schyler D, et al. Slow recovery of human brain MAO B after L-deprenyl (Selegeline) withdrawal. Synapse. 1994;18(2):86-93.

56. Marek K, Jennings D, Seibyl J. Imaging the dopamine system to assess disease-modifying drugs: studies comparing dopamine agonists and levodopa. Neurology. 2003;61(6 Suppl 3):S43-8.

57. Brooks DJ, Ibanez V, Sawle GV, Playford ED, Quinn $\mathrm{N}$, Mathias CJ, et al. Striatal D2 receptor status in patients with Parkinson's disease, striatonigral degeneration, and progressive supranuclear palsy, measured with 11C-raclopride and positron emission tomography. Ann Neurol. 1992;31(2):184-92.

58. Martini A, Dal Lago D, Edelstyn NMJ, Salgarello M, Lugoboni F, Tamburin S. Dopaminergic neurotransmission in patients with Parkinson's disease and impulse control disorders: a systematic review and meta-analysis of PET and SPECT studies. Front Neurol. 2018;9:1018.

59. Nobili F, Arbizu J, Bouwman F, Drzezga A, Agosta F, Nestor P, et al. EANM-EAN Task Force for the Prescription of FDG-PET for Dementing Neurodegenerative Disorders. European Association of Nuclear Medicine and European Academy of Neurology recommendations for the use of brain (18) F-fluorodeoxyglucose positron emission tomography in neurodegenerative cognitive impairment and dementia: Delphi consensus. Eur J Neurol. 2018;25(10):1201-17.

60. Müller VI, Cieslik EC, Serbanescu I, Laird AR, Fox PT, Eickhoff SB. Altered brain activity in unipolar depression revisited: meta-analyses of neuroimaging studies. JAMA Psychiat. 2017;74(1):47-55.

61. Su L, Cai Y, Xu Y, Dutt A, Shi S, Bramon E. Cerebral metabolism in major depressive disorder: a voxelbased meta-analysis of positron emission tomography studies. BMC Psychiatry. 2014;14:321.

62. Sacher J, Neumann J, Fünfstück T, Soliman A, Villringer A, Schroeter ML. Mapping the depressed brain: a meta-analysis of structural and functional alterations in major depressive disorder. J Affect Disord. 2012;140(2):142-8.

63. Nikolaus S, Müller HW, Hautzel H. Different patterns of 5-HT receptor and transporter dysfunction in neuropsychiatric disorders-a comparative analysis of in vivo imaging findings. Rev Neurosci. 2016;27(1):27-59.

64. Fusar-Poli P, Meyer-Lindenberg A. Striatal presynaptic dopamine in schizophrenia, part I: meta-analysis of dopamine active transporter (DAT) density. Schizophr Bull. 2012;39(1):22-32.

65. Fusar-Poli P, Meyer-Lindenberg A. Striatal presynaptic dopamine in schizophrenia, part II: meta-analysis of [(18)F/(11)C]-DOPA PET studies. Schizophr Bull. 2013;39(1):33-42.

66. Egerton A, Modinos G, Ferrera D, McGuire P. Neuroimaging studies of GABA in schizophrenia: a systematic review with meta-analysis. Transl Psychiatry. 2017;7(6):e1147.

67. Hienert M, Gryglewski G, Stamenkovic M, Kasper S, Lanzenberger R. Striatal dopaminergic alterations in Tourette's syndrome: a meta-analysis based on 16 PET and SPECT neuroimaging studies. Transl Psychiatry. 2018;8(1):143. 
68. Fusar-Poli P, Rubia K, Rossi G, Sartori G, Balottin U. Striatal dopamine transporter alterations in ADHD: pathophysiology or adaptation to psychostimulants? A meta-analysis. Am J Psychiatry. 2012;169(3):264-72.

69. Van der Straten AL, Denys D, van Wingen GA. Impact of treatment on resting cerebral blood flow and metabolism in obsessive compulsive disorder: a metaanalysis. Sci Rep. 2017;7(1): 17464.

70. Hannawi Y, Lindquist MA, Caffo BS, Sair HI, Stevens RD. Resting brain activity in disorders of consciousness: a systematic review and meta-analysis. Neurology. 2017;84(12):1272-80.

Open Access This chapter is licensed under the terms of the Creative Commons Attribution 4.0 International License (http://creativecommons.org/licenses/by/4.0/), which permits use, sharing, adaptation, distribution and reproduction in any medium or format, as long as you give appropriate credit to the original author(s) and the source, provide a link to the Creative Commons license and indicate if changes were made.

The images or other third party material in this chapter are included in the chapter's Creative Commons license, unless indicated otherwise in a credit line to the material. If material is not included in the chapter's Creative Commons license and your intended use is not permitted by statutory regulation or exceeds the permitted use, you will need to obtain permission directly from the copyright holder. 


\section{Part VI}

Miscellaneous 


\title{
Meta-Analyses on Technical Aspects of PET
}

\author{
Luca Ceriani
}

\subsection{Introduction}

In literature, there are few meta-analyses that have addressed technical and methodological issues concerning positron emission tomography (PET) imaging despite their important role in determining the quality of the diagnostic results [1-19].

\subsection{Factors Affecting ${ }^{18}$ F-FDG Uptake}

The factors that may affect fluorine-18 fluorodeoxyglucose $\left({ }^{18} \mathrm{~F}-\mathrm{FDG}\right)$ uptake of normal tissues/ organs and tumour lesions have been explored by three studies.

Wang et al. [1] demonstrated that the impact of time interval on standardized uptake value (SUV) in liver and mediastinal blood pool was relatively medium but clinically noticeable. Due to the rare studies, this relationship remains to be verified for other organs (cerebellum, spleen, bone marrow, muscle, bowel and adipose tissue).

\footnotetext{
L. Ceriani $(\bowtie)$

Clinic of Nuclear Medicine and PET/CT Centre, Imaging Institute of Southern Switzerland, Ente Ospedaliero Cantonale, Bellinzona and Lugano, Switzerland

Institute of Oncology Research (IOR), Bellinzona, Switzerland

e-mail: luca.ceriani@eoc.ch
}

Nevertheless, other factors such as body mass index and blood glucose level (BGL) appeared to be important in determining ${ }^{18} \mathrm{~F}$-FDG uptake in normal organs.

The effect of BGL on ${ }^{18} \mathrm{~F}-\mathrm{FDG}$ uptake and SUV has been more extensively explored by Eskian et al. [2] who demonstrated a correlation between increased BGLs and increased SUVmax and SUVmean values in liver and blood pool. Conversely, an increase of BGL is significantly associated to lower SUVmax and SUVmean in brain and muscle while both SUV values in tumours seemed to be affected, with significant reduction, only by BGL $>200 \mathrm{mg} / \mathrm{dl}$. The authors concluded suggesting that in patients with BGL lower than $200 \mathrm{mg} / \mathrm{dl}$ no interventions are needed for lowering BGL, unless the liver is the organ of interest. Nevertheless, new studies are warranted to evaluate sensitivity and specificity of ${ }^{18} \mathrm{~F}$-FDG PET for diagnosis of malignant lesions in patients with hyperglycaemia.

The uptake of ${ }^{18} \mathrm{~F}-\mathrm{FDG}$ in brown adipose tissue (BAT) is another finding that may affect the detection of tumour lesions. Hou et al. [3] demonstrated that gender, season and age are risk factors for ${ }^{18} \mathrm{~F}$-FDG uptake in BAT. In particular, the ${ }^{18} \mathrm{~F}$-FDG uptake rate was 2.16 times in females as that in males, 8.67 times in the minors as that in the adults and 1.94 times in winter as that in summer. 


\subsection{Repeatability of the Quantitative Measurements}

PET is widely used in oncology for the response assessment to treatment by the quantitative measurements of tracer uptake of the tumour lesions. For this purpose, the repeatability of these measurements in metabolic imaging is pivotal and needs to be established. Two studies dealt with the repeatability of the SUV estimation in tumour lesions $[4,5]$.

De Langen et al. [4] demonstrated that in ${ }^{18} \mathrm{~F}$ FDG PET imaging SUVmean had better repeatability performance than SUVmax. For serial PET scans, a combination of $20 \%$ as well as 1.2 SUVmean units was most appropriate threshold to identify a significant metabolic change in tumoural lesions. Nevertheless, both measures showed poor repeatability for lesions with low ${ }^{18} \mathrm{~F}$-FDG uptake since test-retest variability is affected by the level of ${ }^{18} \mathrm{~F}-\mathrm{FDG}$ uptake while tumour volume had minimal influence on repeatability. The authors recommend to report the evaluation of biologic effects in PET by using a combination of minimal relative and absolute changes of SUV.

The same group also analysed the response evaluation using ${ }^{18} \mathrm{~F}$-Fluorothymidine $\left({ }^{18} \mathrm{~F}\right.$-FLT) [5]. In this case, the best repeatability was obtained using SUVpeak. Differences $\geq 25 \%$ in ${ }^{18}$ F-FLT SUV measurements likely represented a true change in tumour uptake. Nevertheless, larger differences are required for FLT metrics comprising volume estimates when no lesion selection criteria are applied.

The partial volume effect is another factor that may hamper accurate quantification of radiopharmaceutical uptake by tumour lesions leading to underestimations of SUV values and possibly compromising the lesion detection. A metaanalysis [6] investigated the clinical impact of the partial volume effect correction factor in oncological PET studies and in particular the potential benefit in its application for diagnosis, staging, prognostication and response assessment concluding that the accumulated evidence does not support routine application of partial volume correction in standard clinical PET practice.

\subsection{Dual-Time-Point Imaging}

A second late acquisition after conventional ${ }^{18} \mathrm{~F}-$ FDG PET/CT imaging (dual-time-point technique) has been suggested to discriminate between inflammatory and neoplastic lesions. This approach is based on the evidence that in inflammatory lesions the ${ }^{18} \mathrm{~F}-\mathrm{FDG}$ uptake is characterized by a progressive washout after an initial trapping, while in tumour tissues, in particular before treatment, the uptake of the tracer increases over time. Two meta-analyses addressed this issue: both showed comparable performance between standard single-time-point and dualtime-point ${ }^{18} \mathrm{~F}$-FDG PET imaging in diagnosing pulmonary nodules [7] and in detecting lymph nodal metastases [8]. The results of the studies do not support the routine use of an additional late acquisition for these two clinical purposes.

\subsection{Correlation Between Proliferation Markers (Ki-67) and Tracer Uptake in Tumours}

Although ${ }^{18} \mathrm{~F}$-FDG is not a tumour-specific agent, several studies showed that ${ }^{18} \mathrm{~F}-\mathrm{FDG}$ uptake may be an index of biological aggressiveness of the disease. Nevertheless, whether ${ }^{18}$ F-FDG PET imaging can be a marker of tumour cell proliferation remains controversial. Deng et al. [9] analysed pooled data from clinical studies focused on this issue. The results demonstrated a moderate positive correlation between ${ }^{18} \mathrm{~F}$-FDG uptake and tumour cell proliferation marker Ki-67 (combined correlation coefficient $=0.44$ ) and suggested that ${ }^{18} \mathrm{~F}$-FDG SUV may be used as an indicator of the tumour proliferation and invasiveness. A subgroup analysis based on different tumour types showed varied degrees of correlation. The correlation was highly significant in thymic epithelial tumours; significant in gastrointestinal stromal tumours (GIST); moderate in lung, breast, bone and soft tissue, pancreatic, oral, thoracic, uterine and ovary cancers; average in brain, oesophageal and colorectal cancers; and poor in head and neck, thyroid, gastric and malignant melanoma tumours. 
The correlation between ${ }^{18} \mathrm{~F}$-FLT uptake and Ki-67 was also investigated. Chalkidou A et al. [10] found sufficient data to support a strong ${ }^{18} \mathrm{~F}$ FLT/Ki-67 correlation only for brain, lung and breast cancer. The authors highlighted the importance of the methodology used to measure Ki-67 expression: the correlation was significant and independent of cancer type only when using Ki-67 average measurements, or measuring Ki-67 maximum expression on whole surgical samples.

\subsection{Correlation Between ${ }^{18}$ F-FDG SUVmax and ADC Values in Tumour Tissues}

Apparent diffusion coefficient (ADC) is a parameter obtained by diffusion-weighted magnetic resonance imaging (MRI), reflecting the brownian movement of water molecules. The ADC value has been shown to link with the cell density, microvascular circulation and membrane integrity of a tumour tissue. Two meta-analyses $[10,11]$ examined the potential relationship between ${ }^{18} \mathrm{~F}$-FDG SUV that characterize the metabolic activity of tumour cells and ADC. Both studies found inverse correlation between ADC and SUV in patients with cancer. This inverse correlation, which was generally weak, appeared higher in the brain tumour, cervix carcinoma and pancreas cancer. However, larger prospective studies are warranted to validate these preliminary findings in different cancer types.

\subsection{Diagnostic Performance of Hybrid Imaging in Oncology}

After the introduction in the last years of hybrid scanners, many experiences indicated that the integration of functional and morphological imaging (hybrid imaging) provides additional diagnostic information useful in different clinical settings and particularly in oncology.

In a meta-analysis published by Gao et al. in 2013 [13], pooled data from comparative studies revealed that integrated PET/CT has higher sen- sitivity (0.95 vs 0.85$)$ and similar specificity (0.96 vs 0.95 ) with respect to PET alone in the detection of distant metastases. Analogous results were obtained comparing integrated PET/CT with CT alone (sensitivity 0.97 vs 0.80 and specificity 0.97 vs 0.94 , respectively), confirming the additional value of the PET/CT hybrid imaging in tumour staging.

More recently published data suggested a complementary role of ${ }^{18} \mathrm{~F}-\mathrm{FDG}$ PET/CT and MRI in oncological patients. Miles et al. [14] compared these two imaging modalities in patients with suspected residual disease or recurrent tumours. PET demonstrated greater sensitivity for detecting lymph nodal recurrence, whereas MRI was more effective than PET/CT in the detection of skeletal and hepatic recurrence. A review of studies assessing therapeutic impact of PET/MRI suggested a greater likelihood for change in clinical management when PET/MRI was used for assessment of suspected residual or recurrent disease rather than tumour staging. Supplementing the evidence-base data for ${ }^{18} \mathrm{~F}-$ FDG PET/MRI with studies that compared the components of this hybrid technology separately, ${ }^{18} \mathrm{~F}-\mathrm{FDG}$ PET/MRI is likely to be clinically effective for the investigation of patients with suspected residual or recurrent cancers.

$\mathrm{Xu}$ et al. [15] demonstrated that ${ }^{18} \mathrm{~F}-\mathrm{FDG}$ PET/CT has similar patient-based sensitivity (0.85 versus 0.85$)$ and specificity (0.96 versus $0.97)$ to MRI in the detection of distant metastases. Similar lesion-based performance was also estimated (PET/CT sensitivity and specificity: 0.85 and 0.90 and MRI sensitivity and specificity: 0.88 and 0.89 ). The analysis of a small number of studies indicated that the combined use of these two modalities may have higher patientbased sensitivity (0.89) than PET/CT (0.82) and whole body MRI (0.81) alone, suggesting that the combined use of these two modalities may provide more benefit than PET/CT and MRI alone.

Finally, Shen et al. [16] after analysing the results of 38 studies that involved 753 patients and 4234 lesions concluded that PET/MRI has excellent diagnostic potential for the overall detection of malignancies in cancer patients. On a per-patient level, the pooled sensitivity and 
specificity were 0.93 and 0.92 , respectively. On a per-lesion level, the corresponding estimates were 0.90 and 0.95 , respectively.

\subsection{Varia}

The ${ }^{18}$ F-FDG PET/CT imaging has been defined by several authors as more accurate than standard radiological imaging in evaluating the response to treatment in oncological patients, in particular when a residual mass is still detectable. Kim et al. [17] compared the tumour response assessment according to the metabolic criteria developed by the European Organization for Research and Treatment of Cancer (EORTC) and morphologic criteria (RECIST1.1.) in patients with malignant solid tumours. The pooled analysis of 181 patients recruited from seven studies demonstrated a moderate agreement of tumour responses between the RECIST and EORTC criteria $(k=0.493)$. The level of agreement was not affected by the anticancer treatments (chemotherapy or targeted therapy). A disagreement was found in 66 of 181 patients $(36.5 \%)$. Tumour response was upgraded in 54 patients and downgraded in 12 when adopting the EORTC criteria. The estimated overall response rates were significantly different between the two criteria $(52.5 \%$ by the EORTC vs. $29.8 \%$ by the RECIST, $p<0.0001$ ). The conclusions confirmed that the metabolic findings are more sensitive than the morphologic criteria to detect tumour response to the treatment.

The PET/CT imaging with radiolabelled choline is a reliable tool for the detection and localization of recurrent disease in patients with prostate carcinoma. A meta-analysis by von Eyben et al. [18] investigated whether the use of different tracers, ${ }^{11} \mathrm{C}$-choline $\left({ }^{11} \mathrm{C}\right.$-Cho) and ${ }^{18} \mathrm{~F}$-fluorocholine $\left({ }^{18} \mathrm{~F}-\mathrm{FCH}\right)$, may provide different diagnostic performance. The detection rates of metastatic sites in studies with ${ }^{11} \mathrm{C}$-Cho and ${ }^{18} \mathrm{~F}-\mathrm{FCH}$ did not differ significantly. The radiation activity of ${ }^{11} \mathrm{C}-\mathrm{Cho}$ and ${ }^{18} \mathrm{~F}-\mathrm{FCH}$ injected was not significantly associated with the detection rate of extra-prostatic lesions. The authors concluded that the detection of metastatic lesions in patients with biochemical recurrence (PSA levels of $1-10 \mathrm{~g} / \mathrm{ml}$ ) was clinically relevant when performed by PET/CT with radiolabelled choline regardless of the radiotracer injected.

The introduction of hybrid medical imaging technology has transformed the practice of diagnostic nuclear medicine and nowadays PET/CT and single photon emission computed tomography/computed tomography (SPECT/CT) have wide acceptance for many clinical investigations. A concern with PET/CT and SPECT/CT imaging is the combined radiation doses from both radiopharmaceutical and X-ray CT components. Therefore, it is imperative to implement a radiation dose optimization process to protect patients from unwarranted high radiation burdens. Alkhybari et al. [19] systematically reviewed data published in literature to determine the variations in reported national diagnostic reference levels (NDRL) methodology and values for adult $\mathrm{PET} / \mathrm{CT}$ and SPECT/CT procedures. Discrepancies were found between the methodologies applied to establish and report both PET/ $\mathrm{CT}$ and SPECT/CT NDRLs. In particular, the authors remarked the opportunity for hybrid imaging to report both radiation doses from the radioactivity injected and the $\mathrm{CT}$ dose rather than a separate NDRL. They concluded that further researches should be focused on reporting more NDRLs for hybrid examinations to collect enough data to establish a robust NDRL standard for the CT portion in PET/CT and SPECT/CT examinations.

\section{References}

1. Wang R, Chen H, Fan C. Impacts of time interval on 18F-FDG uptake for PET/CT in normal organs: a systematic review. Medicine (Baltimore). 2018;97(45):e13122.

2. Eskian M, Alavi A, Khorasanizadeh M, Viglianti BL, Jacobsson H, Barwick TD, et al. Effect of blood glucose level on standardized uptake value (SUV) in 18F-FDG PET-scan: a systematic review and meta-analysis of 20,807 individual SUV measurements. Eur J Nucl Med Mol Imaging. 2019;46(1):224-37.

3. Hou GZ, Zhu ZH, Cheng WY. Meta-analysis of influencing factors of 18F-fluorodeoxyglucose uptake of brown adipose tissue in PET/CT imaging. Zhongguo Yi Xue Ke Xue Yuan Xue Bao. 2017;39(5):649-55.

4. de Langen AJ, Vincent A, Velasquez LM, van Tinteren H, Boellaard R, Shankar LK, et al. Repeatability of 
18F-FDG uptake measurements in tumors: a metaanalysis. J Nucl Med. 2012;53(5):701-8.

5. Kramer GM, Liu Y, de Langen AJ, Jansma EP, Trigonis I, Asselin MC, Jackson A, et al. QuICConCePT Consortium. Repeatability of quantitative 18F-FLT uptake measurements in solid tumors: an individual patient data multi-center meta-analysis. Eur J Nucl Med Mol Imaging. 2018;45(6):951-61.

6. Cysouw MCF, Kramer GM, Schoonmade LJ, Boellaard R, de Vet HCW, Hoekstra OS. Impact of partial-volume correction in oncological PET studies: a systematic review and meta-analysis. Eur J Nucl Med Mol Imaging. 2017;44(12):2105-16.

7. Shen G, Deng H, Hu S, Jia Z. Potential performance of dual-time-point 18F-FDG PET/CT compared with single-time-point imaging for differential diagnosis of metastatic lymph nodes: a meta-analysis. Nucl Med Commun. 2014;35(10):1003-10.

8. Zhao M, Ma Y, Yang B, Wang Y. A meta-analysis to evaluate the diagnostic value of dual-time-point F-fluorodeoxyglucose positron emission tomography/ computed tomography for diagnosis of pulmonary nodules. J Cancer Res Ther. 2016;12(Suppl):C304-8.

9. Deng SM, Zhang W, Zhang B, Chen YY, Li $\mathrm{JH}, \mathrm{Wu} \mathrm{YW}$. Correlation between the uptake of 18F-fluorodeoxyglucose (18F-FDG) and the expression of proliferation-associated antigen $\mathrm{Ki}-67$ in cancer patients: a meta-analysis. PLoS One. 2015;10(6):e0129028.

10. Chalkidou A, Landau DB, Odell EW, Cornelius VR, O'Doherty MJ, Marsden PK. Correlation between Ki-67 immunohistochemistry and 18F-fluorothymidine uptake in patients with cancer: a systematic review and meta-analysis. Eur J Cancer. 2012;48(18):3499-513.

11. Deng S, Wu Z, Wu Y, Zhang W, Li J, Dai N, et al. Meta-analysis of the correlation between apparent diffusion coefficient and standardized uptake value in malignant disease. Contrast Media Mol Imaging. 2017;2017:4729547.

12. Shen G, Ma H, Liu B, Ren P, Kuang A. Correlation of the apparent diffusion coefficient and the standardized uptake value in neoplastic lesions: a meta-analysis. Nucl Med Commun. 2017;38(12):1076-84.

13. Gao G, Gong B, Shen W. Meta-analysis of the additional value of integrated 18FDG PET-CT for tumor distant metastasis staging: comparison with 18FDG PET alone and CT alone. Surg Oncol. 2013;22(3):195-200.

14. Miles K, McQueen L, Ngai S, Law P. Evidence-based medicine and clinical fluorodeoxyglucose PET/MRI in oncology. Cancer Imaging. 2015;15:18.

15. Xu GZ, Li CY, Zhao L, He ZY. Comparison of FDG whole-body PET/CT and gadolinium-enhanced whole-body MRI for distant malignancies in patients with malignant tumours: a meta-analysis. Ann Oncol. 2013;24(1):96-101.

16. Shen G, Hu S, Liu B, Kuang A. Diagnostic performance of whole-body PET/MRI for detecting malignancies in cancer patients: a meta-analysis. PLoS One. 2016;11(4):e0154497.

17. Kim JH, Kim BJ, Jang HJ, Kim HS. Comparison of the RECIST and EORTC PET criteria in the tumor response assessment: a pooled analysis and review. Cancer Chemother Pharmacol. 2017;80(4):729-35.

18. von Eyben FE, Kairemo K. Acquisition with (11) C-choline and (18)F-fluorocholine PET/CT for patients with biochemical recurrence of prostate cancer: a systematic review and meta-analysis. Ann Nucl Med. 2016;30(6):385-92.

19. Alkhybari EM, McEntee MF, Brennan PC, Willowson KP, Hogg P, Kench PL. Determining and updating PET/CT and SPECT/CT diagnostic reference levels: a systematic review. Radiat Prot Dosim. 2018;182(4):532-45.

Open Access This chapter is licensed under the terms of the Creative Commons Attribution 4.0 International License (http://creativecommons.org/licenses/by/4.0/), which permits use, sharing, adaptation, distribution and reproduction in any medium or format, as long as you give appropriate credit to the original author(s) and the source, provide a link to the Creative Commons license and indicate if changes were made.

The images or other third party material in this chapter are included in the chapter's Creative Commons license, unless indicated otherwise in a credit line to the material. If material is not included in the chapter's Creative Commons license and your intended use is not permitted by statutory regulation or exceeds the permitted use, you will need to obtain permission directly from the copyright holder. 